FACIAL EXPRESSION PROCESSING IN PROSOPAGNOSIA

FACIAL EXPRESSION PROCESSING IN DEVELOPMENTAL PROSOPAGNOSIA

BY

LAUREN “TULLY” CLARE BELL

A thesis

Submitted to the Victoria University of Wellington

In fulfilment of the requirements for the degree of

Master of Science in Psychology

Victoria University of Wellington

2018 


\title{
FACIAL EXPRESSION PROCESSING IN PROSOPAGNOSIA
}

\author{
Abstract \\ Individuals with developmental prosopagnosia experience lifelong deficits \\ recognising facial identity, but whether their ability to process facial expression is also \\ impaired is unclear. Addressing this issue is key for understanding the core deficit in \\ developmental prosopagnosia, and for advancing knowledge about the mechanisms and \\ development of normal face processing. In this thesis, I report two online studies on facial \\ expression processing with large samples of prosopagnosics. In Study 1, I compared facial \\ expression and facial identity perception in 124 prosopagnosics and 133 controls. I used three \\ perceptual tasks including simultaneous matching, sequential matching, and sorting. I also \\ measured inversion effects to examine whether prosopagnosics rely on typical face \\ mechanisms. Prosopagnosics showed subtle deficits with facial expression, but they \\ performed worse with facial identity. Prosopagnosics also showed reduced inversion effects \\ for facial identity but normal inversion effects for facial expression, suggesting they use \\ atypical mechanisms for facial identity but normal mechanisms for facial expression. In \\ Study 2, I extended the findings of Study 1 by assessing facial expression recognition in 78 \\ prosopagnosics and 138 controls. I used four labelling tasks that varied on whether the facial \\ expressions were basic (e.g., happy) or complex (e.g., elated), and whether they were \\ displayed via static (i.e., images) or dynamic (i.e., video clips) stimuli. Prosopagnosics \\ showed subtle deficits with basic expressions but performed normally with complex \\ expressions. Further, prosopagnosics did not show reduced inversion effects for both types of \\ expressions, suggesting they use similar recognition mechanisms as controls. Critically, the \\ subtle expression deficits that prosopagnosics showed in both studies can be accounted for by \\ autism traits, suggesting that expression deficits are not a feature of prosopagnosia per se. I \\ also provide estimates of the prevalence of deficits in facial expression perception $(7.70 \%)$ \\ and recognition $(2.56 \%-5.13 \%)$ in prosopagnosia, both of which suggest that facial \\ expression processing is normal in the majority of prosopagnosics. Overall, my thesis \\ demonstrates that facial expression processing is not impaired in developmental \\ prosopagnosia, and suggests that facial expression and facial identity processing rely on \\ separate mechanisms that dissociate in development.
}




\section{Acknowledgements}

First, I would like to thank my supervisor, Dr Tirta Susilo. Tirta, you are a fantastic human being and I have been so lucky to have you as a supervisor. Working alongside you, I feel that I have grown and learnt so much more than simply how to conduct research and write a thesis. I am truly grateful for your guidance and everlasting encouragement.

Second, I'd like to thank my family and friends. Without your support, I would have never reached postgraduate study. Kerri, mum, and dad, you have all been so lovely and kind during this whole process. My grandparents, thank you so much for your wise words and financial aid throughout my years of study. I'm so grateful to have all of you in my life!

Third, I'd like to thank the people who read my thesis and offered constructive feedback. Especially, I'd like to thank Hazel, Cassandra, and Amy who helped me transform this caterpillar of a thesis into a butterfly.

Fourth, I'd like to thank all the Susilo lab members for offering support and technical help when needed. Especially, I'd like to thank Viktoria and Eleanor for helping me create and pilot some of the tasks used in my thesis.

Fifth, I'd like to thank all the individuals with prosopagnosia who participated in my studies. Without your willingness to participate, research like this would be impossible.

Lastly, I'd like to acknowledge the Marsden grant awarded to Tirta from the Royal Society of New Zealand and the Victoria Masters (by thesis) Scholarship awarded to me by the Victoria University of Wellington Scholarships Committee. Without the financial help provided by the Marsden grant and my scholarship, this thesis would not have been possible. 


\section{Table of Contents}

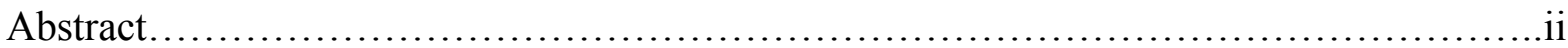

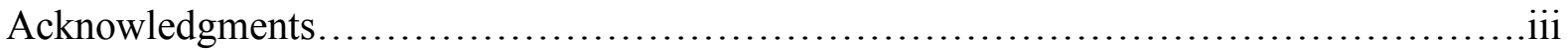

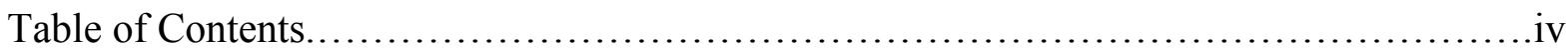

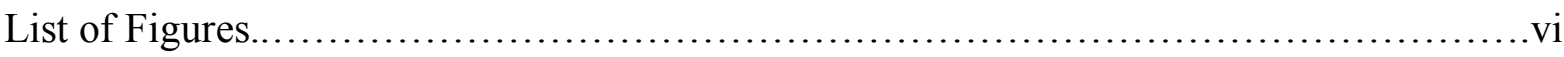

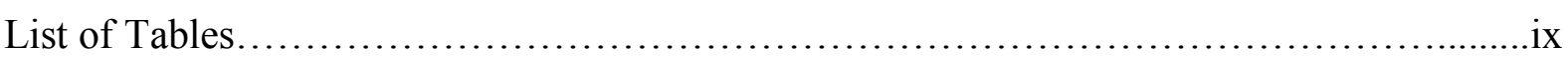

Chapter 1: Introduction........................................................

1.1 Facial identity and facial expression processing .............................

1.2 Past studies of facial expression processing in prosopagnosia................... 7

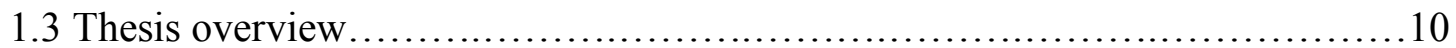

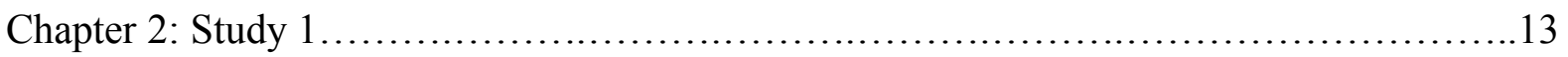

2.1 Method................................................................ 14

2.2 Materials and procedure............................................... 16

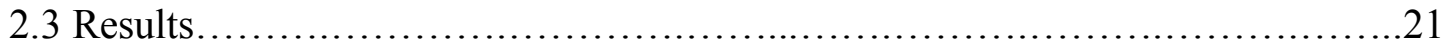

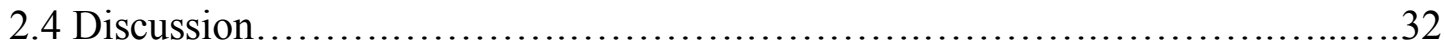

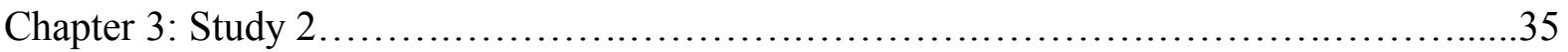

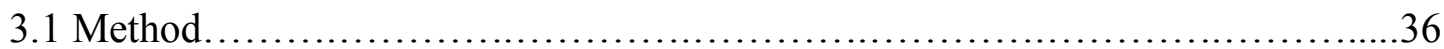

3.2 Materials and procedure................................................ 37

3.3 Results.............................................................4 41

3.4 Discussion..........................................................51

Chapter 4: General Discussion..................................................55

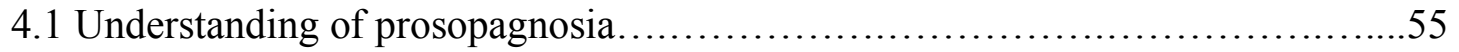

4.2 Organisation and development of normal face processing.....................62

4.3 Online studies of neuropsychology.......................................65

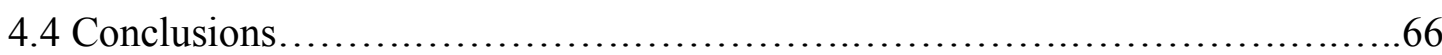

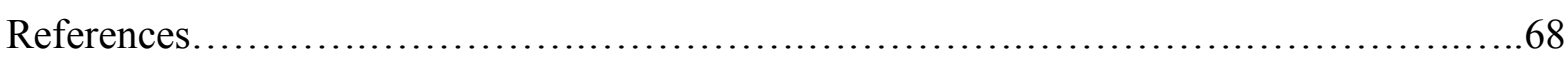

Appendix A: Past studies of facial expression processing in prosopagnosia................87

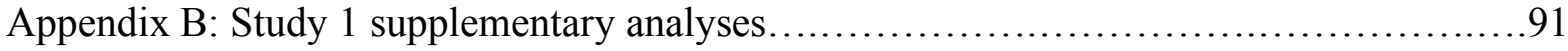

B.1 Individual task validation in independent samples...........................91

B.2 Controls' descriptive statistics and data checks............................93

B.3 Prosopagnosics' descriptive statistics.........................................98

B.4 Sequential matching tasks $d$ ' and criterion analyses........................99 
FACIAL EXPRESSION PROCESSING IN PROSOPAGNOSIA

B.5 Median response time analyses...........................................101

B.6 Adjusted SATQ analyses............................................. 104

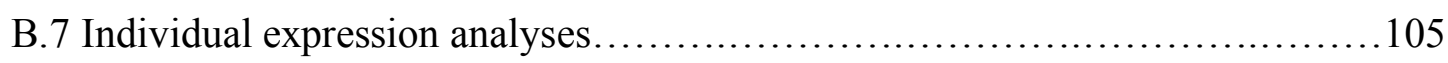

Appendix C: Simultaneous matching tasks modification and development.................110

Appendix D: Subthreshold autism trait questionnaire .............................111

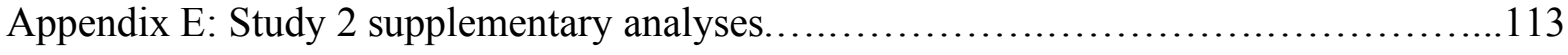

E.1 Individual task validation in independent samples.........................113

E.2 Controls' descriptive statistics and data checks.............................114

E.3 Prosopagnosics' descriptive statistics...................................117

E.4 Median response time analyses........................................118

E.5 Adjusted SATQ analyses............................................ 121

E.6 Individual expression analyses....................................... 122

Appendix F: Development of the complex expression tasks..........................127 
FACIAL EXPRESSION PROCESSING IN PROSOPAGNOSIA

\section{List of Figures}

Figure 1. Bruce and Young's (1986) model of face recognition.

Figure 2. Example of a trial from the expression simultaneous matching task.

Figure 3. Example of a trial from the identity simultaneous matching task.

Figure 4. Schematic representation of a trial from the sequential matching tasks.

Figure 5. Example of a trial from the facial expression sorting task.

Figure 6. Example of a trial from the facial identity sorting task.

Figure 7. Boxplots of prosopagnosics' and controls' accuracy on the facial expression (left) and facial identity (right) tasks for upright trials, collapsed across task formats.

Figure 8. Boxplots of prosopagnosics' and controls' trimmed mean response times on the facial expression (left) and facial identity (right) tasks for upright trials, collapsed across task formats.

Figure 9. Boxplots of prosopagnosics' and controls' inversion effects in accuracy on the facial expression (left) and facial identity (right) tasks, collapsed across task formats.

Figure 10. Boxplots of prosopagnosics' and controls' inversion effects in trimmed mean response times on the facial expression (left) and facial identity (right) tasks, collapsed across task formats.

Figure 11. Scatterplots with lines of best fit for prosopagnosics' SATQ scores and their accuracy on the facial expression (left) and facial identity tasks (right) for upright trials, collapsed across task formats.

Figure 12. Boxplots of prosopagnosics' composite z-scores on the facial expression (left) and facial identity (right) tasks for upright trials.

Figure 13. Example of a trial from the basic facial expression labelling tasks.

Figure 14. Schematic representation of a trial from the complex facial expression labelling tasks.

Figure 15. Boxplots of prosopagnosics' and controls' accuracy on the basic (left) and complex (right) expression recognition tasks on upright trials, collapsed across stimulus type.

Figure 16. Boxplots of prosopagnosics' and controls' trimmed mean response times on the basic (left) and complex (right) expression tasks on upright trials, collapsed across stimulus type.

Figure 17. Boxplots of prosopagnosics' and controls' inversion effects in accuracy on the basic (left) and complex (right) expression tasks, collapsed across stimulus type. 


\section{FACIAL EXPRESSION PROCESSING IN PROSOPAGNOSIA}

Figure 18. Boxplots of prosopagnosics' and controls' inversion effects in trimmed mean response times on the basic (left) and complex (right) expression tasks, collapsed across stimulus type.

Figure 19. Scatterplot with line of best fit for prosopagnosics' SATQ scores and their performance on the basic expression tasks, collapsed across stimulus type.

Figure 20. Boxplot of prosopagnosics' composite z-scores for their accuracy on upright trials of the four expression recognition tasks.

Figure B1. Boxplots of controls' accuracy on the inverted and upright conditions of the facial expression (left) and facial identity (right) simultaneous matching tasks.

Figure B2. Boxplots of controls' accuracy on the inverted and upright conditions of the facial expression (left) and facial identity (right) sequential matching tasks.

Figure B3. Boxplots of controls' accuracy on the inverted and upright conditions of the facial expression (left) and facial identity (right) sorting tasks.

Figure B4. Boxplots depicting prosopagnosics' and controls' d' values on the facial expression (left) and facial identity (right) sequential matching tasks for upright trials.

Figure B5. Boxplots depicting prosopagnosics' and controls' C values on the facial expression (left) and facial identity (right) sequential matching tasks for upright trials.

Figure B6. Boxplots of prosopagnosics' and controls' median response times on the facial expression (left) and facial identity (right) tasks for upright trials, collapsed across task format.

Figure B7. Boxplots of prosopagnosics' and controls' inversion effects in median response times on the facial expression (left) and facial identity (right) tasks, collapsed across task format.

Figure B8. Scatterplots with lines of best fit for prosopagnosics' adjusted SATQ scores and their performance on the facial expression (left) and facial identity (right) tasks for upright trials, collapsed across task format.

Figure B9. Boxplots of prosopagnosics' and controls' accuracy for each facial expression in the simultaneous matching task for upright trials.

Figure B10. Boxplots of prosopagnosics' and controls' accuracy for each facial expression in the sorting task for upright trials.

Figure E1. Boxplots of controls' accuracy on the inverted and upright conditions of the dynamic (left) and static (right) basic expression labelling tasks.

Figure E2. Boxplots of controls' accuracy on the inverted and upright conditions of the dynamic (left) and static (right) complex expression labelling tasks. 


\section{FACIAL EXPRESSION PROCESSING IN PROSOPAGNOSIA}

Figure E3. Boxplots of controls' and prosopagnosics' median response times on the basic (left) and complex (right) facial expression labelling tasks for upright trials, collapsed across stimulus type.

Figure E4. Boxplots of prosopagnosics' and controls' inversion effects in median response times on the basic (left) and complex (right) facial expression labelling tasks, collapsed across stimulus type.

Figure E5. Scatterplot with line of best fit for prosopagnosics' adjusted SATQ scores and their performance on the basic expression tasks, collapsed across stimulus type.

Figure E6. Boxplots of prosopagnosics' and controls' accuracy for each facial expression in the basic expression labelling tasks for upright trials. 


\section{FACIAL EXPRESSION PROCESSING IN PROSOPAGNOSIA}

\section{List of Tables}

Table 1. Study 1 prosopagnosics' diagnostic test scores.

Table 2. Study 2 Prosopagnosics' diagnostic test scores.

Table A1. Summary of past studies that measured facial expression in prosopagnosia.

Table B1. Controls' accuracy on the upright and inverted trials of the Study 1 tasks.

Table B2. Controls' trimmed mean response times on the upright and inverted trials of the Study 1 tasks.

Table B3. Prosopagnosics' accuracy on the upright and inverted trials of the Study 1 tasks.

Table B4. Prosopagnosics' trimmed mean response times on the upright and inverted trials of the Study 1 tasks.

Table B5. Prosopagnosics' and controls' median response times on the upright and inverted trials of the Study 1 tasks.

Table B6. Prosopagnosics' and controls' accuracy on upright trials for each expression in the simultaneous matching task.

Table B7. Prosopagnosics' and controls' accuracy on upright trials for each expression in the sorting task.

Table E1. Controls' accuracy on the upright and inverted trials of the Study 2 tasks.

Table E2. Controls' trimmed mean response times on the upright and inverted trials of the Study 2 tasks.

Table E3. Prosopagnosics' accuracy on the upright and inverted trials of the Study 2 tasks.

Table E4. Prosopagnosics' trimmed mean response times on the upright and inverted trials of the Study 2 tasks.

Table E5. Controls' and prosopagnosics' median response times on the upright and inverted trials of the Study 2 tasks.

Table E6. Prosopagnosics' and controls' accuracy on upright trials for each expression in the basic expression labelling tasks, and $t$ - and p-values from post hoc t-tests.

Table E7. Prosopagnosics' and controls' trimmed mean response times on upright trials for each expression in the basic expression labelling tasks, and $t-, p$-, and Cohen's $d$ values from post hoc t-tests.

Table E8. Prosopagnosics' and controls' inversion effects in accuracy for each expression in the basic expression labelling tasks, and t-, p-, and Cohen's $d$ values from post hoc t-tests. 


\section{Chapter 1: Introduction}

For most of us, it is easy to recognise people by their face. However, for individuals with developmental prosopagnosia (henceforth, 'prosopagnosia'), it is a daily challenge. Prosopagnosia is a developmental condition defined by the lifelong inability to recognise faces (Bate \& Tree, 2017; Dalrymple \& Palermo, 2016; McConachie, 1976). Commonly known as 'face blindness', some researchers refer to this condition as congenital prosopagnosia (based on the notion that it may be present from birth; Behrmann \& Avidan, 2005 ) and other researchers refer to it as hereditary prosopagnosia (because it may run in families; Kennerknecht et al., 2006). Prosopagnosia is estimated to affect one in 50 people (Bowles et al., 2009; Kennerknecht et al., 2006; Kennerknecht, Ho, \& Wong, 2008), which amounts to roughly 150 million people worldwide. Because of their pervasive difficulty with faces, individuals with prosopagnosia tend to avoid social situations, which negatively impacts their well-being, self-esteem, and career opportunities (Dalrymple et al., 2014; Davis et al., 2011; Yardley, McDermott, Pisarski, Duchaine, \& Nakayama, 2008).

Prosopagnosia is characterised by deficits in recognising facial identity. However, there is some evidence that prosopagnosics can have additional problems with other aspects of face processing and broader visual functioning. When processing faces, some prosopagnosics demonstrate deficits when recognising facial expression (e.g., Biotti \& Cook, 2016), facial gender (e.g., Duchaine, Yovel, Butterworth, \& Nakayama, 2006), facial attractiveness (e.g., Le Grand et al., 2006), and facial trustworthiness (Todorov \& Duchaine, 2008). Beyond face processing, some prosopagnosics also have trouble recognising a variety of common objects (e.g., Duchaine \& Nakayama, 2005; Garrido, Duchaine, \& Nakayama, 2008; and see Geskin \& Behrmann, 2017 for a recent review), bodies (Biotti, Gray, \& Cook, 2017), biological motion (e.g,. Lange et al., 2009), or the spatial layout of the environment (Bate, Adams, Bennetts, \& Line, 2017; Corrow et al., 2016). This variability in prosopagnosics' visual and cognitive deficits suggests that prosopagnosia is a heterogeneous condition with different neural and potentially genetic bases (Duchaine, 2011; Susilo \& Duchaine, 2013), but this possibility has not been rigorously examined.

To better understand the nature of prosopagnosia, we need studies with large samples that look systematically at a wide range of face processing and broader visual functions. In this thesis, I conduct such a study by focusing on facial expression processing. Understanding facial expression processing in prosopagnosia has far-reaching implications. First, it will 


\section{FACIAL EXPRESSION PROCESSING IN PROSOPAGNOSIA}

inform whether the core deficit in prosopagnosia is specific to facial identity processing or extends to facial expression processing. Second, understanding facial expression processing in prosopagnosia will provide clues for rehabilitation purposes. Prosopagnosics who have impaired facial expression processing may struggle more with social interactions, and experience greater negative consequences to their well-being, compared to prosopagnosics who have intact facial expression processing. Thus, it is important to determine whether facial expression processing is impaired in prosopagnosia so that appropriate behavioural interventions can be developed. Finally, investigating facial expression processing in prosopagnosia has direct implications for major models of face processing (e.g., Bruce \& Young, 1986; Calder, 2011; Calder \& Young, 2005; Duchaine \& Yovel, 2015; Haxby, Hoffman, \& Gobbini, 2000; 2002). A fundamental, but contentious, aspect of these models is whether facial expression and facial identity are processed in independent systems (e.g., Bruce \& Young, 1986; Haxby et al., 2000) or in a shared system (e.g., Calder, 2011; Calder \& Young, 2005). By systematically testing prosopagnosics facial expression processing ability, my thesis will inform this ongoing debate. Normal facial expression processing in prosopagnosia will constitute support for independent processing systems, whereas impaired facial expression processing in prosopagnosia will be consistent with the idea of shared processing systems.

\subsection{Facial identity and facial expression processing}

Bruce and Young's (1986) highly influential model of face recognition (as depicted in Figure 1) posits a key distinction between facial identity and facial expression processing. Facial expression and facial identity processing segregate early, immediately after structural descriptions of the faces we see in our environment are created. Beyond this distinction, facial expression and facial identity processing differs in two ways. First, they use different types of descriptions. The facial expression analysis module uses view-centred descriptions, which convey basic face information like changes in contrast and light intensity. In contrast, facial identity recognition uses expression-independent descriptions, which extract invariant information about the shape of individual facial features (e.g., the nose and mouth) and their overall configuration. Second, facial expression and facial identity recognition depend on different mechanisms. For expression analysis, the configuration and shape of facial features (e.g., open mouth and raised eyebrows) leads to the categorisation of specific expressions (e.g., surprise). Within identity recognition, different functions are used to process familiar 


\section{FACIAL EXPRESSION PROCESSING IN PROSOPAGNOSIA}

and unfamiliar identities. For familiar identities, newly generated face descriptions are compared against stored descriptions of known faces represented within the face-recognition units module. If the newly generated descriptions match the stored ones, then the person identity nodes (which store semantic information about a person's identity, like their occupation) and the name generation module (where individuals' names are stored) are activated. For the recognition of unfamiliar faces, pictorial descriptions generated from static face images are processed by the directed visual processing module.

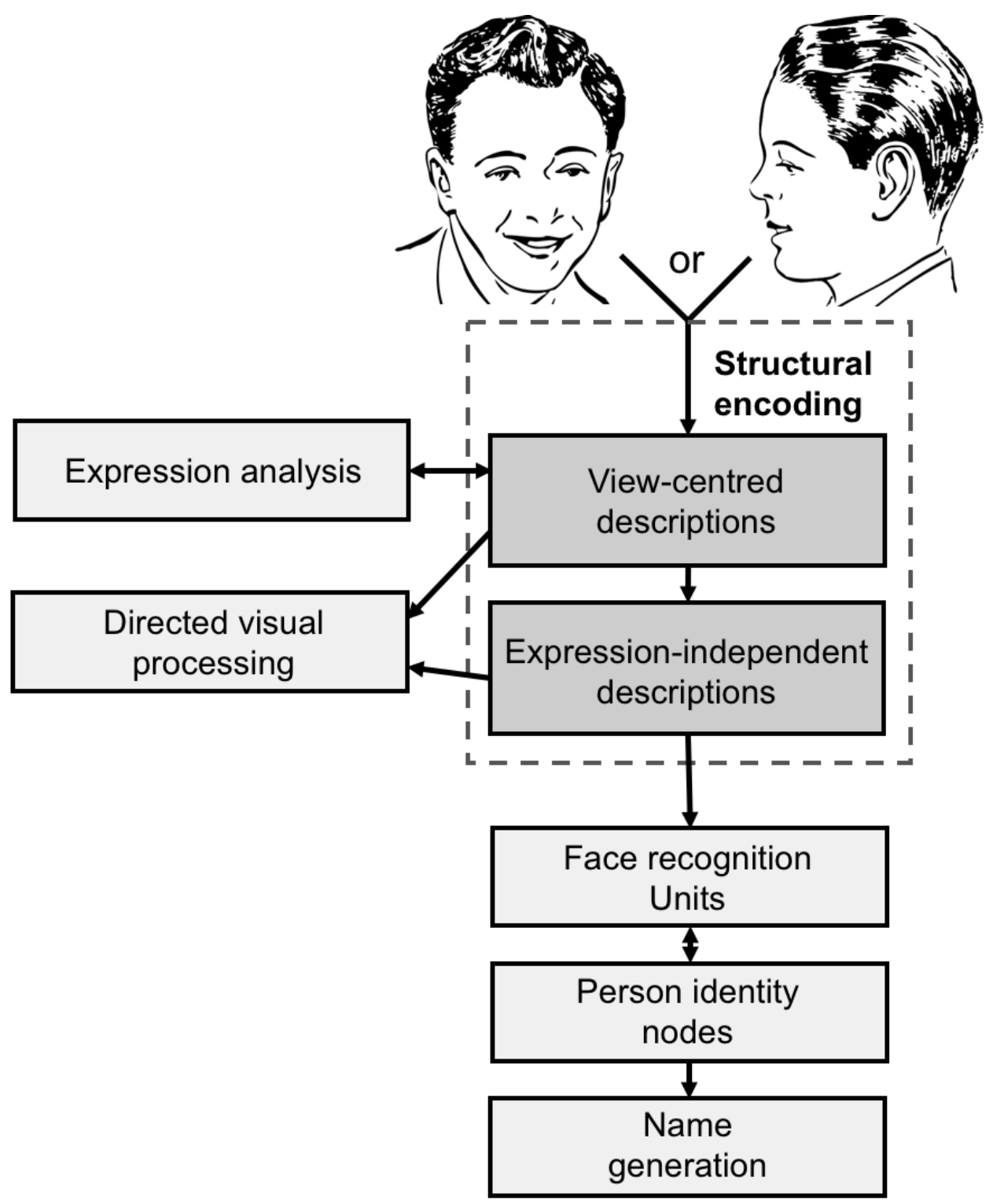

Figure 1. Bruce and Young's (1986) model of face recognition. The 'facial speech analysis' and 'cognitive system' modules have been excluded from this diagram for simplicity.

A key prediction of Bruce and Young's (1986) model is that facial expression and facial identity processing can doubly dissociate. That is, the ability to process facial identity 


\section{FACIAL EXPRESSION PROCESSING IN PROSOPAGNOSIA}

can be impaired while the ability to process facial expression can be left intact, and vice versa. Behavioural data from brain-damaged patients demonstrates this double dissociation (for a review, see Bate \& Bennetts, 2015). Support for one half of the dissociation comes from acquired prosopagnosic patients who have impaired facial identity processing, but intact facial expression processing (e.g., De Renzi \& Di Pellegrino, 1998; Fox, Hanif, Iaria, Duchaine, \& Barton 2011; Mattson, Levin, \& Grafman, 2000; Riddoch, Johnston, Bracewell, Boutsen, Humphreys, 2008; Tranel, Damasio, \& Damasio, 1988). The other half of the dissociation is observed in patients with varied brain damage (e.g., bilateral lesions to the parietal lobes or amygdala) or brain disorders (e.g., Huntington's disease) who have impaired facial expression processing, but normal facial identity processing (e.g., Adolphs, Tranel, Damasio, \& Damasio, 1994; Calder et al., 1997; Humphreys, Donnelly, \& Riddoch, 1993; Sprengelmeyer et al., 1997; Young, Hellawell, Van de Wal, \& Johnson, 1996; Young, Newcombe, Haan, Small, \& Hay, 1993). Taken together, these dissociations provide evidence that facial expression and facial identity processing involve independent mechanisms.

Neurophysiological studies also provide compelling evidence for distinctions between facial expression and facial identity processing. For instance, relative to viewing neutral faces, faces displaying expressions elicit an enhanced early positivity in event-related potential (ERP) recordings (ranging between 100 and 170ms post-stimulus onset, Eimer \& Holmes, 2002; Eimer, Holmes, \& McGlone, 2003; Holmes, Vuilleumier \& Eimer, 2003). However, facial expression does not modulate the face-sensitive N170 ERP component (a negativity present at around 170ms post-stimulus; Eimer et al., 2003; Eimer \& Holmes, 2002; Holmes et al., 2003), which indexes early structural encoding of faces prior to recognition (Bentin, Allison, Puce, Perez, \& McCarthy, 1996; Eimer, 2000). Together, these ERP findings suggest that early processes involved in facial expression and facial identity processing are occur in parallel, but are independent.

Neuroanatomical distinctions between facial identity and facial expression processing come from studies of single-cell recordings in primates (e.g., Hasselmo, Rolls, \& Baylis, 1989; Perrett, Hietanen, Oram, Benson, \& Rolls, 1992), neuroimaging in humans (e.g., Haxby et al., 2000; Winston, Henson, Fine-Goulden, \& Dolan, 2004), and transcranial magnetic stimulation in humans (TMS; Pitcher, 2014; Pitcher, Charles, Devlin, Walsh, \& Duchaine, 2009; Pitcher, Garrido, Walsh, \& Duchaine, 2008). Single-cell recordings in macaque monkeys revealed that neurons responsive to facial identity are predominantly located in ventral regions of the inferior temporal cortex, while neurons responsive to facial 


\section{FACIAL EXPRESSION PROCESSING IN PROSOPAGNOSIA}

expression are located more dorsally, in the superior temporal sulcus (STS; Hasselmo et al., 1989). Haxby and colleagues (Haxby et al., 2000) offered a similar layout of the face processing network in the human cortex. They proposed that the ventrally located lateral fusiform gyrus (which encompasses the fusiform face area; FFA; Kanwisher, McDermott, \& Chun, 1997) is involved in processing invariant aspects of faces such as identity, while the more dorsally located STS is involved in processing changeable aspects of faces such as expression. Causal evidence for this dissociation comes from Pitcher and colleagues' TMS studies (Pitcher, 2014; Pitcher et al., 2008; 2009) in which they show that applying TMS to the right posterior STS disrupts the ability to discriminate facial expressions, but not facial identity. Taken together, this neuroanatomical evidence from primates and humans demonstrates that anatomically distinct brain regions are implicated in processing facial expression and facial identity.

Despite widespread support, the independence of facial identity and facial expression processing has been challenged. Calder and Young (2005; Calder, 2011) argue that other lines of evidence (discussed below) imply a complex interaction between facial expression and facial identity processing, and thus propose that the two face aspects are processed by common mechanisms within a shared system. They do note, however, that the interaction may be more relative than absolute, in that there may be some level of segregation between facial expression and facial identity during structural encoding. Further, they highlight that there are more defined distinctions between facial expression and facial identity processing during higher-level processing when brain regions beyond the visual system participate (e.g., the amygdala's involvement in expression processing; Adolphs, 1999; Pessoa \& Adolphs, 2010).

The notion of a shared system for facial expression and facial identity processing is supported by studies showing interference effects between processing of the two face aspects. Schweinberger and colleagues (Schweinberger, Burton, \& Kelly, 1999; Schweinberger \& Soukup, 1998) observed asymmetric interference between facial expression and facial identity in a Garner-type speeded classification task, in which participants saw face stimuli one by one and had to classify either the identity (person A or B) or expression (anger or happiness). Participants could attend to facial identity and successfully ignore facial expression, but they struggled to ignore facial identity when trying to attend to facial expression. Other researchers observed symmetric interference in a sequential matching task, in which participants had to judge whether successively presented stimuli showed the same or different identities or the same or different facial expressions whilst ignoring the task- 


\section{FACIAL EXPRESSION PROCESSING IN PROSOPAGNOSIA}

irrelevant facial attribute (e.g., Fisher, Towler, \& Eimer, 2016; 2017; Ganel \& GoshenGottstein, 2004). Participants' ability to match facial identity was disrupted by changes in facial expression and their ability to match facial expression was similarly disrupted by changes in facial identity. Both interference effects show that changes in one aspect of the face (be it identity or expression) that is task-irrelevant cannot be completely ignored, suggesting that facial expression and facial identity processing may not be entirely independent.

There is also neurophysiological data that supports the notion of a shared system for facial expression and facial identity processing. For instance, Fisher and colleagues (Fisher et al., 2016; 2017) found that the N250r (an ERP component that is thought to reflect the deployment of identity matching mechanisms) was modulated by task-irrelevant changes in facial expression in a facial identity matching task. Specifically, during repetitions of facial identity, the N250r was delayed and attenuated when facial expression changed as compared to when expression was repeated. This finding suggests that changes in facial expression may interfere with facial identity matching (counter to the conclusions drawn from earlier ERP components, like the N170; Eimer et al., 2003; Eimer \& Holmes, 2002; Holmes et al., 2003), suggesting that facial expression and facial identity may be processed by shared mechanisms.

Further support for a shared system comes from modelling studies. For instance, Calder and colleagues submitted a standardised set of faces (the pictures of facial affect, POFA; Ekman \& Friesen, 1976) to a principal component analysis of their pixel intensities (Calder, Burton, Miller, Young, \& Akamatsu, 2001). The output revealed that some principal components mainly coded facial identity or facial expression, but other components coded both face aspects, suggesting that some facial information is used in both facial identity and facial expression processing. These results imply that it may be possible for a shared system to process both facial expression and facial identity.

More recent support comes from evidence of similar developmental trajectories for facial identity and facial expression processing (Dalrymple, di Oleggio Castello, Elison, \& Gobbini, 2017). Dalrymple and colleagues observed comparable improvements in children's speed and accuracy on facial expression and facial identity discrimination tasks from ages five through to twelve, suggesting that facial identity and facial expression discrimination develop at similar rates in childhood. As the authors note, however, these findings do not rule out the possibility that facial expression and facial identity processing rely on independent systems that mature at the same rate. 


\section{FACIAL EXPRESSION PROCESSING IN PROSOPAGNOSIA}

Overall, the conflicting support for independent systems versus a shared processing system for facial expression and facial identity emphasises that this debate is far from being settled. Much like the studies with acquired prosopagnosic patients, investigations into developmental prosopagnosics' ability to process facial expression and facial identity can also contribute to the debate. Normal facial expression processing in prosopagnosia would imply that facial expression and facial identity processing depend on independent mechanisms. Conversely, impaired facial expression processing in prosopagnosia would be consistent with the notion that facial expression and facial identity processing rely on shared mechanisms. Such inquiries will inform the debate about independent systems versus a shared system by revealing whether there is a dissociation between facial expression and facial identity processing in prosopagnosia. Moreover, these inquiries will advance our general understanding of how face processing works both in prosopagnosics and normal individuals.

\subsection{Past studies of facial expression processing in prosopagnosia}

To date, facial expression processing in prosopagnosia has been examined in 20 studies (for a complete list see Table A1 in Appendix A). Some of these studies report normal expression processing (e.g., Duchaine, Parker, \& Nakayama, 2003; Lee, Duchaine, Wilson, \& Nakayama, 2010; Palermo et al., 2011), while others report impaired performance (e.g., Biotti \& Cook, 2016; Duchaine et al., 2006; Schmalzl, Palermo, \& Coltheart, 2008). These mixed findings make it unclear whether facial expression and facial identity processing dissociate in prosopagnosia. More importantly, the majority of past studies suffer from six critical limitations. These are (1) not checking whether prosopagnosics engage typical mechanisms to process facial expression, (2) circular analysis of prosopagnosics' facial identity recognition, (3) only using static stimuli (e.g., images) to assess facial expression processing, (4) not accounting for the impact of autism traits on facial expression processing, (5) using a limited number and variety of facial expression tasks, and (6) testing small samples. Below I expand on each limitation.

Failure to examine mechanism. Previous studies examined whether prosopagnosics were able to process facial expression as well as controls, but none of these studies (except one) tested how prosopagnosics did it. This limitation is particularly relevant for studies that report intact facial expression processing because prosopagnosics might have achieved normal performance by relying on atypical, compensatory mechanisms. If they do rely on 


\section{FACIAL EXPRESSION PROCESSING IN PROSOPAGNOSIA}

such mechanisms, then this would suggest that facial expression processing is abnormal in prosopagnosia. This limitation can be addressed by comparing performance on trials in which faces are presented upright versus an inverted orientation (i.e., upside-down). This comparison is motivated by a classic hallmark of typical face processing called the "face inversion effect" in which facial identity is much harder to recognise in inverted faces than in upright faces (Yin, 1969). The face inversion effect suggests that upright facial identity is typically processed as a whole (Rossion, 2008; Yin, 1969) and that inverting faces disrupts these holistic processes. The inversion effect also occurs for facial expression, suggesting that we engage holistic mechanisms when processing upright facial expression (e.g., Ambadar, Schooler, \& Cohn, 2005; McKelvie, 1995; Palermo, O’Connor, Davis, Irons, \& McKone, 2013). In this thesis, I test whether prosopagnosics are using similar facial expression processing mechanisms as controls by comparing the size of their inversion effects. Similarsized inversion effects in prosopagnosics and controls would suggest that prosopagnosics use typical mechanisms to process facial expression. Conversely, if prosopagnosics show reduced inversion effects compared to controls', then this would suggest that they use atypical mechanisms, such as those that rely less on holistic processing and are not dependent on the upright orientation of faces.

Circular analysis. Most past studies suffer from the circular analysis of prosopagnosics' facial identity processing (12 out of 20 studies, see Table A1 in Appendix A). Circular analysis (or more colloquially, 'double dipping') is using the same data set twice for selection and selective analyses (Kriegeskorte, Lindquist, Nichols, Poldrack, \& Vul, 2010; Kriegeskorte, Simmons, Bellgowan, \& Baker, 2009). Circular analysis has been a problem for neuroimaging studies when researchers use the same measurements for selecting voxels and for subsequent analyses. Circular analysis is also relevant for prosopagnosia studies because it can occur when working with unique populations that require diagnostic screening. Researchers typically agree that individuals fit diagnostic criteria for prosopagnosia if their performance on a facial identity recognition task is below a certain threshold (e.g., 1.75-2 standard deviations below a neurotypical control sample's mean). If, however, researchers reuse prosopagnosics' diagnostic performance and contrast it against their facial expression performance, then researchers are biased towards reporting statistically inflated dissociations between the two face aspects. This bias is present because the size of the facial identity deficit is pre-determined by the diagnostic cut-off. In this thesis, I combat circular analysis by measuring facial identity processing in prosopagnosics with independent tasks that were not used in diagnostic testing. 
Only using static stimuli. The third limitation is that all past studies only used static stimuli. Because facial expressions are naturally transient and changeable, it is important to also use dynamic stimuli (Johnston, Mayes, Hughes, \& Young, 2013; Kilts, Egan, Gideon, Ely, \& Hoffman, 2003; Recio, Sommer, \& Schacht, 2011). Additionally, testing with static and dynamic stimuli is important because the two types of stimuli engage different brain regions. The ventral face processing stream (which includes the FFA) is implicated in processing static facial attributes, whereas the dorsal stream (which includes the posterior STS; pSTS) is more involved in processing dynamic facial information (Duchaine \& Yovel, 2015; Pitcher, Dilks, Saxe, Triantafyllou, \& Kanwisher, 2011). This distinction has been demonstrated in acquired prosopagnosics (patients HJA and PS) who experienced head trauma to ventral regions of the brain (presumably leaving the more dorsally located STS intact; Humphreys et al., 1993 \& Richoz, Jack, Garrod, Schyns, \& Caldara, 2015). These patients showed impaired facial expression recognition from static stimuli, but normal recognition from dynamic stimuli. In this thesis, I use static and dynamic facial expression stimuli to afford a richer, more ecologically valid assessment of facial expression processing in prosopagnosia, and in doing so, I also provide novel insight regarding whether these abilities can dissociate in prosopagnosia.

Not accounting for autism traits. Past studies typically did not account for the influence of co-occurring autism traits on facial expression processing. A plethora of research suggests that autism is associated face processing deficits (Dawson, Webb, \& McPartland, 2005; Golarai, Grill-Spector, \& Reiss, 2006; Hedley, Brewer, \& Young, 2011; Weigelt, Koldewyn, \& Kanwisher, 2012), including facial expression processing deficits (Humphreys, Minshew, Leonard, \& Behrmann, 2007; Kennedy \& Adolphs, 2012; Loth et al., 2018; Lozier, Vanmeter, \& Marsh, 2014; Uljarevic \& Hamilton, 2013; Wingenbach, Ashwin, \& Brosnan, 2017). Moreover, the prevalence of autism is higher in prosopagnosia than in the general population (Barton et al., 2004; Duchaine, Murray, Turner, White, \& Garrido, 2009; Kracke, 1994; Schultz, 2005). Surprisingly, only six of the 20 past studies measured autism traits in their prosopagnosic samples (these studies are listed in Table A1 of Appendix A). In studies that did not measure autism traits, it is unclear whether prosopagnosics' facial expression processing deficits resulted from the confounding impact of autism traits. Therefore, researchers investigating facial expression processing in prosopagnosia should measure autism traits to either exclude prosopanosics with co-occurring autism or examine whether their scores on a measure of autism traits correlates with their performance on facial expression tasks. In this thesis I do just that-I use prosopagnosics' scores on a measure of 


\section{FACIAL EXPRESSION PROCESSING IN PROSOPAGNOSIA}

autism traits to see if they can account for the prosopagnosics' performance on facial expression tasks.

Limited number and variety of tasks. Previous researchers typically used few facial expression tasks. In most studies (13 out of 20, see Table A1 in Appendix A), researchers only used one task because facial expression processing was not the focus of investigation (e.g., Jones \& Tranel, 2001; Nunn, Postma, \& Pearson, 2001; Schmalzl et al., 2008). Of the studies that were focused on facial expression processing, the most tasks used was four (Duchaine et al., 2003; Palermo et al., 2011). Duchaine and colleagues (2003) tested NM, a 40-year-old woman, using six facial identity recognition tasks and four facial expression tasks. The facial expression tasks varied on expression intensity, task format (matching vs. labelling), amount of facial information presented (whole-face vs. eye-region), and type of expression (basic vs. complex). Duchaine and colleagues were able to conclude that NM's facial expression processing is normal because her performance was consistent across several tasks that assess multiple aspects of facial expression processing. In this thesis, I use multiple and varied facial expression tasks to draw more robust conclusions, and to determine whether specific expression processes are impaired in prosopagnosia (e.g., expression perception vs expression recognition).

Small sample sizes. The final limitation is that all past studies tested relatively small sample sizes. Most studies tested either single cases or less than eleven prosopagnosics (17 out of 20 studies, see Table A1 in Appendix A), and the largest sample so far was 17 prosopagnosics (Biotti \& Cook 2016). While studies with single-cases and small samples can be informative, a large sample is valuable for two reasons. First, it allows for a more precise estimate of prosopagnosics' ability to process facial expression. Second, it increases statistical power to detect subtle facial expression processing deficits. In this thesis, I test a much larger prosopagnosic sample than ever before.

Overall, many studies have investigated facial expression processing in prosopagnosia. However, it remains unclear whether the ability to process facial expression is intact or impaired in prosopagnosia because all past studies were undermined by one or more of the above limitations. Future studies must address and overcome these limitations to draw stronger and more precise conclusions about facial expression processing in prosopagnosia. 


\section{FACIAL EXPRESSION PROCESSING IN PROSOPAGNOSIA}

\subsection{Thesis overview}

In this thesis, I investigate facial expression processing in prosopagnosia across two studies that, together, address the six limitations of past research. First, I test prosopagnosics with facial expression tasks that present trials both in an upright and an inverted orientation, which addresses whether prosopagnosics use similar mechanisms as controls to process facial expression. Second, I avoid circular analysis by testing prosopagnosics with a set of facial identity tasks that are independent of those used to diagnose their prosopagnosia. Third, I investigate prosopagnosics facial expression processing using static and dynamic stimuli. Fourth, I account for the potential influence of autism traits on prosopagnosics facial expression processing. Fifth, I use a large and varied selection of sensitive tasks that assess multiple aspects of facial expression processing. Lastly, I test 124 prosopagnosics - a sample size 7 times larger than the largest study to date. Below, I outline the two studies before presenting them in more detail in separate chapters.

Study 1: Facial expression vs facial identity perception. The aim of Study 1 is to compare prosopagnosics' ability to perceive facial expression against their ability to perceive facial identity. To do this, I use a set of three perceptual tasks: a simultaneous matching task, a sequential matching task, and a sorting task. Each task contrasts expression and identity perception within the same experimental format and difficulty level. Each task also presents trials upright and inverted, which enables me to measure inversion effects as a way to test whether prosopagnosics use typical face mechanisms when processing facial expression and facial identity. This experimental design allows me to determine whether facial expression and facial identity perception dissociate in prosopagnosia, and whether prosopagnosics use atypical face mechanisms for either expression and/or identity. I also examine whether facial expression deficits, should they occur, can be accounted for by co-occurring autism traits. Lastly, I provide an estimate of the proportion of prosopagnosics with facial expression perception deficits.

\section{Study 2: Facial expression recognition for basic and complex expressions with} static and dynamic stimuli. In Study 2, I extend the aim of Study 1 by assessing prosopagnosics' facial expression processing using four recognition tasks. All recognition tasks involve labelling, which require not only the perceptual ability to discriminate between expressions, but also recognition processes to assign verbal labels to specific expressions. Another aim of Study 2 is to provide a more complete analysis of prosopagnosics' facial expression processing in two novel ways. First, I contrast prosopagnosics' ability to 


\section{FACIAL EXPRESSION PROCESSING IN PROSOPAGNOSIA}

recognise facial expressions from static versus dynamic stimuli. Second, I contrast prosopagnosics' ability to label basic expressions (e.g., angry, happy, and sad) versus complex expressions (e.g., elated, mortified, and despondent). No researchers have investigated these two aspects of facial expression processing in prosopagnosia, so Study 2 will provide novel insights into prosopagnosics' ability to recognise static versus dynamic expressions, and basic versus complex expressions. Similar to Study 1, all tasks present trials upright and inverted, which enables me to compute inversion effects and gauge whether prosopagnosics engage typical face mechanisms when recognising facial expressions. As in Study 1, I check whether autism traits can account for facial expression deficits, should they exist. Lastly, I provide an estimate of the proportion of prosopagnosics with facial expression recognition deficits.

Together, Studies 1 and 2 will reveal whether prosopagnosics have normal facial expression processing. If prosopagnosics demonstrate normal performance on all seven expression tasks across Studies 1 and 2, then this will constitute strong evidence that prosopagnosics' facial expression processing is intact. In contrast, if prosopagnosics' performance on the facial expression tasks is impaired in Study 1 and/or 2, then this will this indicate that prosopagnosics have facial expression processing deficits. 


\section{FACIAL EXPRESSION PROCESSING IN PROSOPAGNOSIA}

\section{Chapter 2: Study 1}

In Study 1, I contrast prosopagnosics' ability to perceive facial expression and facial identity. I do this using three perceptual tasks that are equated for format and difficulty across their expression and identity versions. There were two specific aims of Study 1. First, to investigate prosopagnosics' ability to perceive facial expression and facial identity and determine whether these perceptual processes dissociate in prosopagnosia. Second, to determine whether prosopagnosics use typical face mechanisms to process facial expression and facial identity.

Study 1 has important theoretical implications for the ongoing discussion about whether facial expression and facial identity are processed via independent mechanisms (Bruce \& Young, 1986; Haxby et al., 2000) or via shared mechanisms (Calder, 2011; Calder $\&$ Young, 2005). If there is a dissociation between prosopagnosics' ability to process facial expression and facial identity, then they should perform more poorly on the facial identity tasks than on the facial expression tasks, relative to controls. Such a dissociation would support the notion of independent processing systems. Alternatively, if prosopagnosics' ability to process facial expression and facial identity associate, then they should perform similarly on the facial expression and facial identity tasks. The latter finding would support the notion of a shared processing system.

Study 1 will also reveal whether prosopagnosics and controls use typical face mechanisms to process facial expression and facial identity. By comparing inversion effects in the two groups, I can determine whether prosopagnosics engage similar or different mechanisms to process facial expression and facial identity as controls. For instance, if prosopagnosics and controls engage similar mechanisms to process facial expression, then they will show similar-sized inversion effects for facial expression. In contrast, if prosopagnosics engage different mechanisms than controls to process facial expression, then prosopagnosics will have smaller inversion effects, reflecting atypical face processing.

Unlike the majority of past studies, I examine the relationship between prosopagnosics' autism traits and their performance on the facial expression tasks. Facial expression processing deficits are known to be associated with autism (Humphreys et al., 2007; Kennedy \& Adolphs, 2012; Loth et al., 2018; Lozier et al., 2014; Uljarevic \& Hamilton, 2013; Wingenbach et al., 2017). Therefore, if the prosopagnosics demonstrate impaired performance on the facial expression tasks, then it is important to determine 


\section{FACIAL EXPRESSION PROCESSING IN PROSOPAGNOSIA}

whether the expression deficits are a feature of prosopagnosia, or are the result of cooccurring autism traits.

Lastly, with the results of Study 1, I calculate a precise estimate of the prevalence of facial expression perception deficits in prosopagnosia. Unlike past studies, I can provide such an estimate because I test a large prosopagnosic sample and I do not commit circular analysis with the prosopagnosics' facial identity performance.

\subsection{Method}

Prosopagnosic participants. I sourced potential prosopagnosic participants through an online worldwide database for individuals who report difficulty recognising faces (www.faceblind.org). I recruited only participants aged 18-52 years to avoid testing older individuals who may have age-associated cognitive decline, which can confound performance on a range of challenging cognitive tasks (e.g., Deary et al., 2009; Hartshrone \& Germine, 2015). My inclusion criteria for prosopagnosia were (1) subjective complaints of lifetime problems recognising faces, (2) an impaired score on a well-validated scale of prosopagnosia traits (the Prosopagnosia Index 20-item; PI-20, Shah, Gaule, Sowden, Bird, \& Cook, 2015), and (3) impaired scores on two objective tests of facial identity recognition, namely, the Cambridge Face Memory Test (CFMT; Duchaine \& Nakayama, 2006) and a famous faces test (FFT; Duchaine \& Nakayama, 2005). I considered scores on the CFMT and FFT to reflect impairment if they were 1.75 standard deviations below mean scores from neurotypical control samples. My exclusion criteria were (1) a reported history of brain damage (e.g., encephalitis), and/or (2) broader problems of visual processing as captured by the Leuven Perceptual Organisation Screening Test (L-POST; Torfs, Vancleef, Lafosse, Wagemans, \& de-Wit, 2014). In addition, I measured autism traits using the Subthreshold Autism Trait Questionnaire (SATQ; Kanne, Wang, \& Christ, 2012), a self-report measure that assesses a broad range of subthreshold autism traits. I used the SATQ over other, more commonly used autism measures (like the Autism-Spectrum Quotient; Baron-Cohen, Wheelwright, Skinner, Martin, \& Clubley, 2001) because it is brief, easy to complete, and is relevant to the general population (Kanne et al., 2012; Nishiyama et al., 2014). These scores will be used to examine whether autism traits can account for facial expression deficits, if they exist.

A total of 128 prosopagnosics who met the diagnostic criteria above completed Study 1 online on Testable (www.testable.org), a web-based platform for running behavioural 


\section{FACIAL EXPRESSION PROCESSING IN PROSOPAGNOSIA}

studies. I excluded three prosopagnosics from analysis because two attempted the tasks once prior to fully completing them, and one reported being disrupted for an extended period while completing the tasks. The final sample comprised 124 prosopagnosics ( 80 women, 39 men, 5 other). Their scores on the diagnostic tests are presented in Table 1. The mean age was 38.07 years old $(S D=9.48$, range $20-52$ years old). Most prosopagnosics were from the USA $(n=$ 89); the rest were from the UK $(n=18)$, Canada $(n=10)$, Germany $(n=6)$ and France $(n=$ 1). Prosopagnosics' education levels included high school or equivalent $(n=6)$, college or technical school $(n=26)$, bachelor's degree $(n=47)$ and master's/doctorate degree $(n=45)$. I compensated prosopagnosics 10 or 12 US dollars (USD) in the form of an Amazon gift card (www.Amazon.com $)^{1}$.

Table 1. Study 1 prosopagnosics' diagnostic test scores.

\begin{tabular}{|c|c|c|c|c|}
\hline $\begin{array}{l}\text { Diagnostic } \\
\text { test }\end{array}$ & Diagnostic cut-off & $\begin{array}{l}\text { Score } \\
M(S D)\end{array}$ & Range & $\begin{array}{l}\text { Control data } \\
n, M(S D)\end{array}$ \\
\hline CFMT & $=/<42$ (out of 72$)$ & $35.55(4.18)$ & $17-41$ & $n=47,54.30(7.27)$ \\
\hline FFT & $=/<58.00 \%$ & $28.80 \%(13.16)$ & $0.00 \%-57.14 \%$ & $n=97,78.65 \%(11.60 \%)$ \\
\hline PI-20 & $=/>60$ & $81.43(6.27)$ & $64-93$ & $n=242,38.90(10.88)$ \\
\hline L-POST & $\begin{array}{l}\text { Impaired } \\
\text { performance on }=/> \\
4 \text { subtests }\end{array}$ & $\begin{array}{l}\text { Impaired on } \\
0.80(0.98) \\
\text { subtests }\end{array}$ & $\begin{array}{l}\text { Impaired on } 0- \\
3 \text { subtests }\end{array}$ & NA \\
\hline
\end{tabular}

Note. I collected control data for the CFMT and FFT from Amazon Mechanical Turk samples. PI-20 control data was sourced from Shah et al., 2015.

Control participants. I collected control data via online testing methods. A total of 251 individuals located in North America participated via Amazon Mechanical Turk (mTurk; www.mturk.com). I used mTurk to recruit control participants for two reasons. First, online data collected from mTurk is comparable to those obtained from traditional lab-based methods for many areas in psychology (Buhrmester, Kwang, \& Gosling, 2011; Goodman, Cryder, \& Cheema, 2012), including face processing (Germine et al., 2012; Rezlescu, Susilo,

\footnotetext{
${ }^{1}$ Prosopagnosics either received 10 or 12 (USD) depending on whether they completed five $(n=71)$ or 6 tasks $(n=53)$, respectively. Some prosopagnosics only completed 5 tasks if they had already completed the facial identity sorting task in a previous study conducted in Dr Tirta Susilo's lab.
} 


\section{FACIAL EXPRESSION PROCESSING IN PROSOPAGNOSIA}

Wilmer, \& Caramazza, 2017; Susilo, Germine, \& Duchaine, 2013) and prosopagnosia (Biotti et al., 2017; Rezlescu, Susilo, Barton, \& Duchaine, 2014). Second, mTurk affords more timeand cost-efficient data collection compared to lab-based methods. In addition to the six experimental tasks, controls also completed the CFMT to screen out any individuals who may have prosopagnosia. I excluded data from controls if they were older than 52 years of age $(n=43)$ or potentially prosopagnosic as indicated by impaired scores on the CFMT $(n=$ 35). To further enhance data quality, I also screened out controls who did not engage with the tasks, as indexed by accuracy performance at or below chance level for a given task $(n=40)$.

The final control sample comprised 133 individuals ( 89 woman, 44 men). The mean age of the controls was 36.88 years old $(S D=7.58$, range $21-52$ years old), which did not differ from the mean age of the prosopagnosics, $t(255)=1.12, p=.266, d=.14$. The controls' gender distribution did not differ from the prosopagnosics', $\chi^{2}(1)=0.39, p=.531$, $\eta_{p}^{2}<.01$. Controls' education levels included high school or equivalent $(n=32)$, college or technical school $(n=41)$, bachelor's degree $(n=45)$, and master's/doctorate degree $(n=15)$. Controls and prosopagnosics' education levels significantly differed, with prosopagnosics having a higher education level than controls', $\chi^{2}(1)=34.40, p<.001, \eta_{p}^{2}=.12$. However, differences in education level should not impact the results because face recognition and IQ are weakly related (Wilmer et al., 2010; Zhu et al. 2010). Relative to controls, prosopagnosics

had lower CFMT scores $\left(M_{\text {control }}=59.31, S D_{\text {control }}=7.66 ; M_{\text {prosopagnosic }}=35.50, S D_{\text {prosopagnosic }}\right.$ $=4.28 ; t(255)=30.60, p<.001, d=3.82)$. I compensated control participants six USD for participating. Although I compensated mTurk participants less than prosopagnosics, this should not affect the results because differences in compensation rate do not impact data quality (but do, however, impact participation rate; Buhrmester et al., 2011; Mason \& Watts, 2009).

All participants provided consent to participate by clicking an 'agree' button presented below the digital consent form. On completing the tasks, participants were linked to a debriefing form. This study was approved by the School of Psychology Human Ethics Committee under delegated authority of Victoria University of Wellington's Human Ethics Committee. 


\section{FACIAL EXPRESSION PROCESSING IN PROSOPAGNOSIA}

\subsection{Materials and procedure}

Study 1 included three facial expression and three facial identity perception tasks. For each face aspect (expression and identity), I used three different task formats: a simultaneous matching task, a sequential matching task, and a sorting task. These tasks were validated in separate control samples prior to the main experiment to ensure that (1) they did not show ceiling or floor effects, (2) they produced sizeable inversion effects, and (3) that the expression and identity versions of each task format were matched for difficulty. The validation process is detailed in section B.1 of Appendix B.

All participants completed Study 1 on Testable. In total, each participant completed six tasks that were counterbalanced for order. For each task, participants completed trials that were presented in an upright and inverted orientation. Trial orientation was either blocked and counterbalanced for block order (the simultaneous and the sequential matching tasks) or was intermixed within a single block (the sorting tasks). Below, I detail each task format.

Simultaneous matching tasks. In the simultaneous matching tasks, participants viewed three horizontally aligned faces and then selected the face that showed either the 'odd-expression' out (expression task) or 'odd-identity' out (identity task).

Expression simultaneous matching task. In the expression task (Figure 2), the three faces belonged to three different individuals, but two faces displayed the same expression and one displayed a different expression. The expressions were either happy, sad, angry, surprise, disgust, or fear. This task was modified from Palermo and colleagues' (2013) version and details of these modifications are provided in Appendix C.

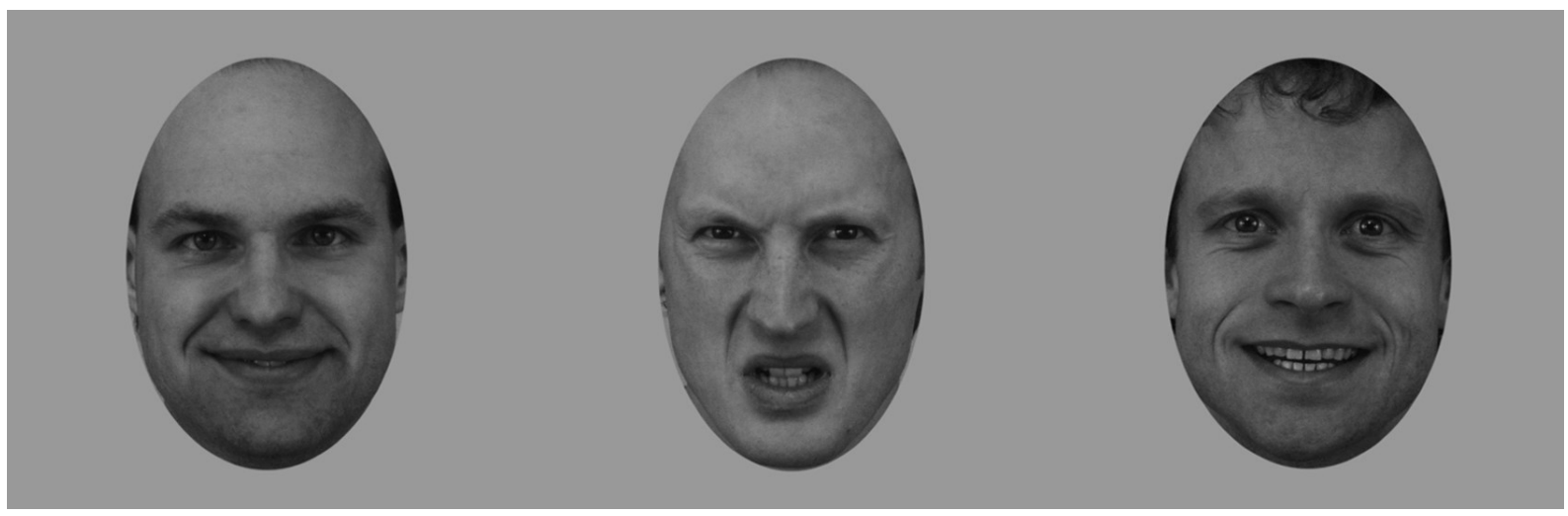

Figure 2. Example of a trial from the expression simultaneous matching task. The target face (centre) shows anger and the two distractor faces (left and right) show happiness. 


\section{FACIAL EXPRESSION PROCESSING IN PROSOPAGNOSIA}

In a trial, the three faces appeared on screen for $4500 \mathrm{~ms}$. Participants responded by pressing the "1", " 2 ", or " 3 " key on a keyboard to select the first, second, or third face, respectively. Participants could respond while or after the faces were shown. An inter-trialinterval (ITI) of $500 \mathrm{~ms}$ separated trials. For each task, participants completed a total of 120 trials, which comprised 60 trials with the faces in an upright orientation and 60 in an inverted orientation. They completed the upright and inverted trials in two separate blocks that were counterbalanced for order. The order of trials within each block was randomised.

Identity simultaneous matching task. In the identity task (Figure 3), the faces displayed three different expressions, but two of the faces belonged to the same individual, and the other face belonged to a different individual. I created the identity task using the same stimulus set as that used in the expression task (the Karolinska Directed Emotional Faces database; Lundqvist, Flykt, \& Öhman, 1998). The details of my method for creating the identity task are in Appendix C. The procedure for the identity task was the same as the expression task.

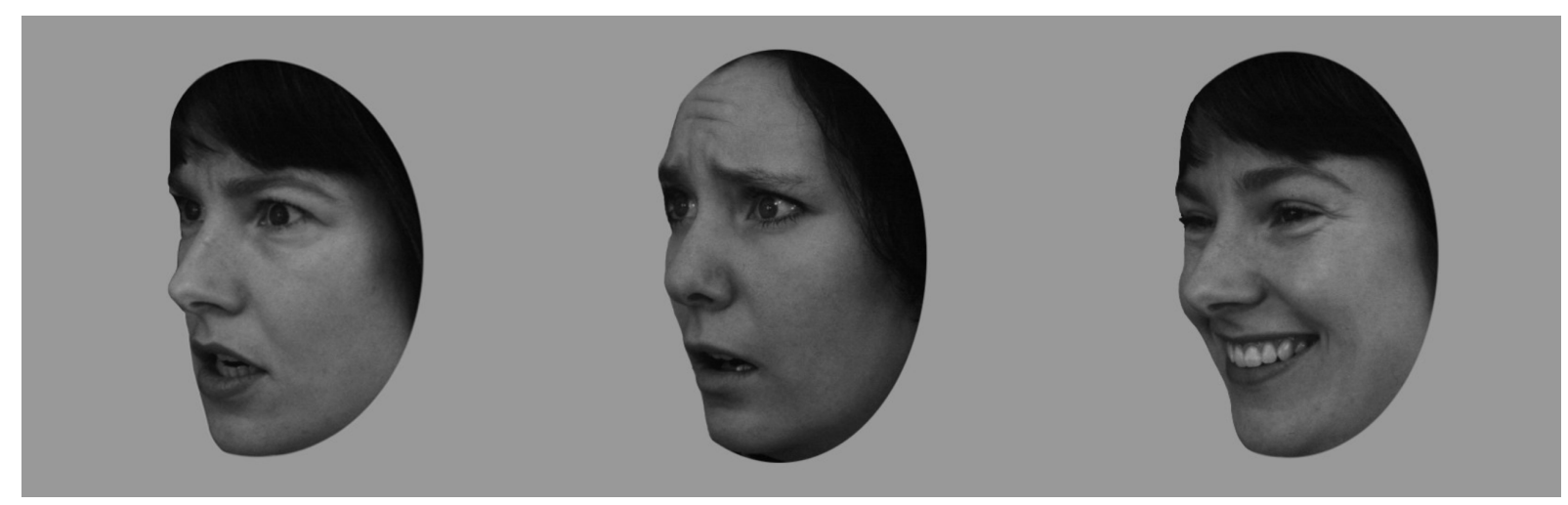

Figure 3. Example of a trial from the identity simultaneous matching task. The target face (centre) shows a different identity (or person) to the two distractor faces (left and right) which show the same identity.

Sequential matching tasks. In the sequential matching tasks, participants viewed two faces in quick succession and judged whether they showed the same or different expressions (expression task) or identities (identity task). These tasks were created by Garrido and colleagues (2009).

Expression sequential matching task. In the expression task, participants had to ignore the identities of the faces and focus on their expressions. The expressions were either happy, sad, angry, surprise, disgust, or fear. On every trial, the identities of the two faces differed. An example trial is depicted in Figure 4. 


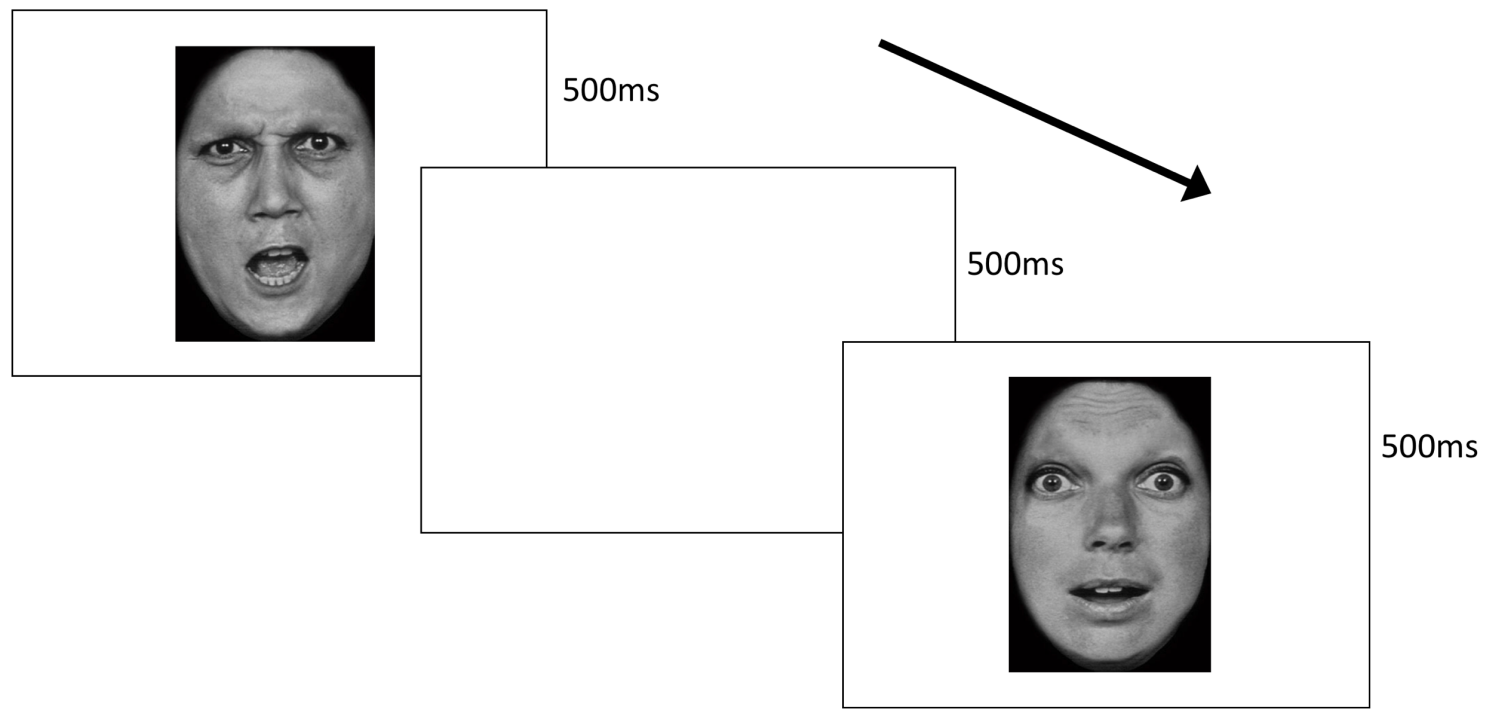

Figure 4. Schematic representation of a trial from the sequential matching tasks. In the expression task, the correct response would be "different" because the first face shows anger and the second shows surprise. In the facial identity task, the correct response would also be "different" as the two faces belong to different individuals.

In the expression task, the first face was shown for $500 \mathrm{~ms}$, then after a $500 \mathrm{~ms}$ interstimulus interval (ISI), the second face was also shown for $500 \mathrm{~ms}$. Participants responded by pressing the " 1 " or " 2 " key on the keyboard to indicate whether the two faces displayed the same or different expression/s, respectively. An ITI of $500 \mathrm{~ms}$ separated trials. The stimulus set comprised 36 greyscale images of six female actors displaying the six basic expressions. Participants completed a total of 144 trials, which comprised 72 trials with the faces shown in an upright orientation and 72 trials with the faces in an inverted orientation. Participants completed the upright and inverted trials in two separate blocks that were counterbalanced for. The order of trials within each block was randomised.

Identity sequential matching task. In the identity task, participants had to ignore the expressions displayed on the faces and focus on their identities. There were six different identities shown throughout the task (to mirror the number of expressions shown). On every trial, the expressions displayed on the two faces differed (as shown in Figure 4). The procedure and stimulus set for the identity task was the same as the expression task, except now participants responded by pressing "1" or " 2 " key on the keyboard to indicate whether the two faces showed the same or different identities, respectively.

Sorting Tasks. In the sorting tasks, participants viewed a target face (shown at a $3 / 4$ viewpoint) presented above six morphed faces (shown at full-front viewpoints). Their task 


\section{FACIAL EXPRESSION PROCESSING IN PROSOPAGNOSIA}

was to sort the six faces with regards to their similarity in expression (expression task) or identity (identity task) to the target face.

Expression sorting task. In the expression task, the target face displayed an expression at full intensity (e.g., anger at 100\% intensity) and the six morph faces showed the same actor displaying the same expression, but at systematically differing intensities (e.g., one face might show a morph between 50\% anger and 50\% neutral). The target faces' expression on a given trial was either angry, sad, happy, or fear. An example trial is shown in Figure 5. Sorting tasks for each basic expression were created by Rezlescu and Susilo (inhouse development), in which all trials of the task involved sorting faces based on their similarity to a specific expression (e.g., the angry sorting task was used in Janik, Rezlescu, \& Banissy, 2015). To create the expression sorting task used in Study 1, I made two minor modifications to the original expression sorting tasks. First, I included a target face to match the format of the identity sorting task. The original expression sorting tasks did not show a target face, instead, participants were instructed what expression to sort the faces by. Second, I used multiple expressions in the task, instead of just one expression.
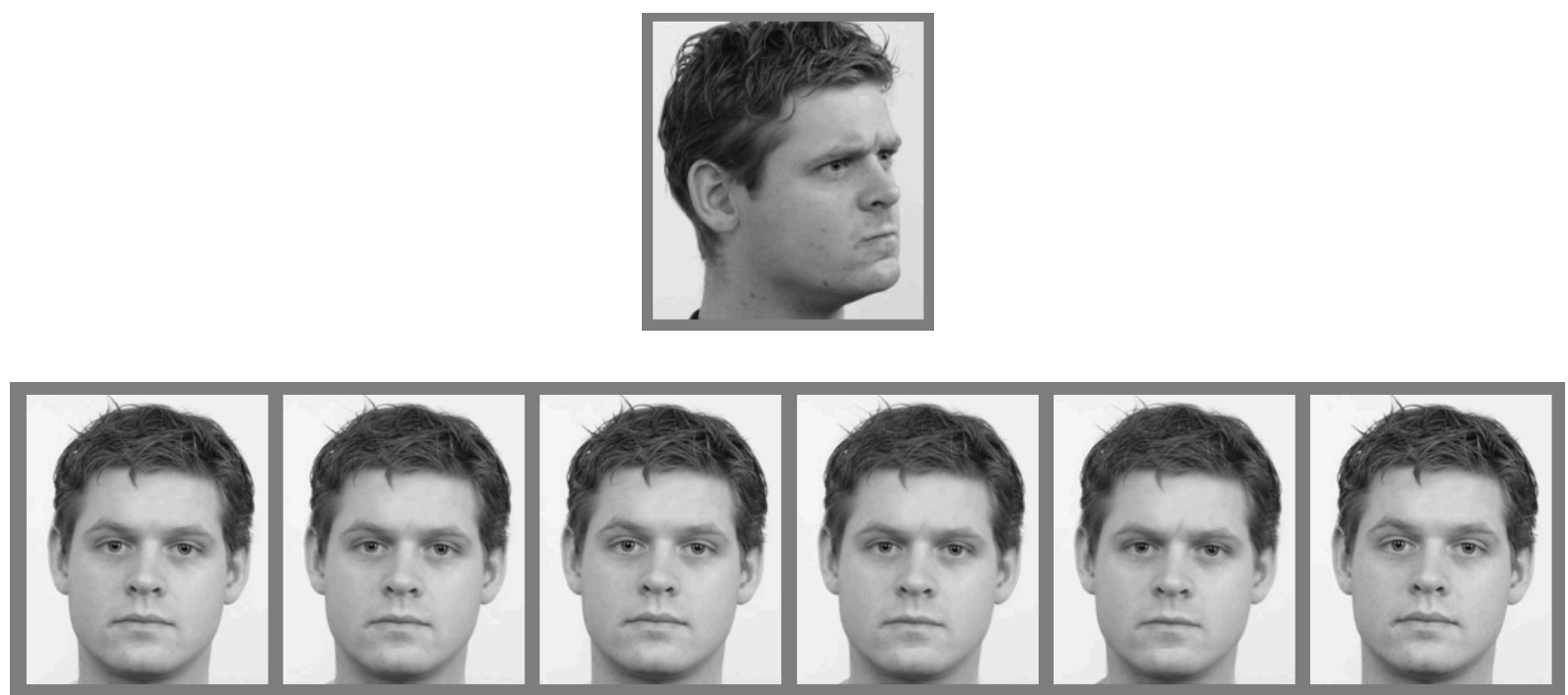

Figure 5. Example of a trial from the facial expression sorting task. If the faces were numbered from 1 to 6 starting from the left face, then the correct sort order for this trial would be face \#5, \#4, \#2, \#1, \#3, and \#6.

In the expression sorting task, participants had a maximum of 40 seconds to complete each trial. Participants sorted the morph faces from most to least similar (left to right) to the target face by clicking and dragging them using a computer mouse. Participants could proceed to the next trial before the current trial had timed out if they believed they had sorted the faces correctly. Each trial began with the morph faces presented in a pre-randomised 


\section{FACIAL EXPRESSION PROCESSING IN PROSOPAGNOSIA}

order in which the total number of deviations from their correctly sorted order was equal to 12. Participants completed 16 experimental trials (eight with the faces in an upright orientation and eight in an inverted orientation). The order of the trials was randomised within a single block.

Identity sorting task. In the identity task (also known as the Cambridge Face Perception Task, Duchaine, Germine, \& Nakayama 2007), the six faces to sort were morphs between the target face's identity and six other face identities. The six faces were morphed in varying proportions so that they systematically differed in similarity to the target face's identity (e.g., one morph face might differ from the target face's identity by $12 \%$, another by $24 \%$, and another by $36 \%$ ). A sample trial is depicted in Figure 6 . The procedure of the identity task was the same as the expression task.
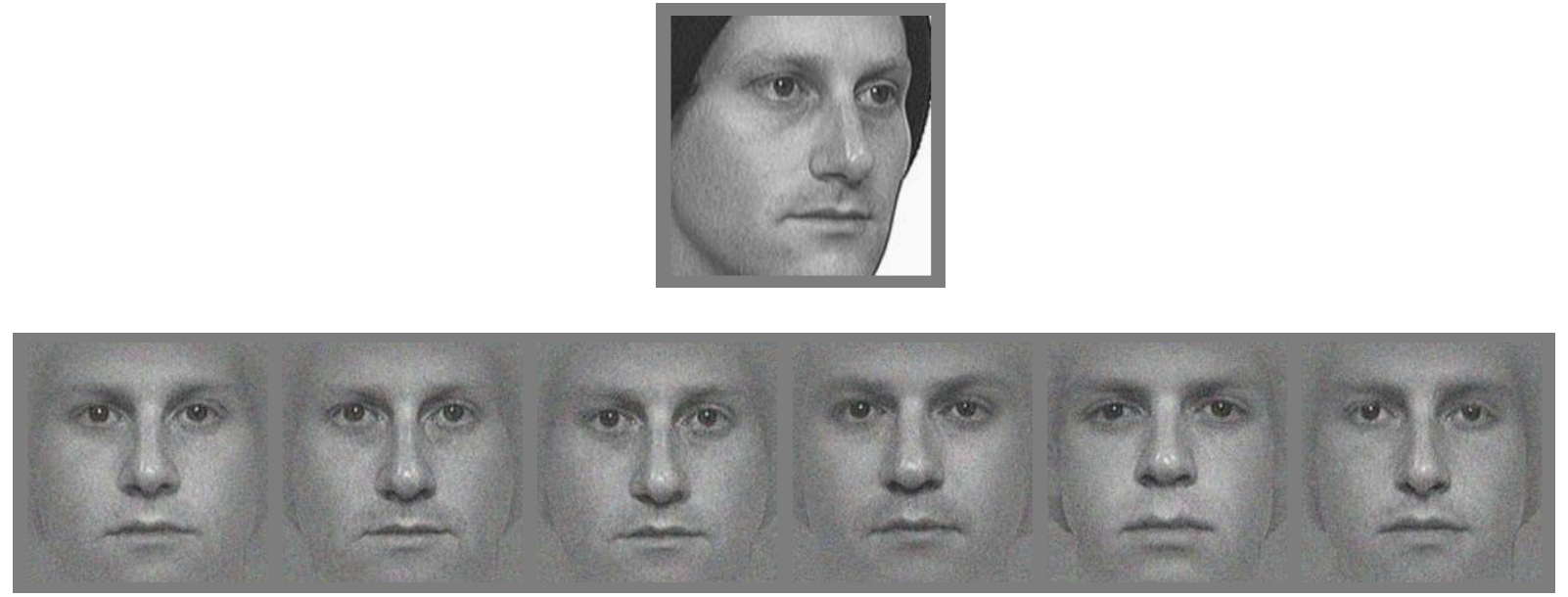

Figure 6. Example of a trial from the facial identity sorting task. If the faces were numbered from 1 to 6 starting from the left face, then the correct sort order for this trial would be face \#2, \#3, \#6, \#1, \#4, and \#5.

\subsection{Results}

I performed all analyses using Jamovi version 0.8 (Jamovi project, 2017) unless otherwise stated. I calculated percent accuracy for the upright and inverted condition of each task. For response time, I calculated trimmed means and medians from correct trials only. To calculate trimmed means, I removed response times 3 SDs greater or less than the mean for a given condition of a task for each participant. I calculated inversion effects (the difference between performance on upright and inverted trials) for percent accuracy and response time for each task. ANOVA results are Greenhouse-Geisser corrected where necessary. For independent $t$-tests, I calculated Cohen's $d$ as a measure of effect size, and for dependent 


\section{FACIAL EXPRESSION PROCESSING IN PROSOPAGNOSIA}

$t$-tests, I calculated $d_{z}$ (Lakens, 2013). $d_{z}$ represents the mean difference divided by the standard deviation of the mean difference.

Descriptive statistics for controls' and prosopagnosics' performance on all tasks are reported in sections B.2 and B.3, respectively, of Appendix B. In section B.2 I also provide analyses that show that controls' performance on the tasks (1) did not show ceiling or floor effects, (2) produced sizeable inversion effects, and (3) were comparable across expression and identity versions of each task.

\subsubsection{Do facial expression and facial identity perception dissociate in prosopagnosia?}

First, I wanted to address the question of whether prosopagnosics' abilities to perceive facial expression and facial identity dissociate. To do this I compared their performance on the facial expression and facial identity tasks, focusing on upright trials.

Accuracy. I ran a 2 (face aspect: expression, identity) x 3 (task format: simultaneous matching, sequential matching, sorting) x 2 (group: prosopagnosia, control) mixed-design analysis of variance (ANOVA) on accuracy scores for upright trials, with face aspect and task format as within-subjects factors, and group as the between-subjects factor. There were significant main effects of face aspect $\left(F(1,255)=15.21, p<.001, \eta_{p}^{2}=.06\right), \operatorname{group}(F(1$, $\left.255)=48.10, p<.001, \eta_{p}^{2}=.16\right)$, and task format $\left(F(1.85,471.87)=204.155, p<.001, \eta_{p}^{2}\right.$ $=.45)$. The main effects were qualified by significant two-way interactions between face aspect and group $\left(F(1,255)=51.00, p<.001, \eta_{p}^{2}=.17\right)$, task format and group $(F(2,510)=$ $\left.8.08, p<.001, \eta_{p}^{2}=.03\right)$, and face aspect and task format $(F(1.86,473.97)=47.07, p<.001$, $\left.\eta_{p}^{2}=.16\right)$. However, the three-way interaction between face aspect, group, and task format was not significant, $F(2,510)=0.29, p=.752, \eta_{p}^{2}<.01$. Because the three-way interaction was not significant, and because my aim was to contrast facial expression perception against facial identity perception in prosopagnosics and controls, I examined the two-way interaction between face aspect and group, collapsing across task format ${ }^{2}$. Post hoc comparisons showed

\footnotetext{
${ }^{2}$ I ran additional analyses with the sequential matching tasks because it is a two-alternative forced choice task, which enables one to investigate performance using $d^{\prime}$, a sensitivity measure. I obtained a similar result when analysing the sequential matching tasks using $d$ ' (these supplementary analyses are detailed in section B.4 of Appendix B).
} 


\section{FACIAL EXPRESSION PROCESSING IN PROSOPAGNOSIA}

that, relative to controls, prosopagnosics performed more poorly on the facial identity tasks, showing a $9.28 \%$ drop in performance $\left(M_{\text {control }}=74.59 \%, S D_{\text {control }}=7.64 \% ; M_{\text {prosopagnosic }}=\right.$ $\left.65.31 \%, S D_{\text {prosopagnosic }}=6.74 \% ; t(255)=10.30, p<.001, d=1.29\right)$. Relative to controls, prosopagnosics also performed more poorly on the facial expression tasks, showing a $2.91 \%$. drop in performance $\left(M_{\text {control }}=73.15 \%, S D_{\text {control }}=9.01 \% ; M_{\text {prosopagnosic }}=70.24 \%\right.$, $\left.S D_{\text {prosopagnosic }}=7.97 \% ; t(255)=2.73, p=.007, d=0.34\right)$. However, as shown in Figure 7 , the drop in prosopagnosics' performance on the facial identity tasks is larger than the drop on the expression tasks, and this difference is what drives the interaction. I did not break down the two-way interactions between task format and group and between face aspect and task format because doing so will not inform whether the abilities to perceive facial expression and facial identity dissociate in prosopagnosia.

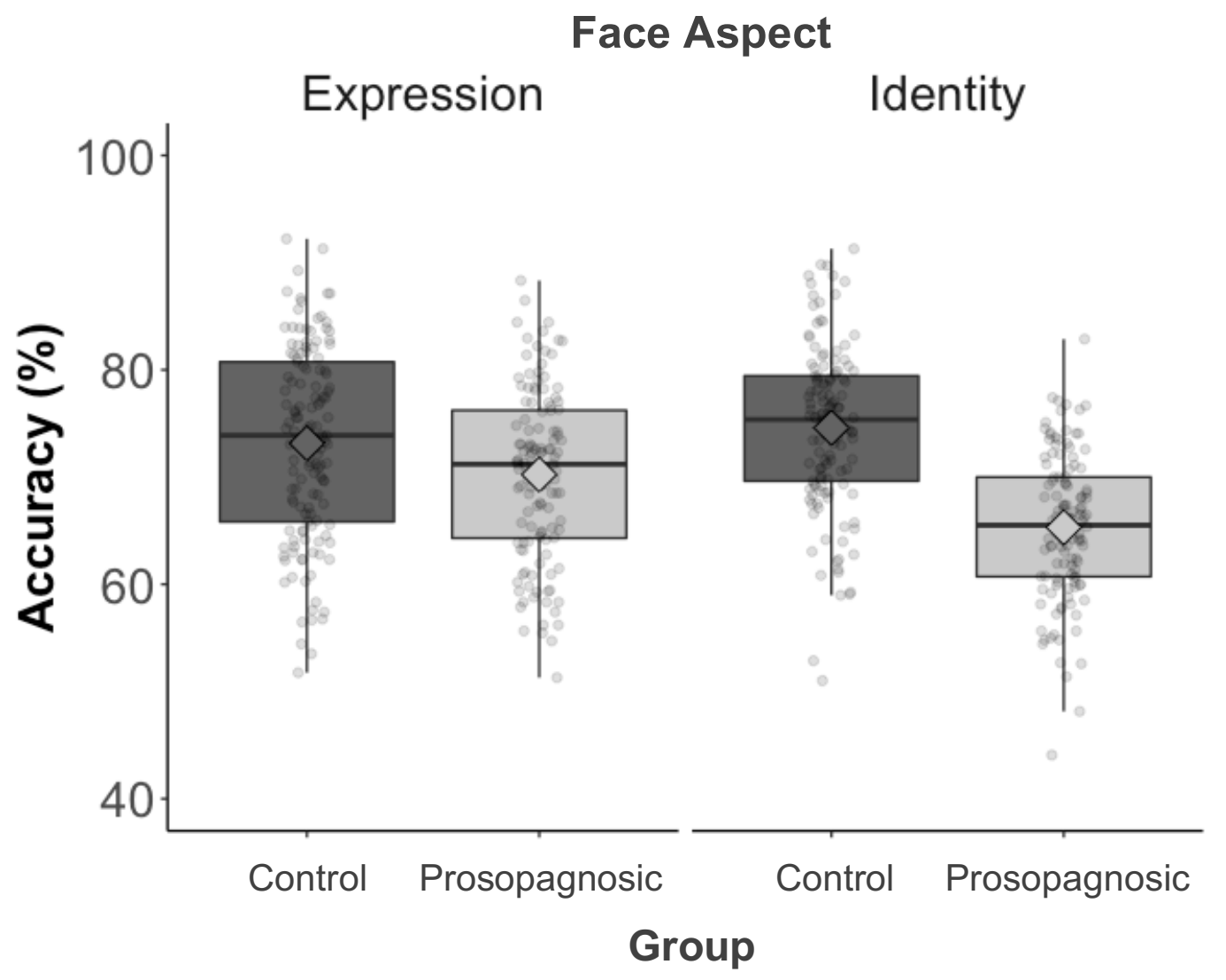

Figure 7. Boxplots of prosopagnosics' and controls' accuracy on the facial expression (left) and facial identity (right) tasks for upright trials, collapsed across task formats. Points represent individual data. Diamonds represent the mean score for each condition.

Response time. Although I am primarily interested in accuracy performance, I also analysed trimmed mean response times to check that differences in response time were not accounting for the pattern of results in accuracy. For instance, if prosopagnosics were slower on the facial expression tasks compared to the facial identity tasks, then this would suggest 


\section{FACIAL EXPRESSION PROCESSING IN PROSOPAGNOSIA}

that prosopagnosics' better performance on the facial expression tasks may be achieved by more time consuming, compensatory strategies. Figure 8 shows the results. I ran a 2 (face aspect: expression, identity) x 2 (group: prosopagnosia, control) mixed-design ANOVA on response times for upright trials, with face aspect as the within-subjects factor and group as the between-subjects factor. There were significant main effects of group $(F(1,255)=64.20$, $\left.p<.001, \eta_{p}^{2}=.20\right)$ and face aspect $\left(F(1,255)=26.23, p<.001, \eta_{p}^{2}=.09\right.$, and the interaction between face aspect and group was also significant $\left(F(1,255)=3.40, p=.046, \eta_{p}^{2}=.02\right)$. To break down the interaction, I ran post hoc comparisons. Relative to controls', prosopagnosics' response times were slower on the facial expression tasks $\left(M_{\text {control }}=8315\right.$ $\mathrm{ms}, S D_{\text {control }}=3170 \mathrm{~ms} ; M_{\text {prosopagnosic }}=11000 \mathrm{~ms}, S D_{\text {prosopagnosic }}=3430 \mathrm{~ms} ; \mathrm{t}(255)=6.52, p<$ $.001, d=0.82)$, and the facial identity tasks $\left(M_{\text {control }}=8743 \mathrm{~ms}, S D_{\text {control }}=2975 \mathrm{~ms}\right.$; $\left.M_{\text {prosopagnosic }}=11978 \mathrm{~ms}, S D_{\text {prosopagnosic }}=3045 \mathrm{~ms} ; t(255)=8.61, p<.001, d=1.08\right)$. (Note that the response times across the three task formats are long because participants had a maximum of 40 seconds per trial to complete their response in the sorting task, and participants were not specifically instructed to respond quickly). Critically, as shown in Figure 8, prosopagnosics' response times were even slower on the facial identity tasks than on the facial expression tasks compared to controls' (a difference of $3235 \mathrm{~ms}$ in the facial identity tasks versus $2685 \mathrm{~ms}$ in the facial expression tasks). The dissociation between prosopagnosics' response times on the facial expression and facial identity tasks mirrors the dissociation observed in accuracy, indicating that response time differences cannot account for the pattern of performance observed in accuracy. A similar result was obtained with median response times (these supplementary analyses are detailed in in section B.5 of Appendix B). 


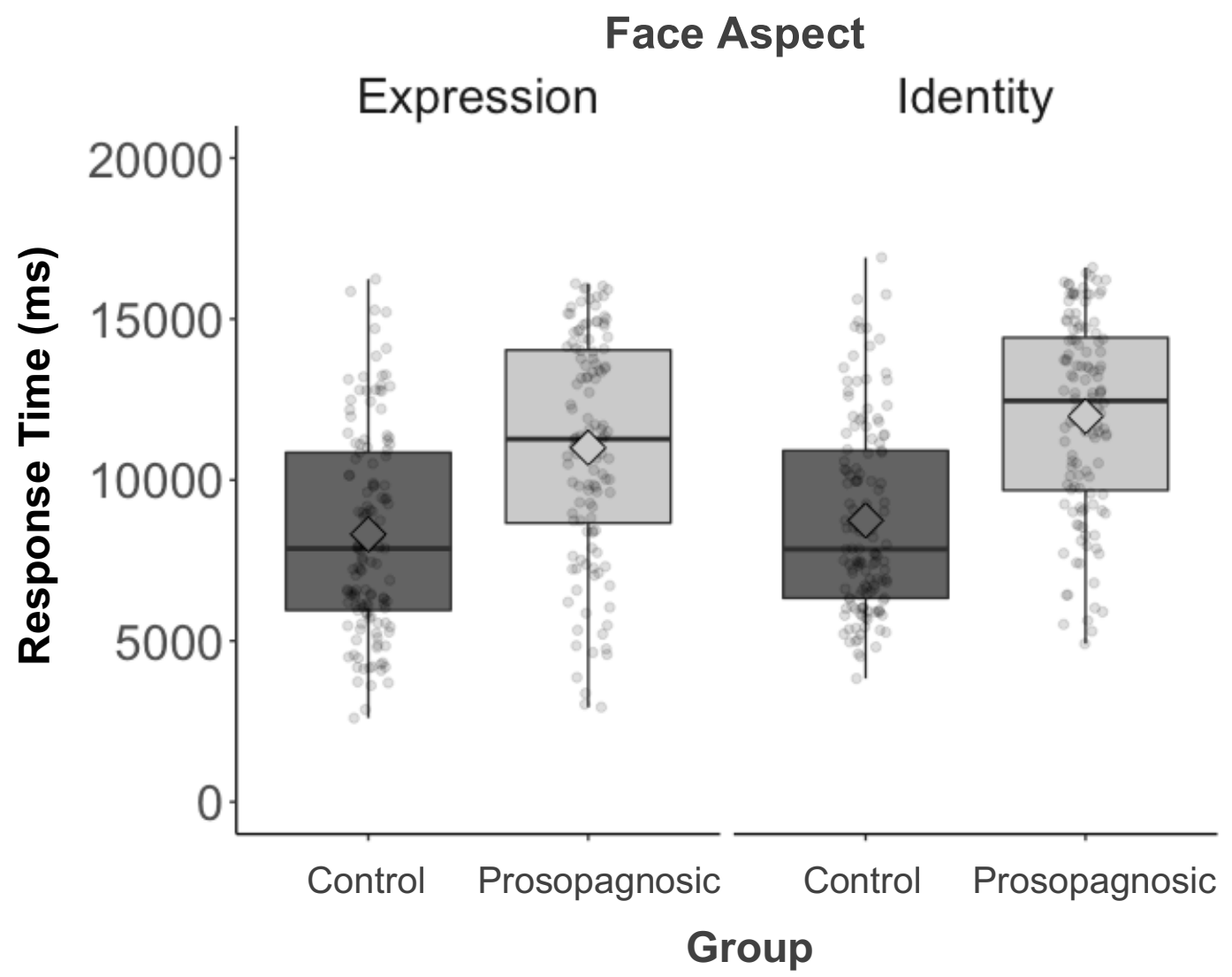

Figure 8. Boxplots of prosopagnosics' and controls' trimmed mean response times on the facial expression (left) and facial identity (right) tasks for upright trials, collapsed across task formats. Points represent individual data. Diamonds represent the mean score for each condition.

Overall, prosopagnosics' deficits for facial expression are smaller than those observed for facial identity. Importantly, speed-accuracy trade-offs do not account for this dissociation. This result suggests that the abilities to perceive facial expression and facial identity dissociate in prosopagnosia. With regard to prosopagnosics' ability to process facial expression itself, because they show a small reduction in performance relative to controls, this suggests that prosopagnosics may have subtle deficits for facial expression perception.

\subsubsection{Do facial expression and facial identity mechanisms dissociate in prosopagnosia?}

The dissociation I observed above raises a question: do prosopagnosics use different mechanisms than controls for perceiving facial identity but similar mechanisms for perceiving facial expression? To address this question, I compared the size of inversion effects in the two groups across expression and identity tasks, collapsing across task formats. If prosopagnosics show similar-sized inversion effects to controls, then this would imply that 


\section{FACIAL EXPRESSION PROCESSING IN PROSOPAGNOSIA}

they use typical face mechanisms, whereas reduced inversion effects would suggest that they engage atypical, compensatory mechanisms.

Accuracy. I calculated inversion effects (i.e., upright accuracy minus inverted accuracy) for prosopagnosics' and controls' performance on the facial expression and facial identity tasks. Figure 9 shows the results. I ran a 2 (face aspect: expression, identity) x 2 (group: prosopagnosia, control) mixed-design ANOVA on inversion effects, with face aspect as the within-subjects factor and group as the between-subjects factor. This revealed significant main effects of face aspect $\left(F(1,255)=4.45, p=.036, \eta_{p}^{2}=.02\right)$ and $\operatorname{group}(F(1$, $\left.255)=42.10, p<.001, \eta_{p}^{2}=.14\right)$, which were qualified by a significant interaction between face aspect and group, $F(1,255)=42.10, p<.001, \eta_{p}^{2}=.14$. Post hoc comparisons revealed that, relative to controls, prosopagnosics showed similar inversion effects for facial expression $\left(M_{\text {control }}=11.31 \%, S D_{\text {control }}=6.26 \% ; M_{\text {prosopagnosic }}=10.03 \%, S D_{\text {prosopagnosic }}=\right.$ $6.34 \% ;(t(255)=1.63, p=.105, d=0.20)$, but smaller inversion effects for facial identity $\left(M_{\text {control }}=12.72 \%, S D_{\text {control }}=6.53 \% ; M_{\text {prosopagnosic }}=6.41 \%, S D_{\text {prosopagnosic }}=5.98 \% ; t(255)=\right.$ $8.06, p<.001, d=1.01)$. Importantly, prosopagnosics' smaller inversion effects for facial identity are not an artefact of "restriction of range" ", because their accuracy scores on the inverted conditions across all identity tasks are sufficiently above chance/floor level (refer to Table B3 in section B.3 of Appendix B). This finding suggests that prosopagnosics engage typical face mechanisms for facial expression, but resort to alternative, compensatory mechanisms for facial identity.

\footnotetext{
${ }^{3}$ See Crookes and McKone (2009) for a detailed discussion of "restriction of range" problems in the face processing literature. In brief, the problem of restriction of range has affected researchers' ability to contrast face recognition ability in children and adults. Specifically, childrens' performance typically suffers restriction of range (due to near floor performance on a basline condition, like performance on the upright condition of an inversion effect study; e.g., Carey, Diamond, \& Woods, 1980), but adults performance often does not (their performance is usually below ceiling and above chance on the baseline condition; e.g., Carey, 1981).
} 


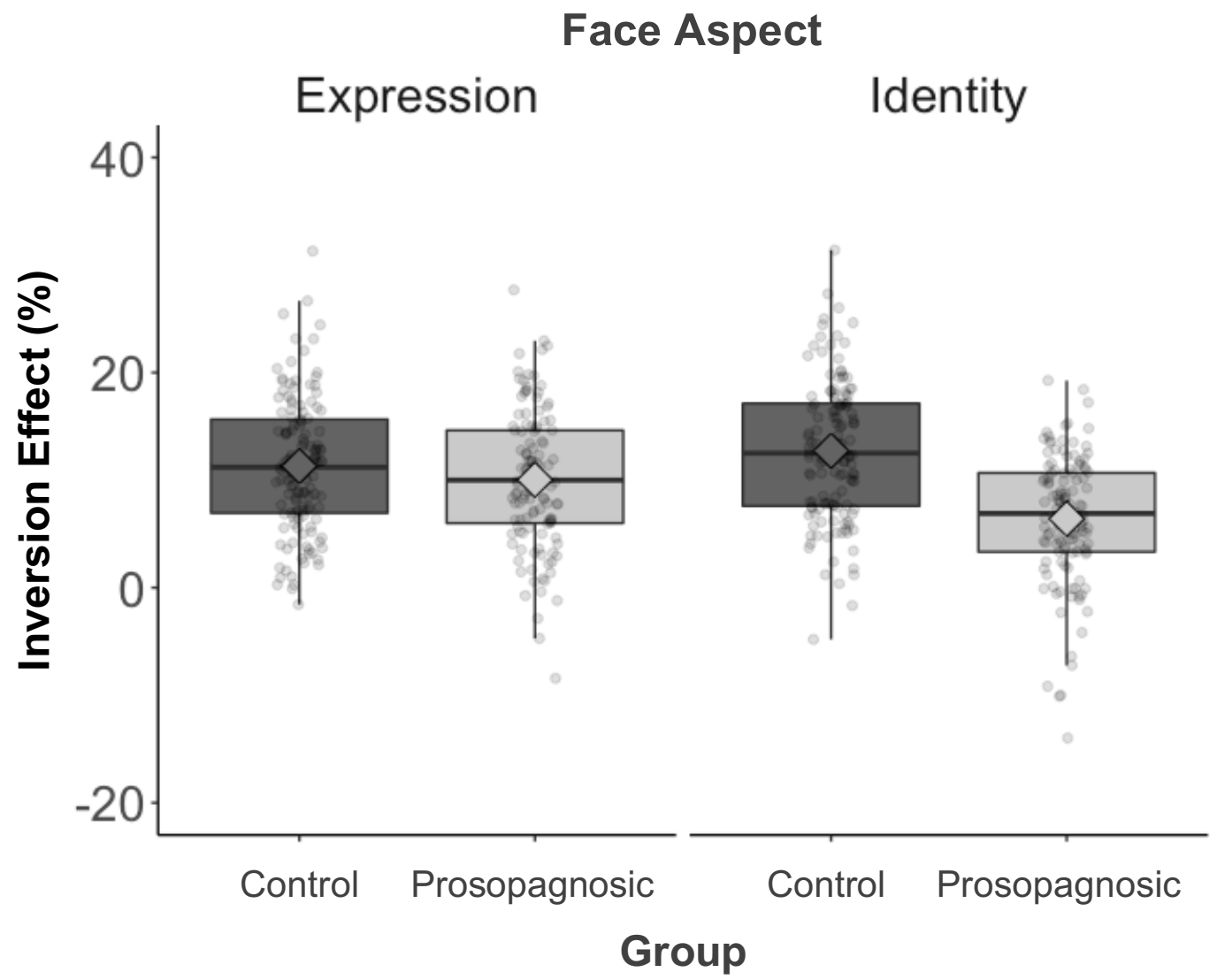

Figure 9. Boxplots of prosopagnosics' and controls' inversion effects in accuracy on the facial expression (left) and facial identity (right) tasks, collapsed across task formats. Points represent individual data. Diamonds represent the mean score for each condition.

Response times. Next, I calculated inversion effects from trimmed mean response times (i.e., upright response time minus inverted response time) to check whether differences in response time could account for the pattern of inversion effects in accuracy. Figure 10 shows the results. I ran a 2 (face aspect: expression, identity) x 2 (group: prosopagnosic, control) mixed-design ANOVA on response time inversion effects, with face aspect as the within-subjects factor and group as the between-subjects factor. There was a significant main effect of group, indicating that prosopagnosics' inversion effects were larger across both the facial expression and facial identity tasks relative to controls $\left(M_{\text {control }}=364 \mathrm{~ms}, S D_{\text {control }}=\right.$ $4013 \mathrm{~ms} ; M_{\text {prosopagnosic }}=479 \mathrm{~ms}, S D_{\text {prosopagnosic }}=1748 \mathrm{~ms} ; F(1,255)=5.48, p=.020, \eta_{p}^{2}=$ $.02)$. The main effect of face aspect $\left(F(1,255)=1.19, p=.277, \eta_{p}^{2}<.01\right)$ and the interaction between face aspect and group were not significant $\left(F(1,255)=0.97, p=.327, \eta_{p}^{2}<.01\right)$, indicating that the dissociation between facial expression and facial identity inversion effects in accuracy cannot be accounted for by response time differences. A similar result was 
obtained with median response times (these supplementary analyses are detailed in section B.5 of Appendix B).

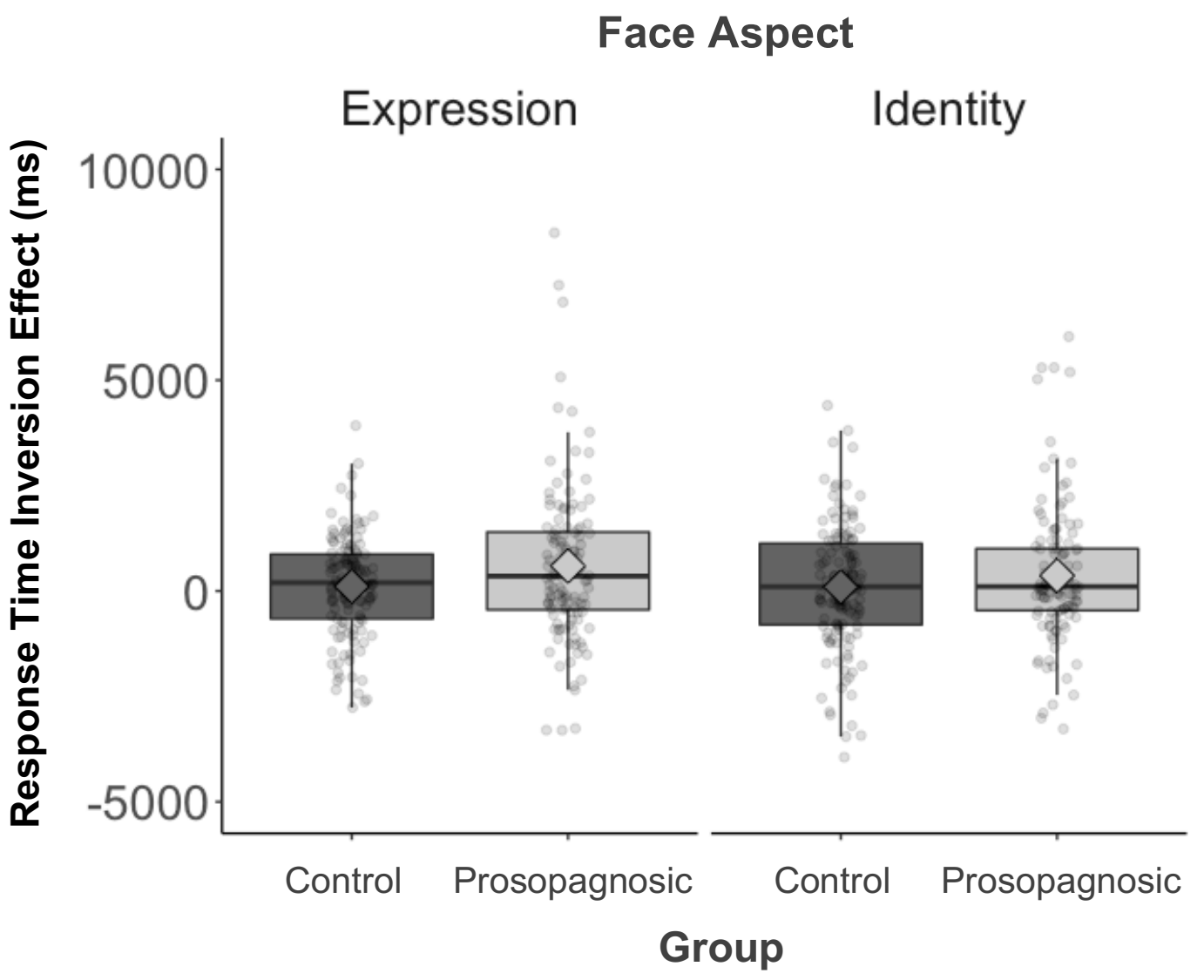

Figure 10. Boxplots of prosopagnosics' and controls' inversion effects in trimmed mean response times on the facial expression (left) and facial identity (right) tasks, collapsed across task formats. Points represent individual data. Diamonds represent the mean score for each condition.

Overall, prosopagnosics' inversion effects were reduced for facial identity, but were of similar size for facial expression relative to controls. Taken together, these results suggest that prosopagnosics may perceive facial expression from upright faces using similar specialised face mechanisms as controls, but that prosopagnosics may perceive facial identity using atypical, less effective mechanisms than controls.

\subsubsection{Is the subtle facial expression deficit a core feature of prosopagnosia?}

Although prosopagnosics performed better on the facial expression tasks than on the facial identity tasks, they still showed subtle deficits on the facial expression tasks compared to controls. Is this subtle deficit is a core feature of prosopagnosia, or a feature of other developmental conditions that co-occur with prosopagnosia such as autism? 


\section{FACIAL EXPRESSION PROCESSING IN PROSOPAGNOSIA}

To tackle this question, I began by comparing prosopagnosics' SATQ scores (a selfreport measure of subthreshold autism traits, Kanne et al., 2012;) with those collected from a new control sample. I ran the SATQ with a sample of mTurk participants, which comprised 49 individuals ( 30 women, 18 men, 1 other). Their mean age was 37.63 years old ( $S D=6.89$, range 29-51), which was comparable to the prosopagnosics' mean age $(t(171)=0.30, p=$ $.768, d=0.05)$. Relative to controls', prosopagnosics' SATQ scores were higher, suggesting elevated rates of autism traits in prosopagnosia $\left(M_{\text {control }}=23.38, S D_{\text {control }}=11.51\right.$, range $0-65$; $M_{\text {prosopagnosic }}=29.51 S D_{\text {prosopagnosic }}=14.05$, range 6-67; $t(171)=2.71, p=.007, d=0.46$ ).

Next, I ran two analyses. First, I correlated prosopagnosics' SATQ scores with their performance on the upright trials of the facial expression and facial identity tasks. Figure 11 shows the correlations. If the subtle facial expression deficits are a feature of prosopagnosia, then prosopagnosics' SATQ scores should correlate (or not correlate) similarly with their scores on both the facial expression tasks and the facial identity tasks. However, if the subtle facial expression deficits are a feature of co-occurring autism traits, then prosopagnosics' SATQ scores should correlate more strongly with their performance on the facial expression tasks than on the facial identity tasks. There was a negative correlation between prosopagnosics' SATQ scores and their performance on the facial expression tasks, indicating that as autism traits increase, facial expression perception tends to worsen $(r(122)$ $=-.29, p=.001)$. Critically, there was no correlation between prosopagnosics' SATQ scores and their performance on the facial identity tasks, $r(122)=.03, p=.734$ (the difference between the two correlations was significant, $z=-3.95$; Lee \& Preacher, 2013). This analysis suggests that the subtle facial expression deficits I observed is not a feature of prosopagnosia, but rather a feature of co-occurring autism traits. In addition, I ran the same analysis after removing scores from three scale items that specifically measured 'Reading facial expressions' to check that the significant correlation between prosoapgnosics SATQ scores and their performance on the facial expression tasks was not driven by these three items. Importantly, the same pattern of results was observed with these adjusted SATQ scores (these supplementary analyses are detailed in section B.6 of Appendix B). 


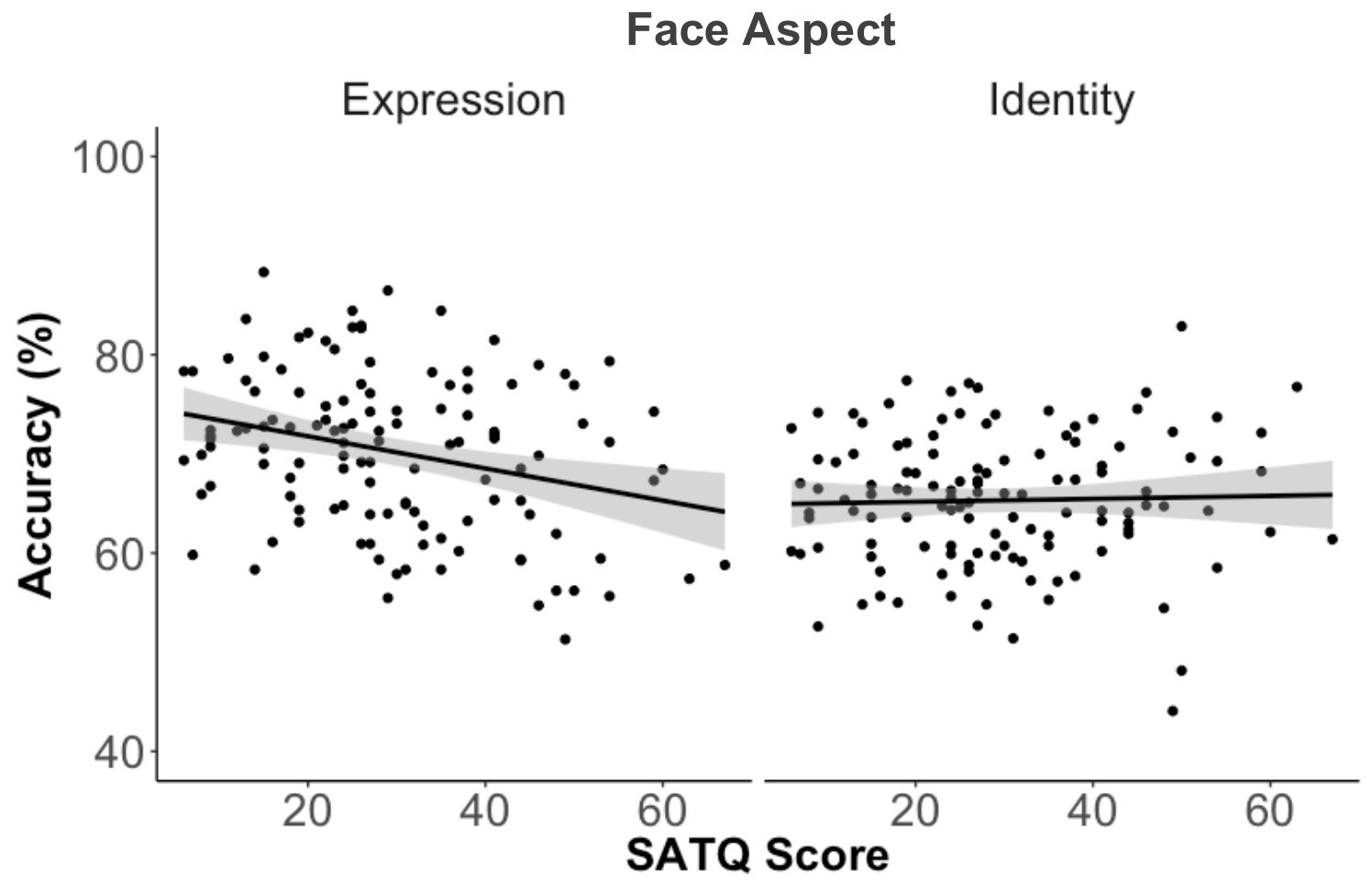

Figure 11. Scatterplots with lines of best fit for prosopagnosics' SATQ scores and their accuracy on the facial expression (left) and facial identity tasks (right) for upright trials, collapsed across task formats. Grey shading represents the $95 \%$ confidence interval.

In a second analysis, I excluded prosopagnosics with high SATQ scores (indicating high levels of autism traits) from the sample to determine if this eliminates the prosopagnosics' small facial expression deficits. I created a SATQ cut-off score using the abovementioned mTurk controls' mean score, which was set at 1.75 standard deviations above the mean (i.e., at $>43.51$ ). Using this cut-off, I excluded 24 prosopagnosics, leaving a sample of 100 prosopagnosics with SATQ scores below $43.51^{4}$. With this adjusted sample of prosopagnosics, I ran a 2 (face aspect: expression, identity) x 2 (group: prosopagnosia, control) mixed-design ANOVA on accuracy for upright trials, with face aspect as the withinsubjects factor and group as the between-subjects factor. There were significant main effects of face aspect $\left(F(1,231)=27.80, p<.001, \eta_{p}^{2}=.11\right)$ and $\operatorname{group}(F(1,231)=36.50, p<.001$,

\footnotetext{
${ }^{4}$ Controls did not complete the SATQ therefore I could not also remove high SATQ scoring controls. However, based on the control sample from which the SATQ cut-off score was generated, two out of 49 controls (4.08\%) had scores above the cut-off. Using this estimate, I would have removed roughly five individuals from the Study 1 control sample. The impact of five individuals would likely have slightly shifted up the controls performance on the facial expression tasks. This potential limitation also applies to the SATQ analyses in Study 2.
} 


\section{FACIAL EXPRESSION PROCESSING IN PROSOPAGNOSIA}

$\left.\eta_{p}^{2}=.14\right)$, which were qualified by a significant interaction between face aspect and group $\left(F(1,231)=71.80, p<.001, \eta_{p}^{2}=.24\right)$. Post hoc comparisons showed that prosopagnosics' and controls' performance were now comparable on the facial expression tasks $\left(M_{\text {control }}=\right.$ $73.15 \%, S D_{\text {control }}=9.01 \% ; M_{\text {prosopagnosic }}=71.45 \%, S D_{\text {prosopagnosic }}=7.36 \% ; t(231)=1.34, p=$ $.125, d=0.20)$, but prosopagnosics still performed worse on the facial identity tasks $\left(M_{\text {control }}\right.$ $=74.59 \%, S D_{\text {control }}=7.64 \% ; M_{\text {prosopagnosic }}=65.23 \%, S D_{\text {prosopagnosic }}=6.18 \% ; t(231)=10.03, p$ $<.001, d=1.33$ ). Consistent with the prior correlation analysis, excluding prosopagnosics with high SATQ scores abolished the prosopagnosics' subtle deficits for facial expression, but did not alter their larger deficits for facial identity processing.

Together, these analyses suggest that autism traits can account for prosopagnosics' subtle deficits in facial expression perception but cannot account for their larger deficits in facial identity perception. These results mean that the subtle facial expression perception deficits are not a core feature of prosopagnosia, but may be the result of co-occurring autism traits.

\subsubsection{Proportion of prosopagnosics with facial expression perception deficits}

In addition to the analyses above, I calculated composite z-scores to estimate of the proportion of prosopagnosics who have facial expression perception impairments. Such an estimate has not been possible in previous studies due to the circular analysis of facial identity processing ability and inadequate prosopagnosic sample sizes. I calculated z-scores (using the Study 1 control mean scores and standard deviations) for prosopagnosics' performance on the upright trials of each facial expression and facial identity task. From these z-scores, I calculated prosopagnosics' composite facial expression and facial identity zscores. Figure 12 shows the composite z-scores. I considered prosopagnosics as having impairments for perceiving a given face aspect if their composite z-scores were equal to or less than - 1.75. For facial expression, only one prosopagnosic had a z-score in the impaired range, whereas for facial identity, 13 prosopagnosics had z-scores in the impaired range. This means that out of every 13 prosopagnosics who have facial identity perception impairments, one prosopagnosic will have facial expression perception impairments. Therefore, it can be estimated that roughly $7.70 \%$ of prosopagnosics have facial expression perception impairments, suggesting that the majority of prosopagnosics have normal facial expression perception. 


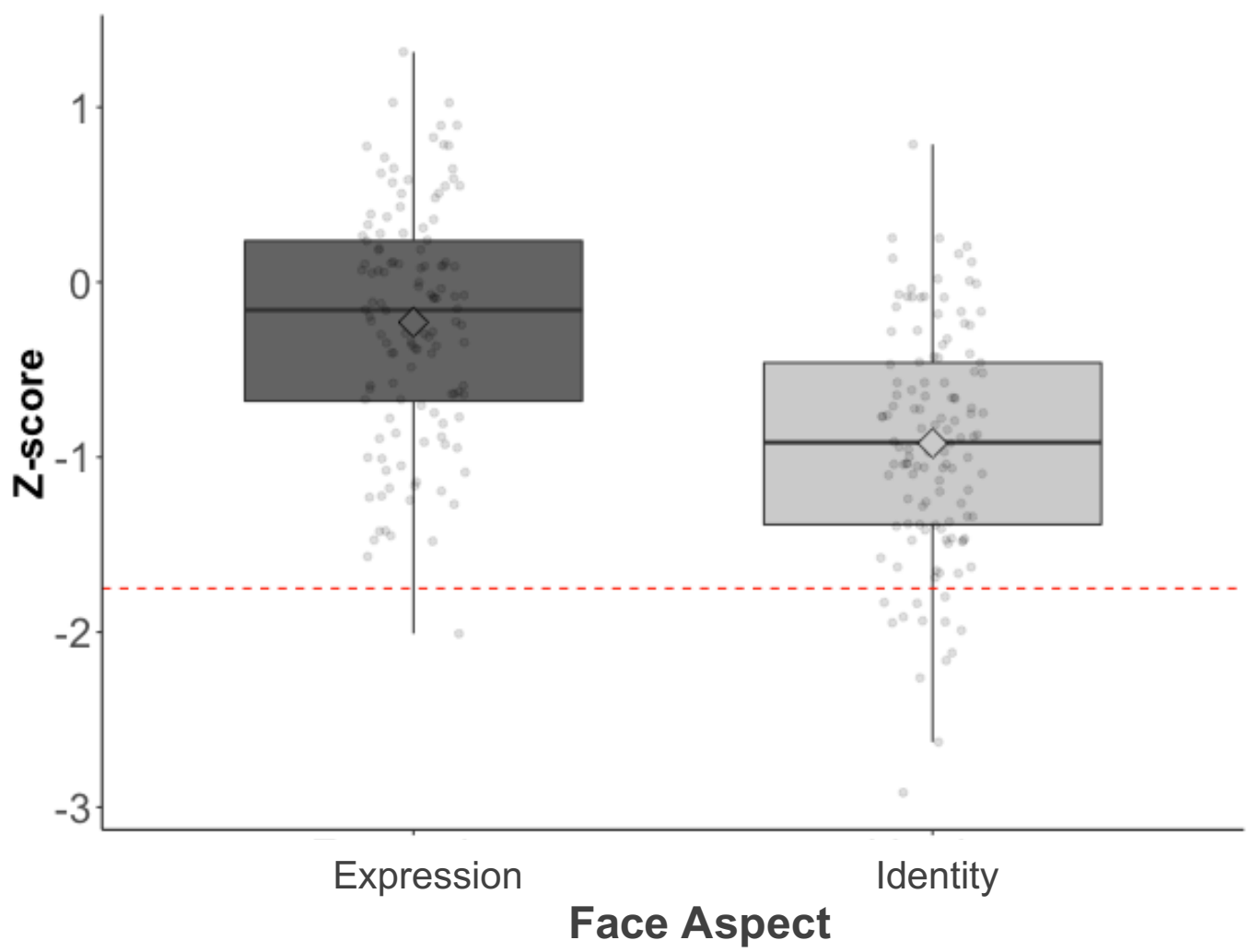

Figure 12. Boxplots of prosopagnosics' composite z-scores on the facial expression (left) and facial identity (right) tasks for upright trials. Points represent individual data. Diamonds represent the mean score for each condition. The red dotted line marks -1.75 on the y-axis.

\subsection{Discussion}

There were two specific aims of Study 1. First, to investigate prosopagnosics' ability to perceive facial expression and facial identity and determine whether these perceptual processes dissociate in prosopagnosia. Relative to controls, prosopagnosics performed more poorly on the facial identity tasks than on the facial expression tasks, suggesting that the ability to perceive the two facial aspects dissociates in prosopagnosia. The second aim was to determine whether prosopagnosics use typical face mechanisms to percieve facial expression and facial identity as controls do. The dissociation between facial expression and facial identity performance was not only observed in raw accuracy, but also in inversion effects. The similar-sized inversion effects for prosopagnosics' and controls' performance on the facial expression tasks, but not the facial identity tasks, suggests that prosopagnosics perceive facial expression using similar mechanisms to controls, but perceive facial identity using different mechanisms to controls. 


\section{FACIAL EXPRESSION PROCESSING IN PROSOPAGNOSIA}

Prosopagnosics' scores on a measure of subthreshold autism traits accounted for their small facial expression deficits. Not only did prosopagnosics SATQ scores negatively correlate with their performance on the facial expression tasks (indicating that higher levels of subthreshold autism traits were related to poorer performance on the facial expression tasks), but the exclusion of high SATQ scoring prosopagnosics reduced the small deficit for facial expression perception. Importantly, SATQ scores were unrelated to performance on the facial identity tasks. Together, these findings indicate that autism traits may account for prosopagnosics' small deficits in facial expression perception but cannot account for their deficits in facial identity perception.

My results enable me to calculate an unbiased estimate of the prevalence of facial expression perception deficits in prosopagnosia. Past studies have been unable to do this for two reasons. First, studies that did not have facial identity tasks independent of those used for diagnosis would have committed circular analysis, resulting in a biased estimate. Second, the sample sizes of past studies are too small (the largest study tested 17 prosopagnosics). I was able to calculate an unbiased estimate because my sample size is much larger than past studies and because I can compare the number of prosopagnosics impaired on the facial expression tasks against the number impaired on parallel facial identity tasks. Out of 124 prosopagnosics I tested in Study 1, one was impaired across all expression tasks, whereas 13 were impaired across all identity tasks, giving a prevalence of $7.69 \%$ (i.e., 1 of every 13 prosopagnosics have facial expression perception deficits). By contrast, a circular analysis would arrive at a much lower prevalence of $0.81 \%$ (i.e., 1 of every 124 prosopagnosics have facial expression perception deficits). That only 13 out of 124 prosopagnosics were impaired with facial identity may seem surprising. However, facial identity processing was assessed with facial identity perceptual tasks (with little or no memory demand), not facial identity recognition tasks (with a heavier memory component) similar to those used to diagnose prosopagnosia. Thus, the low number of prosopagnosics impaired with the facial identity tasks in Study 1 is likely the result of the tasks tapping earlier, more perceptual processes, instead of later, more memory-dependent processes that are more impaired in prosopagnosia (Dalrymple, Garrido, \& Duchaine, 2014).

Given that there is a dissociation between prosopagnosics' ability to process facial identity and facial expression-despite the tasks being mainly perceptual with low memory demands - the split between facial expression and facial identity processing may occur early in the face processing stream. This notion of a relatively early segregation between the processing of facial identity and facial expression is in line with Bruce and Young's (1986) 


\section{FACIAL EXPRESSION PROCESSING IN PROSOPAGNOSIA}

and Haxby and colleagues' (2000) proposals of independent systems for processing the two face aspects, as opposed to a shared system.

Although this is not central to the thesis, I ran additional analyses to check whether the small facial expression deficits observed in Study 1 are driven by specific facial expressions (e.g., fear; these supplementary analyses are detailed in section B.7 of Appendix B). These analyses were motivated by Biotti and Cook's (2015) finding that 17 prosopagnosics showed subtle facial expression deficits specific to the categorisation of fear and surprise. Briefly, my analyses revealed that prosopagnosics' performance was comparable to controls' for the six basic facial expressions assessed in the Study 1 tasks, suggesting that prosopagnosics' small facial expression deficits are not the result of impaired processing of specific facial expressions.

Overall, Study 1 shows that prosopagnosics have small deficits for matching facial expressions. Relative to expression matching tasks, expression labelling tasks differ in two respects. First, expression labelling tasks tax memory to a greater extent than expression matching tasks (Phillips, Channon, Tunstall, \& Hedenstrom, \& Lyons, 2008). Second, expression labelling and matching tasks may engage distinct mechanisms (with labelling tasks requiring more post-perceptual mechanisms; Palermo et al., 2013). It is important then, to use both expression matching and expression labelling tasks to provide a comprehensive assessment of facial expression processing in prosopagnosia. To this end, in Study 2, I investigate prosopagnosics' facial expression processing using expression labelling tasks. 


\section{FACIAL EXPRESSION PROCESSING IN PROSOPAGNOSIA}

\section{Chapter 3: Study 2}

Study 1 revealed that prosopagnosics' have subtle deficits for facial expression perception. In Study 2, I investigate if they also have subtle deficits for facial expression recognition. I use four labelling tasks that vary in whether the facial expressions are basic (e.g., sad, happy, angry) or complex (e.g., distressed, elated, mortified) and whether the facial expressions are presented via static (i.e., images) or dynamic (i.e., video clips) stimuli. It is important to use both expression matching and expression labelling tasks in this thesis because labelling tasks tax working memory to a greater extent than matching tasks (Phillips et al., 2008) and require additional post-perceptual mechanisms (Palermo et al., 2011).

Study 2 also extends the findings of Study 1 in two ways. First, I contrast prosopagnosics' ability to recognise basic and complex facial expressions, which no past studies have done. Basic and complex expressions differ in meaningful ways. Basic expressions are thought to be expressed and recognised across cultures (Ekman et al., 1987; Ekman \& Frisen, 1971; Scherer \& Wallbott, 1994) and are similarly expressed in sighted and congenitally blind individuals (Eibl-Eibesfeldt, 1973; Galati, Scherer, \& Ricci-Bitti, 1997; Roch-Levecq, 2006), supporting the notion that basic expressions are evolutionarily old and biologically hardwired (Darwin \& Prodger, 1999; Susskind et al., 2008). In contrast, complex expressions tend to be more culturally and context specific, and recognition of them often involves both the attribution of a cognitive state as well as an emotion (Griffiths, 2008; Izard, 2007). Second, I contrast prosopagnosics' ability to recognise facial expression from static and dynamic stimuli. No past studies have investigated prosopagnosics' ability to process dynamic facial expressions. This is surprising because facial motion is widely considered important for face processing (Calder, 2011; Longmore \& Tree, 2013; Yovel \& O’Toole, 2016). Assessing facial expression processing with dynamic stimuli is also particularly important because facial expressions are naturally transient and changeable (Johnston et al., 2013; Kilts et al., 2003; Recio et al., 2011). By using both static and dynamic stimuli to test recognition of basic and complex expressions, I provide a more complete assessment of facial expression processing in prosopagnosia than past studies.

As in Study 1, I examine inversion effects to gauge whether prosopagnosics use typical face mechanisms to recognise basic and complex expressions from static and dynamic stimuli. If prosopagnosics engage typical mechanisms to recognise facial expression, then they should show similar-sized inversion effects to controls. But if they compensate and use atypical mechanisms that are less sensitive to orientation, then they should show smaller 


\section{FACIAL EXPRESSION PROCESSING IN PROSOPAGNOSIA}

inversion effects than controls. I also check whether prosopagnosics' performance on facial expression recognition tasks is related to autism traits. If the prosopagnosics demonstrate subtle deficits on the facial expression recognition tasks (like they did on the facial expression perception tasks in Study 1), then it is important to determine whether the deficits are a feature of prosopagnosia, or are the result of co-occurring autism. Finally, I calculate an estimate of the prevalence of facial expression recognition deficits in prosopagnosia.

\subsection{Method}

Prosopagnosic participants. I recruited prosopagnosic participants in the same manner as for Study 1. A total of 81 prosopagnosics (66 of whom completed Study 1) completed Study 2 online on Testable. I excluded three individuals from analysis because of technical errors (e.g., stimuli not appearing). The final sample comprised 78 individuals (50 women, $28 \mathrm{men})$. The mean age was 39.69 years old $(S D=8.22$, range 21-52). Most prosopagnosics were from the USA $(n=49)$; the rest were from the UK $(n=15)$, Canada $(n$ $=9)$, Germany $(n=3)$, and France $(n=2)$. Prosopagnosics' education levels included high school or equivalent $(n=2)$, college or technical school $(n=11)$, bachelor's degree $(n=35)$, and master's/doctorate degree $(n=30)$. I compensated prosopagnosics with an Amazon gift card valued at 10 USD. A summary of the prosopagnosics' diagnostic test scores are presented in Table 2.

Table 2. Study 2 Prosopagnosics' diagnostic test scores.

\begin{tabular}{lllll}
\hline $\begin{array}{l}\text { Diagnostic } \\
\text { Test }\end{array}$ & Diagnostic Cut-off & $\begin{array}{l}\text { Score } \\
M(S D)\end{array}$ & Range & $\begin{array}{l}\text { Control data } \\
n(S D)\end{array}$ \\
\hline CFMT & $=/<42($ out of 72$)$ & $35.68(4.41)$ & $17-41$ & $n=47,54.30(7.27)$ \\
FFT & $=/<58.00 \%$ & $29.65 \%(13.47)$ & $0.00 \%-57.14 \%$ & $n=97,78.65 \%(11.60 \%)$ \\
PI-20 & $=/>60$ & $80.97(6.36)$ & $64-93$ & $n=242,38.90(10.88)$ \\
& & & & \\
L-POST & $\begin{array}{l}\text { Impaired } \\
\text { performance on }=>>\end{array}$ & $\begin{array}{l}\text { Impaired on } 0.71 \\
\text { (0.93) subtests }\end{array}$ & $\begin{array}{l}\text { Impaired on } 0-3 \\
\text { subtests }\end{array}$ & $\mathrm{NA}$ \\
& 4 subtests & & \\
\hline
\end{tabular}

Note. I collected control data for the CFMT and FFT from Amazon Mechanical Turk samples. PI-20 control data was sourced from Shah et al., 2015. 


\section{FACIAL EXPRESSION PROCESSING IN PROSOPAGNOSIA}

Control participants. I collected data from 209 individuals located in North America through mTurk. As in Study 1, I excluded data from individuals if they were older than 52 years of age $(n=27)$ or potentially prosopagnosic as indicated by impaired scores on the CFMT $(n=38)$. I also excluded data from controls who reported technical errors $(n=5)$. Controls were also removed if they did not engage with the tasks as indexed by accuracy scores at or below chance level for a given task $(n=1)$. The final control sample comprised 138 individuals (90 women, 48 men). The controls' gender distribution did not differ from the prosopagnosics', $\chi^{2}(1)=0.03, p=.869, \eta_{p}^{2}=<.01$. The mean age of the controls was 36 years old $(S D=7.84$, range 22-52), which was younger than the prosopagnosics mean age, $t(214)=3.45, p<.001, d=0.49$. The slightly younger age of the controls is unlikely to impact the results because face recognition abilities tend to peak in early 30 's and plateau beyond (Germine, Duchaine, \& Nakayama, 2011; Susilo et al., 2013), and both the controls' and prosopagnosics' mean age is in the mid/late 30's age bracket. Controls' education levels included high school or equivalent $(n=36)$, college or technical school $(n=47)$, bachelor's degree $(n=41)$, and master's/doctorate degree $(n=11)$. Controls' and prosopagnosics' education levels significantly differed, with prosopagnosics having a higher education level than controls, $\chi^{2}(1)=45.50, p<.001, \eta_{p}^{2}=0.18$. As in Study 1 , this education level difference between prosopagnosics and controls should not affect performance because face recognition abilities are only weakly related to IQ (Wilmer et al., 2010; Zhu et al., 2010). Relative to controls', prosopagnosics' CFMT scores were lower $\left(M_{\text {control }}=58.94, S D_{\text {control }}=\right.$ $\left.8.24 ; M_{\text {prosopagnosic }}=35.68, S D_{\text {prosopagnosic }}=4.41 ; t(214)=23.10, p<.001, d=3.27\right) . \mathrm{I}$ compensated controls with five USD for their participation.

All participants provided consent to participate by clicking an 'agree' button presented below the digital consent form. On completing the tasks, participants were linked to a debriefing form. This study was approved by the School of Psychology Human Ethics Committee under delegated authority of Victoria University of Wellington's Human Ethics Committee.

\subsection{Materials and procedure}

Study 2 included two basic expression and two complex expression labelling tasks. One version of each task showed static stimuli (images), and the other showed dynamic stimuli (video clips). These tasks were validated in separate control samples prior to the main 


\section{FACIAL EXPRESSION PROCESSING IN PROSOPAGNOSIA}

experiment to ensure that (1) they did not show ceiling or floor effects, (2) they produced sizeable inversion effects, and (3) the static and dynamic versions of each task were matched for difficulty. The validation process is detailed in section E.1 of Appendix E.

All participants completed Study 2 on Testable. In total, each participant completed four tasks that were counterbalanced for order. For each task, participants completed trials that were presented in an upright and inverted orientation. Trial orientation was blocked and counterbalanced for order in the complex expression tasks, whereas trial orientation was intermixed within two blocks in the basic expression tasks. Below, I outline the Study 2 tasks in more detail.

Basic expression labelling tasks. In the basic expression labelling tasks, participants viewed faces showing anger, disgust, fear, happiness, surprise, or sadness. For each face, participants' task was to select one of six expression labels that best described the expression conveyed (Figure 13).

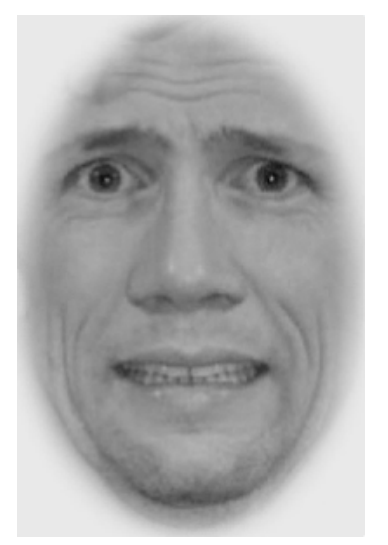

\section{\begin{tabular}{ll|lll} 
Anger Disgust & Fear & Happy & Sad & Surprise
\end{tabular}}

Figure 13. Example of a trial from the basic facial expression labelling tasks. For this trial, the correct response is "Fear".

Dynamic task. In the dynamic task, the face stimuli were short video clips that showed faces morphing in real-time from a neutral expression to an emotional one. This task was adapted from Wilhelm and colleagues (Wilhelm, Hildebrandt, Manske, Schacht, and Sommer, 2014) $)^{5}$.

\footnotetext{
${ }^{5}$ In the original task, the stimuli shown in the upright (36 stimuli) and inverted (36 stimuli) conditions were different. I adapted the task by matching stimuli shown in each condition by flipping the inverted stimuli and adding them to the upright condition (now 72 upright stimuli in total) and inverting the upright stimuli and also adding them to the inverted condition (now 72 stimuli in total).
} 


\section{FACIAL EXPRESSION PROCESSING IN PROSOPAGNOSIA}

In a trial, the face stimuli video clip ran for $500 \mathrm{~ms}$. Using a computer mouse, participants then selected one of six expression labels presented beneath the target face. An ITI of $500 \mathrm{~ms}$ separated trials. Participants completed 144 trials in total (72 trials in an upright orientation and 72 in an inverted orientation), with 24 trials per facial expression. Trial orientation was intermixed across the task. The order of trials was randomised.

Static task. In the static task, the face stimuli were images. I created the stimuli by capturing screenshots of the final stills of each video clip (i.e., the static stimuli were images of the final portrayals of the expressions displayed in the video clip stimuli). The procedure for the static task was the same as the dynamic, with the images also being displayed for 500 ms on each trial.

Complex expression labelling tasks. In the complex expression labelling tasks, participants first viewed an emotional adjective (e.g., shocked). Next, they viewed three sequential stimuli of the same actor displaying three different expressions (e.g., suspicious, shocked, and mocking). An example trial is depicted in Figure 14. The participants' task was to select which of the three faces best displayed the expression suggested by the emotional adjective. I modelled the complex expression labelling tasks on the Films Facial Expression Task created by Garrido and colleagues (2009). How I created, rated, and selected stimuli, and later validated the tasks is described in Appendix F. 


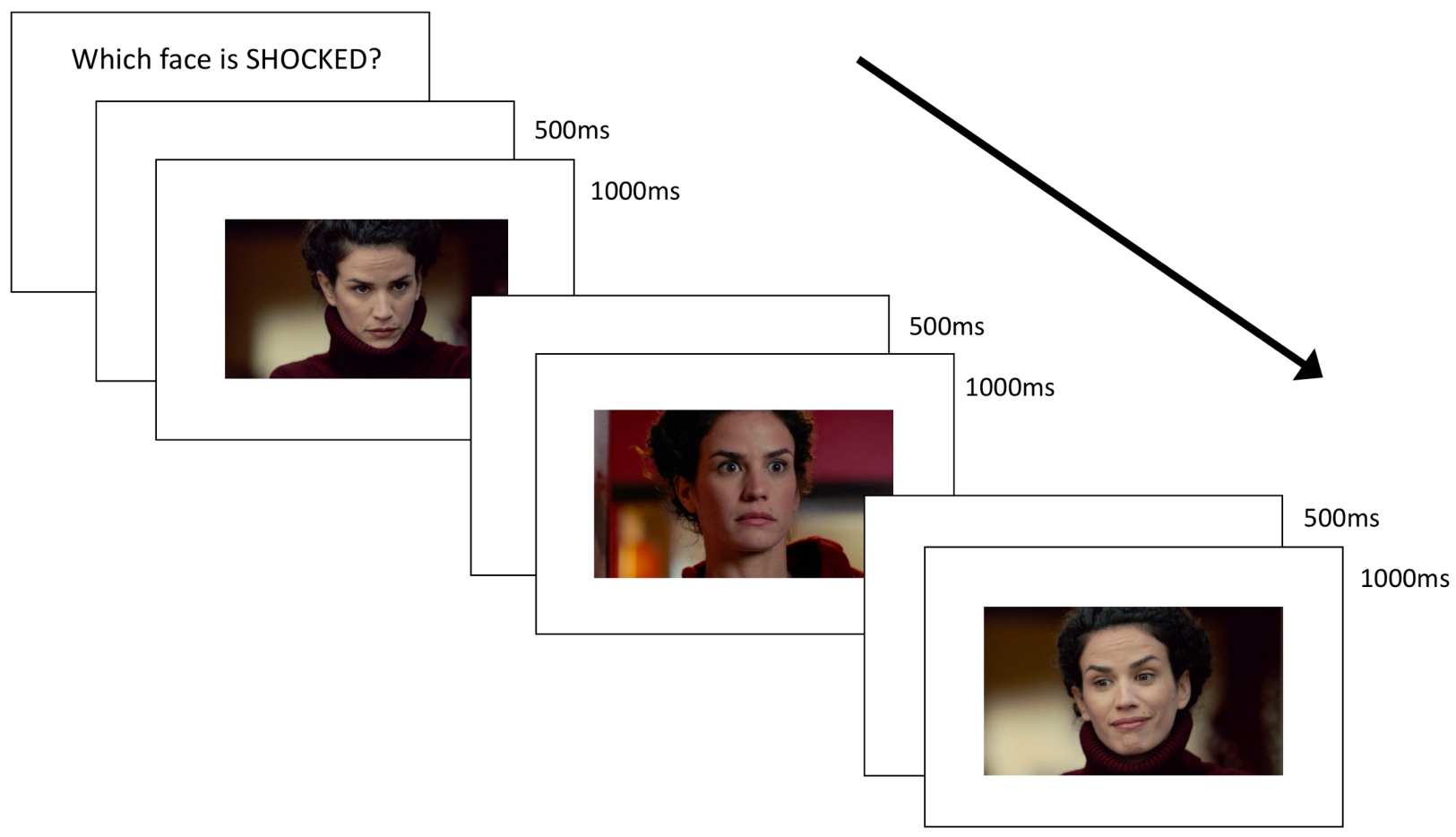

Figure 14. Schematic representation of a trial from the complex facial expression labelling tasks. Each face stimulus is presented for $1000 \mathrm{~ms}$ (either as an image or video clip) with a $500 \mathrm{~ms}$ ISI. In this example trial, the face that best matches the emotional adjective of 'shocked' is the second face within the presentation sequence.

Dynamic task. In the dynamic task, stimuli were short video clips of actors displaying expressions. At the beginning of the task, participants viewed a glossary (detailed in Appendix F) containing definitions and example sentences of the emotional adjectives used in the task. For example, 'amused' was defined as, 'finding something funny' and was used in the example sentence, 'I was amused by a funny joke someone told me'. Each trial began with the presentation of an emotional adjective. If participants were unfamiliar with the adjective, they could refer to the adjective glossary. If/when they were familiar with the adjective, participants performed a mouse click to view the three faces. Three video clips were then presented in sequence, with each video clip running for $1000 \mathrm{~ms}$. A $500 \mathrm{~ms}$ ISI separated each stimulus. Participants indicated which face best depicted the emotional adjective by pressing the "1", "2", or " 3 " key on the keyboard, to select the "1st", "2nd", or "3rd" face, respectively. An ITI of 500 ms separated trials. Participants completed 88 experimental trials in total (44 in an upright orientation and 44 in an inverted orientation). Participants completed the upright and inverted trials in two separate blocks that were counterbalanced for order. The order of trials within each block was also randomised.

Static task. In the in the static task, stimuli were screenshots of the final still of the video clips (i.e., images of the final portrayals of the expressions displayed in the video 


\section{FACIAL EXPRESSION PROCESSING IN PROSOPAGNOSIA}

clips). The procedure of the static task was the same as the dynamic task, with each image also being presented for $1000 \mathrm{~ms}$.

\subsection{Results}

I performed all analyses using Jamovi version 0.8 (Jamovi project, 2017) unless otherwise stated. I calculated percent accuracy for the upright and inverted condition of each task. For response time, I calculated trimmed means and medians from correct trials only. To calculate trimmed means, I removed response times 3 SDs greater or less than the mean for a given condition of a task for each participant. I calculated inversion effects (the difference between performance on upright and inverted trials) for percent accuracy and response time for each task. ANOVA results are Greenhouse-Geisser corrected where necessary. For independent $t$-tests, I calculated Cohen's $d$ as a measure of effect size, and for dependent $t$-tests, I calculated $d_{z}$ (Lakens, 2013).

Descriptive statistics for controls' and prosopagnosics' performance are reported in sections E.2 and E.3, respectively, of Appendix E. In section E.2 I also provide data checks that show that controls' performance on the tasks (1) did not approach ceiling or floor, (2) produced sizeable inversion effects, and (3) were comparable across the static and dynamic versions of each task.

\subsubsection{Do recognition of basic and complex expressions from static and dynamic stimuli dissociate in prosopagnosia?}

First, I wanted to address whether prosopagnosics' abilities to recognise facial expressions differs when expressions are basic versus complex, and/or when they are static versus dynamic. To do this, I compared their performance on four facial expression labelling tasks that varied based on expression type (i.e., basic versus complex) and stimulus type (i.e., static versus dynamic), focusing on upright trials.

Accuracy. I ran a 2 (stimulus type: static, dynamic) x 2 (expression type: basic, complex) x 2 (group: prosopagnosic, control) mixed-design ANOVA on labelling accuracy for upright trials, with stimulus type and expression type as within-subjects factors, and group as the between-subjects factor. There was a significant main effect of expression type $(F(1$, $\left.214)=718.53, p<.001, \eta_{p}^{2}=.77\right)$, indicating that complex expressions were recognised better than basic expressions. However, this result is not of interest because the basic and 


\section{FACIAL EXPRESSION PROCESSING IN PROSOPAGNOSIA}

complex expression tasks were not designed to be matched on difficulty. The main effect of group $\left(F(1,214)=3.43, p=.065, \eta_{p}^{2}=.02\right)$ and stimulus type were not significant $(F(1,214)$ $\left.=0.76, p=.383, \eta_{p}^{2}<.01\right)$. The main effect of expression type was qualified by significant two-way interactions between expression type and group $\left(F(1,214)=4.37, p=.038, \eta_{p}^{2}=\right.$ $.02)$ and stimulus type and expression type $\left(F(1,214)=34.16, p<.001, \eta_{p}^{2}=.14\right)$. However, the two-way interaction between stimulus type and group $(F(1,214)=0.04, p=$ $\left..845, \eta_{p}^{2}<.01\right)$ and the three-way interaction between stimulus type, group and expression type were not significant $\left(F(1,214)=0.56, p=.454, \eta_{p}^{2}<.01\right)$.

Next, I broke down the two-way interaction between expression type and group to test whether prospagnosics' abilities to label basic versus complex expressions dissociate, collapsing across stimulus type. Figure 15 shows the results. Post hoc comparisons showed that, relative to controls, prosopagnosics performed slightly more poorly on the basic expression tasks, showing a 3.46\% performance drop $\left(M_{\text {control }}=64.14 \%, S D_{\text {control }}=8.99 \%\right.$; $\left.M_{\text {prosopagnosic }}=60.68 \%, S D_{\text {prosopagnosic }}=9.56 \% ; t(214)=2.66, p=.009, d=0.38\right)$. In contrast, controls' and prosopagnosics' performance on the complex expression tasks was comparable $\left(M_{\text {control }}=78.55, S D_{\text {control }}=10.06 ; M_{\text {prosopagnosic }}=77.53, S D_{\text {prosopagnosic }}=9.02, t(214)=0.74, p\right.$ $=.459, d=0.11)$. 


\section{Expression Type}

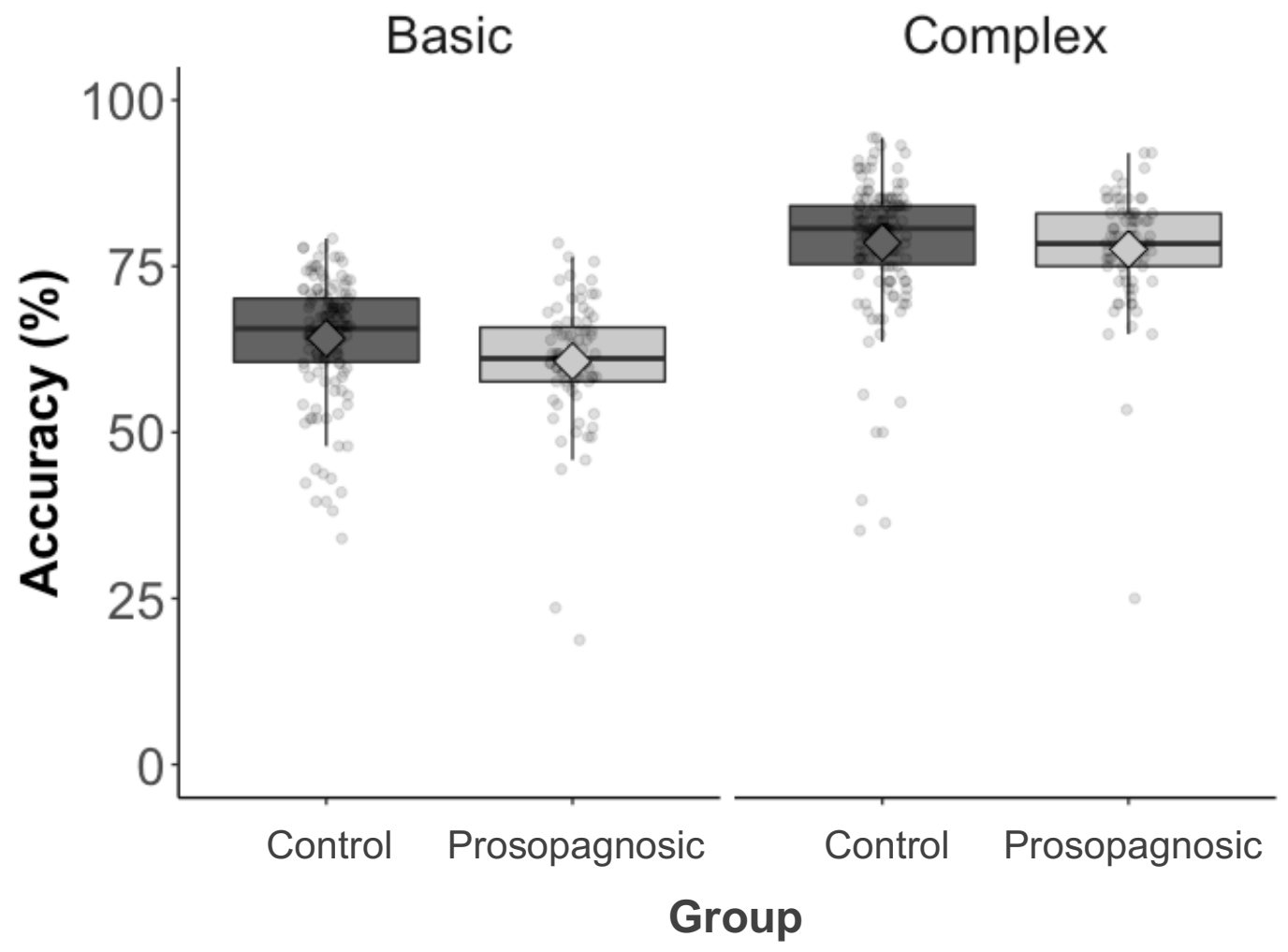

Figure 15. Boxplots of prosopagnosics' and controls' accuracy on the basic (left) and complex (right) expression recognition tasks on upright trials, collapsed across stimulus type. Points represent individual data. Diamonds represent the mean score for each condition.

Response times. Although I am primarily interested in accuracy performance, I also analysed response times to check that differences in response time could not account for the pattern of performance in accuracy. If prosopagnosics were slower than controls on the complex expression tasks, then this would imply that prosopagnosics' normal performance on the complex expression tasks may be achieved by more time consuming, compensatory strategies. Figure 16 shows the results. I ran a 2 (expression type: basic, complex) x 2 (group: prosopagnosic, control) mixed-design ANOVA on response times for upright trials, with expression type as the within-subjects factor and group as the between-subjects factor. There was a significant main effect of group, indicating that prosopagnosics' response times on the basic expression and complex expression tasks were slower than controls' $\left(M_{\text {control }}=3825\right.$ $\mathrm{ms}, S D_{\text {control }}=1624 \mathrm{~ms} ; M_{\text {prosopagnosic }}=4004 \mathrm{~ms}, S D_{\text {prosopagnosic }}=1629 \mathrm{~ms} ; F(1,214)=12.60$, $\left.p<.001, \eta_{p}^{2}=.06\right)$. There was also a significant main effect of expression type, indicating that both prosopagnosics' and controls' response times were slower on the complex 


\section{FACIAL EXPRESSION PROCESSING IN PROSOPAGNOSIA}

expression tasks compared to the basic expression tasks ${ }^{6}\left(M_{\text {complex }}=5455 \mathrm{~ms}, S D_{\text {complex }}=520\right.$ $\left.\mathrm{ms} ; M_{\text {basic }}=2324 \mathrm{~ms}, S D_{\text {basic }}=321 \mathrm{~ms} ; F(1,214)=9246.65, p<.001, \eta_{p}^{2}=.98\right)$.

Importantly, the interaction between expression type and group was not significant, indicating that the dissociation between prosopagnoics' accuracy on the basic and complex expression tasks is not accounted for by response time differences, $F(1,214)=0.09, p=.762$, $\eta_{p}^{2}<.01$. A similar result was obtained with median response times (see section E.4 of Appendix E for these supplementary analyses).

\section{Expression Type}

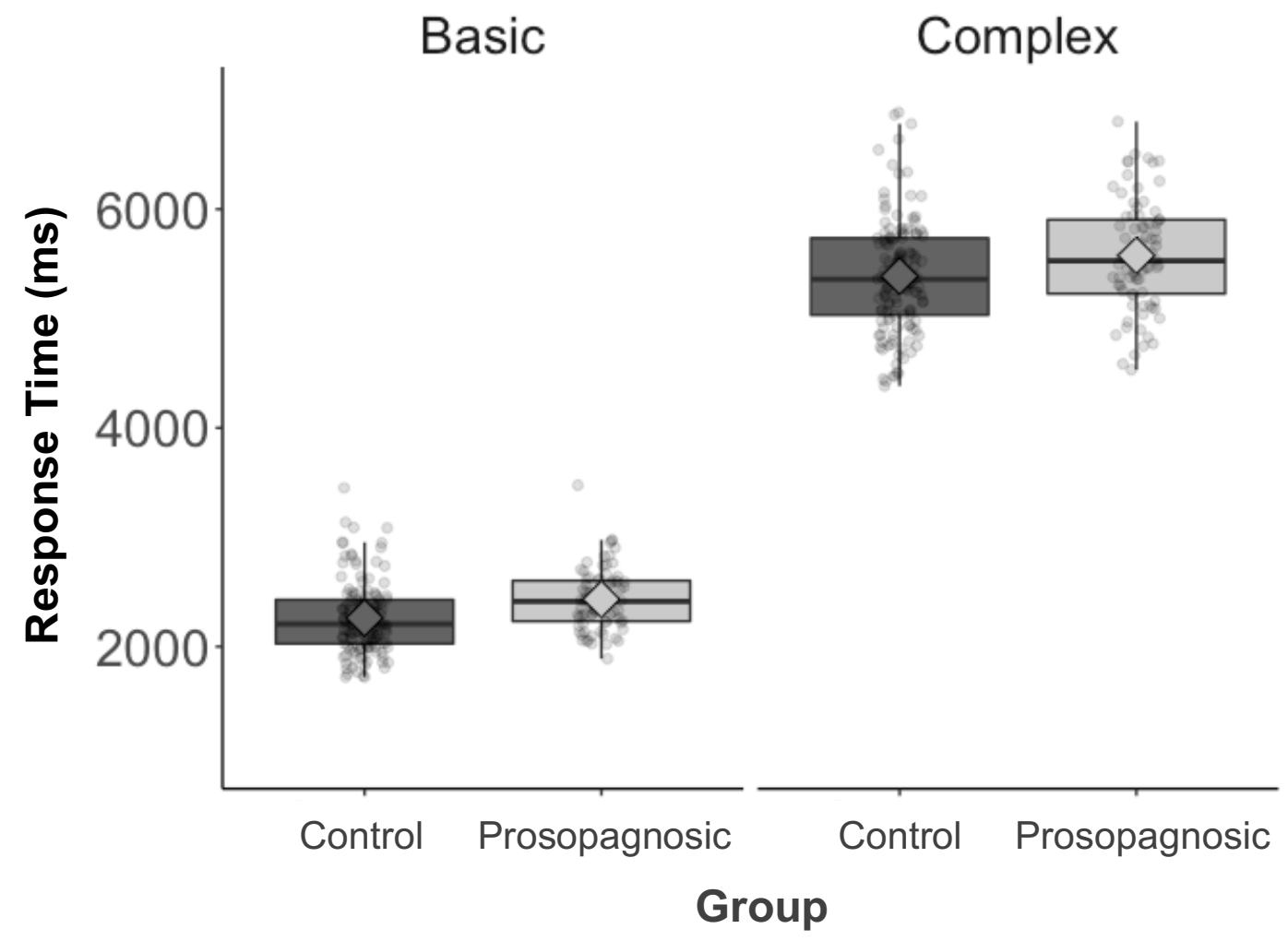

Figure 16. Boxplots of prosopagnosics' and controls' trimmed mean response times on the basic (left) and complex (right) expression tasks on upright trials, collapsed across stimulus type. Points represent individual data. Diamonds represent the mean score for each condition.

Overall, prosopagnosics showed impaired performance on the basic expression tasks but normal performance on the complex expression tasks, suggesting that the ability to

\footnotetext{
${ }^{6}$ Slower response times in the complex expression task compared to the basic expression task is an artefact of the complex expression task's design and the functionalities of the testing platform I used (i.e., Testable.com). The Testable response timer starts at the onset of stimulus presentation, thus the longer response times for the complex task are due to the longer stimulus presentation sequence (3000 ms to present three stimuli plus 1000 $\mathrm{ms}$ of ISI time) compared to the basic task (only $500 \mathrm{~ms}$ stimulus presentation).
} 


\section{FACIAL EXPRESSION PROCESSING IN PROSOPAGNOSIA}

recognise the two expression types dissociates in prosopagnosia. Furthermore, the small drop in prosopagnosics' performance on the basic expression tasks relative to controls' suggests that prosopagnosics have subtle deficits for recognising basic facial expressions.

\subsubsection{Do basic and complex expression mechanisms dissociate in prosopagnosia?}

The dissociation I observed between prosopagnosics' basic and complex expression recognition raises an interesting question: do prosopagnosics use different mechanisms than controls for recognising basic expressions but similar mechanisms as controls for complex expressions? Here, I test whether prosopagnosics and controls engage similar (or different) mechanism by comparing the size of their inversion effects across basic expression and complex expression tasks, collapsing across stimulus type. Similar-sized inversion effects in prosopagnosics and controls would imply that prosopagnosics use mechanisms typical of face processing, whereas reduced inversion effects in prosopagnosics would suggest that prosopagnosics engage atypical mechanisms.

Accuracy. I calculated inversion effects (i.e., upright accuracy minus inverted accuracy) for prosopagnosics' and controls' performance on the basic and complex expression tasks, collapsed across stimulus type. Figure 17 shows the results. I ran a 2 (expression type: basic, complex) x 2 (group: prosopagnosia, control) mixed-design ANOVA on inversion effects, with expression type as the within-subjects factor and group as the between-subjects factor. This revealed significant main effects of expression type $(F(1,214)$ $\left.=18.40, p<.001, \eta_{p}^{2}=.08\right)$ and group $\left(F(1,214)=6.47, p=.012, \eta_{p}^{2}=.03\right)$, which were qualified by a significant interaction between expression type and group, $F(1,214)=18.60, p$ $<.001, \eta_{p}^{2}=.08$. Post hoc comparisons revealed that, relative to controls, prosopagnosics' showed similar inversion effects for basic expressions $\left(M_{\text {control }}=13.60 \%, S D_{\text {control }}=6.23 \%\right.$; $\left.M_{\text {prosopagnosic }}=12.94 \%, S D_{\text {prosopagnosic }}=5.53 \%, t(214)=0.78, p=.437, d=.11\right)$, but, surprisingly, larger inversion effects for complex expressions $\left(M_{\text {control }}=8.70 \%, S D_{\text {control }}=\right.$ $\left.7.14 \% ; M_{\text {prosopagnosic }}=12.95 \%, S D_{\text {prosopagnosic }}=6.08 \% ; t(214)=4.43, p<.001, d=.63\right)$. 


\section{Expression Type}

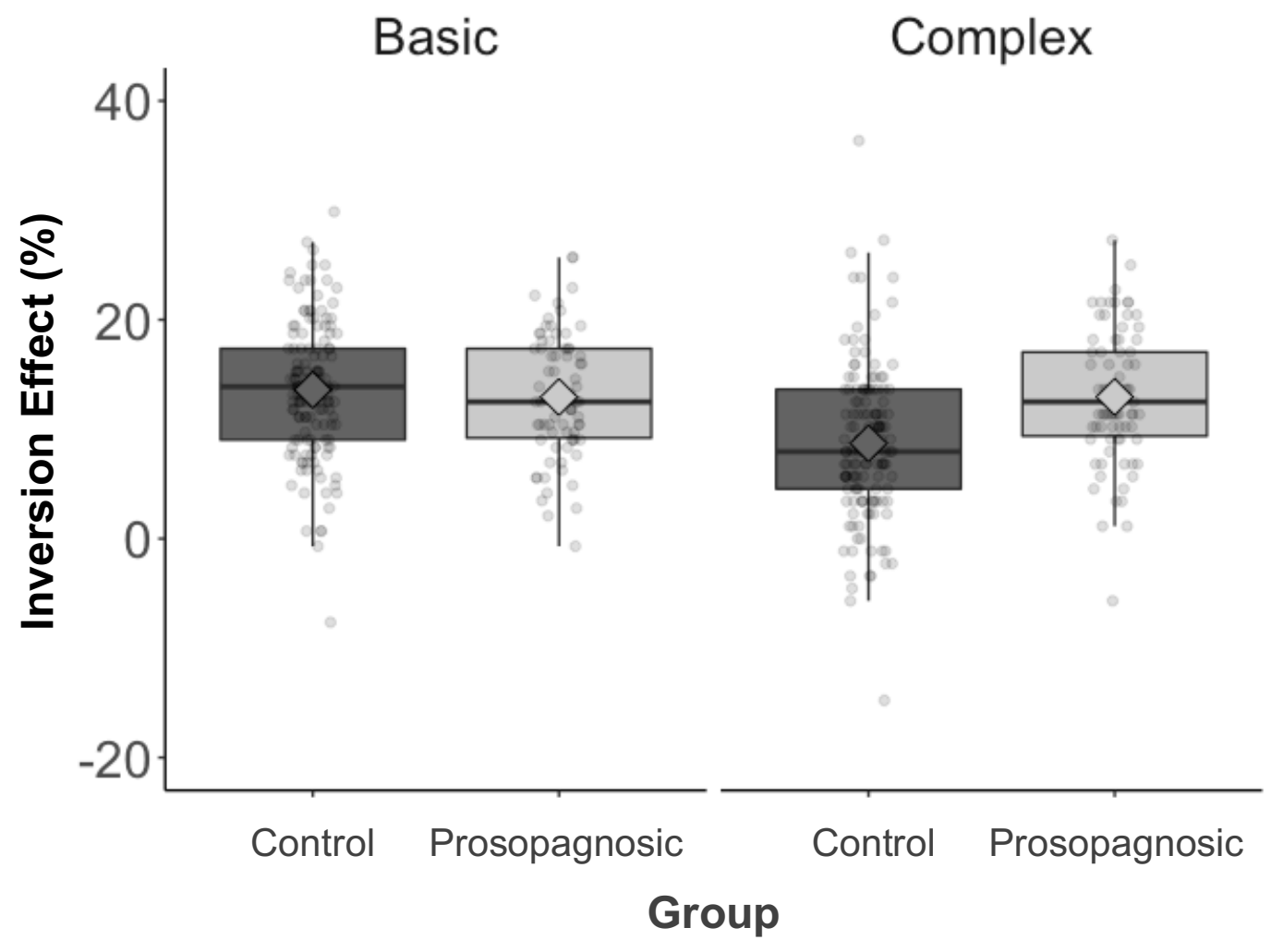

Figure 17. Boxplots of prosopagnosics' and controls' inversion effects in accuracy on the basic (left) and complex (right) expression tasks, collapsed across stimulus type. Points represent individual data. Diamonds represent the mean score for each condition.

Response time. Next, I calculated inversion effects from trimmed mean response times (i.e., upright response time minus inverted response time) to check that differences in response time cannot account for the pattern of inversion effects in accuracy. Figure 18 shows the results. I ran a 2 (expression type: basic, complex) x 2 (group: prosopagnosic, control) mixed-design ANOVA on response time inversion effects, with expression type as the within-subjects factor and group as the between-subjects factor. The main effect of group $\left(F(1,214)=3.50, p=.063, \eta_{p}^{2}=.02\right)$ and the interaction between expression type and group $\left(F(1,214)=3.69, p=.056, \eta_{p}^{2}=.02\right)$ were not significant, indicating that the dissociation between prosopagnosics' accuracy inversion effects on the basic and complex expression tasks is not accounted for by response time differences. There was a significant main effect of expression type, indicating that the size of controls' and prosopagnosics' inversion effects on the complex expression tasks differed to those on the basic expression tasks $\left(M_{\text {complex }}=44\right.$ 
$\mathrm{ms}, S D_{\text {complex }}=354 \mathrm{~ms} ; M_{\text {basic }}=-123 \mathrm{~ms}, S D_{\text {basic }}=178 \mathrm{~ms} ; F(1,214)=44.53, p<.001, \eta_{p}^{2}=$ .17). A similar result was obtained with median response times (see section E.4 of Appendix E for these supplementary analyses).

\section{Expression Type}

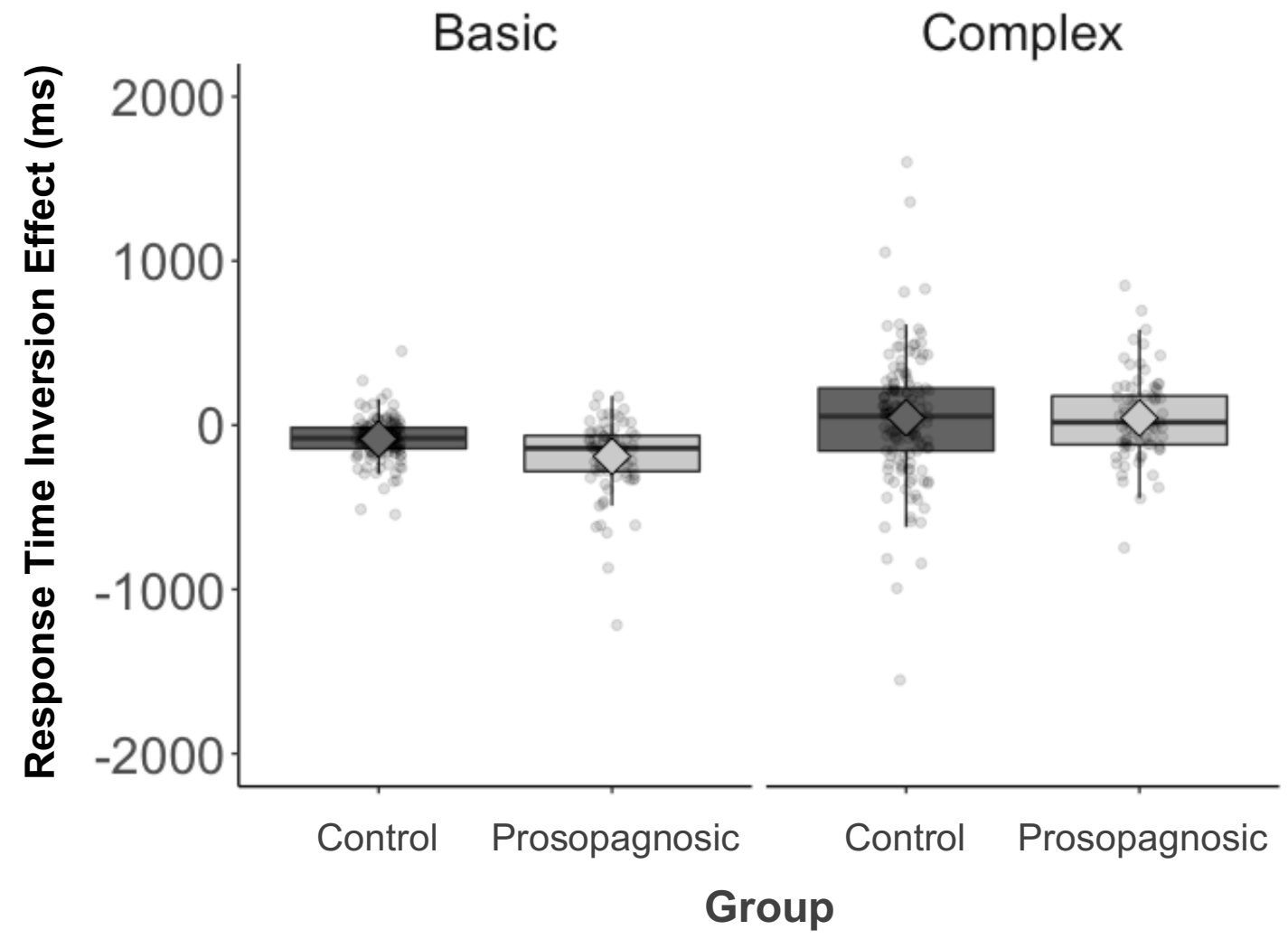

Figure 18. Boxplots of prosopagnosics' and controls' inversion effects in trimmed mean response times on the basic (left) and complex (right) expression tasks, collapsed across stimulus type. Points represent individual data. Diamonds represent the mean score for each condition.

Overall, prosopagnosics' and controls' similar-sized inversion effects for basic expressions suggests that despite prosopagnosics' small deficits at recognising basic expressions, they seem to process them using similar mechanisms as controls (but use them less effectively). A curious finding is that prosopagnosics showed larger inversion effects for complex expressions relative to controls. A close inspection reveals that the larger inversion effects are driven by their poorer performance on the inverted trials (see Table E3 in section E.3 of Appendix E). It may be the case that prosopagnosics are more sensitive to orientation manipulations with complex expressions compared to controls, and so their performance is more impaired on inverted trials relative to controls. Further, given that prosopagnosics' performance on the upright trials of the complex expression tasks was similar to controls, 


\section{FACIAL EXPRESSION PROCESSING IN PROSOPAGNOSIA}

suggests that they seem to engage similar mechanisms as controls to process upright expressions. Taken together, the inversion effect results suggest that the dissociation between basic and complex expression recognition in prosopagnosics arises from their reduced ability to analyse basic expressions, not from the kind of mechanisms they use to process them.

\subsubsection{Is the subtle basic expression deficit a core feature of prosopagnosia?}

Prosopagnosics showed subtle deficits when recognising basic expressions. As in Study 1, the question arises whether these deficits are a feature of prosopagnosia, or a feature of co-occuring autism traits. I ran two analyses to address this question. First, I computed Pearson product-moment correlation coefficients to assess the relationship between prosopagnosics' autism traits and their basic expression recognition. If the subtle deficits are not a feature of co-occuring autism traits, then prosopagnosics' SATQ scores should not correlate with performance on the basic expression tasks. However, if the deficits are a feature of co-occurring autism traits, then prosopagnosics' SATQ scores should correlate with performance on the basic expression tasks. As shown in Figure 19, there was a significant negative correlation between prosopagnosics' SATQ scores and their performance on the basic expression tasks, indicating that as autism traits increase, basic expression recognition tends to worsen, $r(76)=-.27, p=.017$. I also ran the same analysis after removing scores from three SATQ items that explicitly measured 'Reading facial expressions' to check whether these items were driving the correlation. I found the same pattern of results (see section E.5 of Appendix E for these supplementary analyses). 


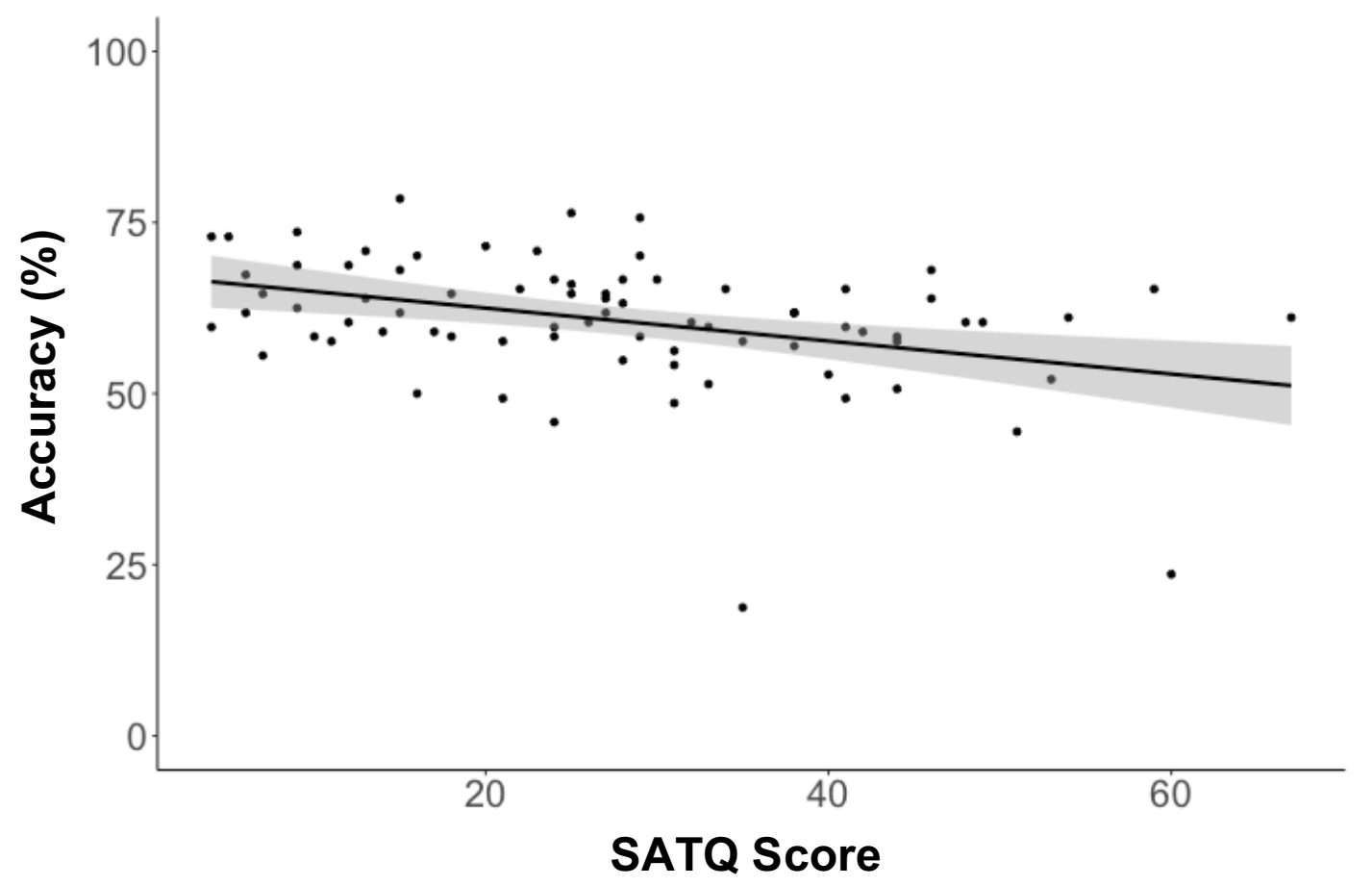

Figure 19. Scatterplot with line of best fit for prosopagnosics' SATQ scores and their performance on the basic expression tasks, collapsed across stimulus type. Grey shading represents the $95 \%$ confidence interval.

Second, I excluded prosopagnosics with high SATQ scores (indicating high levels of subthreshold autism traits) from the sample to determine if this abolished the subtle deficits. Thirteen prosopagnosics with a SATQ score over 43.51 (i.e., a cut-off set at 1.75 standard deviation above the neurotypical control sample's mean) were removed, leaving a sample of 65 prosopagnosics. With this adjusted sample, I ran a 2 (expression type: basic, complex) x 2 (group: prosopagnosic, control) mixed-design ANOVA on accuracy for upright trials, with expression type as the within-subjects variable and group as the between-subjects variable. There was a significant main effect of expression type, indicating that complex expressions were recognised better than basic expressions $\left(M_{\text {complex }}=78.24 \%, S D_{\text {complex }}=9.89 \% ; M_{\text {basic }}=\right.$ $\left.63.35 \%, S D_{\text {basic }}=9.02 \% ; F(1,201)=675.24, p<.001, \eta_{p}^{2}=.77\right)$. The main effect of group $\left(F(1,201)=1.80, p=.181, \eta_{p}^{2}=.01\right)$ was not significant. Critically, unlike the analysis with the full sample, the interaction between expression type and group was no longer significant $\left(F(1,201)=1.70, p=.194, \eta_{p}^{2}=.01\right)$, indicating that prosopagnosics and controls performed similarly across both types of expression. In accord with the correlation analysis, excluding prosopagnosics with high SATQ scores abolished the prosopagnosics' subtle deficits for basic expression recognition. 


\section{FACIAL EXPRESSION PROCESSING IN PROSOPAGNOSIA}

Together, these analyses indicate that autism traits can account for prosopagnosics' subtle deficits in basic expression recognition. These results support the idea that the subtle basic expression processing deficits are not a core feature of prosopagnosia, but rather the result of co-occurring autism traits.

\subsubsection{Proportion of prosopagnosics with facial expression recognition deficits}

In addition to the analyses above, I calculated composite z-scores to estimate of the proportion of prosopagnosics who have facial expression recognition deficits. I calculated zscores for prosopagnosics' performance on the four facial expression recognition tasks for the upright trials. From these z-scores, I calculated prosopagnosics' composite facial expression recognition z-score. Figure 20 shows prosopagnosics' composite z-scores. I considered prosopagnosics as having impairments for recognising facial expression if their composite zscores were equal to or less than - 1.75 . Only two prosopagnosics had a z-score in the impaired range. Because I did not have parallel facial identity recognition tasks I cannot determine what proportion of prosopagnosics would have facial identity deficits. However, given that facial identity recognition deficits are used to diagnose prosopagnosia, we could conservatively estimate that at least half of the prosopagnosic sample (i.e., 39 out of 78) would be impaired on parallel facial identity recognition tasks. Therefore, it can be estimated that between $2.56 \%$ (i.e., 2/78) and 5.13\% (i.e., 2/39) prosopagnosics may have facial expression recognition impairments. This analysis suggests that the majority of prosopagnosics have normal facial expression recognition. 


\section{Facial Expression Recognition}

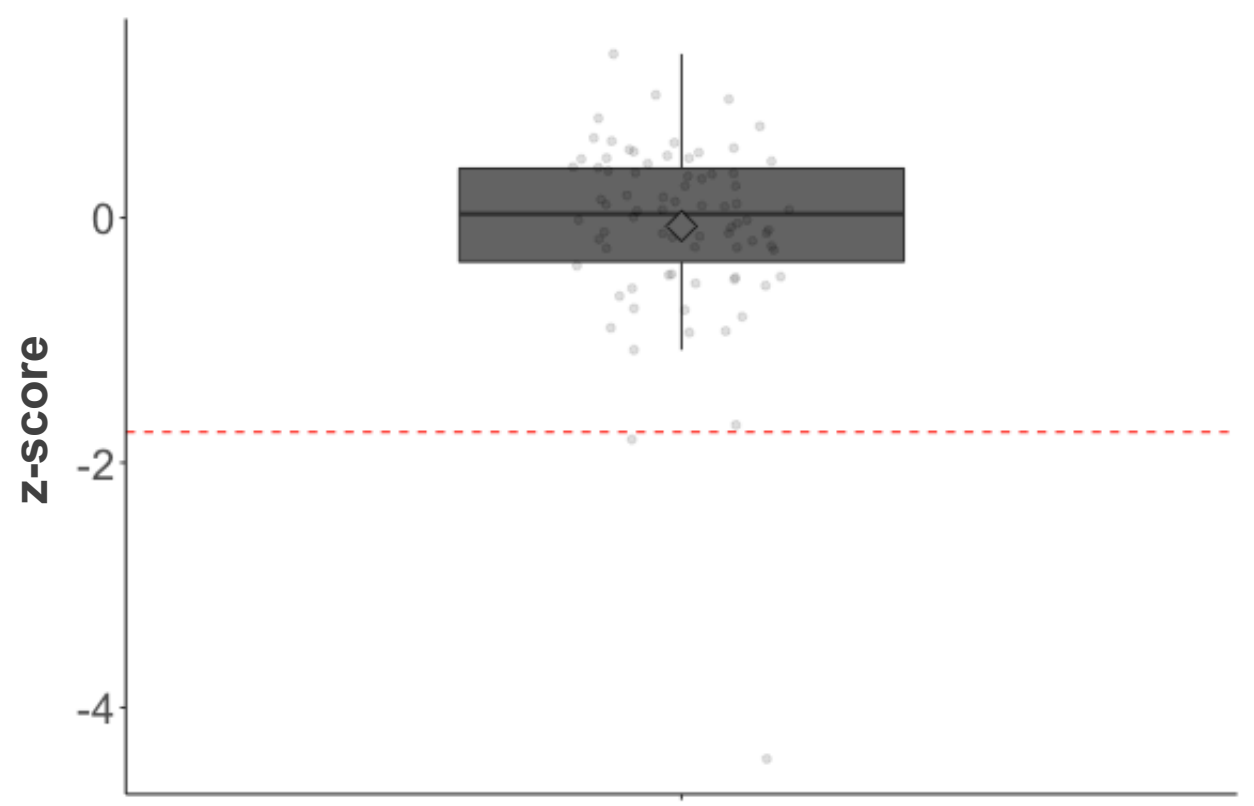

Figure 20. Boxplot of prosopagnosics' composite z-scores for their accuracy on upright trials of the four expression recognition tasks. Points represent individual data. Diamonds represent the mean score for each condition. The red dotted line marks -1.75 of the y-axis.

\subsection{Discussion}

In Study 2, I sought to extend the findings of Study 1 by investigating whether prosopagnosics' show small deficits for recognising basic versus complex facial expressions from static versus dynamic stimuli. Relative to controls, prosopagnosics showed small deficits for recognising basic expressions, yet normal recognition of complex expressions; indicating that the ability to process basic and complex expressions dissociates in prosopagnosia. However, prosopagnosics' and controls' inversion effects for basic expressions were comparable; suggesting that despite prosopagnosics' performance deficit, they engage similar mechanisms to recognise basic facial expressions as controls do. Although prosopagnosics' performance on the basic and complex expression tasks dissociated, their performance on the static and dynamic tasks did not as they showed comparable performance on the static and dynamic tasks relative to controls.

There are two tentative explanations for the dissociation between prosopagnosics' ability to recognise basic versus complex expressions. First, the basic and complex expression labelling tasks differed in format. The basic expression task presented six possible labels beneath the target face and participants had to select one label on each trial. In contrast, 


\section{FACIAL EXPRESSION PROCESSING IN PROSOPAGNOSIA}

in the complex expression task, participants are first primed with an expression (an emotional adjective) and then must select one out of three faces that best depicts that expression. It may be that prosopagnosics' show normal performance on expression labelling tasks when they are primed with which specific expression to single out, but struggle with labelling when they are not primed (as in the case of the basic expression labelling task). One way to test this possibility would be to make a parallel version of the basic expression labelling task using the complex expression stimuli. For instance, on each trial participants would be presented with one image/video clip showing a complex expression (e.g., hurt) and beneath it would be six complex expression labels to choose from (e.g., mortified, hurt, regretful, nostalgic, enraged, suspicious). If prosopagnosics truly have normal complex expression recognition, then they would perform normally on such a test. Conversely, if prosopagnosics have subtle deficits for complex expression recognition, then they might perform poorly on a complex expression labelling test that does not prime which specific expression to look for.

The second possible explanation for the dissociation between prosopagnosics' ability to recognise basic versus complex expressions is related to the stimuli used in the tasks. The stimuli used in the basic and complex expression recognition tasks differed in two respects. First, the basic expression stimuli comprised tightly cropped faces (i.e., see Figure 13 in the methods section), whereas the complex expression stimuli comprised more generously cropped stimuli, which sometimes included non-face cues (i.e., shoulders; see Figure 14 in the methods section). It could be that the non-face cues provided in the complex stimuli aided prosopagnosics more than controls in their ability to recognise complex expressions. In which case, the prosopagnosics may have shown impaired performance relative to controls had there been no non-face cues (as with the basic expression stimuli). This limitation could be addressed in a future study by creating a new set of complex expression stimuli that are more tightly cropped than those used in this thesis.

The second way the stimuli differed was that the complex expression stimuli represented more realistic depictions of facial expressions than the highly posed basic expression stimuli. It is possible that prosopagnosics are more sensitive to the realistic nature of facial expression stimuli than controls, and hence prosopagnosics show slight recognition deficits in their performance, relative to controls, when the stimuli are highly posed. I sourced the complex stimuli from films in which actors were (presumably) not strictly directed with regards to how they should move their faces to convey specific expressions. In contrast, the stimuli used in the basic facial expression labelling tasks were created using in-house models who had a series of photos taken of their facial expressions during an emotion induction, 


\section{FACIAL EXPRESSION PROCESSING IN PROSOPAGNOSIA}

personal experience, and imitation phase (Wilhelm et al., 2014). In the last phase, for example, the models were guided, with strict instruction, on how to imitate each of the basic facial expressions by performing specific muscle movements according to Ekman and Friesen's descriptions (1976). Future studies should test the possibility that the realistic nature of the facial expression stimuli may have affected prosopagnosics' performance more than controls'. One such way to test this possibility would be to match the realistic quality of the basic and complex expression stimuli by collecting a set of basic expression stimuli from films.

Although two past studies reported that some acquired prosopagnosics who are impaired at recognising expression from static stimuli are normal with dynamic stimuli (e.g., Humphreys et al. 1993; Richoz et al., 2015), I did not observe such a dissociation in my study. Similarly, despite past studies showing a dynamic advantage for facial expression recognition in healthy participants (in that their recognition is better with dynamic expressions compared to static expressions; Ambadar et al., 2005; Cunningham \& Wallraven, 2009; Knappmeyer, Thornton, \& Bülthoff, 2003), I did not observe such an advantage in the controls. Instead, my results are in line with recent evidence suggesting limited or no dynamic advantage for facial expression recognition (Fiorentini \& Vivani, 2011; Gold et al., 2013). This finding informs the dynamic advantage debate by demonstrating no advantage for basic or complex expression recognition from dynamic stimuli in both prosopagnosics and healthy controls.

As in Study 1, prosopagnosics' scores on a measure of subthreshold autism traits accounted for their small deficit for basic expression recognition. Not only did their SATQ scores negatively correlate with their basic facial expression recognition performance, but the exclusion of high SATQ scoring prosopagnosics also eliminated the small deficit. These results are in line with those from Study 1, and suggest that facial expression processing deficits in prosopagnosia can be largely accounted for by co-occurring autism traits.

I also provided estimates of the prevalence of facial expression recognition deficits in prosopagnosia. The range of estimates for facial expression recognition deficits in prosopagnosia were low (i.e., 2.56\% - 5.13\%) similar to that for facial expression perception deficits calculated in Study 1 (i.e., 7.70\%). However, the estimates calculated in Study 2 are not as precise as that calculated in Study 1 because I did not have parallel facial identity recognition tasks for the facial expression recognition tasks. However, the range of estimates that I provide give a rough idea of the proportion of prosopagnosics who may have facial expression recognition deficits. 


\section{FACIAL EXPRESSION PROCESSING IN PROSOPAGNOSIA}

Although these analyses are not central to the thesis, as in Study 1, I also ran analyses to check whether prosopagnosics' small deficit for basic expressions was driven by specific expressions (refer to section E.6 of Appendix E for these analyses). Briefly, prosopagnosics and controls showed comparable performance for each expression, except for disgust, fear, and happy expressions. Thus, prosopagnosics' disproportionately poor ability to recognise these three expressions might be driving their small deficit for basic expression recognition. However, the size of prosopagnosics' inversion effects for disgust, fear, and happy expressions were comparable to controls', suggesting that they use similar mechanisms to process them as controls. 


\section{Chapter 4: General Discussion}

In this thesis, I investigated prosopagnosics' ability to process facial expression across two studies that addressed key limitations of past research. In Study 1, participants completed three facial expression matching tasks and three parallel facial identity matching tasks. Prosopagnosics' performance on the facial identity tasks was more impaired than on the facial expression tasks, suggesting that their ability to process the two facial attributes dissociates. Moreover, prosopagnosics showed reduced inversion effects for facial identity but normal inversion effects for facial expression, suggesting they used atypical mechanisms for processing facial identity but normal mechanisms for facial expression. In Study 2, participants completed four facial expression labelling tasks that contrasted the ability to process basic versus complex facial expressions from static versus dynamic stimuli. Prosopagnosics showed a small deficit for basic expression recognition but performed comparably to controls on the complex expression task, suggesting that the ability to process the two expression classes dissociates in prosopagnosia. Further, prosopagnosics did not show reduced inversion effects for both types of expressions, indicating they used similar recognition mechanisms as controls. In both studies, prosopagnosics' scores on a measure of subthreshold autism traits accounted for their subtle facial expression deficits, suggesting that facial expression deficits are not a core feature of prosopagnosia, but rather a carryover from co-occurring autism traits.

Below, I go through the implications of my thesis for three broad areas. First, I discuss implications for our understanding of prosopagnosia. Second, I discuss implications regarding the organisation and development of normal face processing. Lastly, I discuss implications of this thesis regarding future online studies of neuropsychology.

\subsection{Understanding of prosopagnosia}

Below, I discuss how my thesis advances our understanding of prosopagnosia in eight different ways. First, I discuss how the dissociation between prosopagnosics' abilities to process facial expression and facial identity suggests that facial expression deficits are not a core feature of prosopagnosia. Second, I outline ways to further extend our understanding of the mechanisms prosopagnosics use to process facial expression. Third, I discuss how my findings allude to the level of processing (e.g., perception versus recognition) at which the dissociation between facial expression and facial identity processing occurs. Fourth, I detail 


\section{FACIAL EXPRESSION PROCESSING IN PROSOPAGNOSIA}

how the results of this thesis can inform fMRI studies investigating the neural basis of prosopagnosia. Fifth, I outline how my thesis provides the first precise estimate of facial expression processing deficits in prosopagnosia. Sixth, I discuss the importance of considering the influence of co-occurring developmental conditions on prosopagnosics' facial expression processing, with a focus on autism and alexithymia. Seventh, I argue how my findings challenge the "atypical face orienting" account of prosopagnosia, which holds that prosopagnosics' face processing deficits are the result of atypical orienting to faces early in development. Finally, I discuss the novel contribution of my thesis to understanding how prosopagnosics' process static versus dynamic face stimuli.

Core deficit. A major contribution of my thesis is to demonstrate that facial expression and facial identity processing dissociate in prosopagnosia. My use of large samples, multiple tasks, and inversion effects means that the evidence for the dissociation I observed is particularly robust. This dissociation supports the notion that the core deficit in prosopagnosia does not encompass facial expression processing, and may be specific to facial identity. Moreover, the inversion effect findings provide novel and fundamental insight about the nature of the dissociation. Prosopagnosics showed reduced inversion effects for facial identity but normal inversion effects for facial expression, suggesting that they used atypical mechanisms for processing facial identity but typical mechanisms for facial expression. These inversion results provide compelling evidence that the dissociation between facial expression and facial identity in prosopagnosia results from how they process facial expression and facial identity, not simply from their abilities to process the two face aspects.

Mechanisms of facial expression processing. My thesis also sheds light on the mechanisms that prosopagnosics use to process facial expression. The inversion effect data across both studies suggest that prosopagnosics process facial expression normally, using typical face mechanisms that are highly sensitive to orientation. But the face inversion effect is not the only signature of typical face processing. Other signatures include the face composite effect, which captures holistic interference between different face regions (e.g., it is harder to detect differences between two faces halves when they are aligned compared to misaligned; Hole, 1994; Young, Hellawell, \& Hay, 1987) and the face part-whole effect, which taps the advantage of whole-face processing over feature-based processing (e.g., it is easier to recognise a single feature of a face in a whole face than in isolation; Donnelly $\&$ Davidoff, 1999; Tanaka \& Farah, 1993). It may be the case that different signatures of face processing lead to different conclusions about facial expression mechanisms in prosopagnosia. For example, Palermo and colleagues (2011) found that the size of the 


\section{FACIAL EXPRESSION PROCESSING IN PROSOPAGNOSIA}

composite effect for facial expression was smaller in 12 prosopagnosics than in 17 controls, suggesting that holistic processing of facial expression may be disrupted in prosopagnosia ${ }^{7}$. Future studies should clarify how prosopagnosics process facial expression by testing multiple face signatures simultaneously in the same prosopagnosic sample.

To further our understanding of facial expression mechanisms in prosopagnosia, future studies should also examine where prosopagnosics look on faces displaying expressions and what specific facial information they use to recognise expressions. This can be done using eye-tracking and the "Bubbles" technique (Gosselin \& Schyns, 2001). Eyetracking can reveal whether prosopagnosics and controls look at similar facial locations when analysing facial expression. For example, prosopagnosics tend to over-fixate on external facial features (e.g., forehead/brow and cheeks) than internal features (e.g., eyes and nose) when recognising facial identity, whereas controls did the opposite (Barton, Radcliffe, Cherkasova, \& Edelman, 2007; Schwarzer et al., 2007). Atypical looking behaviour when processing facial expression would suggest that despite their normal performance and normal-sized inversion effects, prosopagnosics may not process facial expression normally. The Bubbles technique (in which different regions of faces are revealed to participants at different spatial frequencies inside bubble-like shapes of varied sizes; Gosselin \& Schyns, 2001) can complement eye-tracking data by revealing which local facial information actually contributes to successful performance. A Bubbles study with typical participants found that the most diagnostic cue for recognising the six basic expressions is the mouth (Blais, Roy, Fiset, Arguin, \& Gosselin, 2012). It would be interesting to see whether prosopagnosics also used the mouth when recognising basic facial expressions. If not, then prosopagnosics' subtle difficulty with basic expression recognition may result from suboptimal use of local facial information.

Level of dissociation and stage of processing. My results speak to the stage of processing at which facial expression and facial identity processing dissociate in prosopagnosia. The matching and sorting tasks I used in Study 1 are largely perceptual, in that they place minimal memory demands. The dissociation I observed using such tasks

\footnotetext{
${ }^{7}$ Palermo and colleagues (2011) tested 12 prosopagnosics using three facial expression labelling tasks and found normal performance. Prosopagnosics also completed a face composite task. In this task, participants viewed two face segments - a top and a bottom half, split horizontally at the centre of the face - and they must judge whether the expression of the top half is the same or different to the expression of the bottom half. Performance is typically less accurate and sometimes slower when the face segments are aligned vertically (showing a complete face) than when they are misaligned. Prosopagnosics showed a smaller difference between aligned and misaligned trials compared to controls, but only on response times, not accuracy. Moreover, close inspection of the data reveals that an outlier prosopagnosic might have driven the response time difference.
} 


\section{FACIAL EXPRESSION PROCESSING IN PROSOPAGNOSIA}

suggests that facial expression and facial identity mechanisms segregate early in face processing stages. This early segregation is in line with EEG data showing that the N170 ERP - an index of facial identity analysis - is unaffected by changes in facial expression (Eimer et al., 2003; Eimer \& Holmes, 2002; Holmes et al., 2003). It is unclear whether the dissociation between facial expression and facial identity might be more or less pronounced during later, more memory dependent stages of processing. Future studies could use memorybased tasks to see if a larger or smaller dissociation between facial expression and facial identity processing occurs. A potential facial expression memory task that could be used involves memorising facial expressions displayed by the same individuals at three different intensities (e.g., anger displayed at low intensity (20\% anger and 70\% neutral morph), medium intensity (50\% anger and 50\% neutral morph), and high intensity ( $80 \%$ anger and $20 \%$ neutral morph), for such a task, see Wilhelm et al., 2014). In using such a task, if a larger dissociation between facial expression and facial identity processing is observed, then it would suggest that distinctions between facial expression and facial identity processing in prosopagnosia become more pronounced at later stages in the face processing stream. Conversely, a smaller dissociation between facial expression and facial identity processing using memory tasks would suggest that that the distinction becomes less pronounced at later stages in the face processing stream.

Neural basis. My findings are consistent with fMRI studies of prosopagnosia that detect abnormalities in prosopagnosics' face-selective regions in the ventral stream (like the FFA and the face-selective region in the anterior temporal lobe; fATL), which are primarily involved in facial identity processing, rather than face-selective regions in the dorsal stream (like the pSTS), which are more involved in facial expression processing. These studies have generally found differences in both activation and structure of face-selective regions in the ventral stream of prosopagnosics relative to controls. For example, prosopagnosics show reduced face-selective responses in the FFA (Furl, Garrido, Dolan, Driver, \& Duchaine, 2011) and reduced grey matter volume in sections of the fusiform gyrus and the inferior temporal gyrus (Garrido et al., 2009). More recent studies have also reported atypical connectivity between face-selective regions in the ventral stream (Gomez et al., 2015; Lohse et al., 2016; Rosenthal et al., 2017; Song et al., 2015; Thomas et al., 2009).

Prevalence of facial expression deficits. In this thesis I was able to provide new insight into the prevalence of facial expression processing deficits in prosopagnosia. My prevalence estimates revealed that few prosopagnosics had facial expression perception deficits in Study 1 (i.e. $7.70 \%$ of the sample), and, similarly, few prosopagnosics had facial 


\section{FACIAL EXPRESSION PROCESSING IN PROSOPAGNOSIA}

expression recognition deficits in Study 2 (i.e. $2.56 \%-5.13 \%$ of the sample). The estimate from Study 1 is particularly robust because facial identity performance was not determined through circular analysis (rather, the prosopagnosics completed facial identity tasks that were independent of those used for diagnosis, and were parallel to the facial expression tasks). The estimate from Study 2 is more limited because I did not have parallel facial identity recognition tasks. However, because prosopagnosia is diagnosed based on deficits in facial identity recognition, the estimate should not be discounted.

In addition to the prevalence estimates provided separately for facial expression perception (Study 1) and facial expression recognition (Study 2), I also examined the proportion of prosopagnosics who have deficits across both levels of facial expression processing. To do this, I first compiled data from prosopagnosics who completed both studies $(n=66)$. I then calculated a composite z-score from the prosopagnosics z-scores for all seven facial expression tasks used in this thesis. Only one of these 66 prosopagnosics had a z-score that was below -1.75 . Of these 66 prosopagnosics, nine had z-scores that fell in the impaired range for the facial identity perception tasks in Study 1. A conservative estimate for the number of prosopagnosics who would be impaired across both facial identity perception and recognition would be nine out of 66 prosopagnosics (i.e. $13.64 \%$ of the sample). Therefore, I can provide a rough estimate that between $1.52 \%$ of prosopagnosics (i.e. $1 / 66$ ) and $11.11 \%$ of prosopagnosics (i.e. 1/9) may have facial expression processing deficits that involve both perception and recognition. Taken together, the low estimates of deficits for facial expression perception, facial expression recognition, and overall facial expression processing (perception and recognition combined) in prosopagnosia suggest that, on the whole, facial expression processing is not impaired in the majority of prosopagnosics.

Co-occurring developmental conditions. Prosopagnosics' small facial expression deficits across both studies were accounted for by subthreshold autism traits as measured using the SATQ (Keanne et al., 2012). Prosopagnosics' facial expression performance negatively correlated with SATQ scores (such that poorer performance on the facial expression tasks was associated with higher levels of autism traits), and the removal of high SATQ scoring prosopagnosics eliminated the deficits. These analyses support the idea that facial expression deficits are not a feature of prosopagnosia itself, but rather a result of cooccurring autism traits. These findings highlight the importance of measuring autism traits in studies of facial expression processing in prosopagnosia to either exclude potential individuals with autism or correlate autism traits with performance on tasks of interest. 


\section{FACIAL EXPRESSION PROCESSING IN PROSOPAGNOSIA}

Another developmental condition relevant to facial expression processing is alexithymia. Alexithymia is characterised by the inability to identify and describe one's own emotions (Bird \& Cook, 2013; Sifneos, 1973). Alexithymia can also impact expression processing more broadly, hindering expression recognition from faces (Cook, Brewer, Shah, \& Bird, 2013; Parker, Taylor, \& Bagby, 1993; Prkachin, Casey, \& Prkachin, 2009), voices (Heaton et al., 2012), and music (Allen, Davis, \& Hill, 2013). A recent proposal suggests that expression problems in autism might be a feature of co-occurring alexithymia, rather than of autism itself (Bird \& Cook, 2013; Cook et al., 2013). Elevated rates of alexithymia have been observed in several conditions including schizophrenia, anorexia nervosa, and social anxiety (Dalbudak et al., 2013; Speranza, Loas, Wallier, \& Corcos, 2007; Van't Wout, Aleman, Bermond, \& Kahn, 2007), so future studies should examine whether alexithymia co-occurs with prosopagnosia, and whether it can account for some of prosopagnosics' facial expression deficits, above and beyond that explained by autism traits.

More generally, my thesis illustrates the importance of considering the influence of co-occurring developmental conditions when studying prosopagnosia. Co-occurrence is common among many developmental conditions, and is likely the result of shared genetic and environmental risk factors (Bishop \& Rutter, 2009; Duchaine et al., 2009; Gilger \& Kaplan, 2001). For example, many conditions co-occur with autism including alexithymia (Bird \& Cook, 2013; Ketelaars, Mol, Swaab, \& van Rijn, 2016), dyslexia (Jones et al., 2009), and synaesthesia (Baron-Cohen et al., 2013). More specific to prosopagnosia, Gray and Cook (2018) propose that co-occurring object agnosia and body agnosia might have a higher incidence in prosopagnosics than in the general population. Future studies should therefore investigate the influence of co-occurring conditions on prosopagnosia, to determine which processing deficits are specific to prosopagnosia, and which are the result of a co-occurring, but independent condition.

Atypical face orienting account. My results challenge the notion that prosopagnosia is caused by atypical orienting to faces early in life and/or during a critical period of learning (Johnson, 2011). This account posits that prosopagnosics are impaired at processing faces because they do not orient sufficiently to them. This account predicts that prosopagnosics should be impaired with all aspects of face processing, yet my results show that prosopagnosics are more impaired with facial identity than with facial expression. One caveat is that facial expression may develop earlier than facial identity (Chatterjee \& Nakayama, 2012), because with facial expressions, we only need to learn six basic categories, whereas with identity, there is a potentially infinite number of individual faces to recognise. However, 


\section{FACIAL EXPRESSION PROCESSING IN PROSOPAGNOSIA}

given that facial expression and facial identity processing appear to develop at a similar rate in typically developing children (Dalrymple et al., 2017) facial expression may not be easier to learn than facial identity. To clarify this issue, future studies should contrast prosopagnosics' abilities to process facial expression against other non-identity face aspects, like age or race. Not only would such comparisons benefit from the fact that both face processing abilities under investigation are independent from the diagnostic aspect of prosopagnosia (namely, facial identity), but the number of categories to learn for facial expression is better matched for facial age (e.g., infant, child, adolescent, young adult, middle-aged, elderly) and race (e.g., European, Latin American, Asian, Middle Eastern, African) than for facial identity (almost an endless number of identities). If dissociations were observed between prosopagnosics abilities to process facial expression and other nonidentity face aspects, then this would further imply that atypical orienting to faces is an inadequate account of prosopagnosia.

Static versus dynamic face stimuli. Finally, my thesis suggests that prosopagnosics' abilities to process static and dynamic facial expressions are comparable. A dissociation between static and dynamic facial expression processing had been reported in two acquired prosopagnosics who were impaired at recognising expression from static stimuli, but were normal with dynamic stimuli (case HJA in Humphreys et al., 1993; case PS in Richoz et al., 2015). Unlike these acquired cases, the prosopagnosics in my thesis did not perform better with dynamic compared to static facial expressions. Although this finding suggests that prosopagnosics' ability to recognise facial expressions does not benefit from facial movement, their ability to recognise other aspects of the face might. For example, prosopagnosics' facial identity recognition was better with dynamic than static stimuli, suggesting that prosopagnosics can use facial movements as a cue to identity (Bennetts, Butcher, Lander, Udale, \& Bate, 2015; Longmore \& Tree, 2013). Future prosopagnosia studies should aim to include dynamic face stimuli when investigating a broad range of face processing abilities to provide a more ecologically valid test of face recognition abilities than exclusively using static stimuli. 


\subsection{Organisation and development of normal face processing}

In this section, I discuss how my thesis contributes to our understanding of the organisation and development of normal face processing ${ }^{8}$. First, I discuss how the dissociation between prosopagnosics' abilities to process facial expression and facial identity informs cognitive and neural models of face processing. Second, I discuss how additional support for the distinction between facial expression and facial identity processing would come from evidence of the opposite dissociation to the one I reported in this thesis (namely, individuals with a developmental condition who have impaired facial expression processing but intact facial identity processing). Lastly, I discuss how my results shed light on when facial expression and facial identity processing may segregate in development.

Models of face processing. The dissociation between prosopagnosics' facial expression and facial identity processing reported in this thesis is in line with influential cognitive (Bruce \& Young, 1986) and neural (Haxby et al., 2000) models of face processing. More specifically, the dissociation between facial expression and facial identity processing adds to the wide-ranging evidence that supports the notion of independent processing systems for facial expression and facial identity, rather than a shared processing system (Calder \& Young, 2005). For instance, my findings are consistent with data from brain-damaged patients that demonstrate a double dissociation between facial expression and facial identity processing (e.g., Adolphs et al., 1994; De Renzi \& Di Pellegrino, 1998; Fox et al., 2011). They are also in line with EEG data that imply early distinctions between the processing of facial expression and facial identity (e.g., Eimer et al., 2003; Eimer \& Holmes, 2002; Holmes et al., 2003). Taken together, these findings converge on the conclusion that the mechanisms involved in facial expression and facial identity processing are independent.

The results of my thesis are also consistent with neural models of face processing that propose anatomical distinctions between facial expression and facial identity processing

\footnotetext{
${ }^{8}$ A long-standing argument claims that only acquired impairments, not developmental deficits, can provide valid inferences about the organisation and development of normal cognition (Bishop, 1997; Karmiloff-Smith, Scerif, \& Ansari, 2003; Calder \& Young, 2005). The basic argument is that impairments in acquired cases and developmental conditions are not comparable. In acquired cases, the impairments affect an otherwise normally developing cognitive system. In developmental cases, however, it can only be assumed that cognition developed normally except for the specified function (which is thought to be an unlikely occurrence). However, a large and growing literature shows that some developmental conditions, like dyslexia, specific language impairment, and prosopagnosia can result from circumscribed dysfunctions restricted to specific cognitive mechanisms (Duchaine et al., 2006; Friedmann \& Gvion, 2002; Rasmus, 2002; Van der Lely, 2005). Indeed, face processing deficits in developmental prosopagnosia can be as selective as those observed in acquired cases (e.g., Bentin, DeGutis, D'Esposito, \& Robertson, 2007; Duchaine et al., 2006; Humphreys, Avidan, \& Behrmann, 2007; Shah, Gaule, Gaigg, Bird, \& Cook, 2015).
} 


\section{FACIAL EXPRESSION PROCESSING IN PROSOPAGNOSIA}

(Haxby et al., 2000). In Haxby and collagues' model, ventral regions, like the fusiform face area (FFA), are more involved in processing invariant facial information (e.g., identity), while dorsal regions, like the posterior superior temporal sulcus (pSTS), are more involved in processing changeable facial information (e.g., expression). This distinction has been demonstrated using fMRI-adaptation techniques, where repetition of facial identity leads to adaptation in fusiform cortex, whereas repetition of facial expression leads to adaptation in the STS (Winston et al., 2004). Similarly, TMS studies have implicated the involvement of the pSTS in facial expression processing and the FFA in facial identity processing (Pitcher, 2014; Pitcher et al., 2008; 2009).

In their revision of the Haxby and colleagues' model, Duchaine and Yovel (2015) propose that the dorsal and ventral face processing streams should be conceptualised as pathways for processing dynamic versus static face information, rather than changeable versus invariant face information. This proposed change is based on recent findings showing that dorsal face-selective regions, including the STS, are much more responsive to dynamic than to static face stimuli. For example, ventral regions like the OFA and FFA show a slightly higher response to dynamic faces compared to static ones, whereas the pSTS's response to dynamic faces is significantly larger compared to the response to static faces (Fox et al., 2009; Pitcher et al., 2011). Interestingly, the prosopagnosics I tested performed comparably with dynamic and static stimuli, suggesting that processing of static versus dynamic facial expressions does not dissociate in prosopagnosia. Therefore, the results reported in this thesis fit better with Haxby and colleagues' (2000) key distinction between processing of changeable (e.g., expression) versus invariant (e.g., identity) facial information.

Single versus double dissociation. Although this thesis shows a dissociation between prosopagnosics' facial expression and facial identity processing, evidence of a double dissociation is necessary to more convincingly support the independent systems account. Currently, there is no clear evidence of the other half of the double dissociation (impaired facial expression processing but normal facial identity processing) in individuals who have developmental conditions, but it has been demonstrated in brain-damaged patients. Like the prosopagnosics reported in this thesis, some acquired prosopagnosics have impaired facial identity processing, but intact facial expression processing (e.g., De Renzi \& Di Pellegrino, 1998; Fox et al., 2011; Mattson et al., 2000; Riddoch, et al., 2008; Tranel et al., 1988). Other patients who have different areas damaged (e.g., bilateral lesions to the amygdala) than in acquired prosopagnosia show the reverse pattern: impaired facial expression processing, but normal facial identity processing (e.g., Adolphs et al., 1994; Calder et al., 1997; Humphreys 


\section{FACIAL EXPRESSION PROCESSING IN PROSOPAGNOSIA}

et al., 1993; Sprengelmeyer et al., 1997; Young et al., 1993; 1996). This double dissociation between facial identity and facial expression processing provides strong support for the independent systems account of face processing. Future studies should pursue systematic evidence of intact facial identity processing but impaired facial expression processing in individuals with developmental conditions. If found, such a dissociation would provide even more convincing support for Bruce and Young's (1986) model.

Development of face processing. Because I tested developmental prosopagnosics, my results imply not only that facial expression and facial identity processing rely on different mechanisms, but also that these mechanisms dissociate in development. However, it is not clear from the data in this thesis when facial expression and facial identity mechanisms split. One possibility is that the split occurs early and that facial expression and facial identity mechanisms develop independently. Alternatively, facial expression and facial identity mechanisms develop together and are both impaired in child prosopagnosics, but because facial expression is easier to learn (or compensate for), the majority of adult prosopagnosics demonstrate normal or close to normal facial expression processing. This second pattern has been observed with prosopagnosics' face perception and face memory processing. Dalrymple and colleagues (2014) found that while child prosopagnosics were impaired with both face perception and face memory, only half of adult prosopagnosics were impaired with face perception (all adults were impaired with face memory). Because all child prosopagnosics demonstrate impaired face perception, but only some adult prosopagnosics do suggests that face perception is easier to learn (or compensate for) than face memory.

Support for a split early in development comes from the inversion effect data in this thesis. Prosopagnosics never showed reduced inversion effects on all facial expression tasks, suggesting that they use similar face mechanisms to match and label facial expressions, as typically developing controls. This results suggests that prosopagnosics' did not compensate their performance on the facial expression processing tasks using alternative mechanisms. Stronger evidence of an early split between the processing of facial expression and facial identity would come from intact facial expression processing in child prosopagnosics. Previous studies of facial expression processing in child prosopagnosia found mixed results. Ariel and Sadeh (1996) reported impaired facial expression recognition in LG, an 8-year-old boy, whereas Jones and Tranel (2001) observed normal recognition in TA, a 5-year-old boy (although performance was close to ceiling level for both TA and controls). A future study tracking the development of a large sample of child prosopagnosics' facial expression and facial identity processing would answer when in development the split occurs. 


\section{FACIAL EXPRESSION PROCESSING IN PROSOPAGNOSIA}

\subsection{Online studies of neuropsychology}

This thesis makes a methodological contribution to the field of cognitive neuropsychology. By collecting large quantities of high-quality data over a relatively short period (roughly 6 months), my research serves as a model for high-throughput and highpowered neuropsychology studies of face processing. Such rapid and large-scale data collection is only made possible by online testing methods because it enables efficient evaluation and testing of geographically widespread groups of participants, like prosopagnosics. Online testing opens up new possibilities for investigating other developmental conditions that, like prosopagnosia, have a relatively high prevalence in the general population yet are not well understood. Some of these conditions include, phonagnosia (inability to recognise voices, which is estimated to affect $3.2 \%$ of the adult population; Shilowich \& Biederman, 2016), dyscalculia (difficulty with mathematical calculations, which is estimated to affect $3-6.5 \%$ of school-age children; Gross-Tsur, Manor, \& Shalev, 1996; Shalev, Auerbach, Manor, \& Gross-Tsur, 2000), and topographagnosia (inability to orient in environments, however there is no estimate of prevalence yet; Iaria \& Barton, 2010).

Future prosopagnosia studies should aspire to collect data from even larger samples than those in this thesis to enable cluster analyses for condition subtyping. One particularly impressive study that analysed data from 19,133 individuals with self-reported synaesthesia did just this (Novich, Cheng, \& Eagleman, 2011). Novich and colleagues' key finding was that synaesthetes could be clustered into five different subtypes, implying that synaesthesia is not a unitary phenomenon, but instead, a collective term that encompasses a variety of forms. Conducting a similar study with prosopagnosics would enable researchers to demarcate prosopagnosia subtypes (if they should exist).

A particular challenge for online studies in neuropsychology is to ensure that the control participants produce quality data. Although I had several reasons for using mTurk (e.g., reliable data and time/cost-effectiveness), a potential problem arises from mTurk participants not being restricted with regards to the studies in which they participate. Thus, the likelihood of mTurk participants being naïve to stimulus sets (especially commonly used ones like Ekman and Friesen's (1976) POFA set) and specific tasks is lower than what would be expected in an undergraduate student sample (Chandler, Mueller, \& Paolacci, 2014). If the control participants in this thesis had indeed been exposed to some of the stimuli sets and tasks used in Studies 1 and 2, then they may have performed better across the tasks than if 


\section{FACIAL EXPRESSION PROCESSING IN PROSOPAGNOSIA}

they had been naïve. If this is the case, then the controls' performance on the tasks within this thesis might be an over-estimation of a typically developing control samples performance, and consequently result in over-estimations of the prosopagnosics' deficits in facial expression and facial identity processing. To account for this potential limitation, future studies should collect control data using both online and in-house laboratory testing 9 . Although this will require more time and resources, similar patterns of performance across online and laboratory control samples will allow researchers to draw stronger conclusions.

\subsection{Conclusions}

The aim of this thesis was to comprehensively investigate facial expression processing in prosopagnosia. To do this, I conducted two studies. In Study 1, I contrasted prosopagnosics' ability to perceive facial expression against their ability to perceive facial identity. Participants completed three facial expression tasks and three parallel facial identity tasks matched on format and difficulty. Relative to controls, prosopagnosics' performance on facial identity tasks was more impaired than their performance on the expression tasks, demonstrating a dissociation between their ability to process the two face aspects. The dissociation was also observed in inversion effects, with prosopagnosics producing comparable inversion effects to controls on the facial expression tasks, but smaller inversion effects on the facial identity tasks. Together, these results suggest that prosopagnosics use similar mechanisms as controls to perceive facial expression, but different mechanisms to controls to perceive facial identity. In Study 2, I provided a more thorough investigation of prosopagnosics' facial expression processing by looking at their ability to recognise facial expressions. Participants completed four expression labelling tasks that measured their recognition of basic and complex expressions from static and dynamic stimuli. Relative to controls, prosopagnosics performed more poorly on the basic expression tasks but performed comparably on the complex expression tasks. Whether the face stimuli were static or dynamic did not affect participants performance. Although prosopagnosics showed a slight deficit in their ability to label basic expressions, the inversion data suggests that they use comparable mechanisms to recognise them. Across both studies, subthreshold autism traits

\footnotetext{
${ }^{9}$ I piloted all of the tasks in this thesis across two undergraduate student samples $(n=22$ and $n=23)$ from Victoria University of Wellington, although the type and combination of tasks they completed is not identical to those used in Study 1 and 2. Nevertheless, the students performed comparably to mTurk controls across all tasks, suggesting that the mTurk data are as reliable as those obtained from lab-based testing methods.
} 


\section{FACIAL EXPRESSION PROCESSING IN PROSOPAGNOSIA}

accounted for prosopagnosics' subtle expression processing deficits. Further, the proportion of prosopagnosics who either had deficits for facial expression perception or facial expression recognition were small, indicating that the majority of prosopagnosics have normal facial expression processing.

Taken together, Study 1 and 2 of my thesis provide strong evidence that the ability to process facial expression is normal in prosopagnosia. This thesis informs our understanding of prosopagnosia by supporting the idea that the core processing deficit in prosopagnosia is specific to facial identity, rather than a deficit that also encompasses facial expression processing. This thesis also adds to the wide-spread evidence supporting the notion of independent mechanisms for facial expression and facial identity processing (e.g., Bruce \& Young, 1986; Haxby et al., 2000), and suggests that these mechanisms dissociate in development. In doing so, my thesis provides a valuable step toward bettering our understanding of prosopagnosia and the functional organisation of normal face processing. 


\section{FACIAL EXPRESSION PROCESSING IN PROSOPAGNOSIA}

\section{References}

Adolphs, R. (1999). Social cognition and the human brain. Trends in cognitive sciences, 3(12), 469-479. doi:10.1016/S1364-6613(99)01399-6

Adolphs, R., Tranel, D., Damasio, H., \& Damasio, A. (1994). Impaired recognition of emotion in facial expressions following bilateral damage to the human amygdala. Nature, 372(6507), 669. doi:10.1038/372669a0

Allen, R., Davis, R., \& Hill, E. (2013). The effects of autism and alexithymia on physiological and verbal responsiveness to music. Journal of autism and developmental disorders, 43(2), 432-444. doi:10.1007/s10803-012-1587-8

Ambadar, Z., Schooler, J. W., \& Cohn, J. F. (2005). Deciphering the enigmatic face: The importance of facial dynamics in interpreting subtle facial expressions. Psychological science, 16(5), 403-410. doi:10.1111/j.0956-7976.2005.01548.x

Ariel, R., \& Sadeh, M. (1996). Congenital visual agnosia and prosopagnosia in a child: a case report. Cortex, 32(2), 221-240. doi:10.1016/S0010-9452(96)80048-7

Baron-Cohen, S., Johnson, D., Asher, J., Wheelwright, S., Fisher, S. E., Gregersen, P. K., \& Allison, C. (2013). Is synaesthesia more common in autism?. Molecular autism, 4(1), 40. doi:10.1186/2040-2392-4-40

Baron-Cohen, S., Wheelwright, S., Hill, J., Raste, Y., \& Plumb, I. (2001). The "Reading the Mind in the Eyes" Test revised version: a study with normal adults, and adults with Asperger syndrome or high-functioning autism. The Journal of Child Psychology and Psychiatry and Allied Disciplines, 42(2), 241-251. doi:10.1017/S0021963001006643

Baron-Cohen, S., Wheelwright, S., Skinner, R., Martin, J., \& Clubley, E. (2001). The autismspectrum quotient (AQ): Evidence from asperger syndrome/high-functioning autism, malesand females, scientists and mathematicians. Journal of autism and developmental disorders, 31(1), 5-17. doi:10.1023/A:1005653411471

Barton, J. J., Cherkasova, M. V., Hefter, R., Cox, T. A., O'connor, M., \& Manoach, D. S. (2004). Are patients with social developmental disorders prosopagnosic? Perceptual heterogeneity in the Asperger and socio-emotional processing disorders. Brain, 127(8), 1706-1716. doi:10.1093/brain/awh194

Barton, J. J., Radcliffe, N., Cherkasova, M. V., \& Edelman, J. A. (2007). Scan patterns during the processing of facial identity in prosopagnosia. Experimental brain research, 181(2), 199-211. doi:10.1007/s00221-007-0923-2 


\section{FACIAL EXPRESSION PROCESSING IN PROSOPAGNOSIA}

Bate, S., Adams, A., Bennetts, R., \& Line, H. (2017). Developmental prosopagnosia with concurrent topographical difficulties: A case report and virtual reality training programme. Neuropsychological rehabilitation, 1-23. doi:10.1080/09602011.2017.1409640

Bate, S., \& Bennetts, R. (2015). The independence of expression and identity in faceprocessing: evidence from neuropsychological case studies. Frontiers in psychology, 6. doi:10.3389/fpsyg.2015.00770

Bate, S., \& Tree, J. J. (2017). The definition and diagnosis of developmental prosopagnosia. doi:10.1080/17470218.2016.1195414

Behrmann, M., \& Avidan, G. (2005). Congenital prosopagnosia: face-blind from birth. Trends in cognitive sciences, 9(4), 180-187. doi:10.1016/j.tics.2005.02.011

Bennetts, R. J., Butcher, N., Lander, K., Udale, R., \& Bate, S. (2015). Movement cues aid face recognition in developmental prosopagnosia. Neuropsychology, 29(6), 855. doi:10.1037/neu0000187

Bentin, S., Allison, T., Puce, A., Perez, E., \& McCarthy, G. (1996). Electrophysiological studies of face perception in humans. Journal of cognitive neuroscience, 8(6), 551-565. doi:10.1162/jocn.1996.8.6.551

Bentin, S., DeGutis, J. M., D'Esposito, M., \& Robertson, L. C. (2007). Too many trees to see the forest: performance, event-related potential, and functional magnetic resonance imaging manifestations of integrative congenital prosopagnosia. Journal of Cognitive Neuroscience, 19(1), 132-146. doi:10.1162/jocn.2007.19.1.132

Bird, G., \& Cook, R. (2013). Mixed emotions: the contribution of alexithymia to the emotional symptoms of autism. Translational psychiatry, 3(7), e285. doi:10.1038/tp.2013.61

Biotti, F., \& Cook, R. (2016). Impaired perception of facial emotion in developmental prosopagnosia. Cortex, 81, 126-136. doi:10.1016/j.cortex.2016.04.008

Biotti, F., Gray, K. L., \& Cook, R. (2017). Impaired body perception in developmental prosopagnosia. Cortex, 93, 41-49. doi:10.1016/j.cortex.2017.05.006

Bishop, D. V. (1997). Cognitive neuropsychology and developmental disorders:

Uncomfortable bedfellows. The Quarterly Journal of Experimental Psychology Section A, 50(4), 899-923. doi:10.1080/713755740

Bishop, D., \& Rutter, M. (2009). Neurodevelopmental disorders: conceptual issues (pp. 3241). Blackwell Publishing Ltd. doi:10.1002/9781444300895.ch3 


\section{FACIAL EXPRESSION PROCESSING IN PROSOPAGNOSIA}

Blais, C., Roy, C., Fiset, D., Arguin, M., \& Gosselin, F. (2012). The eyes are not the window to basic emotions. Neuropsychologia, 50(12), 2830-2838. doi:10.1016/j.neuropsychologia.2012.08.010

Bowles, D. C., McKone, E., Dawel, A., Duchaine, B., Palermo, R., Schmalzl, L., ... \& Yovel, G. (2009). Diagnosing prosopagnosia: Effects of ageing, sex, and participant-stimulus ethnic match on the Cambridge Face Memory Test and Cambridge Face Perception Test. Cognitive Neuropsychology, 26(5), 423-455. doi:10.1080/02643290903343149

Bruce, V., \& Young, A. (1986). Understanding face recognition. British journal of psychology, 77(3), 305-327. doi:10.1111/j.2044-8295.1986.tb02199.x

Buhrmester, M., Kwang, T., \& Gosling, S. D. (2011). Amazon's Mechanical Turk: A new source of inexpensive, yet high-quality, data?. Perspectives on psychological science, 6(1), 3-5. doi:10.1177/1745691610393980

Burns, E. J., Martin, J., Chan, A. H., \& Xu, H. (2017). Impaired processing of facial happiness, with or without awareness, in developmental prosopagnosia. Neuropsychologia, 102, 217-228. doi:10.1016/j.neuropsychologia.2017.06.020

Calder, A. J. (1996). Facial emotion recognition after bilateral amygdala damage: differentially severe impairment of fear. Cognitive Neuropsychology, 13(5), 699-745. doi:10.1080/026432996381890

Calder, A. J. (2011). Does facial identity and facial expression recognition involve separate visual routes? In A. Calder (Ed.), Oxford handbook of face perception. (pp. 411-430) doi:10.1093/oxfordhb/9780199559053.013.0022

Calder, A. J., Burton, A. M., Miller, P., Young, A. W., \& Akamatsu, S. (2001). A principal component analysis of facial expressions. Vision research, 41(9), 1179-1208. doi:10.1016/S0042-6989(01)00002-5

Calder, A. J., Keane, J., Lawrence, A. D., \& Manes, F. (2004). Impaired recognition of anger following damage to the ventral striatum. Brain, 127(9), 1958-1969. doi:10.1093/brain/awh214

Calder, A. J., Keane, J., Manes, F., Antoun, N., \& Young, A. W. (2000). Impaired recognition and experience of disgust following brain injury. Nature neuroscience, 3(11), 1077. doi:10.1038/80586

Calder, A. J., \& Young, A. W. (2005). Understanding the recognition of facial identity and facial expression. Nature Reviews Neuroscience, 6(8), 641-651. doi:10.1038/nrn1724

Calder, A. J., Young, A. W., Karnat, A., Sprengelmeyer, R., Perrett, D. I., \& Rowland, D. (1997). Selective deficits in emotional expression recognition following brain 


\section{FACIAL EXPRESSION PROCESSING IN PROSOPAGNOSIA}

damage. International Journal of Psychophysiology, 1(25), 69. Retrieved from https://www.infona.pl

Carey, S. (1981). The development of face perception. In G. Davies, H. D. Ellis, \& J. Shepherd (Eds.), Perceiving and remembering faces (pp. 9-38). New York: Academic Press Inc.

Carey, S., Diamond, R., \& Woods, B. (1980). Development of face recognition: A maturational component?. Developmental Psychology, 16(4), 257. doi:10.1037/00121649.16.4.257

Chandler, J., Mueller, P., \& Paolacci, G. (2014). Nonnaïveté among Amazon Mechanical Turk workers: Consequences and solutions for behavioral researchers. Behavior research methods, 46(1), 112-130. doi:10.3758/s13428-013-0365-7

Chatterjee, G., \& Nakayama, K. (2012). Normal facial age and gender perception in developmental prosopagnosia. Cognitive Neuropsychology, 29(5-6), 482-502. doi:10.1080/02643294.2012.756809

Cook, R., Brewer, R., Shah, P., \& Bird, G. (2013). Alexithymia, not autism, predicts poor recognition of emotional facial expressions. Psychological Science, 24(5), 723-732. doi:10.1177/0956797612463582

Corrow, J. C., Corrow, S. L., Lee, E., Pancaroglu, R., Burles, F., Duchaine, B., ... \& Barton, J. J. (2016). Getting lost: Topographic skills in acquired and developmental prosopagnosia. cortex, 76, 89-103. doi:10.1016/j.cortex.2016.01.003

Crookes, K., \& McKone, E. (2009). Early maturity of face recognition: No childhood development of holistic processing, novel face encoding, or facespace. Cognition, 111(2), 219-247. doi:10.1016/j.cognition.2009.02.004

Cunningham, D. W., \& Wallraven, C. (2009). Dynamic information for the recognition of conversational expressions. Journal of Vision, 9(13), 7-7. doi:10.1097/WNR.0b013e3283320e3f

Dalbudak, E., Evren, C., Aldemir, S., Coskun, K. S., Yıldırım, F. G., \& Ugurlu, H. (2013). Alexithymia and personality in relation to social anxiety among university students. Psychiatry research, 209(2), 167-172. doi:10.1016/j.psychres.2012.11.027

Dalrymple, K. A., di Oleggio Castello, M. V., Elison, J. T., \& Gobbini, M. I. (2017). Concurrent development of facial identity and expression discrimination. PloS one, 12(6), e0179458. doi:10.1371/journal.pone.0179458

Dalrymple, K. A., Fletcher, K., Corrow, S., das Nair, R., Barton, J. J., Yonas, A., \& Duchaine, B. (2014). "A room full of strangers every day": The psychosocial impact of 


\section{FACIAL EXPRESSION PROCESSING IN PROSOPAGNOSIA}

developmental prosopagnosia on children and their families. Journal of psychosomatic research, 77(2), 144-150. doi:10.1016/j.jpsychores.2014.06.001

Dalrymple, K. A., Garrido, L., \& Duchaine, B. (2014). Dissociation between face perception and face memory in adults, but not children, with developmental prosopagnosia. Developmental cognitive neuroscience, 10, 10-20. doi:10.1016/j.dcn.2014.07.003

Dalrymple, K. A., \& Palermo, R. (2016). Guidelines for studying developmental prosopagnosia in adults and children. Wiley Interdisciplinary Reviews: Cognitive Science, 7(1), 73-87. doi:10.1002/wcs.1374

Darwin, C., \& Prodger, P. (1998). The expression of the emotions in man and animals. Retrieved from https://books.google.co.nz

Davis, J. M., McKone, E., Dennett, H., O'Connor, K. B., O'Kearney, R., \& Palermo, R. (2011). Individual differences in the ability to recognise facial identity are associated with social anxiety. PloS one, 6(12), e28800. Retrieved from http://journals.plos.org

Dawson, G., Webb, S. J., \& McPartland, J. (2005). Understanding the nature of face processing impairment in autism: insights from behavioral and electrophysiological studies. Developmental neuropsychology, 27(3), 403-424. doi:10.1371/journal.pone.0028800

Deary, I. J., Corley, J., Gow, A. J., Harris, S. E., Houlihan, L. M., Marioni, R. E., ... \& Starr, J. M. (2009). Age-associated cognitive decline. British medical bulletin, 92(1), 135-152. doi:10.1093/bmb/ldp033

De Haan, E. H., \& Campbell, R. (1991). A fifteen year follow-up of a case of developmental prosopagnosia. Cortex, 27(4), 489-509. doi:10.1016/S0010-9452(13)80001-9

De Renzi, E., \& Di Pellegrino, G. (1998). Prosopagnosia and alexia without object agnosia. Cortex, 34(3), 403-415. doi:10.1016/S0010-9452(08)70763-9

Dobel, C., Bölte, J., Aicher, M., \& Schweinberger, S. R. (2007). Prosopagnosia without apparent cause: Overview and diagnosis of six cases. Cortex, 43(6), 718-733. doi:10.1016/S0010-9452(08)70501-X

Donnelly, N., \& Davidoff, J. (1999). The mental representations of faces and houses: Issues concerning parts and wholes. Visual cognition, 6(3-4), 319-343. doi:10.1080/135062899395000

Duchaine, B. (2011). Developmental prosopagnosia: cognitive, neural, and developmental investigations. In A. Calder (Ed.), Oxford handbook of face perception. (pp. 764-780) doi:10.1093/oxfordhb/9780199559053.013.0042 


\section{FACIAL EXPRESSION PROCESSING IN PROSOPAGNOSIA}

Duchaine, B., Germine, L., \& Nakayama, K. (2007). Family resemblance: Ten family members with prosopagnosia and within-class object agnosia. Cognitive neuropsychology, 24(4), 419-430. doi:10.1080/02643290701380491

Duchaine, B., Murray, H., Turner, M., White, S., \& Garrido, L. (2009). Normal social cognition in developmental prosopagnosia. Cognitive neuropsychology, 26(7), 620634. doi:10.1080/02643291003616145

Duchaine, B., \& Nakayama, K. (2005). Dissociations of face and object recognition in developmental prosopagnosia. Journal of Cognitive Neuroscience, 17(2), 249-261. doi:10.1162/0898929053124857

Duchaine, B., \& Nakayama, K. (2006). The Cambridge Face Memory Test: Results for neurologically intact individuals and an investigation of its validity using inverted face stimuli and prosopagnosic participants. Neuropsychologia, 44(4), 576-585. doi:10.1016/j.neuropsychologia.2005.07.001

Duchaine, B. C., Parker, H., \& Nakayama, K. (2003). Normal recognition of emotion in a prosopagnosic. Perception, 32(7), 827-838. doi:10.1068/p5067

Duchaine, B., \& Yovel, G. (2015). A revised neural framework for face processing. Annual Review of Vision Science, 1, 393-416. doi:10.1146/annurev-vision-082114-035518

Duchaine, B. C., Yovel, G., Butterworth, E. J., \& Nakayama, K. (2006). Prosopagnosia as an impairment to face-specific mechanisms: Elimination of the alternative hypotheses in a developmental case. Cognitive neuropsychology, 23(5), 714-747. doi:10.1080/02643290500441296

Eibl-Eibesfeldt, I. (1973). The expressive behavior of the deaf-and-blind born. In Social Comm. and Mov., Ed. I. (pp. 163-193). Academic Press. Retrieved from http://hdl.handle.net

Eimer, M. (2000). The face-specific N170 component reflects late stages in the structural encoding of faces. Neuroreport, 11(10), 2319-2324. Retrieved from http://journals.lww.com

Eimer, M., \& Holmes, A. (2002). An ERP study on the time course of emotional face processing. Neuroreport, 13(4), 427-431. Retrieved from http://journals.lww.com

Eimer, M., Holmes, A., \& McGlone, F. P. (2003). The role of spatial attention in the processing of facial expression: an ERP study of rapid brain responses to six basic emotions. Cognitive, Affective, \& Behavioral Neuroscience, 3(2), 97-110. doi:10.3758/CABN.3.2.97 


\section{FACIAL EXPRESSION PROCESSING IN PROSOPAGNOSIA}

Ekman, P., \& Friesen, W. V. (1971). Constants across cultures in the face and emotion. Journal of personality and social psychology, 17(2), 124. doi:10.1037/h0030377

Ekman, P., \& Friesen, W. V. (1976). Measuring facial movement. Environmental psychology and nonverbal behavior, 1(1), 56-75. doi:10.1007/BF01115465

Ekman, P., Friesen, W. V., O'sullivan, M., Chan, A., Diacoyanni-Tarlatzis, I., Heider, K., ... \& Scherer, K. (1987). Universals and cultural differences in the judgments of facial expressions of emotion. Journal of personality and social psychology, 53(4), 712. doi:10.1037/0022-3514.53.4.712

Fiorentini, C., \& Viviani, P. (2011). Is there a dynamic advantage for facial expressions?. Journal of Vision, 11(3), 17-17. doi:10.1167/11.3.17

Fisher, K., Towler, J., \& Eimer, M. (2016). Facial identity and facial expression are initially integrated at visual perceptual stages of face processing. Neuropsychologia, 80, 115125. doi:10.1016/j.neuropsychologia.2015.11.011

Fisher, K., Towler, J., \& Eimer, M. (2017). Face identity matching is selectively impaired in developmental prosopagnosia. cortex, 89, 11-27. doi:10.1016/j.cortex.2017.01.003

Fox, C. J., Hanif, H. M., Iaria, G., Duchaine, B. C., \& Barton, J. J. (2011). Perceptual and anatomic patterns of selective deficits in facial identity and expression processing. Neuropsychologia, 49(12), 3188-3200. doi:10.1016/j.neuropsychologia.2011.07.018

Friedmann, N., \& Gvion, A. (2002). Modularity in developmental disorders: Evidence from Specific Language Impairment and peripheral dyslexias. Behavioral and Brain Sciences, 25(6), 756-757. doi:10.1017/S0140525X02270132

Furl, N., Garrido, L., Dolan, R. J., Driver, J., \& Duchaine, B. (2011). Fusiform gyrus face selectivity relates to individual differences in facial recognition ability. Journal of Cognitive Neuroscience, 23(7), 1723-1740. doi: 10.1162/jocn.2010.21545

Galati, D., Scherer, K. R., \& Ricci-Bitti, P. E. (1997). Voluntary facial expression of emotion: Comparing congenitally blind with normally sighted encoders. Journal of personality and social psychology, 73(6), 1363. doi:10.1037/0022-3514.73.6.1363

Ganel, T., \& Goshen-Gottstein, Y. (2004). Effects of familiarity on the perceptual integrality of the identity and expression of faces: the parallel-route hypothesis revisited. Journal of Experimental psychology: Human perception and Performance, 30(3), 583. doi:10.1037/0096-1523.30.3.583

Garrido, L., Duchaine, B., \& Nakayama, K. (2008). Face detection in normal and prosopagnosic individuals. Journal of Neuropsychology, 2(1), 119-140. doi:10.1348/174866407X246843 


\section{FACIAL EXPRESSION PROCESSING IN PROSOPAGNOSIA}

Garrido, L., Furl, N., Draganski, B., Weiskopf, N., Stevens, J., Tan, G. C. Y., ... \& Duchaine, B. (2009). Voxel-based morphometry reveals reduced grey matter volume in the temporal cortex of developmental prosopagnosics. Brain, 132(12), 3443-3455. doi:10.1093/brain/awp271

Germine, L. T., Duchaine, B., \& Nakayama, K. (2011). Where cognitive development and aging meet: Face learning ability peaks after age 30. Cognition, 118(2), 201-210. doi:10.1016/j.cognition.2010.11.002

Germine, L., Nakayama, K., Duchaine, B. C., Chabris, C. F., Chatterjee, G., \& Wilmer, J. B. (2012). Is the Web as good as the lab? Comparable performance from Web and lab in cognitive/perceptual experiments. Psychonomic bulletin \& review, 19(5), 847-857. doi:10.3758/s13423-012-0296-9

Geskin, J., \& Behrmann, M. (2017). Congenital prosopagnosia without object agnosia? A literature review. Cognitive neuropsychology, 1-51. doi:10.1080/02643294.2017.1392295

Gilger, J. W., \& Kaplan, B. J. (2001). Atypical brain development: a conceptual framework for understanding developmental learning disabilities. Developmental neuropsychology, 20(2), 465-481. doi: 10.1207/S15326942DN2002_2

Golarai, G., Grill-Spector, K., \& Reiss, A. L. (2006). Autism and the development of face processing. Clinical neuroscience research, 6(3-4), 145-160. doi:10.1016/j.cnr.2006.08.001

Gold, J. M., Barker, J. D., Barr, S., Bittner, J. L., Bromfield, W. D., Chu, N., ... \& Srinath, A. (2013). The efficiency of dynamic and static facial expression recognition. Journal of vision, 13(5), 23-23. doi:10.1167/13.5.23

Gomez, J., Pestilli, F., Witthoft, N., Golarai, G., Liberman, A., Poltoratski, S., ... \& GrillSpector, K. (2015). Functionally defined white matter reveals segregated pathways in human ventral temporal cortex associated with category-specific processing. Neuron, 85(1), 216-227. doi:10.1016/j.neuron.2014.12.027

Goodman, J. K., Cryder, C. E., \& Cheema, A. (2013). Data collection in a flat world: The strengths and weaknesses of Mechanical Turk samples. Journal of Behavioral Decision Making, 26(3), 213-224. doi:10.1002/bdm.1753

Gosselin, F., \& Schyns, P. G. (2001). Bubbles: a technique to reveal the use of information in recognition tasks. Vision research, 41(17), 2261-2271. doi:10.1016/S00426989(01)00097-9 


\section{FACIAL EXPRESSION PROCESSING IN PROSOPAGNOSIA}

Gray, K., \& Cook, R. (2018). Should developmental prosopagnosia, developmental body agnosia, and developmental object agnosia be considered independent neurodevelopmental conditions?. Cognitive Neuropsychology. Retrieved from http://www.richcooklab.com

Griffiths, P. E. (2008). What emotions really are: The problem of psychological categories. Retrieved from https://books.google.co.nz

Gross-Tsur, V., Manor, O., \& Shalev, R. S. (1996). Developmental dyscalculia: Prevalence and demographic features. Developmental Medicine \& Child Neurology, 38(1), 25-33. doi:10.1111/j.1469-8749.1996.tb15029.x

Hasselmo, M. E., Rolls, E. T., \& Baylis, G. C. (1989). The role of expression and identity in the face-selective responses of neurons in the temporal visual cortex of the monkey. Behavioural brain research, 32(3), 203-218. doi:10.1016/S01664328(89)80054-3

Haxby, J. V., Hoffman, E. A., \& Gobbini, M. I. (2000). The distributed human neural system for face perception. Trends in cognitive sciences, 4(6), 223-233. doi:10.1016/S13646613(00)01482-0

Haxby, J. V., Hoffman, E. A., \& Gobbini, M. I. (2002). Human neural systems for face recognition and social communication. Biological psychiatry, 51(1), 59-67. doi:10.1016/S0006-3223(01)01330-0

Hartshorne, J. K., \& Germine, L. T. (2015). When does cognitive functioning peak? The asynchronous rise and fall of different cognitive abilities across the life span. Psychological science, 26(4), 433-443. doi:10.1177/0956797614567339

Heaton, P., Reichenbacher, L., Sauter, D., Allen, R., Scott, S., \& Hill, E. (2012). Measuring the effects of alexithymia on perception of emotional vocalizations in autistic spectrum disorder and typical development. Psychological medicine, 42(11), 2453-2459. doi:10.1017/S0033291712000621

Hedley, D., Brewer, N., \& Young, R. (2011). Face recognition performance of individuals with Asperger syndrome on the Cambridge Face Memory Test. Autism Research, 4(6), 449-455. doi:10.1002/aur.214

Hole, G. J. (1994). Configurational factors in the perception of unfamiliar faces. Perception, 23(1), 65-74. doi:10.1068/p230065

Holmes, A., Vuilleumier, P., \& Eimer, M. (2003). The processing of emotional facial expression is gated by spatial attention: evidence from event-related brain 


\section{FACIAL EXPRESSION PROCESSING IN PROSOPAGNOSIA}

potentials. Cognitive Brain Research, 16(2), 174-184. doi:10.1016/S09266410(02)00268-9

Humphreys, K., Avidan, G., \& Behrmann, M. (2007). A detailed investigation of facial expression processing in congenital prosopagnosia as compared to acquired prosopagnosia. Experimental Brain Research, 176(2), 356-373. doi:10.1007/s00221006-0621-5

Humphreys, G. W., Donnelly, N., \& Riddoch, M. J. (1993). Expression is computed separately from facial identity, and it is computed separately for moving and static faces: Neuropsychological evidence. Neuropsychologia, 31(2), 173-181. doi:10.1016/00283932(93)90045-2

Humphreys, K., Minshew, N., Leonard, G. L., \& Behrmann, M. (2007). A fine-grained analysis of facial expression processing in high-functioning adults with autism. Neuropsychologia, 45(4), 685-695. doi:10.1016/j.neuropsychologia.2006.08.003

Iaria, G., \& Barton, J. J. (2010). Developmental topographical disorientation: a newly discovered cognitive disorder. Experimental brain research, 206(2), 189-196. doi:10.1007/s00221-010-2256-9

Izard, C. E. (2007). Basic emotions, natural kinds, emotion schemas, and a new paradigm. Perspectives on psychological science, 2(3), 260-280. doi:10.1111/j.17456916.2007.00044.x

Janik, A. B., Rezlescu, C., \& Banissy, M. J. (2015). Enhancing anger perception with transcranial alternating current stimulation induced gamma oscillations. Brain Stimulation: Basic, Translational, and Clinical Research in Neuromodulation, 8(6), 1138-1143. doi:10.1016/j.brs.2015.07.032

Johnson, M. (2011). Face perception: a developmental perspective. In A. Calder (Ed.), Oxford handbook of face perception. (pp. 32-42) doi:10.1093/oxfordhb/9780199559053.013.0042

Johnston, P., Mayes, A., Hughes, M., \& Young, A. W. (2013). Brain networks subserving the evaluation of static and dynamic facial expressions. Cortex, 49(9), 2462-2472. doi:10.1016/j.cortex.2013.01.002

Jones, C. R., Happé, F., Golden, H., Marsden, A. J., Tregay, J., Simonoff, E., ... \& Charman, T. (2009). Reading and arithmetic in adolescents with autism spectrum disorders: peaks and dips in attainment. Neuropsychology, 23(6), 718. doi:10.1037/a0016360 


\section{FACIAL EXPRESSION PROCESSING IN PROSOPAGNOSIA}

Jones, R. D., \& Tranel, D. (2001). Severe developmental prosopagnosia in a child with superior intellect. Journal of Clinical and Experimental Neuropsychology, 23(3), 265273. doi:10.1076/jcen.23.3.265.1183

Kanne, S. M., Wang, J., \& Christ, S. E. (2012). The Subthreshold Autism Trait Questionnaire (SATQ): Development of a brief self-report measure of subthreshold autism traits. Journal of autism and developmental disorders, 42(5), 769-780. doi:10.1007/s10803-011-1308-8

Kanwisher, N., McDermott, J., \& Chun, M. M. (1997). The fusiform face area: a module in human extrastriate cortex specialized for face perception. Journal of neuroscience, 17(11), 4302-4311. Retrieved from http://www.jneurosci.org

Karmiloff-Smith, A., Scerif, G., \& Ansari, D. (2003). Double dissociations in developmental disorders? Theoretically misconceived, empirically dubious. Cortex, 39(1), 161-163. doi:10.1016/S0010-9452(08)70091-1

Kennedy, D. P., \& Adolphs, R. (2012). Perception of emotions from facial expressions in high-functioning adults with autism. Neuropsychologia, 50(14), 3313-3319. doi:10.1016/j.neuropsychologia.2012.09.038

Kennerknecht, I., Grueter, T., Welling, B., Wentzek, S., Horst, J., Edwards, S., \& Grueter, M. (2006). First report of prevalence of non-syndromic hereditary prosopagnosia (HPA). American Journal of Medical Genetics Part A, 140(15), 1617-1622. doi:10.1002/ajmg.a.31343

Kennerknecht, I., Ho, N. Y., \& Wong, V. C. (2008). Prevalence of hereditary prosopagnosia (HPA) in Hong Kong Chinese population. American Journal of Medical Genetics Part A, 146(22), 2863-2870. doi:10.1002/ajmg.a.32552

Ketelaars, M. P., Mol, A., Swaab, H., \& van Rijn, S. (2016). Emotion recognition and alexithymia in high functioning females with autism spectrum disorder. Research in Autism Spectrum Disorders, 21, 51-60. doi:10.1016/j.rasd.2015.09.006

Kilts, C. D., Egan, G., Gideon, D. A., Ely, T. D., \& Hoffman, J. M. (2003). Dissociable neural pathways are involved in the recognition of emotion in static and dynamic facial expressions. Neuroimage, 18(1), 156-168. doi:10.1006/nimg.2002.1323

Knappmeyer, B., Thornton, I. M., \& Bülthoff, H. H. (2003). The use of facial motion and facial form during the processing of identity. Vision research, 43(18), 1921-1936. doi:10.1016/S0042-6989(03)00236-0 


\section{FACIAL EXPRESSION PROCESSING IN PROSOPAGNOSIA}

Kracke, I. (1994). Developmental prosopagnosia in Asperger syndrome: presentation and discussion of an individual case. Developmental Medicine \& Child Neurology, 36(10), 873-886. doi:10.1111/j.1469-8749.1994.tb11778.x

Kress, T., \& Daum, I. (2003). Developmental prosopagnosia: A review. Behavioural neurology, 14(3-4), 109-121. doi:10.1155/2003/520476

Kriegeskorte, N., Lindquist, M. A., Nichols, T. E., Poldrack, R. A., \& Vul, E. (2010). Everything you never wanted to know about circular analysis, but were afraid to ask. Journal of Cerebral Blood Flow \& Metabolism, 30(9), 1551-1557. doi:10.1038/jcbfm.2010.86

Kriegeskorte, N., Simmons, W. K., Bellgowan, P. S., \& Baker, C. I. (2009). Circular analysis in systems neuroscience: the dangers of double dipping. Nature neuroscience, 12(5), 535-540. doi:10.1038/nn.2303

Lakens, D. (2013). Calculating and reporting effect sizes to facilitate cumulative science: a practical primer for t-tests and ANOVAs. Frontiers in psychology, 4, 863. doi:10.3389/fpsyg.2013.00863

Lange, J., De Lussanet, M., Kuhlmann, S., Zimmermann, A., Lappe, M., Zwitserlood, P., \& Dobel, C. (2009). Impairments of biological motion perception in congenital prosopagnosia. PLoS One, 4(10), e7414. doi:10.1371/journal.pone.0007414

Lawrence, A. D., Calder, A. J., McGowan, S. W., \& Grasby, P. M. (2002). Selective disruption of the recognition of facial expressions of anger. Neuroreport, 13(6), 881884. doi:10.1097/00001756-200205070-00029

Lee, Y, Duchaine, B., Wilson, H. R., \& Nakayama, K. (2010). Three cases of developmental prosopagnosia from one family: Detailed neuropsychological and psychophysical investigation of face processing. cortex, 46(8), 949-964. doi:10.1016/j.cortex.2009.07.012

Lee, I. A., \& Preacher, K. J. (2013, September). Calculation for the test of the difference between two dependent correlations with one variable in common [Computer software]. Available from http://quantpsy.org.

Le Grand, R., Cooper, P. A., Mondloch, C. J., Lewis, T. L., Sagiv, N., de Gelder, B., \& Maurer, D. (2006). What aspects of face processing are impaired in developmental prosopagnosia?. Brain and cognition, 61(2), 139-158. doi:10.1016/j.bandc.2005.11.005

Lohse, M., Garrido, L., Driver, J., Dolan, R. J., Duchaine, B. C., \& Furl, N. (2016). Effective connectivity from early visual cortex to posterior occipitotemporal face areas supports 


\section{FACIAL EXPRESSION PROCESSING IN PROSOPAGNOSIA}

face selectivity and predicts developmental prosopagnosia. Journal of Neuroscience, 36(13), 3821-3828. doi:10.1523/JNEUROSCI.3621-15.2016

Longmore, C. A., \& Tree, J. J. (2013). Motion as a cue to face recognition: evidence from congenital prosopagnosia. Neuropsychologia, 51(5), 864-875. doi:10.1016/j.neuropsychologia.2013.01.022

Loth, E., Garrido, L., Ahmad, J., Watson, E., Duff, A., \& Duchaine, B. (2018). Facial expression recognition as a candidate marker for autism spectrum disorder: how frequent and severe are deficits?. Molecular Autism, 9(1), 7. doi:10.1186/s13229-0180187-7

Lozier, L. M., Vanmeter, J. W., \& Marsh, A. A. (2014). Impairments in facial affect recognition associated with autism spectrum disorders: a meta-analysis. Development and psychopathology, 26(4pt1), 933-945. doi:10.1017/S0954579414000479

Lundqvist, D., Flykt, A., \& Öhman, A. (1998). The Karolinska directed emotional faces (KDEF). CD ROM from Department of Clinical Neuroscience, Psychology section, Karolinska Institutet, (1998).

Mason, W., \& Watts, D. J. (2010). Financial incentives and the performance of crowds. $A C M$ SigKDD Explorations Newsletter, 11(2), 100-108. doi:10.1145/1809400.1809422

Mattson, A. J., Levin, H. S., \& Grafman, J. (2000). A case of prosopagnosia following moderate closed head injury with left hemisphere focal lesion. Cortex, 36(1), 125-137. doi:10.1016/S0010-9452(08)70841-4

McConachie, H. R. (1976). Developmental prosopagnosia. A single case report. Cortex, 12(1), 76-82. doi:10.1016/S0010-9452(76)80033-0

McKelvie, S. J. (1995). Emotional expression in upside-down faces: Evidence for configurational and componential processing. British Journal of Social Psychology, 34(3), 325-334. doi:10.1111/j.2044-8309.1995.tb01067.x

Minnebusch, D. A., Suchan, B., Ramon, M., \& Daum, I. (2007). Event-related potentials reflect heterogeneity of developmental prosopagnosia. European Journal of Neuroscience, 25(7), 2234-2247. doi:10.1111/j.1460-9568.2007.05451.x

Nishiyama, T., Suzuki, M., Adachi, K., Sumi, S., Okada, K., Kishino, H., ... \& Kanne, S. M. (2014). Comprehensive comparison of self-administered questionnaires for measuring quantitative autistic traits in adults. Journal of Autism and Developmental Disorders, 44(5), 993-1007. doi: 10.1007/s10803-013-2020-7

Novich, S., Cheng, S., \& Eagleman, D. M. (2011). Is synaesthesia one condition or many? A large-scale analysis reveals subgroups. Journal of Neuropsychology, 5(2), 353-371. 


\section{FACIAL EXPRESSION PROCESSING IN PROSOPAGNOSIA}

doi:10.1111/j.1748-6653.2011.02015.x

Nunn, J. A., Postma, P., \& Pearson, R. (2001). Developmental prosopagnosia: should it be taken at face value?. Neurocase, 7(1), 15-27. doi:10.1093/neucas/7.1.15

Palermo, R., O’Connor, K. B., Davis, J. M., Irons, J., \& McKone, E. (2013). New tests to measure individual differences in matching and labelling facial expressions of emotion, and their association with ability to recognise vocal emotions and facial identity. PloS one, 8(6), e68126. doi:10.1371/journal.pone.0068126

Palermo, R., Willis, M. L., Rivolta, D., McKone, E., Wilson, C. E., \& Calder, A. J. (2011). Impaired holistic coding of facial expression and facial identity in congenital prosopagnosia. Neuropsychologia, 49(5), 1226-1235. doi:10.1016/j.neuropsychologia.2011.02.021

Parker, J. D., Taylor, G. J., \& Bagby, M. (1993). Alexithymia and the recognition of facial expressions of emotion. Psychotherapy and psychosomatics, 59(3-4), 197-202. doi:10.1159/000288664

Perrett, D. I., Hietanen, J. K., Oram, M. W., Benson, P. J., \& Rolls, E. T. (1992). Organization and functions of cells responsive to faces in the temporal cortex. Philosophical Transactions of the Royal Society of London B: Biological Sciences, 335(1273), 23-30. doi:10.1098/rstb.1992.0003

Pessoa, L., \& Adolphs, R. (2010). Emotion processing and the amygdala: from a 'low road' to 'many roads' of evaluating biological significance. Nature reviews neuroscience, 11(11), 773-783. doi:10.1038/nrn2920

Phillips, L. H., Channon, S., Tunstall, M., Hedenstrom, A., \& Lyons, K. (2008). The role of working memory in decoding emotions. Emotion, 8(2), 184. doi:10.1037/15283542.8.2.184

Pitcher, D. (2014). Facial expression recognition takes longer in the posterior superior temporal sulcus than in the occipital face area. Journal of Neuroscience, 34(27), 91739177. doi:10.1523/JNEUROSCI.5038-13.2014

Pitcher, D., Charles, L., Devlin, J. T., Walsh, V., \& Duchaine, B. (2009). Triple dissociation of faces, bodies, and objects in extrastriate cortex. Current Biology, 19(4), 319-324. doi:10.1016/j.cub.2009.01.007

Pitcher, D., Dilks, D. D., Saxe, R. R., Triantafyllou, C., \& Kanwisher, N. (2011). Differential selectivity for dynamic versus static information in face-selective cortical regions. Neuroimage, 56(4), 2356-2363. doi:10.1016/j.neuroimage.2011.03.067 


\section{FACIAL EXPRESSION PROCESSING IN PROSOPAGNOSIA}

Pitcher, D., Garrido, L., Walsh, V., \& Duchaine, B. C. (2008). Transcranial magnetic stimulation disrupts the perception and embodiment of facial expressions. Journal of Neuroscience, 28(36), 8929-8933. doi:10.1523/JNEUROSCI.1450-08.2008

Prkachin, G. C., Casey, C., \& Prkachin, K. M. (2009). Alexithymia and perception of facial expressions of emotion. Personality and Individual Differences, 46(4), 412-417. doi:10.1016/j.paid.2008.11.010

Ramus, F. (2002). Evidence for a domain-specific deficit in developmental dyslexia. Behavioral and Brain Sciences, 25(6), 767-768. doi:10.1017/S0140525X02390137

Recio, G., Sommer, W., \& Schacht, A. (2011). Electrophysiological correlates of perceiving and evaluating static and dynamic facial emotional expressions. Brain research, 1376, 66-75. doi:10.1016/j.brainres.2010.12.041

Rezlescu, C., Susilo, T., Barton, J. J., \& Duchaine, B. (2014). Normal social evaluations of faces in acquired prosopagnosia. cortex, 50, 200-203. doi:10.1016/j.cortex.2013.07.015

Rezlescu, C., Susilo, T., Wilmer, J. B., \& Caramazza, A. (2017). The inversion, part-whole, and composite effects reflect distinct perceptual mechanisms with varied relationships to face recognition. Journal of Experimental Psychology: Human Perception and Performance, 43(12), 1961. doi:10.1037/xhp0000400

Richoz, A. R., Jack, R. E., Garrod, O. G., Schyns, P. G., \& Caldara, R. (2015). Reconstructing dynamic mental models of facial expressions in prosopagnosia reveals distinct representations for identity and expression. Cortex, 65, 50-64. doi:10.1016/j.cortex.2014.11.015

Riddoch, M. J., Johnston, R. A., Bracewell, R. M., Boutsen, L., \& Humphreys, G. W. (2008). Are faces special? A case of pure prosopagnosia. Cognitive Neuropsychology, 25(1), 326. doi:10.1080/02643290801920113

Roch-Levecq, A. C. (2006). Production of basic emotions by children with congenital blindness: Evidence for the embodiment of theory of mind. British Journal of Developmental Psychology, 24(3), 507-528. doi:10.1348/026151005X50663

Rosenthal, G., Tanzer, M., Simony, E., Hasson, U., Behrmann, M., \& Avidan, G. (2017). Altered topology of neural circuits in congenital prosopagnosia. Elife, 6. doi:10.7554/eLife. 25069

Rossion, B. (2008). Picture-plane inversion leads to qualitative changes of face perception. Acta psychologica, 128(2), 274-289. doi:10.1016/j.actpsy.2008.02.003 


\section{FACIAL EXPRESSION PROCESSING IN PROSOPAGNOSIA}

Scherer, K. R., \& Wallbott, H. G. (1994). Evidence for universality and cultural variation of differential emotion response patterning. Journal of personality and social psychology, 66(2), 310. doi:10.1037/0022-3514.66.2.310

Schmalzl, L., Palermo, R., \& Coltheart, M. (2008). Cognitive heterogeneity in genetically based prosopagnosia: A family study. Journal of Neuropsychology, 2(1), 99-117. doi:10.1348/174866407X256554

Schultz, R. T. (2005). Developmental deficits in social perception in autism: the role of the amygdala and fusiform face area. International Journal of Developmental Neuroscience, 23(2), 125-141. doi:10.1016/j.ijdevneu.2004.12.012

Schwarzer, G., Huber, S., Grüter, M., Grüter, T., Groß, C., Hipfel, M., \& Kennerknecht, I. (2007). Gaze behaviour in hereditary prosopagnosia. Psychological research, 71(5), 583-590. doi:10.1007/s00426-006-0068-0

Schweinberger, S. R., Burton, A. M., \& Kelly, S. W. (1999). Asymmetric dependencies in perceiving identity and emotion: Experiments with morphed faces. Attention, Perception, \& Psychophysics, 61(6), 1102-1115. doi:10.3758/BF03207617

Schweinberger, S. R., \& Soukup, G. R. (1998). Asymmetric relationships among perceptions of facial identity, emotion, and facial speech. Journal of Experimental Psychology: Human perception and performance, 24(6), 1748. doi:10.1037/0096-1523.24.6.1748

Shah, P., Gaule, A., Gaigg, S. B., Bird, G., \& Cook, R. (2015). Probing short-term face memory in developmental prosopagnosia. Cortex, 64, 115-122. doi:10.1016/j.cortex.2014.10.006

Shah, P., Gaule, A., Sowden, S., Bird, G., \& Cook, R. (2015). The 20-item prosopagnosia index (PI20): a self-report instrument for identifying developmental prosopagnosia. Open Science, 2(6), 140343. doi:10.1098/rsos.140343

Shalev, R. S., Auerbach, J., Manor, O., \& Gross-Tsur, V. (2000). Developmental dyscalculia: prevalence and prognosis. European child \& adolescent psychiatry, 9(2), S58-S64. doi: $10.1007 / \mathrm{s} 007870070009$

Shilowich, B. E., \& Biederman, I. (2016). An estimate of the prevalence of developmental phonagnosia. Brain and language, 159, 84-91. doi:10.1016/j.bandl.2016.05.004

Sifneos, P. E. (1973). The prevalence of 'alexithymic'characteristics in psychosomatic patients. Psychotherapy and psychosomatics, 22(2-6), 255-262. doi:10.1159/000286529

Song, S., Garrido, L., Nagy, Z., Mohammadi, S., Steel, A., Driver, J., ... \& Furl, N. (2015). Local but not long-range microstructural differences of the ventral temporal cortex in 


\section{FACIAL EXPRESSION PROCESSING IN PROSOPAGNOSIA}

developmental prosopagnosia. Neuropsychologia, 78, 195-206. doi:

10.1016/j.neuropsychologia.2015.10.010

Speranza, M., Loas, G., Wallier, J., \& Corcos, M. (2007). Predictive value of alexithymia in patients with eating disorders: A 3-year prospective study. Journal of psychosomatic research, 63(4), 365-371. doi:10.1016/j.jpsychores.2007.03.008

Sprengelmeyer, R., Young, A. W., Calder, A. J., Karnat, A., Lange, H., Hömberg, V., ... \& Rowland, D. (1996). Loss of disgust: perception of faces and emotions in Huntington's disease. Brain, 119(5), 1647-1665. doi:10.1093/brain/119.5.1647

Sprengelmeyer, R., Young, A. W., Sprengelmeyer, A., Calder, A. J., Rowland, D., Perrett, D., ... \& Lange, H. (1997). Recognition of facial expressions: Selective impairment of specific emotions in Huntington's disease. Cognitive Neuropsychology, 14(6), 839-879. doi:10.1080/026432997381376

Susilo, T., \& Duchaine, B. (2013). Advances in developmental prosopagnosia research. Current opinion in neurobiology, 23(3), 423-429. doi:10.1016/j.conb.2012.12.011

Susilo, T., Germine, L., \& Duchaine, B. (2013). Face recognition ability matures late: Evidence from individual differences in young adults. Journal of experimental psychology: human perception and performance, 39(5), 1212. doi:10.1037/a0033469

Susskind, J. M., Lee, D. H., Cusi, A., Feiman, R., Grabski, W., \& Anderson, A. K. (2008). Expressing fear enhances sensory acquisition. Nature neuroscience, 11(7), 843-850. doi:10.1038/nn.2138

Suzuki, A., Hoshino, T., Shigemasu, K., \& Kawamura, M. (2006). Disgust-specific impairment of facial expression recognition in Parkinson's disease. Brain, 129(3), 707717. doi:10.1093/brain/aw1011

Tanaka, J. W., \& Farah, M. J. (1993). Parts and wholes in face recognition. The Quarterly journal of experimental psychology, 46(2), 225-245. doi:10.1080/14640749308401045

Thomas, C., Avidan, G., Humphreys, K., Jung, K. J., Gao, F., \& Behrmann, M. (2009). Reduced structural connectivity in ventral visual cortex in congenital prosopagnosia. Nature neuroscience, 12(1), 29. doi: 10.1038/nn.2224

Todorov, A., \& Duchaine, B. (2008). Reading trustworthiness in faces without recognizing faces. Cognitive Neuropsychology, 25(3), 395-410. doi:10.1080/02643290802044996

Torfs, K., Vancleef, K., Lafosse, C., Wagemans, J., \& de-Wit, L. (2014). The Leuven Perceptual Organization Screening Test (L-POST), an online test to assess mid-level visual perception. Behavior Research Methods, 46(2), 472-487. doi:10.3758/s13428013-0382-6 


\section{FACIAL EXPRESSION PROCESSING IN PROSOPAGNOSIA}

Tranel, D., Damasio, A. R., \& Damasio, H. (1988). Intact recognition of facial expression, gender, and age in patients with impaired recognition of face identity. Neurology, 38(5), 690-690. doi:10.1212/WNL.38.5.690

Uljarevic, M., \& Hamilton, A. (2013). Recognition of emotions in autism: a formal metaanalysis. Journal of autism and developmental disorders, 43(7), 1517-1526. doi:10.1007/s10803-012-1695-5

Uono, S., Sato, W., \& Toichi, M. (2011). The specific impairment of fearful expression recognition and its atypical development in pervasive developmental disorder. Social Neuroscience, 6(5-6), 452-463. doi:10.1080/17470919.2011.605593

Van der Lely, H. K. (2005). Domain-specific cognitive systems: insight from GrammaticalSLI. Trends in cognitive sciences, 9(2), 53-59. doi:10.1016/j.tics.2004.12.002

Van't Wout, M., Aleman, A., Bermond, B., \& Kahn, R. S. (2007). No words for feelings: alexithymia in schizophrenia patients and first-degree relatives. Comprehensive psychiatry, 48(1), 27-33. doi:10.1016/j.comppsych.2006.07.003

Weigelt, S., Koldewyn, K., \& Kanwisher, N. (2012). Face identity recognition in autism spectrum disorders: a review of behavioral studies. Neuroscience \& Biobehavioral Reviews, 36(3), 1060-1084. doi:10.1016/j.neubiorev.2011.12.008

Wilhelm, O., Hildebrandt, A., Manske, K., Schacht, A., \& Sommer, W. (2014). Test battery for measuring the perception and recognition of facial expressions of emotion. Frontiers in psychology, 5. doi:10.1212/WNL.38.5.690

Wilmer, J. B., Germine, L., Chabris, C. F., Chatterjee, G., Williams, M., Loken, E., ... \& Duchaine, B. (2010). Human face recognition ability is specific and highly heritable. Proceedings of the National Academy of sciences, 107(11), 5238-5241. doi:10.1073/pnas.0913053107

Wingenbach, T. S., Ashwin, C., \& Brosnan, M. (2017). Diminished sensitivity and specificity at recognising facial emotional expressions of varying intensity underlie emotionspecific recognition deficits in autism spectrum disorders. Research in Autism Spectrum Disorders, 34, 52-61. doi:10.1016/j.rasd.2016.11.003

Winston, J. S., Henson, R. N. A., Fine-Goulden, M. R., \& Dolan, R. J. (2004). fMRIadaptation reveals dissociable neural representations of identity and expression in face perception. Journal of neurophysiology, 92(3), 1830-1839. doi:10.1152/jn.00155.2004

Yardley, L., McDermott, L., Pisarski, S., Duchaine, B., \& Nakayama, K. (2008). Psychosocial consequences of developmental prosopagnosia: A problem of recognition. Journal of psychosomatic research, 65(5), 445-451. doi:10.1016/j.jpsychores.2008.03.013 


\section{FACIAL EXPRESSION PROCESSING IN PROSOPAGNOSIA}

Yin, R. K. (1969). Looking at upside-down faces. Journal of experimental psychology, 81(1), 141. doi:10.1037/h0027474

Young, A. W., Hellawell, D., \& Hay, D. C. (1987). Configurational information in face perception. Perception, 42(11), 1166-1178. doi:10.1068/p160747n

Young, A. W., Hellawell, D. J., Van De Wal, C., \& Johnson, M. (1996). Facial expression processing after amygdalotomy. Neuropsychologia, 34(1), 31-39. doi:10.1016/0028-3932(95)00062-3

Young, A. W., Newcombe, F., Haan, E. H. D., Small, M., \& Hay, D. C. (1993). Face perception after brain injury: Selective impairments affecting identity and expression. Brain, 116(4), 941-959. doi:10.1093/brain/116.4.941

Yovel, G., \& O’Toole, A. J. (2016). Recognizing people in motion. Trends in cognitive sciences, 20(5), 383-395. doi:10.1016/j.tics.2016.02.005

Zhu, Q., Song, Y., Hu, S., Li, X., Tian, M., Zhen, Z., ... \& Liu, J. (2010). Heritability of the specific cognitive ability of face perception. Current Biology, 20(2), 137-142. doi:10.1016/j.cub.2009.11.067 
FACIAL EXPRESSION PROCESSING IN PROSOPAGNOSIA

Appendix A

Past studies of facial expression processing in prosopagnosia

Table A1. Summary of past studies that measured facial expression in prosopagnosia.

\begin{tabular}{|c|c|c|c|c|c|c|c|c|c|c|c|c|}
\hline $\begin{array}{c}\text { Author/s } \\
\text { (year) }\end{array}$ & $\begin{array}{c}\text { Facial } \\
\text { expression } \\
\text { deficit? }\end{array}$ & $\begin{array}{l}\text { Reported } \\
\text { response } \\
\text { times? }\end{array}$ & $\begin{array}{c}\text { Prosop- } \\
\text { agnosic } \\
\text { sample } \\
\text { size (age, } \\
\text { gender) } \\
\end{array}$ & $\begin{array}{c}\text { Control sample } \\
\text { size (age, } \\
\text { gender) }\end{array}$ & $\begin{array}{l}\text { \# of } \\
\text { tasks }\end{array}$ & $\begin{array}{c}\text { Inverted } \\
\text { condition or } \\
\text { equivalent? }\end{array}$ & $\begin{array}{l}\text { Overcame } \\
\text { circular } \\
\text { analysis? }\end{array}$ & Task format & $\begin{array}{c}\text { Labelling } \\
\text { and/or } \\
\text { matching } \\
\text { tasks? }\end{array}$ & $\begin{array}{l}\text { Dynamic } \\
\text { stimuli? }\end{array}$ & $\begin{array}{c}\text { Complex } \\
\text { and/or basic } \\
\text { expressions? }\end{array}$ & $\begin{array}{c}\text { Autism } \\
\text { measure? }\end{array}$ \\
\hline $\begin{array}{c}\text { Ariel \& } \\
\text { Sadeh } \\
(1996)\end{array}$ & Yes & No & $\begin{array}{l}1 \text { (LG, } 8 \\
\text { y/o, boy) }\end{array}$ & $\begin{array}{l}4 \text { (age and gender } \\
\text { matched) }\end{array}$ & 1 & No & No & $\begin{array}{c}\text { (1) 4-AFC labelling } \\
\text { test }\end{array}$ & Labelling & No & Basic & No \\
\hline $\begin{array}{l}\text { Bennetts et } \\
\text { al. (2015) }\end{array}$ & No & No & $\begin{array}{c}9(\mathrm{~m}=54 \\
\mathrm{y} / \mathrm{o}, 4 \mathrm{man})\end{array}$ & $\begin{array}{c}14 \text { (age and } \\
\text { gender matched) }\end{array}$ & 1 & No & Yes & $\begin{array}{c}\text { (1) 4-AFC Reading } \\
\text { the Mind in the } \\
\text { Eyes test }\end{array}$ & Labelling & No & Complex & No \\
\hline $\begin{array}{l}\text { Bentin et al. } \\
\text { (2007) }\end{array}$ & No & $\begin{array}{l}\text { Yes (same } \\
\text { pattern as } \\
\text { accuracy) }\end{array}$ & $\begin{array}{c}1(\mathrm{KW}, 26 \\
\mathrm{y} / \mathrm{o}, \text { woman })\end{array}$ & $\begin{array}{l}12 \text { under-graduate } \\
\text { students }\end{array}$ & 1 & No & Yes & $\begin{array}{c}\text { (1) expression (and } \\
\text { parallel identity) } \\
\text { matching tests }\end{array}$ & Matching & No & Basic & No \\
\hline $\begin{array}{c}\text { Biotti \& } \\
\text { Cook } \\
(2016)\end{array}$ & Yes & No & $\begin{array}{l}17(\mathrm{~m}=46 \\
\mathrm{y} / \mathrm{o}, 5 \mathrm{men})\end{array}$ & $\begin{array}{c}\text { Test } 1: 23(\mathrm{~m}=43 \\
\text { y/o, } 6 \mathrm{men}) . \text { Test } \\
2: 23(\mathrm{~m}=44 \mathrm{y} / \mathrm{o}, \\
7 \mathrm{men}) . \text { Test } 3: 22 \\
(\mathrm{~m}=43 \mathrm{y} / \mathrm{o}, 8 \\
\text { men })\end{array}$ & 3 & No & No & $\begin{array}{l}\text { (1) 2-AFC labelling } \\
\text { test (2) 4-AFC } \\
\text { labelling test (eye- } \\
\text { region stimuli) (3) } \\
\text { 6-AFC vocal affect } \\
\text { labelling test }\end{array}$ & Labelling & No & Basic & $\begin{array}{c}\text { Did not } \\
\text { measure } \\
\text { autism, but } \\
\text { prosop- } \\
\text { agnosics did } \\
\text { not "have a } \\
\text { history" of } \\
\text { autism. }\end{array}$ \\
\hline $\begin{array}{l}\text { Burns et al. } \\
\text { (2017) }\end{array}$ & $\begin{array}{l}\text { Yes (they } \\
\text { did not } \\
\text { adapt to } \\
\text { happiness } \\
\text { normally) } \\
\end{array}$ & $\begin{array}{l}\text { Yes (same } \\
\text { pattern as } \\
\text { accuracy) }\end{array}$ & $\begin{array}{l}10(\mathrm{~m}=29 \\
\mathrm{y} / \mathrm{o}, 3 \mathrm{men})\end{array}$ & $\begin{array}{c}10 \text { (age- and } \\
\text { gender-matched) }\end{array}$ & 1 & No & No & $\begin{array}{c}\text { (1) 2-AFC } \\
\text { adaptation test }\end{array}$ & Labelling & No & Basic & No \\
\hline
\end{tabular}


FACIAL EXPRESSION PROCESSING IN PROSOPAGNOSIA

\begin{tabular}{|c|c|c|c|c|c|c|c|c|c|c|c|c|}
\hline $\begin{array}{l}\text { Author/s } \\
\text { (year) }\end{array}$ & $\begin{array}{c}\text { Facial } \\
\text { expression } \\
\text { deficit? }\end{array}$ & $\begin{array}{l}\text { Reported } \\
\text { response } \\
\text { times? }\end{array}$ & $\begin{array}{l}\text { Prosop- } \\
\text { agnosic } \\
\text { sample } \\
\text { size (age, } \\
\text { gender) }\end{array}$ & $\begin{array}{c}\text { Control sample } \\
\text { size (age, } \\
\text { gender) }\end{array}$ & $\begin{array}{c}\# \text { of } \\
\text { tasks }\end{array}$ & $\begin{array}{c}\text { Inverted } \\
\text { condition or } \\
\text { equivalent? }\end{array}$ & $\begin{array}{l}\text { Overcame } \\
\text { circular } \\
\text { analysis? }\end{array}$ & Task format & $\begin{array}{c}\text { Labelling } \\
\text { and/or } \\
\text { matching } \\
\text { tasks? }\end{array}$ & $\begin{array}{l}\text { Dynamic } \\
\text { stimuli? }\end{array}$ & $\begin{array}{c}\text { Complex } \\
\text { and/or basic } \\
\text { expressions? }\end{array}$ & $\begin{array}{l}\text { Autism } \\
\text { measure? }\end{array}$ \\
\hline $\begin{array}{l}\text { De Haan \& } \\
\text { Campbell } \\
\text { (1991) }\end{array}$ & Yes & No & $\begin{array}{c}1(\mathrm{AB}, 27 \\
\mathrm{y} / \mathrm{o}, \text { woman })\end{array}$ & $\begin{array}{c}4 \text { (age- and } \\
\text { gender-matched) }\end{array}$ & 2 & No & Yes & $\begin{array}{c}\text { (1) matching task } \\
\text { (2) 6-AFC labelling } \\
\text { test }\end{array}$ & $\begin{array}{l}\text { Labelling } \\
\text { and } \\
\text { matching }\end{array}$ & No & Basic & No \\
\hline $\begin{array}{l}\text { Dobel et al. } \\
\text { (2007) }\end{array}$ & $\begin{array}{l}\text { Mixed }(1 / 6 \\
\text { prosopagnos } \\
\text { ics } \\
\text { impaired) }\end{array}$ & No & $\begin{array}{c}6(\mathrm{~m}=42 \\
\mathrm{y} / \mathrm{o}, \text { range }= \\
27-56 \mathrm{y} / \mathrm{o}, 4 \\
\text { men })\end{array}$ & $\begin{array}{c}6 \text { (age- and } \\
\text { gender-matched) }\end{array}$ & 1 & No & No & $\begin{array}{l}\text { (1) 4-AFC labelling } \\
\text { test (Tubinger } \\
\text { Affect Battery) }\end{array}$ & Labelling & No & Basic & $\begin{array}{c}\text { Yes } \\
\text { (assessment } \\
\text { not specified, } \\
\text { but report 'no } \\
\text { evidence of } \\
\text { social } \\
\text { dysfunction') }\end{array}$ \\
\hline $\begin{array}{l}\text { Duchaine et } \\
\text { al. (2006) }\end{array}$ & $\begin{array}{l}\text { Yes (only } \\
\text { on the } \\
\text { Reading the } \\
\text { Mind in the } \\
\text { Eyes test } \\
\text { and } \\
\text { matching } \\
\text { task) }\end{array}$ & No & $\begin{array}{c}1 \text { (Edward, } \\
53 \mathrm{y} / \mathrm{o}, \mathrm{man})\end{array}$ & $\begin{array}{l}14 \text { under-graduate } \\
\text { students (range } \\
55-64 \mathrm{y} / \mathrm{o})\end{array}$ & 3 & No & Yes & $\begin{array}{c}\text { (1) 6-AFC Emotion } \\
\text { Hexagon test (2) 4- } \\
\text { AFC Reading the } \\
\text { Mind in the Eyes } \\
\text { test (3) 3-AFC } \\
\text { match-to-sample } \\
\text { test }\end{array}$ & $\begin{array}{l}\text { Labelling } \\
\text { and } \\
\text { matching }\end{array}$ & No & $\begin{array}{l}\text { Complex and } \\
\text { basic }\end{array}$ & No \\
\hline $\begin{array}{l}\text { Duchaine et } \\
\text { al. (2009) }\end{array}$ & Yes & No & $\begin{array}{l}2 \text { (DH and } \\
\mathrm{TU}, 31 \text { and } \\
32 \mathrm{y} / \mathrm{o}, \mathrm{men})\end{array}$ & $\begin{array}{c}18(\mathrm{~m}=29 \mathrm{y} / \mathrm{o}, 11 \\
\text { women })\end{array}$ & 1 & No & No & $\begin{array}{c}\text { (1) 3-AFC Films } \\
\text { Facial Expression } \\
\text { test }\end{array}$ & Labelling & No & $\begin{array}{l}\text { Complex and } \\
\text { basic }\end{array}$ & $\begin{array}{c}\text { Yes, } \\
\text { Interview, } \\
\text { Autism } \\
\text { Diagnostic } \\
\text { Observation } \\
\text { Schedule, and } \\
\text { Autism } \\
\text { Quotient }\end{array}$ \\
\hline $\begin{array}{l}\text { Duchaine et } \\
\text { al. (2003) }\end{array}$ & No & $\begin{array}{l}\text { Yes (same } \\
\text { pattern as } \\
\text { accuracy) }\end{array}$ & $\begin{array}{c}1(\mathrm{NM}, 40 \\
\mathrm{y} / \mathrm{o}, \text { woman })\end{array}$ & $\begin{array}{l}25 \text { under-graduate } \\
\text { students (not age- } \\
\text { matched) }\end{array}$ & 4 & No & No & $\begin{array}{c}\text { (1) 6-AFC Emotion } \\
\text { Hexagon test (2) 4- } \\
\text { AFC Reading the } \\
\text { Mind in the Eyes } \\
\text { test (3) matching } \\
\text { test (4) emotional } \\
\text { intensity judgement } \\
\text { test }\end{array}$ & $\begin{array}{l}\text { Labelling } \\
\text { and } \\
\text { matching }\end{array}$ & No & $\begin{array}{l}\text { Complex and } \\
\text { basic }\end{array}$ & No \\
\hline
\end{tabular}


FACIAL EXPRESSION PROCESSING IN PROSOPAGNOSIA

\begin{tabular}{|c|c|c|c|c|c|c|c|c|c|c|c|c|}
\hline $\begin{array}{l}\text { Author/s } \\
\text { (year) }\end{array}$ & $\begin{array}{c}\text { Facial } \\
\text { expression } \\
\text { deficit? }\end{array}$ & $\begin{array}{l}\text { Reported } \\
\text { response } \\
\text { times? }\end{array}$ & $\begin{array}{l}\text { Prosop- } \\
\text { agnosic } \\
\text { sample } \\
\text { size (age, } \\
\text { gender) }\end{array}$ & $\begin{array}{c}\text { Control sample } \\
\text { size (age, } \\
\text { gender) }\end{array}$ & $\begin{array}{l}\text { \# of } \\
\text { tasks }\end{array}$ & $\begin{array}{c}\text { Inverted } \\
\text { condition or } \\
\text { equivalent? }\end{array}$ & $\begin{array}{l}\text { Overcame } \\
\text { circular } \\
\text { analysis? }\end{array}$ & Task format & $\begin{array}{l}\text { Labelling } \\
\text { and/or } \\
\text { matching } \\
\text { tasks? }\end{array}$ & $\begin{array}{l}\text { Dynamic } \\
\text { stimuli? }\end{array}$ & $\begin{array}{c}\text { Complex } \\
\text { and/or basic } \\
\text { expressions? }\end{array}$ & $\begin{array}{c}\text { Autism } \\
\text { measure? }\end{array}$ \\
\hline $\begin{array}{l}\text { Duchaine et } \\
\text { al. (2007) }\end{array}$ & No & No & $\begin{array}{l}10 \text { members } \\
\text { of an } \\
\text { extended } \\
\text { family }\end{array}$ & $\begin{array}{l}20 \text { (12 age- } \\
\text { matched with } \\
\text { kids, and } 8 \\
\text { matched with } \\
\text { adults) }\end{array}$ & 1 & No & No & $\begin{array}{c}\text { (1) 4-AFC Reading } \\
\text { the Mind in the } \\
\text { Eyes test }\end{array}$ & Labelling & No & Complex & No \\
\hline $\begin{array}{l}\text { Fisher et al. } \\
\text { (2017) }\end{array}$ & No & $\begin{array}{l}\text { Yes (same } \\
\text { pattern as } \\
\text { accuracy) }\end{array}$ & $\begin{array}{c}12(\mathrm{~m}=33 \\
\mathrm{y} / \mathrm{o}, \text { range }= \\
21-49 \mathrm{y} / \mathrm{o}, 4 \\
\text { men })\end{array}$ & $\begin{array}{c}12(\mathrm{~m}=32 \mathrm{y} / \mathrm{o} \\
\text { range }=21-46 \mathrm{y} / \mathrm{o} \\
3 \mathrm{men})\end{array}$ & 2 & No & Yes & $\begin{array}{l}\text { (1) 4-AFC Reading } \\
\text { the Mind in the } \\
\text { Eyes test (2) } \\
\text { expression (and } \\
\text { parallel identity) } \\
\text { matching test }\end{array}$ & $\begin{array}{l}\text { Labelling } \\
\text { and } \\
\text { matching }\end{array}$ & No & $\begin{array}{l}\text { Complex and } \\
\text { basic }\end{array}$ & No \\
\hline $\begin{array}{l}\text { Humphreys } \\
\text { et al. (2007) }\end{array}$ & No & $\begin{array}{l}\text { Yes (same } \\
\text { pattern as } \\
\text { accuracy) }\end{array}$ & $\begin{array}{c}3(\mathrm{~m}=43 \\
\mathrm{y} / \mathrm{o}, \text { range }= \\
28-60 \mathrm{y} / \mathrm{o}, 2 \\
\text { men })\end{array}$ & $\begin{array}{c}2 \text { (age- and } \\
\text { gender-matched) }\end{array}$ & 1 & No & Yes & $\begin{array}{l}\text { (1) 6-AFC Emotion } \\
\text { Hexagon test }\end{array}$ & Labelling & No & Basic & $\begin{array}{l}\text { Yes (measure } \\
\text { not detailed } \\
\text { but excluded } \\
\text { anyone with } \\
\text { autism) }\end{array}$ \\
\hline $\begin{array}{c}\text { Jones \& } \\
\text { Tranel } \\
(2001)\end{array}$ & No & No & $\begin{array}{l}1 \text { (TA, } 5 \\
\text { y/o, boy) }\end{array}$ & $\begin{array}{c}2 \text { (age- and } \\
\text { gender-matched) }\end{array}$ & 1 & No & No & $\begin{array}{c}\text { (1) 2-AFC labelling } \\
\text { test }\end{array}$ & Labelling & No & Basic & No \\
\hline $\begin{array}{l}\text { Kress \& } \\
\text { Daum } \\
(2003)\end{array}$ & No & No & $\begin{array}{c}2(\mathrm{~m}=44 \\
\mathrm{y} / \mathrm{o}, \text { range }= \\
34-54 \mathrm{y} / \mathrm{o}, \\
\text { all women })\end{array}$ & $\begin{array}{l}4 \text { for each prosop- } \\
\text { agnosic (age- and } \\
\text { gender-matched) }\end{array}$ & $\begin{array}{l}1(4 \\
\text { sub- } \\
\text { tests })\end{array}$ & No & Yes & $\begin{array}{c}\text { (1) } 4 \text { subtests of } \\
\text { Tubinger Affect } \\
\text { Battery: affect } \\
\text { discrimination, } \\
\text { naming, } \\
\text { identification and } \\
\text { matching. }\end{array}$ & $\begin{array}{l}\text { Labelling } \\
\text { and } \\
\text { matching }\end{array}$ & No & Basic & No \\
\hline $\begin{array}{l}\text { Lee et al. } \\
(2010)\end{array}$ & No & No & $\begin{array}{l}3(\mathrm{~m}=47 \\
\mathrm{y} / \mathrm{o}, \text { range: } \\
34-67 \mathrm{y} / \mathrm{o}, \\
\text { father and } \\
\quad \text { two } \\
\text { daughters })\end{array}$ & $\begin{array}{l}\text { Test 1: Baron- } \\
\text { Cohen et al., } \\
\text { (2001) norm data. } \\
\text { Test 2: not } \\
\text { detailed }\end{array}$ & 2 & No & No & $\begin{array}{l}\text { (1) 4-AFC Reading } \\
\text { the Mind in the } \\
\text { Eyes test (2) 3-AFC } \\
\text { match-to-sample } \\
\text { task }\end{array}$ & $\begin{array}{l}\text { Labelling } \\
\text { and } \\
\text { matching }\end{array}$ & No & $\begin{array}{l}\text { Complex and } \\
\text { basic }\end{array}$ & $\begin{array}{l}\text { Yes (measure } \\
\text { not detailed } \\
\text { but no prosop- } \\
\text { agnosics } \\
\text { 'showed signs' } \\
\text { of autism) }\end{array}$ \\
\hline
\end{tabular}




\section{FACIAL EXPRESSION PROCESSING IN PROSOPAGNOSIA}

\begin{tabular}{|c|c|c|c|c|c|c|c|c|c|c|c|c|}
\hline $\begin{array}{c}\text { Author/s } \\
\text { (year) }\end{array}$ & $\begin{array}{l}\text { Facial } \\
\text { expression } \\
\text { deficit? }\end{array}$ & $\begin{array}{l}\text { Reported } \\
\text { response } \\
\text { times? }\end{array}$ & $\begin{array}{l}\text { Prosop- } \\
\text { agnosic } \\
\text { sample } \\
\text { size (age, } \\
\text { gender) }\end{array}$ & $\begin{array}{c}\text { Control sample } \\
\text { size (age, } \\
\text { gender) }\end{array}$ & $\begin{array}{l}\text { \# of } \\
\text { tasks }\end{array}$ & $\begin{array}{c}\text { Inverted } \\
\text { condition or } \\
\text { equivalent? }\end{array}$ & $\begin{array}{l}\text { Overcame } \\
\text { circular } \\
\text { analysis? }\end{array}$ & Task format & $\begin{array}{l}\text { Labelling } \\
\text { and/or } \\
\text { matching } \\
\text { tasks? }\end{array}$ & $\begin{array}{l}\text { Dynamic } \\
\text { stimuli? }\end{array}$ & $\begin{array}{c}\text { Complex } \\
\text { and/or basic } \\
\text { expressions? }\end{array}$ & $\begin{array}{c}\text { Autism } \\
\text { measure? }\end{array}$ \\
\hline $\begin{array}{l}\text { Minnebusch } \\
\text { et al. (2007) }\end{array}$ & Yes & No & $\begin{array}{c}4(\mathrm{~m}=37 \\
\mathrm{y} / \mathrm{o}, 2 \\
\text { women })\end{array}$ & $\begin{array}{c}9(\mathrm{~m}=40 \mathrm{y} / \mathrm{o}, 4 \\
\text { women })\end{array}$ & $\begin{array}{l}1(4 \\
\text { sub- } \\
\text { tests) }\end{array}$ & No & Yes & $\begin{array}{l}\text { (1) } 4 \text { subtests of } \\
\text { Tubinger Affect } \\
\text { Battery: affect } \\
\text { discrimination, } \\
\text { naming, } \\
\text { identification and } \\
\text { matching }\end{array}$ & $\begin{array}{l}\text { Labelling } \\
\text { and } \\
\text { matching }\end{array}$ & No & Basic & No \\
\hline $\begin{array}{l}\text { Nunn et al. } \\
\text { (2001) }\end{array}$ & No & No & $\begin{array}{l}1(\mathrm{EP}, 37 \\
\mathrm{y} / \mathrm{o}, \mathrm{man})\end{array}$ & $\begin{array}{c}10 \text { (age- and } \\
\text { gender-matched) }\end{array}$ & 1 & No & No & $\begin{array}{l}\text { (1) 6-AFC Ekman } \\
60 \text { Faces labelling } \\
\text { test }\end{array}$ & Labelling & No & Basic & No \\
\hline $\begin{array}{l}\text { Palermo et } \\
\text { al. }(2011)\end{array}$ & $\begin{array}{l}\text { No (but, } \\
\text { show } \\
\text { weakened } \\
\text { expression } \\
\text { composite } \\
\text { effect } \\
\text { relative to } \\
\text { controls) }\end{array}$ & $\begin{array}{l}\text { Yes (for } \\
\text { composite } \\
\text { task, but not } \\
\text { for other } \\
\text { tasks) }\end{array}$ & $\begin{array}{c}12(\mathrm{~m}=41 \\
\mathrm{y} / \mathrm{o}, \text { range }= \\
20-60 \mathrm{y} / \mathrm{o}, 4 \\
\text { men })\end{array}$ & $\begin{array}{c}17(\mathrm{~m}=39 \mathrm{y} / \mathrm{o} \\
\text { range }=19-60 \mathrm{y} / \mathrm{o}, \\
7 \mathrm{men})\end{array}$ & 4 & $\begin{array}{l}\text { Yes } \\
\text { (composite } \\
\text { expression } \\
\text { task) }\end{array}$ & No & $\begin{array}{l}\text { (1) 6-AFC Ekman } \\
60 \text { Faces labelling } \\
\text { test (2) 6-AFC } \\
\text { Emotion Hexagon } \\
\text { test (3) 4-AFC } \\
\text { Reading the Mind in } \\
\text { the Eyes test (4) } \\
\text { Expression } \\
\text { Composite test }\end{array}$ & Labelling & No & $\begin{array}{l}\text { Complex and } \\
\text { basic }\end{array}$ & $\begin{array}{l}\text { Yes, Autism } \\
\text { Quotient } \\
\text { (showed } \\
\text { normal } \\
\text { scores) }\end{array}$ \\
\hline $\begin{array}{l}\text { Schmalzl et } \\
\text { al. (2008) }\end{array}$ & $\begin{array}{l}\text { Mixed (4/7 } \\
\text { prosopagnos } \\
\text { ics } \\
\text { impaired) }\end{array}$ & No & $\begin{array}{c}7 \text { (range }= \\
4-87 \mathrm{y} / \mathrm{o}) \\
\text { note: four } \\
\text { generations } \\
\text { of the same } \\
\text { family }\end{array}$ & $\begin{array}{c}5 \text { each for } 5 \\
\text { control groups for } \\
\text { the different age } \\
\text { brackets }\end{array}$ & 1 & No & No & $\begin{array}{c}\text { (1) 6-AFC labelling } \\
\text { task }\end{array}$ & Labelling & No & Basic & No \\
\hline
\end{tabular}

Abbreviations: $\mathrm{AFC}=$ alternative forced choice, $\mathrm{y} / \mathrm{o}=$ years old 


\section{Appendix B}

\section{Study 1 supplementary analyses}

\section{B.1 Individual task validation in independent samples}

Prior to the main experiment, Study 1 tasks were validated with independent mTurk samples to ensure they met three criteria. First, mean task performance did not suffer from ceiling or floor effects. Second, the expression and identity version of each task format were matched on difficulty. Third, each task produced sizeable inversion effects. For all tasks, each participant completed the upright and inverted conditions.

Participants were excluded from analyses if they (1) were older than 52 years of age (to match our prosopagnosic samples' age range), (2) completed both the identity and expression version of a given format, and/or (3) performed at or below chance level for a given task. For each task format, I ran a 2 (stimulus orientation: upright, inverted) x 2 (task format: expression, identity) mixed-design ANOVA on accuracy, with stimulus orientation as the within-subjects factor and task format as the between-subjects factor.

Simultaneous matching tasks. Participants completed the expression and identity simultaneous matching tasks ( $n=100$ each). After exclusion, the final samples comprised 56 individuals for the expression task and 51 for the identity task. The mean scores on the expression task were $71.10 \%(S D=14.13 \%)$ in the upright condition and $63.07 \%(S D=$ $15.10 \%)$ in the inverted condition. The mean scores on the identity task were $70.34 \%(S D=$ $15.29 \%)$ in the upright condition and $58.77 \%(S D=15.28 \%)$ in the inverted condition. There was a main effect of stimulus orientation, indicating that, on both tasks, performance was better upright than inverted $\left(M_{\text {upright }}=70.74, S D_{\text {upright }}=14.63 ; M_{\text {inverted }}=61.02, S D_{\text {inverted }}=\right.$ $\left.15.27 ; F(1,105)=82.28, p<.001, \eta_{p}^{2}=.44\right)$. The main effect of task format $(F(1,105)=$ $0.89, p=.349, \eta_{p}^{2}=.01$ ), and the interaction between stimulus orientation and task format were not significant $\left(F(1,105)=2.67, p=.105, \eta_{p}^{2}=.03\right)$.

Performance on the expression and identity simultaneous matching tasks was below ceiling and above floor (chance performance is 33.33\%). Sizeable inversion effects were observed for both tasks. The lack of main effect of task format indicates that the expression and identity tasks are matched on difficulty. The non-significant interaction between task type and stimulus orientation suggests that both tasks produce comparable inversion effects. 


\section{FACIAL EXPRESSION PROCESSING IN PROSOPAGNOSIA}

Sequential matching tasks. Participants completed the expression and identity sequential matching tasks ( $n=100$ each). After exclusion, the final samples comprised 60 individuals for the expression task and 57 for the identity task. The mean scores on the expression task were $73.17 \%(S D=9.56 \%)$ in the upright condition and $68.15 \%(S D=$ $9.53 \%)$ in the inverted condition. The mean scores on the identity task were $72.22 \%(S D=$ $10.39 \%)$ in the upright condition and $64.67 \%(S D=10.20 \%)$ in the inverted condition. There was a main effect of stimulus orientation, indicating that, on both tasks, performance was better upright than inverted $\left(M_{\text {upright }}=72.71, S D_{\text {upright }}=9.94 ; M_{\text {inverted }}=66.45, S D_{\text {inverted }}=\right.$ 9.97; $\left.F(1,115)=71.85, p<.001, \eta_{p}^{2}=.39\right)$. The main effect of task format $(F(1,115)=$ $1.74, p=.189, \eta_{p}^{2}=.02$ ) and the interaction between task type and stimulus orientation were not significant $\left(F(1,115)=2.91, p=.091, \eta_{p}^{2}=.03\right)$.

Performance on the expression and identity sequential matching tasks was below ceiling and above floor (chance performance is 50.00\%). Sizeable inversion effects were observed for both tasks. The lack of main effect of task format indicates that the expression and identity tasks are matched on difficulty. The non-significant interaction between task format and stimulus orientation suggests both tasks produce comparable inversion effects.

Sorting tasks. Participants completed the expression $(n=99)$ and identity $(n=100)$ sorting tasks. After exclusion, the final samples comprised 31 individuals for the expression task and 29 for the identity task. The mean scores on the expression task were $65.99 \%(S D=$ $14.58 \%)$ in the upright condition and $46.95 \%(S D=11.47 \%)$ in the inverted condition. The mean scores on the identity task were $69.44 \%(S D=10.41 \%)$ in the upright condition and $50.29 \%(S D=10.32 \%)$ in the inverted condition. There was a main effect of stimulus orientation, indicating that, on both tasks, performance was better upright than inverted $\left(M_{\text {upright }}=67.66 \%, S D_{\text {upright }}=12.74 \% ; M_{\text {inverted }}=48.56 \%, S D_{\text {inverted }}=10.97 \% ; F(1,58)=\right.$ $\left.170.69, p<.01, \eta_{p}^{2}=.75\right)$. The main effect of task format $\left(F(1,58)=1.58, p=.213, \eta_{p}^{2}=\right.$ $.03)$, and the interaction between stimulus orientation and task type were not significant $(F(1$, $\left.58)<0.01, p=.969, \eta_{p}^{2}<.01\right)$.

Performance on the expression and identity sorting tasks was below ceiling and above floor (chance performance is $36.00 \%$ ). Sizeable inversion effects were observed for both tasks. The lack of main effect of task format indicates that the facial expression and facial 


\section{FACIAL EXPRESSION PROCESSING IN PROSOPAGNOSIA}

identity tasks are matched on difficulty. The non-significant interaction between task format and stimulus orientation suggests that both tasks produce similar-sized inversion effects.

\section{B.2 Controls' descriptive statistics and data checks}

I checked that controls' performance on the Study 1 tasks (1) did not show ceiling or floor effects, (2) revealed sizeable inversion effects, and (3) was comparable on the expression and identity version of each task format. Controls' accuracy and trimmed mean response times on each task are presented in Table B1 and B2, respectively. For each task format, I ran a 2 (stimulus orientation: upright, inverted) x 2 (task format: expression, identity) repeated-design ANOVA on accuracy, with stimulus orientation and task format as the within-subjects factors.

Table B1. Controls' accuracy on the upright and inverted trials of the Study 1 tasks.

\begin{tabular}{llcc}
\hline Face Aspect & Task Format & $\begin{array}{c}\text { Upright } \\
M(S D)\end{array}$ & $\begin{array}{c}\text { Inverted } \\
M(S D)\end{array}$ \\
& & & \\
& Simultaneous Matching & $77.76(10.82)$ & $70.76(10.82)$ \\
Expression & Sequential Matching & $76.80(9.75)$ & $70.72(8.26)$ \\
& Sorting & $64.89(14.09)$ & $43.85(12.13)$ \\
& Simultaneous Matching & $77.28(11.22)$ & $65.78(12.82)$ \\
& Sequential Matching & $74.56(9.53)$ & $67.34(10.09)$ \\
& Sorting & $71.94(9.89)$ & $52.50(10.48)$ \\
\hline
\end{tabular}


FACIAL EXPRESSION PROCESSING IN PROSOPAGNOSIA

Table B2. Controls' trimmed mean response times on the upright and inverted trials of the Study 1 tasks.

\begin{tabular}{llcc}
\hline Face Aspect & Task Format & Upright & Inverted \\
& & $M(S D)$ & $M(S D)$ \\
\hline \multirow{2}{*}{ Expression } & Simultaneous Matching & $2159(357)$ & $2092(355)$ \\
& Sequential Matching & $2402(195)$ & $2426(199)$ \\
& Sorting & $20373(9304)$ & $20101(10431)$ \\
Identity & Simultaneous Matching & $2280(369)$ & $2421(495)$ \\
& Sequential Matching & $2439(222)$ & $2463(206)$ \\
& Sorting & $21511(8724)$ & $21054(9996)$ \\
\hline
\end{tabular}

Simultaneous Matching Task. Figure B1 shows the results. The ANOVA revealed significant main effects of face aspect $\left(F(1,132)=235.10, p<.001, \eta_{p}^{2}=.64\right)$ and orientation $\left(F(1,132)=235.10, p<.001, \eta_{p}^{2}=.64\right)$, which were qualified by a significant interaction between face aspect and orientation, $F(1,132)=14.60, p<.001, \eta_{p}^{2}=.10$. I ran post hoc comparisons to break down this interaction. Controls' performance on the upright condition of the facial expression and facial identity tasks were comparable $\left(M_{\text {expression }}=\right.$ $77.76 \%, S D_{\text {expression }}=10.82 \% ; M_{\text {identity }}=77.28 \%, S D_{\text {identity }}=11.22 \% ; t(132)=0.50, p=.618$, $\left.d_{\mathrm{z}}=.04\right)$. However, controls' performance on the inverted condition was better on the facial expression task than the facial identity task $\left(M_{\text {expression }}=70.95 \%, S D_{\text {expression }}=10.43 \%\right.$; $\left.M_{\text {identity }}=65.78 \%, S D_{\text {identity }}=12.82 \% ; t(132)=4.55, p<.001, d_{\mathrm{z}}=.39\right)$. I ran a follow-up paired samples t-test to compare the size of controls inversion effects for the facial expression and the facial identity task, which revealed that the inversion effect for the facial expression task was smaller than that for the facial identity task $\left(M_{\text {expression }}=6.80 \%, S D_{\text {expression }}=7.99 \%\right.$; $\left.\left.M_{\text {identity }}=11.50 \%, S D_{\text {identity }}=11.49 \%\right), t(132)=3.81, p<.001, d_{z}=0.33\right)$. 


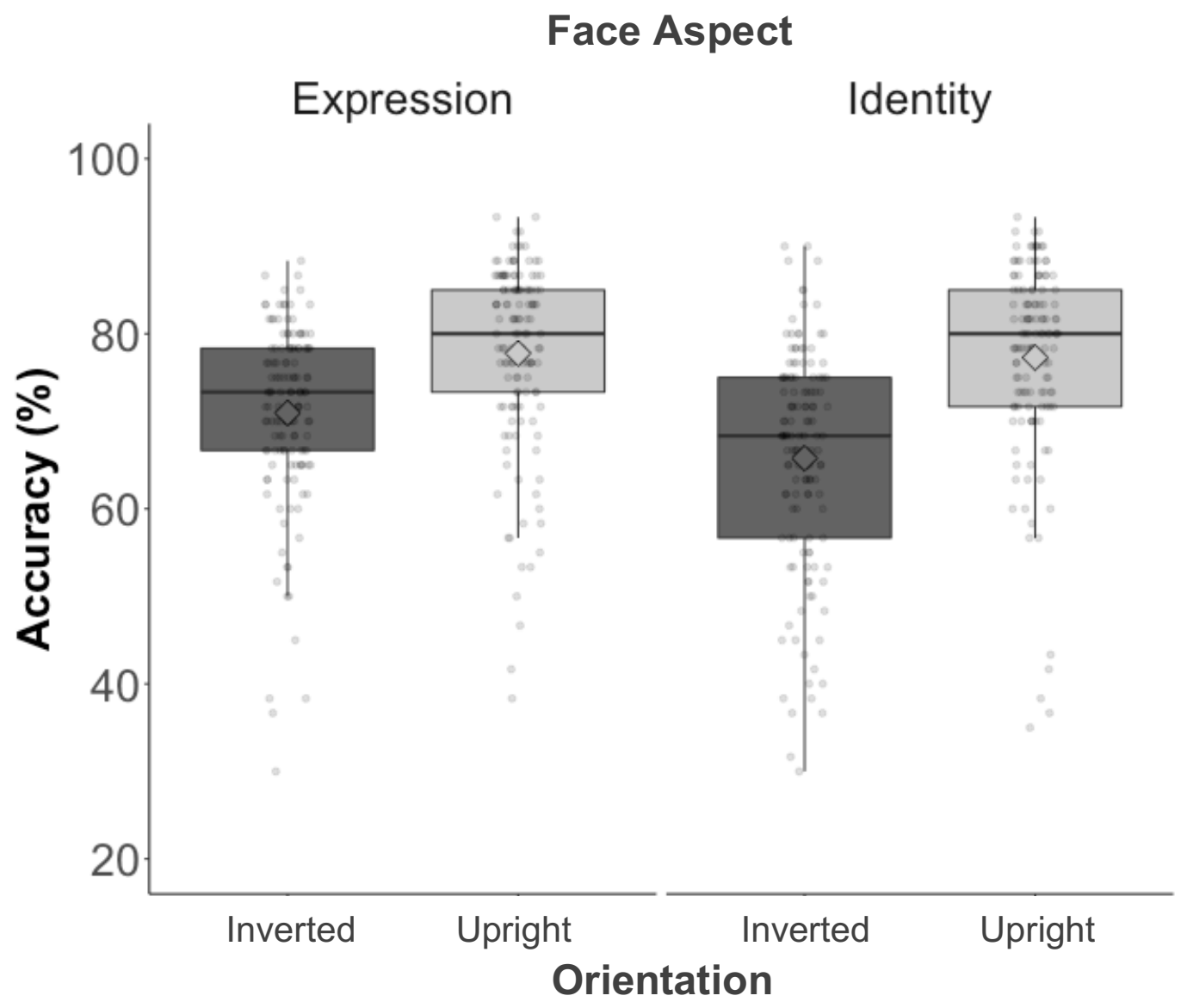

Figure B1. Boxplots of controls' accuracy on the inverted and upright conditions of the facial expression (left) and facial identity (right) simultaneous matching tasks. Points represent individual data. Diamonds represent the mean score for each condition.

Regarding the three data checks, first, controls did not show ceiling or floor performance on the upright or inverted conditions of the expression and identity tasks. Second, both tasks produced sizeable inversion effects, although they were larger for the identity task than for the expression task. Third, controls' performance on the upright condition of both tasks was comparable, indicating that the difficulty level for the upright trials is matched. However, performance on the inverted condition of both tasks was not matched.

Sequential Matching Task. Figure B2 shows the results. The ANOVA revealed a significant main effect of face aspect, indicating that controls' performance on the facial expression task was sightly better than on the facial identity task $\left(M_{\text {expression }}=73.76\right.$, $S D_{\text {expression }}=9.52 ; M_{\text {identity }}=70.95 \%, S D_{\text {identity }}=10.44 \% ; F(1,132)=14.54, p<.001, \eta_{p}^{2}=$ .10). There was also a significant main effect of orientation, indicating that controls' performance on the inverted conditions of both tasks was poorer than their performance on 


\section{FACIAL EXPRESSION PROCESSING IN PROSOPAGNOSIA}

the upright conditions $\left(M_{\text {inverted }}=70.87 \%, S D_{\text {inverted }}=9.76 \% ; M_{\text {upright }}=74.03 \%, S D_{\text {upright }}=\right.$ $\left.9.52 \% ; F(1,132)=199.21, p<.001, \eta_{p}^{2}=.60\right)$. The interaction between face aspect and orientation was not significant, indicating that the inversion effects for the facial expression and facial identity tasks were comparable, $F(1,132)=1.48, p=.226, \eta_{p}^{2}=.01$.

\section{Face Aspect}

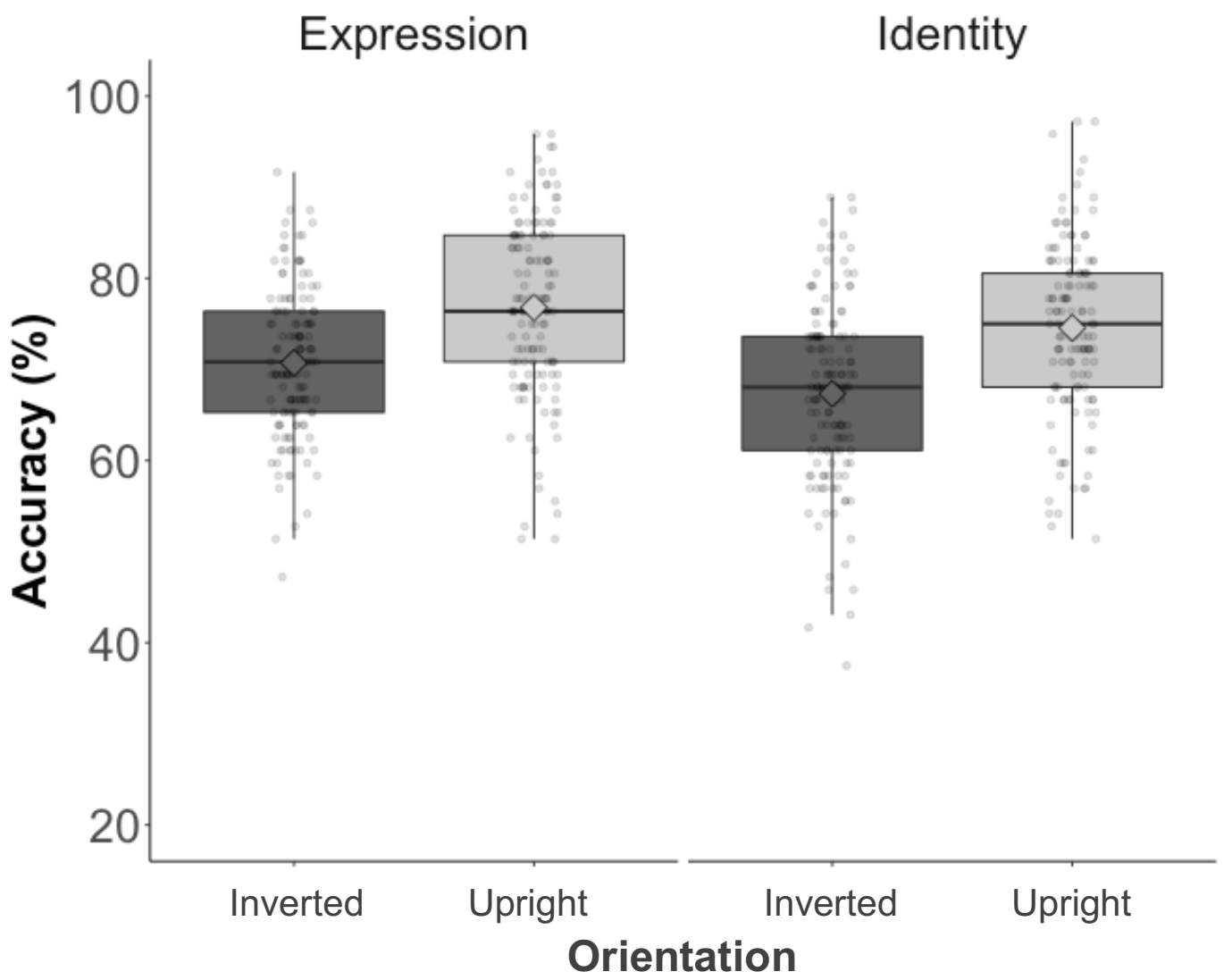

Figure B2. Boxplots of controls' accuracy on the inverted and upright conditions of the facial expression (left) and facial identity (right) sequential matching tasks. Points represent individual data. Diamonds represent the mean score for each condition.

Regarding the three data checks, first, controls did not show ceiling or floor performance on the upright or inverted conditions of the facial expression and facial identity tasks. Second, both tasks produced sizeable inversion effects that are of comparable size. Third, controls' performance on the upright and inverted condition of the two tasks was not matched, with better performance overall in the facial expression task.

Sorting Task. Figure B3 shows the results. The ANOVA revealed a significant main effect of face aspect, indicating that controls' performance on the facial expression task was poorer than their performance on the facial identity task $\left(M_{\text {expression }}=54.37 \%, S D_{\text {expression }}=\right.$ 


\section{FACIAL EXPRESSION PROCESSING IN PROSOPAGNOSIA}

$\left.16.83 \% ; M_{\text {identity }}=62.22 \%, S D_{\text {identity }}=14.08 \% ; F(1,132)=80.32, p<.001, \eta_{p}^{2}=.38\right)$. There was also a significant main effect of orientation, indicating that controls' performance on the inverted conditions of both tasks was poorer than their performance on the upright conditions $\left(M_{\text {inverted }}=56.10 \%, S D_{\text {inverted }}=16.00 \% ; M_{\text {upright }}=60.23 \%, S D_{\text {upright }}=17.02 \% ; F(1,132)=\right.$ $\left.588.51, p<.001, \eta_{p}^{2}=.82\right)$. The interaction between face aspect and orientation was not significant, indicating that the size of controls inversion effects for the facial expression and facial identity tasks were comparable $\left(F(1,132)=1.28, p=.220, \eta_{p}^{2}=.01\right)$.

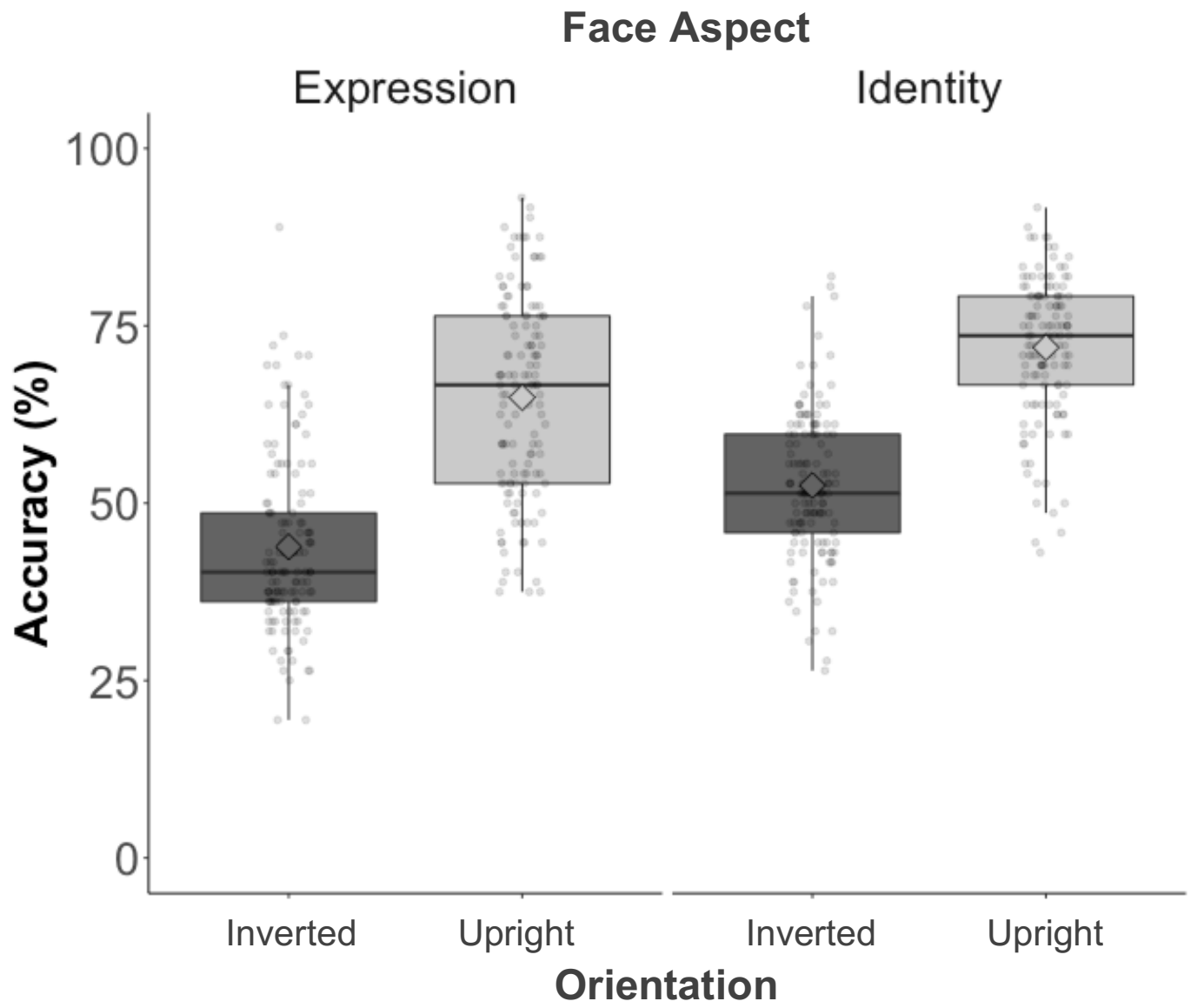

Figure B3. Boxplots of controls' accuracy on the inverted and upright conditions of the facial expression (left) and facial identity (right) sorting tasks. Points represent individual data. Diamonds represent the mean score for each condition.

Regarding the three data checks, first, controls did not show ceiling or floor performance on the upright or inverted conditions of the facial expression and facial identity tasks. Second, both tasks produced sizeable inversion effects that were of comparable size. Third, controls' performance on the upright and inverted conditions of both tasks was not 


\section{FACIAL EXPRESSION PROCESSING IN PROSOPAGNOSIA}

comparable, with the facial expression task being more difficult across both orientations compared to the facial identity task.

\section{B.3 Prosopagnosics' descriptive statistics}

Prosopagnosics' accuracy and trimmed mean response times on the upright and inverted trials of the Study 1 tasks are presented in Table B3 and B4, respectively.

Table B3. Prosopagnosics' accuracy on the upright and inverted trials of the Study 1 tasks.

\begin{tabular}{|c|c|c|c|}
\hline \multirow[t]{2}{*}{ Face Aspect } & \multirow[t]{2}{*}{ Task Format } & & \multirow{2}{*}{$\begin{array}{l}\text { Inverted } \\
M(S D)\end{array}$} \\
\hline & & $M(S D)$ & \\
\hline \multirow{3}{*}{ Expression } & Simultaneous Matching & $76.09(9.54)$ & $69.35(9.69)$ \\
\hline & Sequential Matching & $75.12(8.75)$ & $67.74(8.89)$ \\
\hline & Sorting & $59.50(13.58)$ & $43.53(9.42)$ \\
\hline \multirow{3}{*}{ Identity } & Simultaneous Matching & $70.09(10.31)$ & $64.07(11.13)$ \\
\hline & Sequential Matching & $66.17(8.16)$ & $62.88(7.34)$ \\
\hline & Sorting & $59.67(10.34)$ & $49.75(10.18)$ \\
\hline
\end{tabular}

Table B4. Prosopagnosics' trimmed mean response times on the upright and inverted trials of the Study 1 tasks.

\begin{tabular}{llcc}
\hline Face Aspect & Task Format & $\begin{array}{c}\text { Upright } \\
M(S D)\end{array}$ & $\begin{array}{c}\text { Inverted } \\
M(S D)\end{array}$ \\
& & $2641(376)$ & $2652(411)$ \\
Expression & Simultaneous Matching & $2669(192)$ & $2693(213)$ \\
& Sequential Matching & $27689(10092)$ & $25897(11369)$ \\
& Simultaneous Matching & $2924(511)$ & $3018(629)$ \\
Identity & Sequential Matching & $2648(214)$ & $2682(221)$ \\
& Sorting & $30362(8925)$ & $29137(10913)$ \\
\hline
\end{tabular}




\section{FACIAL EXPRESSION PROCESSING IN PROSOPAGNOSIA}

\section{B.4 Sequential matching tasks $d$ ' and criterion analyses}

d' scores were calculated for prosopagnosics' and controls' performance on the facial expression and facial identity sequential matching tasks to check that the same pattern of performance was observed with a bias-free measure of sensitivity. Figure B4 shows the results. I ran a 2 (face aspect: expression, identity) x 2 (group: prosopagnosic, control) mixeddesign ANOVA on $d$ ' scores for upright trials, with face aspect as the within-subjects factor and group as the between-subjects factor. There were significant main effects of face aspect $\left(F(1,255)=75.60, p<.001, \eta_{p}^{2}=.23\right)$ and $\operatorname{group}\left(F(1,255)=26.50, p<.001, \eta_{p}^{2}=.09\right)$, and a significant interaction between face aspect and $\operatorname{group}\left(F(1,255)=20.00, p<.001, \eta_{p}^{2}\right.$ $=.07)$. Post hoc comparisons showed that controls' and prosopagnosics' $d$ ' scores were comparable on the facial expression task, indicating that prosopagnosics and controls have similar response sensitivity to discriminating facial expressions $\left(M_{\text {control }}=1.64, S D_{\text {control }}=\right.$ $\left.0.71 ; M_{\text {prosopagnosic }}=1.50, S D_{\text {prosopagnosic }}=0.60 ; t(255)=1.70, p=.090, d=.21\right)$. Conversely, relative to controls', prosopagnosics' $d$ ' scores were smaller on the facial identity task, indicating that prosopagnosics have reduced discriminative sensitivity to facial identity compared to controls $\left(M_{\text {control }}=1.45, S D_{\text {control }}=0.69 ; M_{\text {prosopagnosic }}=0.92, S D_{\text {prosopagnosic }}=\right.$ $0.49 ; t(255)=7.05, p<.001, d=.88)$. Overall, the pattern of performance observed with $d^{\prime}$ scores mirrored that observed in raw accuracy scores. 


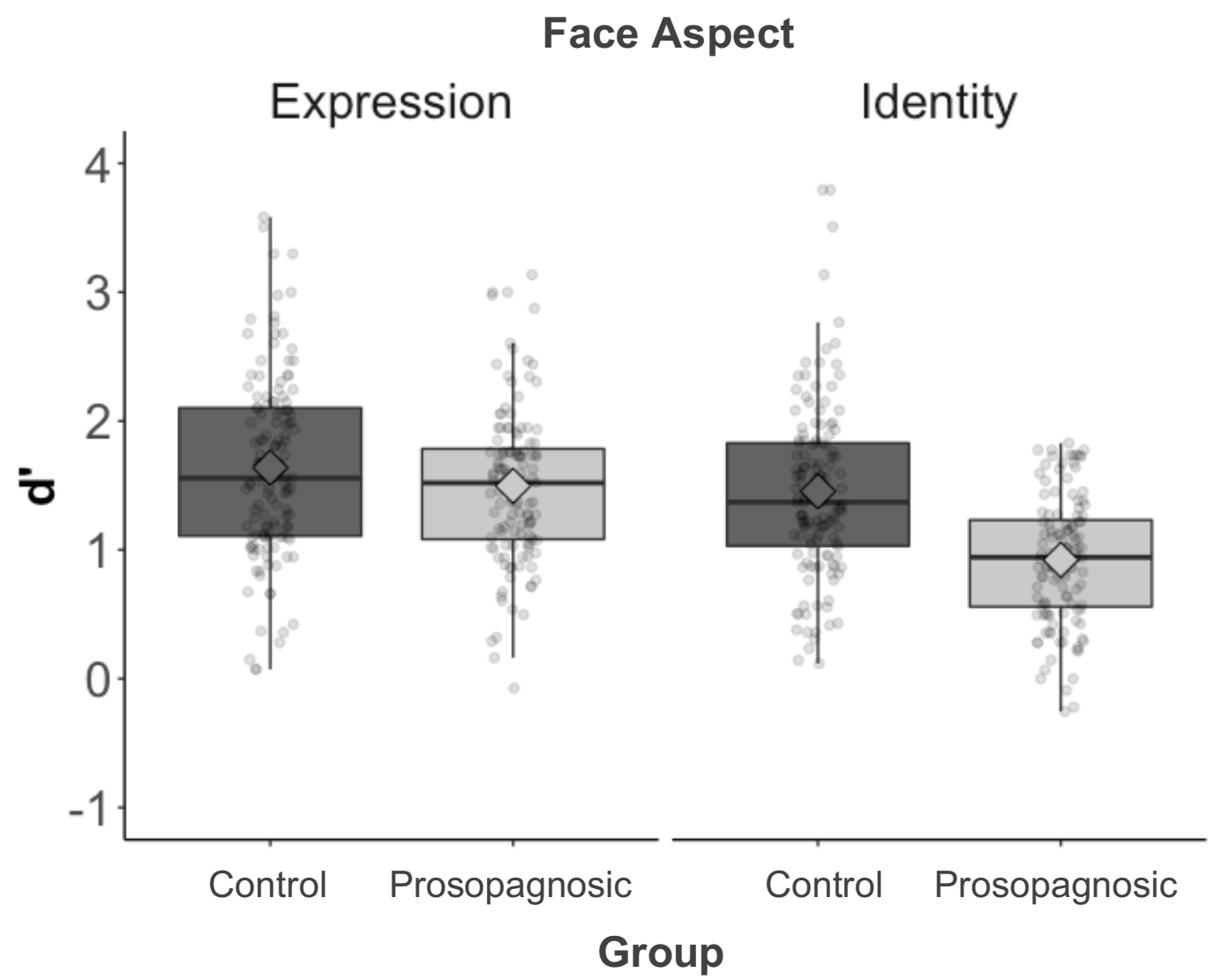

Figure B4. Boxplots depicting prosopagnosics' and controls' $d$ 'values on the facial expression (left) and facial identity (right) sequential matching tasks for upright trials. Points represent individual data. Diamonds represent the mean score for each condition.

Criterion (C) scores were also calculated to see if prosopagnosics and controls showed differing response biases for responding 'same' or 'different' in the facial expression and facial identity sequential matching tasks. Figure B5 shows the results. I ran a 2 (face aspect: expression, identity) x 2 (group: prosopagnosic, control) mixed-design ANOVA on C scores for upright trials, with face aspect as the within-subjects factor and group as the between-subjects factor. The main effects of face aspect $\left(F(1,255)=0.59, p=.442, \eta_{p}^{2}<.01\right)$ and group $\left(F(1,255)=3.19, p=.075, \eta_{p}^{2}<.01\right)$, and the interaction between face aspect and group were not significant, $F(1,255)=0.82, p=.365, \eta_{p}^{2}<.01$. These results indicate that prosopagnosics' and controls' response biases were comparable for the facial expression $\left(M_{\text {prosopagnosic }}=-0.04, S D_{\text {prosopagnosic }}=0.38 ; M_{\text {control }}=.05, S D_{\text {control }}=.36\right)$ and facial identity $\left(M_{\text {prosopagnosic }}=0.01, S D_{\text {prosopagnosic }}=0.43 ; M_{\text {control }}=.05, S D_{\text {control }}=.32\right)$ sequential matching tasks. 


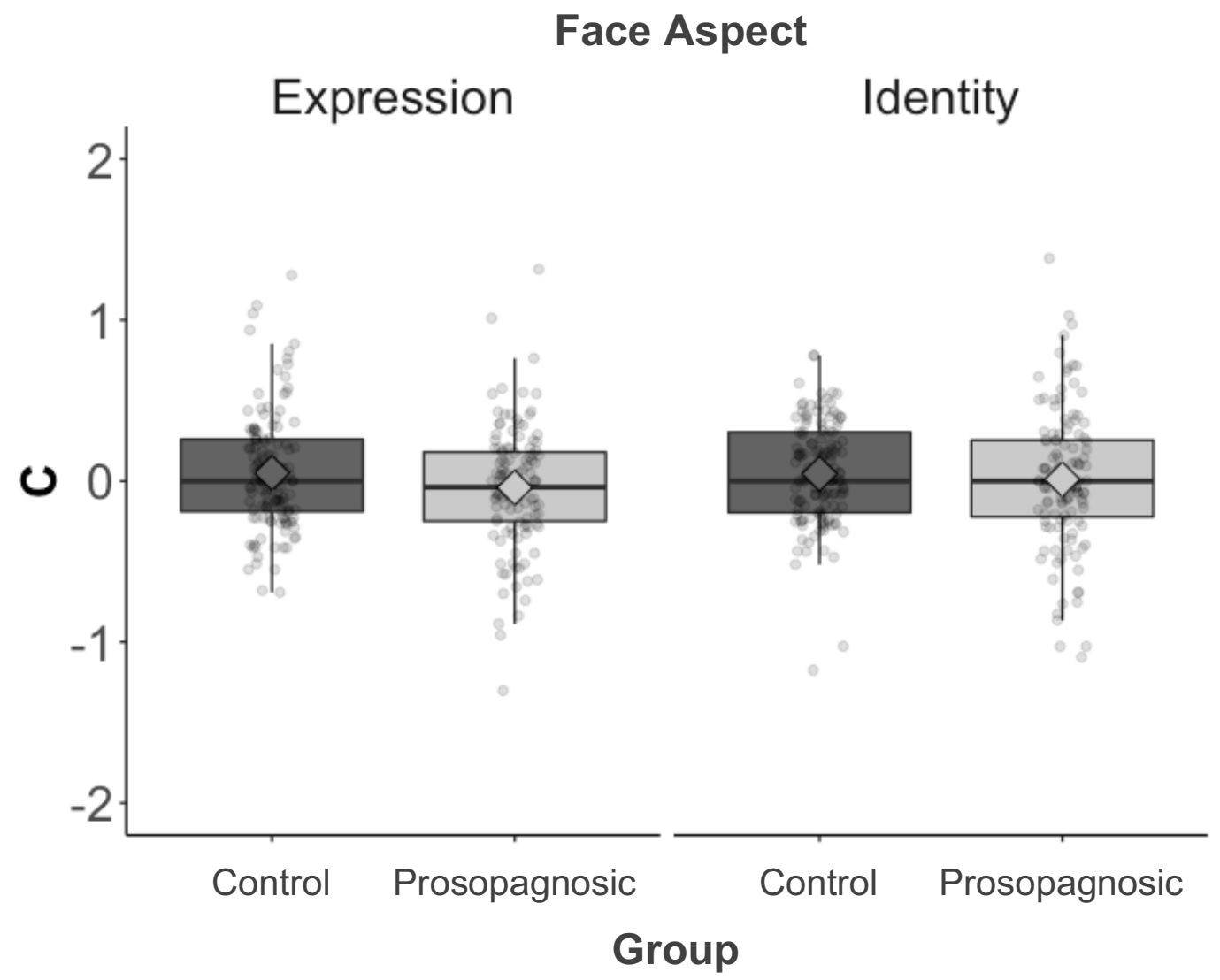

Figure B5. Boxplots depicting prosopagnosics' and controls' C values on the facial expression (left) and facial identity (right) sequential matching tasks for upright trials. Points represent individual data. Diamonds represent the mean score for each condition.

\section{B.5 Median response time analyses}

In addition to trimmed mean response times, I also analysed median response times (see Table B5) to further check that differences in response time could not account for the pattern of results observed in accuracy.

Dissociation between facial expression and facial identity. Figure B6 shows the results. I ran a 2 (face aspect: expression, identity) x 2 (group: prosopagnosic, control) mixeddesign ANOVA on response times for upright trials, collapsing across task format, with face aspect as the within-subjects factor and group as the between-subjects factor. There was a main effect of group, indicating that controls were faster than prosopagnosics for both face aspects $\left(M_{\text {control }}=8403 \mathrm{~ms}, S D_{\text {control }}=3276 \mathrm{~ms} ; M_{\text {prosopagnosic }}=11557 \mathrm{~ms}, S D_{\text {prosopagnosic }}=\right.$ $\left.3568 \mathrm{~ms} ; F(1,255)=62.20, p<.001, \eta_{p}^{2}=.20\right)$. There was also a main effect of face aspect, indicating that both groups were slower with identity than with expression tasks $\left(M_{\text {identity }}=\right.$ 


\section{FACIAL EXPRESSION PROCESSING IN PROSOPAGNOSIA}

$10255 \mathrm{~ms}, S D_{\text {identity }}=3648 \mathrm{~ms} ; M_{\text {expression }}=9595 \mathrm{~ms}, S D_{\text {expression }}=3854 \mathrm{~ms} ; F(1,255)=$

21.33, $\left.p<.001, \eta_{p}^{2}=.08\right)$. Critically, the interaction between face aspect and group was not significant, indicating that the dissociation I observed in accuracy cannot be accounted for by response time differences, $F(1,255)=2.54, p=.112, \eta_{p}^{2}=.01$.

Table B5. Prosopagnosics' and controls' median response times on the upright and inverted trials of the Study 1 tasks.

\begin{tabular}{|c|c|c|c|c|c|}
\hline \multirow{3}{*}{$\begin{array}{l}\text { Face } \\
\text { Aspect }\end{array}$} & \multirow{3}{*}{ Task Format } & \multicolumn{2}{|l|}{ Upright } & \multicolumn{2}{|l|}{ Inverted } \\
\hline & & Controls & Prosopagnosics & Controls & Prosopagnosics \\
\hline & & $M$ & $(S D)$ & \multicolumn{2}{|c|}{$M \quad(S D)$} \\
\hline \multirow{3}{*}{ Expression } & $\begin{array}{l}\text { Simultaneous } \\
\text { Matching }\end{array}$ & $2136(537)$ & 2657 (619) & $2043(511)$ & 2637 (669) \\
\hline & $\begin{array}{l}\text { Sequential } \\
\text { Matching }\end{array}$ & 2367 (207) & $2646(244)$ & $2401(223)$ & $2666(267)$ \\
\hline & Sorting & 20049 (9702) & $28020(11096)$ & 19798 (10989) & $26012(12466)$ \\
\hline \multirow{3}{*}{ Identity } & $\begin{array}{l}\text { Simultaneous } \\
\text { Matching }\end{array}$ & 2215 (490) & 2901 (739) & $2392(653)$ & 2957 (872) \\
\hline & $\begin{array}{l}\text { Sequential } \\
\text { Matching }\end{array}$ & 2376 (197) & $2619(273)$ & $2412(201)$ & 2649 (295) \\
\hline & Sorting & $21274(9371)$ & 30499 (9511) & $20849(10612)$ & $29112(11725)$ \\
\hline
\end{tabular}




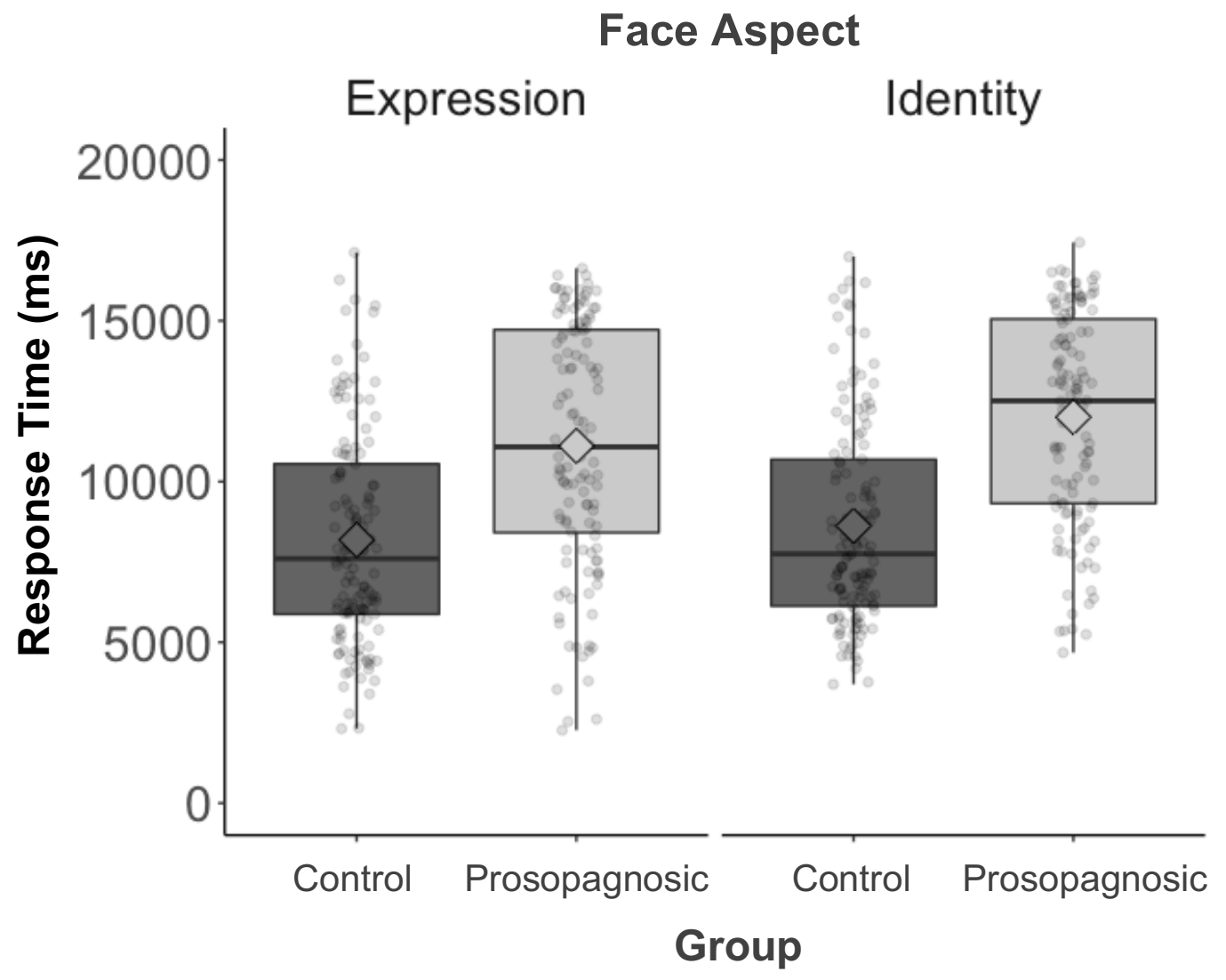

Figure B6. Boxplots of prosopagnosics' and controls' median response times on the facial expression (left) and facial identity (right) tasks for upright trials, collapsed across task format. Points represent individual data. Diamonds represent the mean score for each condition.

Inversion effects. Figure B7 shows the results. I ran a 2 (face aspect: expression, identity) x 2 (group: prosopagnosic, control) mixed-design ANOVA on response time inversion effects, collapsing across task format, with face aspect as the within-subjects factor and group as the between-subjects factor. There was a main effect of group, indicating that prosopagnosics' inversion effects were larger across both face aspects relative to controls' $\left(M_{\text {control }}=87 \mathrm{~ms}, S D_{\text {control }}=1478 \mathrm{~ms} ; M_{\text {prosopagnosic }}=552 \mathrm{~ms}, S D_{\text {prosopagnosic }}=2063 \mathrm{~ms} ; F(1\right.$, $\left.255)=6.58, p=.011, \eta_{p}^{2}=.03\right)$. The main effect of face aspect was not significant $(F(1$, $\left.255)=1.07, p=.302, \eta_{p}^{2}<.01\right)$. Importantly, the interaction between face aspect and group was not significant, indicating that the dissociation I found in accuracy cannot be accounted for by response time differences, $F(1,255)=0.61, p=.436, \eta_{p}^{2}<.01$. 


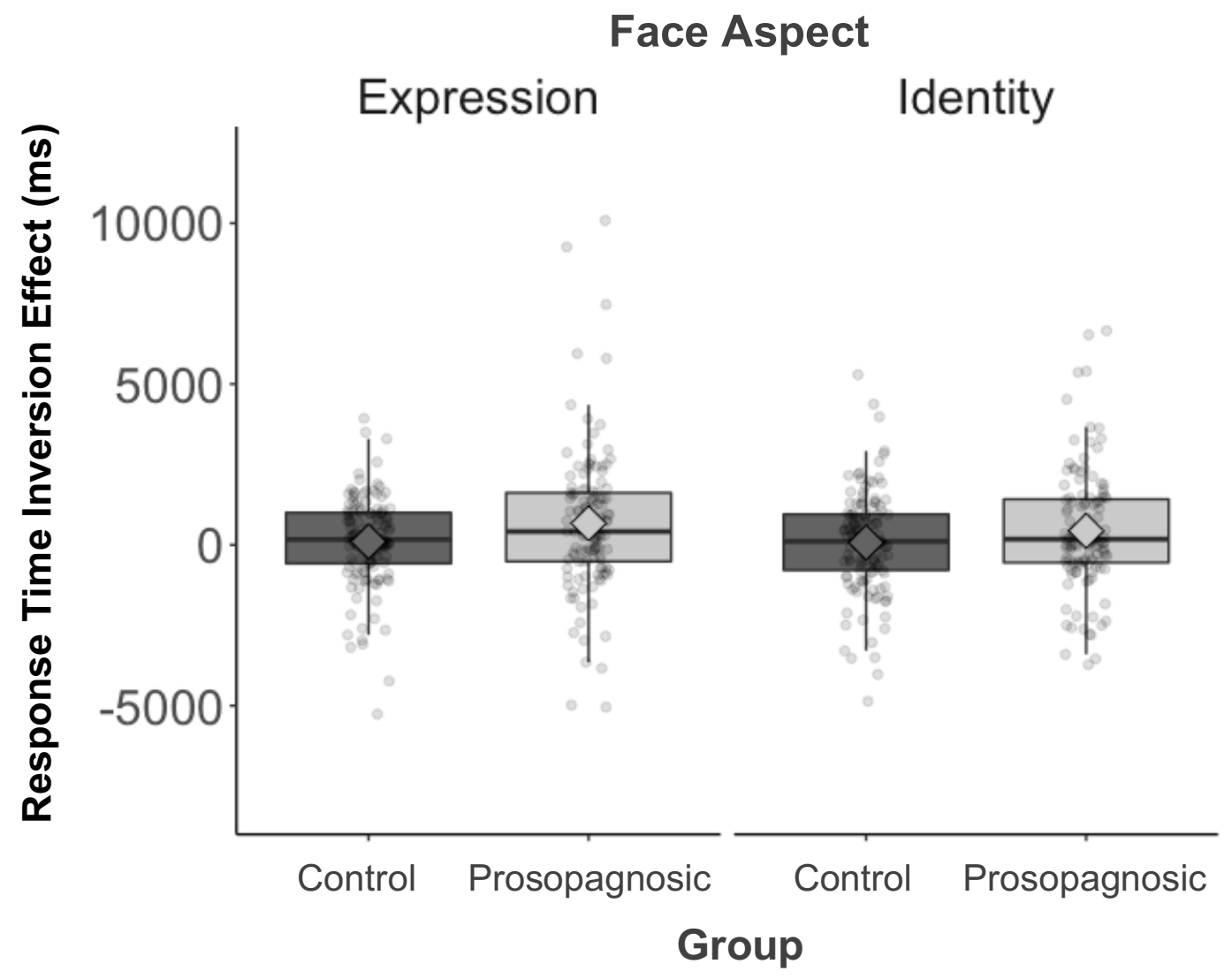

Figure B7. Boxplots of prosopagnosics' and controls' inversion effects in median response times on the facial expression (left) and facial identity (right) tasks, collapsed across task format. Points represent individual data. Diamonds represent the mean score for each condition.

\section{B.6 Adjusted SATQ analyses}

The SATQ is built up of five factors, and one of these factors ("Reading facial expressions") assesses facial expression processing with the following three items: ' $I \mathrm{am}$ good at knowing what others are feeling by watching their facial expressions or listening to the tone of their voice', 'I can sense that someone is not interested in what I'm saying by reading their facial expressions', and 'I make eye contact when talking with others'. To check whether these items were driving the relationship between prosopagnosics' SATQ scores and their performance on the facial expression tasks, I ran correlations with prosopagnosics' SATQ scores that excluded the three 'reading facial expressions' items (herein, the 'adjusted SATQ score').

I computed a Pearson product-moment correlation coefficients to assess the relationship between prosopagnosics' adjusted SATQ scores and their performance on the upright trials of the facial expression and facial identity tasks. Figure B8 shows the 


\section{FACIAL EXPRESSION PROCESSING IN PROSOPAGNOSIA}

correlations. There was a negative correlation between prosopagnosics' adjusted SATQ scores and their performance on the facial expression tasks, indicating that as autism traits increase, performance on the facial expression tasks tends to decrease, $r(122)=-.28, p=$ .002 (the correlations computed with the adjusted SATQ scores and the unadjusted scores were comparable, $z=0.68, p=.497$; Lee $\&$ Preacher, 2013). There was no correlation between prosopagnosics' adjusted SATQ scores and their performance on the facial identity tasks, $r(122)=.06, p=.520$ (the correlation computed with the adjusted SATQ scores was stronger (despite being non-significant) than the correlation with the unadjusted scores, $z=$ $2.51, p=.012)$.

\section{Face Aspect}

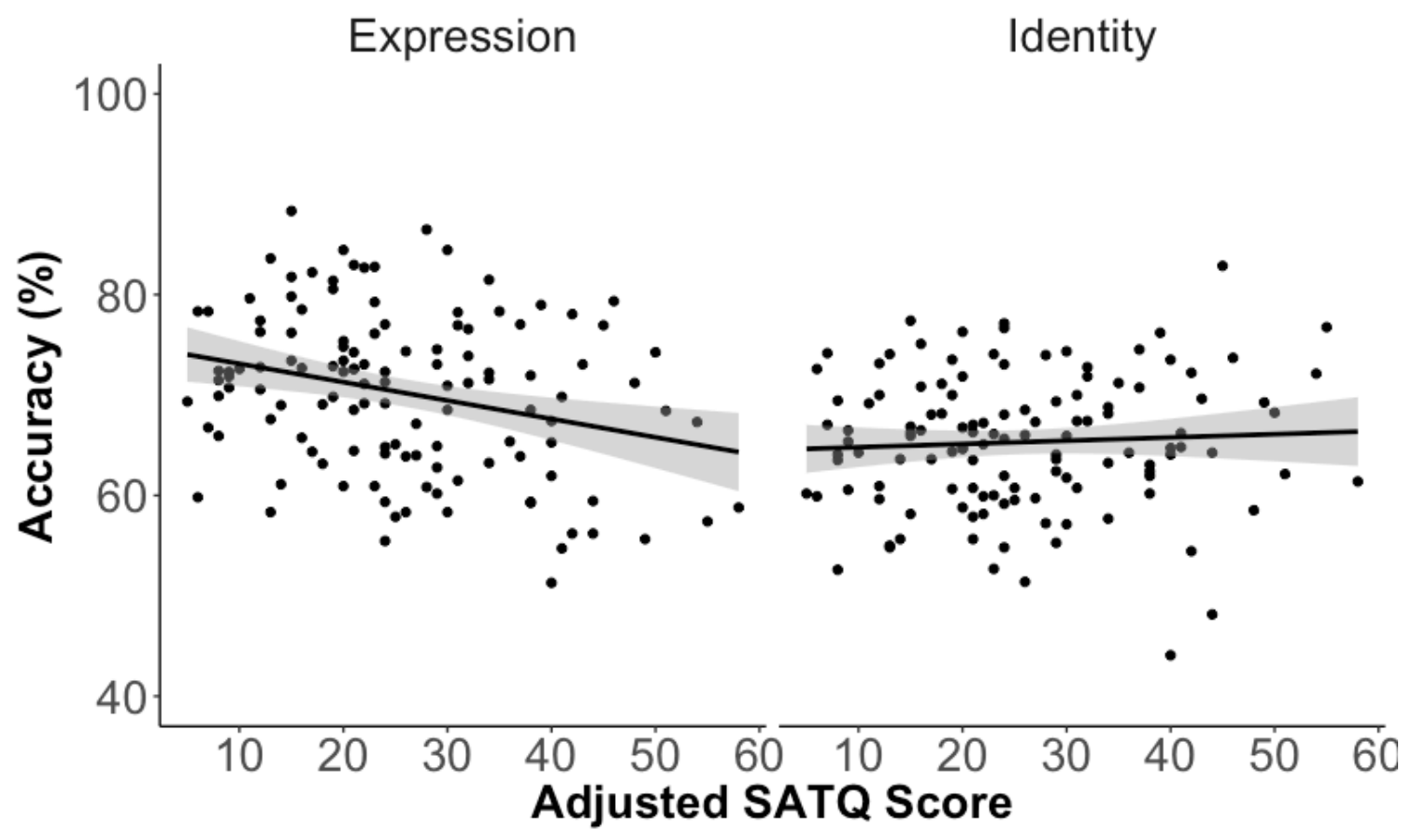

Figure B8. Scatterplots with lines of best fit for prosopagnosics' adjusted SATQ scores and their performance on the facial expression (left) and facial identity (right) tasks for upright trials, collapsed across task format. Grey shading represents the $95 \%$ confidence interval.

\section{B.7 Individual expression analyses}

In this analysis, I examined whether prosopagnosics have specific impairments for individual expressions. Various patient studies have shown that the ability to process specific facial expression can be impaired, including disgust (Calder, Keane, Manes, Antoun, \& Young, 2000; Sprengelmeyer et al., 1996; Suzuki, Hoshino, Shigemasu, \& Kawamura, 2006), 


\section{FACIAL EXPRESSION PROCESSING IN PROSOPAGNOSIA}

fear (Adolphs et al., 1994; Calder, 1996; Uono, Sato, \& Toichi, 2011), and anger (Calder, Keane, Lawrence, \& Manes, 2004; Lawrence, Calder, McGowan, \& Grasby, 2002). More specific to prosopagnosia, Biotti and Cook (2016) recently reported that prosopagnosics were impaired at categorising morph faces on a fear-surprise continuum, but normal at categorising faces on angry-happy and sad-disgust continua.

To address this issue, I analysed individual expression data from the simultaneous matching task and the sorting task. I did not analyse individual expression data from the sequential expression matching task because the "same" versus "different" response format makes it unclear what the target facial expression is for a given trial.

Facial expression simultaneous matching task. I calculated prosopagnosics' and controls' accuracy for each facial expression (see Table B6 for these values). Figure B9 shows the results. I ran a 6 (facial expression: angry, sad, disgust, fear, happy, surprise) x 2 (group: prosopagnosic, control) mixed-design ANOVA on accuracy for upright trials, with facial expression as the within-subjects factor and group as the between-subjects factor. There was a main effect of facial expression, indicating that prosopagnosics and controls were better at recognising some expressions over others $(F(4.49,1146.19)=269.38, p<$ $\left..001, \eta_{p}^{2}=.51\right)$. However, given that the individual expressions in this task were not matched for difficulty, this finding is not particularly relevant. The main effect of group $(F(1,255)=$ $\left.1.47, p=.227, \eta_{p}^{2}=.006\right)$, and the interaction between facial expression and group were not significant $\left(F(5,1275)=1.05, p=.388, \eta_{p}^{2}=.004\right)$, indicating that prosopagnosics showed comparable performance for all expressions tested as compared to controls, which is also true across the inversion effect analyses. Across all expressions, prosopagnosics' response times were slower than controls. 
Table B6. Prosopagnosics' and controls' accuracy on upright trials for each expression in the simultaneous matching task.

\begin{tabular}{lcc}
\hline Expression & $\begin{array}{c}\text { Controls } \\
M(S D)\end{array}$ & $\begin{array}{c}\text { Prosopagnosics } \\
M(S D)\end{array}$ \\
\hline Angry & $85.86(13.60)$ & $85.40(12.12)$ \\
Fear & $72.56(17.35)$ & $69.44(17.87)$ \\
Disgust & $56.84(15.09)$ & $53.71(15.85)$ \\
Happy & $89.17(14.57)$ & $88.95(13.48)$ \\
Sad & $75.94(18.99)$ & $73.31(16.01)$ \\
Surprised & $85.41(13.11)$ & $85.73(13.01)$ \\
\hline
\end{tabular}

\section{Facial Expression}

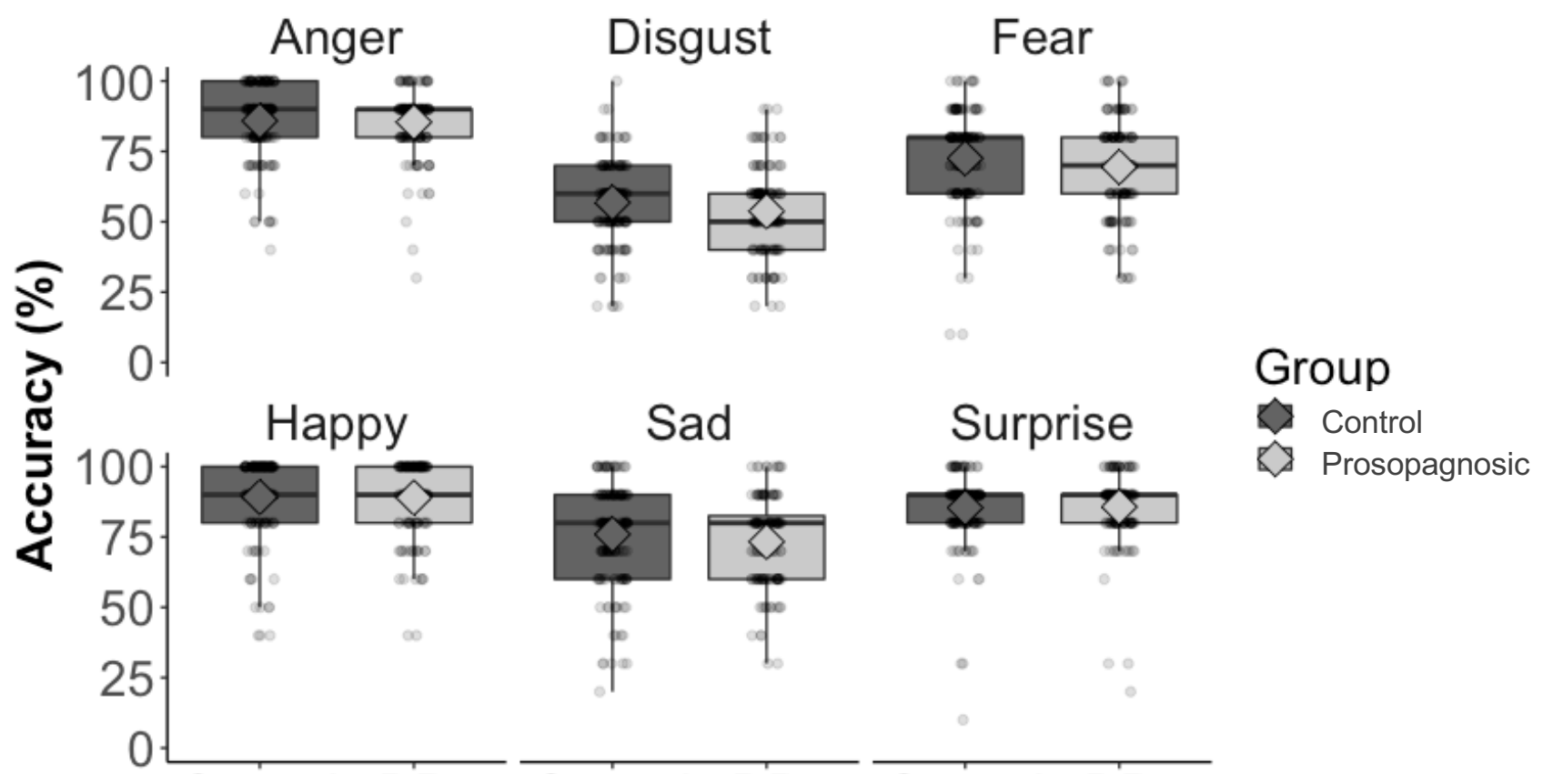

Figure B9. Boxplots of prosopagnosics' and controls' accuracy for each facial expression in the simultaneous matching task for upright trials. Points represent individual data. Diamonds represent the mean score for each condition.

Facial expression sorting task. I calculated prosopagnosics' and controls' accuracy for each facial expression (see Table B7 for these values). See Figure B10 for the results. I 


\section{FACIAL EXPRESSION PROCESSING IN PROSOPAGNOSIA}

ran a 4 (facial expression: angry, sad, fear, happy) x 2 (group: prosopagnosics, control) mixed-design ANOVA on accuracy for upright trials, with facial expression as the betweensubjects factor and group as the within-subjects factor. This revealed a significant main effect of facial expression, indicating that prosopagnosics' and controls' accuracy was higher for some expressions over others $\left(F(3,765)=72.15, p<.001, \eta_{p}^{2}=.22\right)$. As with the simultaneous matching task, the different facial expressions were not matched for difficulty level making this finding of no particular interest. There was also a significant main effect of group, indicating that prosopagnosics performed more poorly than controls across all expressions $\left(F(1,255)=9.73, p=.002, \eta_{p}^{2}=.04\right)$. The interaction between facial expression and group was not significant, indicating that prosopagnosics do not show a disproportionate deficit for some expressions over others $\left(F(3,765)=1.28, p=.282, \eta_{p}^{2}<.01\right)$, which is also true across the inversion effect analyses. Across all facial expressions, prosopagnosics' response times were slower than controls'.

Table B7. Prosopagnosics' and controls' accuracy on upright trials for each expression in the sorting task.

\begin{tabular}{lcc}
\hline Expression & $\begin{array}{c}\text { Controls } \\
M(S D)\end{array}$ & $\begin{array}{c}\text { Prosopagnosics } \\
M(S D)\end{array}$ \\
\hline Angry & $75.73(18.09)$ & $69.00(20.48)$ \\
Fear & $58.48(20.50)$ & $54.30(17.49)$ \\
Happy & $58.56(17.41)$ & $55.29(18.13)$ \\
Sad & $66.79(17.67)$ & $59.41(17.18)$ \\
\hline
\end{tabular}


Facial Expression

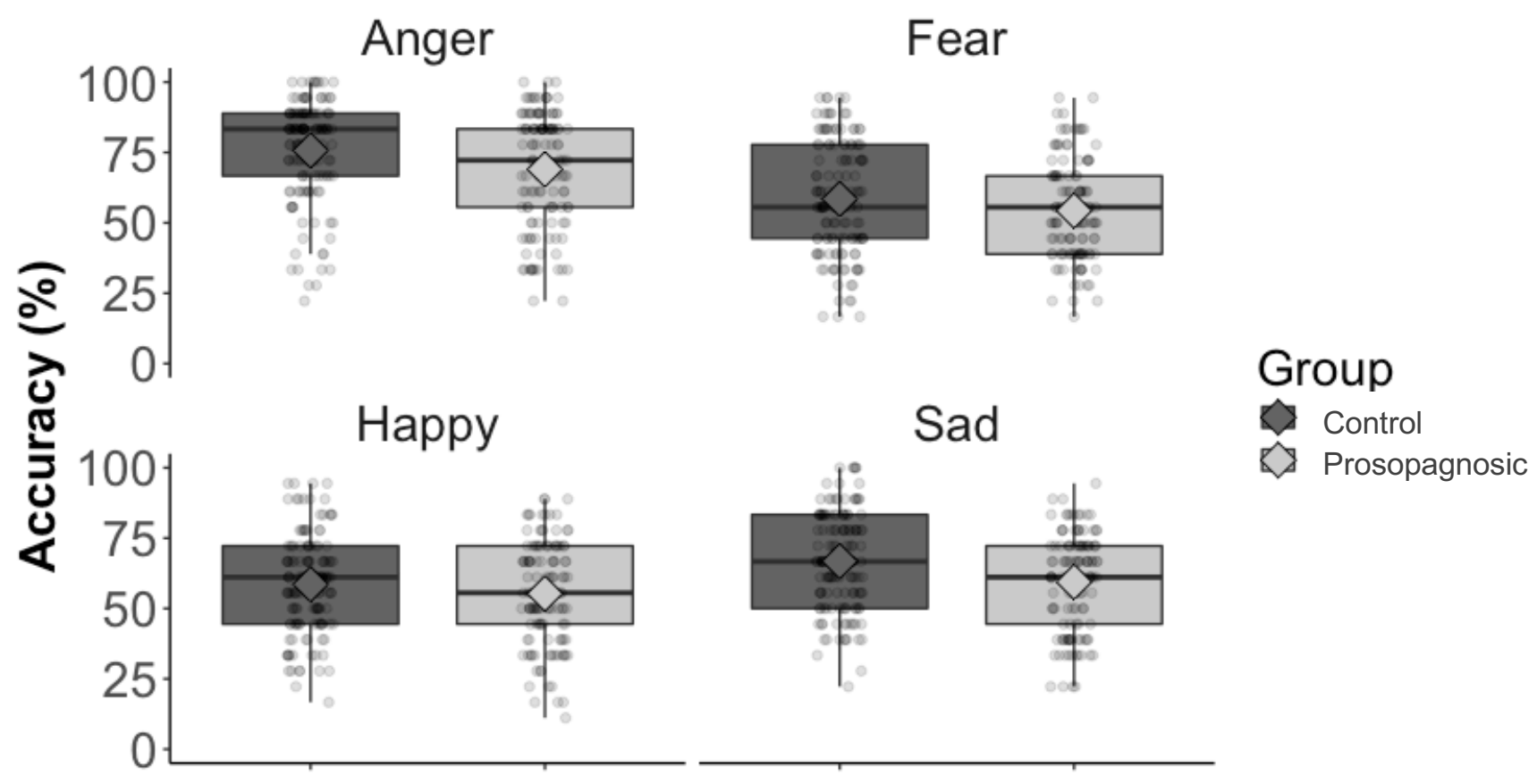

Figure B10. Boxplots of prosopagnosics' and controls' accuracy for each facial expression in the sorting task for upright trials. Points represent individual data. Diamonds represent the mean score for each condition.

Overall, these analyses suggest that prosopagnosics' small expression deficit is not driven by problems with particular expressions. Instead, prosopagnosics' seem to show similar-sized, subtle deficits across all expressions assessed in the simultaneous matching task and in the sorting task. Further, prosopagnosics showed similar-sized inversion effects to controls for each expression, suggesting that prosopagnosics process each expression similarly to controls. 


\section{Appendix C \\ Simultaneous matching tasks modification and development}

Expression task modification. I made three minor modifications to Palermo and colleagues' (2013) facial expression simultaneous matching task. First, I reduced the number of trials from 100 to 60 to both shorten the duration of and optimise the task. From pilot data collected via mTurk, I removed trials in which accuracy was close to chance or ceiling. Second, all images were changed from full-colour to grey-scale to reduce the salience of skin or hair colour cues (this was done primarily for the identity version of the task). Third, I balanced the task on three aspects, including number of trials with (1) male and female actors (30 trials per gender category), (2) a specific target emotion (10 trials per emotion category, 5 per gender), and (3) left, right and full-front facing images (20 trials per orientation). I piloted the modified version of the task on mTurk. The mean accuracy score from the modified task ( $n=17, M=79.00 \%, S D=5.00 \%)$ was comparable to Palermo and colleagues' original task $(n=80, M=78.00 \%, S D=7.60 \%), t(95)=0.52, p=.606, d=.14$.

Identity task development. I created an identity version of Palermo and colleagues' (2013) facial expression simultaneous matching task. The stimuli for the identity task were created from the original stimuli set for the expression task. The face triplets were made by selecting target faces and distractor faces that belonged to similar looking actors (e.g., the two actor identities presented in a trial might both have full lips and dark hair). The stimuli were edited using GNU Image Manipulation Program (http:/gimp.org). I piloted the first version of the identity matching task through mTurk. Several reiterations of the task were performed (which involved changing target faces within the triplets for ones that looked more or less similar to the distractor faces) until the average accuracy performance was comparable to that of the expression matching task. 


\title{
Appendix D
}

\section{Subthreshold Autism Trait Questionnaire (SATQ; Kanne et al., 2012)}

\author{
items the best that you can. \\ $0=$ False, not at all true \\ $1=$ Slightly true \\ 2 = Mainly true \\ $3=$ Very true
}

A brief, self-report measure that assesses a broad range of subthreshold ASD traits in the general population. For each item, please use the scale below to rate the extent to which it describes you on most days. There are no right or wrong answers. Please answer all of the

Note. The items below have been grouped based on which of the five autism constructs they measure. Items with "( $\mathrm{R})$ " after them are reverse coded items.

\section{Social interaction \& enjoyment}

1. I like being around other people. (R)

2. I enjoy social situations where I can meet new people and chat (i.e. parties, dances, sports, games).(R)

3. I seek out and approach others for social interactions. (R)

4. I like to share my enjoyment with others. (R)

5. Others consider me warm, caring, and/or friendly. (R)

6. I respond appropriately to other people's emotions (for example, comforting someone who is upset).(R)

7. I can have a back and forth conversation (listen well and change topics appropriately). (R)

8. I use many gestures when speaking with others such as shrugging, "talking with my hands,' nodding my head, etc. (R)

\section{Oddness}

9. Others think that I am strange or bizarre.

10. I have some behaviours that others consider strange or odd. 


\section{FACIAL EXPRESSION PROCESSING IN PROSOPAGNOSIA}

11. I sometimes say things that others tell me are rude or inappropriate.

12. I use odd phrases or tend to repeat certain words or phrases over and over again.

13. I am very interested in things related to numbers (i.e. dates, phone numbers, etc.).

\section{Reading facial expressions}

14. I am good at knowing what others are feeling by watching their facial expressions or listening to the tone of their voice. (R)

15. I can sense that someone is not interested in what I'm saying by reading their facial expressions. (R)

16. I make eye contact when talking with others. (R)

\section{Expressive language}

17. I am good at using words to express my thoughts and ideas. (R)

18. I have difficulty getting my ideas across to others in a conversation.

19. I have a good imagination. (R)

\section{Rigidity}

20. I am comfortable with spontaneity, such as going to new places and trying new things. $(\mathrm{R})$

21. I tend to stick to routines in my day to day life, preferring to do things the same way.

22. I am considered "laid back" and am able to "go with the flow'.' (R)

23. I sometimes take things too literally, such as missing the point of a joke or having trouble understanding sarcasm.

24. I tend to focus on individual parts and details more than the big picture. 


\section{Appendix E}

\section{Study 2 supplementary analyses}

\section{E.1 Individual task validation in independent samples}

The Study 2 tasks were each validated with independent mTurk samples. Like the Study 1 tasks, I wanted to ensure that the Study 2 tasks met three validation criteria. First, mean task performance did not suffer from ceiling or floor effects. Second, the static and dynamic versions of each labelling task were matched on difficulty. Third, each task produced sizeable inversion effects. For each task, participants completed the upright and inverted conditions. Participants were excluded from analyses if they (1) were older than 52 years of age (to match the prosopagnosic samples' age range), (2) completed both static and dynamic versions of a given task, and/or (3) performed at or below chance level for a given task. For the basic expression and complex expression tasks I ran 2 (stimulus orientation: upright, inverted) x 2 (stimulus type: static, dynamic) mixed-design ANOVAs on accuracy, with stimulus orientation as the within-subjects factor and stimulus type as the betweensubjects factor.

Basic expression tasks. One hundred participants completed the static and dynamic basic expression tasks each. After exclusion, the final samples comprised 56 individuals for the static task and 53 for the dynamic task. The mean scores on the static task were $61.71 \%$ $(S D=11.43 \%)$ in the upright condition and $46.03 \%(S D=10.27 \%)$ in the inverted condition. The mean scores in the dynamic task were $64.04 \%(S D=12.32 \%)$ in the upright condition and $48.28 \%(S D=10.99 \%)$ in the inverted condition. The ANOVA revealed a significant main effect of orientation, indicating that controls performed better on the upright condition of both tasks compared to the inverted condition $\left(M_{\text {upright }}=62.85 \%, S D_{\text {upright }}=11.88 \%\right.$; $\left.M_{\text {inverted }}=47.13 \%, S D_{\text {inverted }}=10.64 \% ; F(1,108)=454.76, p<.001, \eta_{p}^{2}=.81\right)$. The main effect of stimulus type $\left(F(1,108)=1.29, p=.259, \eta_{p}^{2}=.01\right)$ and the interaction between stimulus orientation and stimulus type were not significant $\left(F(1,108)=0.004, p=.950, \eta_{p}^{2}<\right.$ $.00)$.

Controls' performance on the static and dynamic tasks did not suffer from ceiling or floor effects (chance is $16.66 \%$ ). Both tasks produced sizeable inversion effects. The lack of main effect of stimulus type indicates that the static and dynamic tasks are matched on difficulty. The non-significant interaction between stimulus type and stimulus orientation suggests that the size of the inversion effects are comparable for the static and dynamic tasks. 


\section{FACIAL EXPRESSION PROCESSING IN PROSOPAGNOSIA}

Complex facial expression tasks. Ninety-seven participants completed the static task and 101 completed the dynamic task. In addition to the three exclusion criteria, participants data was excluded if their median response time was faster than the time needed for all three stimuli to be presented in sequence (i.e., faster than $4000 \mathrm{~ms}$ ). After exclusion, the final sample comprised 55 individuals for the static task and 56 for the dynamic task. In the static task, the mean scores were $78.53 \%(S D=11.63 \%)$ in the upright condition and $66.84 \%(S D$ $=9.73 \%)$ in the inverted condition. In the dynamic task, the mean scores were $76.68 \%(S D=$ $10.67 \%)$ in the upright condition and $64.70 \%(S D=9.79 \%)$ in the inverted condition. The ANOVA revealed a significant main effect of stimulus orientation, indicating that controls performed better on the upright condition of both tasks compared to the inverted condition $\left(M_{\text {upright }}=77.59 \%, S D_{\text {upright }}=11.15 \% ; M_{\text {inverted }}=65.76 \%, S D_{\text {inverted }}=9.77 \% ; F(1,109)=\right.$ $\left.142.35, p<.001, \eta_{p}^{2}=.57\right)$. The main effect of stimulus type $\left(F(1,109)=1.34, p=.250, \eta_{p}^{2}\right.$ $=.01)$ and the interaction between stimulus orientation and stimulus type were not significant $\left(F(1,109)=0.02, p=.884, \eta_{p}^{2}<.01\right)$.

Controls' performance on the static and dynamic task did not suffer from ceiling or floor effects (chance is $33.33 \%$ ). Both tasks produced sizeable inversion effects. The lack of main effect of stimulus type indicates that the static and dynamic tasks are matched on difficulty. The non-significant interaction between stimulus type and stimulus orientation suggests that the size of the inversion effects are comparable for the static and dynamic tasks.

\section{E.2 Controls' descriptive statistics and data checks}

I checked that controls' performance on the Study 2 tasks (1) did not show ceiling or floor effects, (2) revealed sizeable inversion effects, and (3) was comparable on the static and dynamic version of each task. Below I report controls' performance on the Study 2 tasks and address whether it satisfies the three criteria outlined above. Controls' accuracy and trimmed mean response times on the upright and inverted trials of each Study 2 task are presented in Table E1 and E2, respectively. For both the basic and complex expression tasks, I ran 2 (stimulus orientation: upright, inverted) x 2 (stimulus type: static, dynamic) repeated-design ANOVAs on accuracy, with stimulus orientation and stimulus type as within-subjects factors. 
FACIAL EXPRESSION PROCESSING IN PROSOPAGNOSIA

Table E1. Controls' accuracy on the upright and inverted trials of the Study 2 tasks.

\begin{tabular}{llcc}
\hline Expression Type & Stimulus Type & $\begin{array}{c}\text { Upright } \\
M(S D)\end{array}$ & $\begin{array}{c}\text { Inverted } \\
\end{array}$ \\
& Static & $62.77(10.04)$ & $49.99(9.60)$ \\
Basic & Dynamic & $65.50(10.14)$ & $51.09(9.93)$ \\
& Static & $79.61(10.89)$ & $70.32(12.14)$ \\
Complex & Dynamic & $77.49(10.55)$ & $69.37(11.42)$ \\
& & & \\
\hline
\end{tabular}

Table E2. Controls' trimmed mean response times on the upright and inverted trials of the Study 2 tasks.

\begin{tabular}{llcc}
\hline Expression Type & Stimulus Type & $\begin{array}{c}\text { Upright } \\
M(S D)\end{array}$ & $\begin{array}{c}\text { Inverted } \\
\text { Basic }\end{array}$ \\
& Static & $1673(265)$ & $1732(287)$ \\
& Dynamic & $2852(440)$ & $2963(527)$ \\
Complex & Static & $4188(402)$ & $4263(450)$ \\
& Dynamic & $6586(792)$ & $6422(1029)$ \\
\hline
\end{tabular}

Basic expression labelling tasks. Figure E1 shows the results. The ANOVA revealed significant main effects of orientation $\left(F(1,137)=657.01, p<.001, \eta_{p}^{2}=.83\right)$ and stimulus type $\left(F(1,137)=9.64, p=.002, \eta_{p}^{2}=.07\right)$. The main effects were qualified by an significant interaction between orientation and stimulus type, $F(1,137)=4.24, p=.041, \eta_{p}^{2}=.03$. I ran post hoc comparisons to break down this interaction. In the upright condition, controls' performance was better on the dynamic task than the static task $\left(M_{\text {dynamic }}=65.50 \%, S D_{\text {dynamic }}\right.$ $\left.=10.14 \% ; M_{\text {static }}=62.77 \%, S D_{\text {static }}=10.04 \% ; t(137)=3.50, p=.001, d_{z}=.30\right)$. However, in the inverted condition, controls' performance the dynamic and static tasks was comparable $\left(M_{\text {dynamic }}=51.09 \%, S D_{\text {dynamic }}=9.93 \% ; M_{\text {static }}=49.99 \%, S D_{\text {static }}=9.60 \% ; t(137)=1.62, p=\right.$ $\left..108, d_{z}=.14\right)$. To compare controls' inversion effects from the static and dynamic tasks, I conducted a follow-up paired samples t-test on inversion effects. Controls' inversion effect 
for the dynamic task was larger than their inversion effect for the static task $\left(M_{\text {dynamic }}=\right.$ $14.41 \%, S D_{\text {dynamic }}=7.87 \% ; M_{\text {static }}=12.78 \%, S D_{\text {static }}=7.68 \% ; t(137)=2.06, p=.041, d_{z}=$ $.18)$.

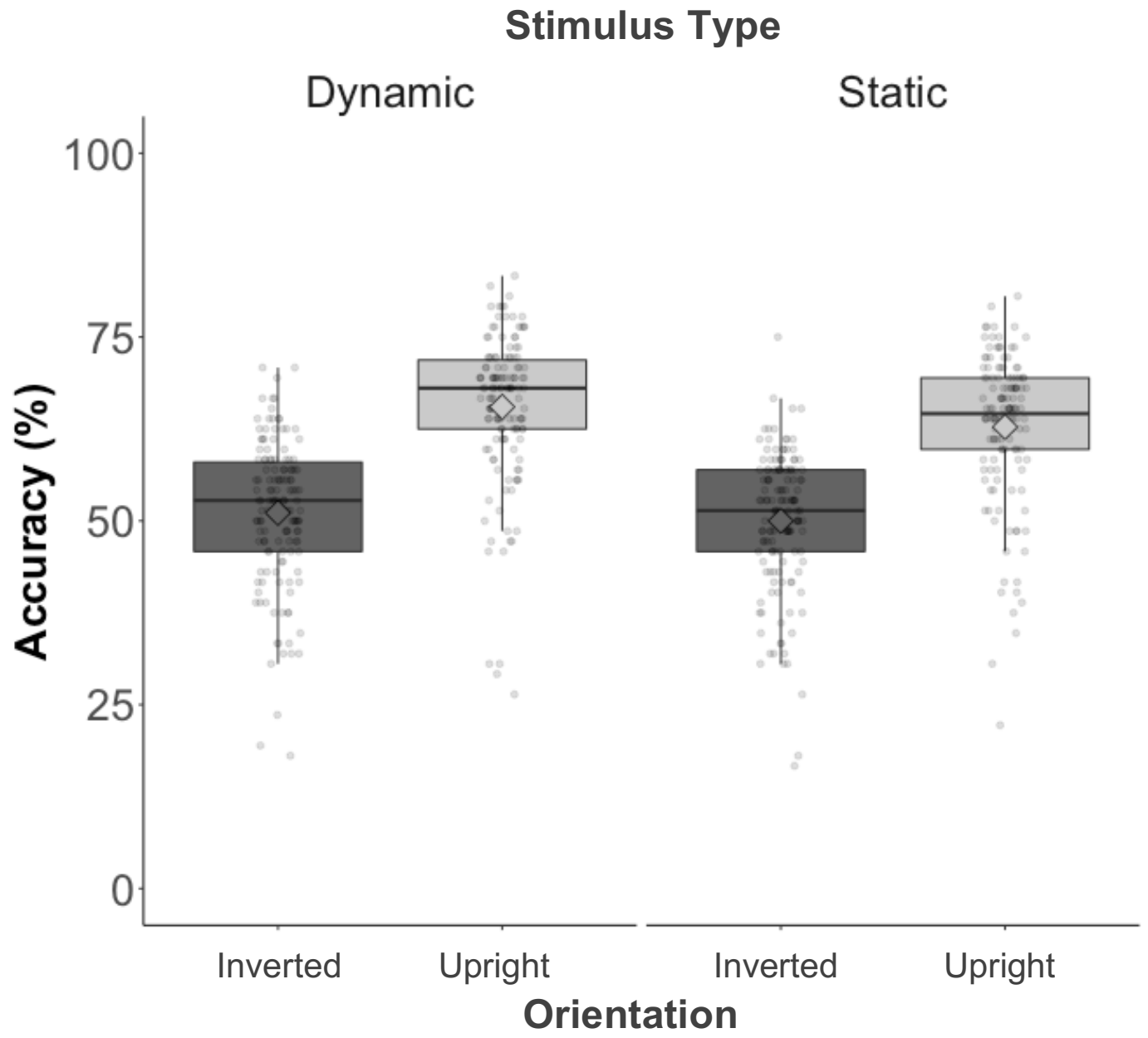

Figure E1. Boxplots of controls' accuracy on the inverted and upright conditions of the dynamic (left) and static (right) basic expression labelling tasks. Points represent individual data. Diamonds represent the mean score for each condition.

Regarding the three checks, first, controls did not show ceiling or floor performance on either orientation of both stimulus types. Second, both stimulus types produced sizeable inversion effects, although the dynamic inversion effect was slightly larger than the static inversion effect. Third, controls' performance on the upright conditions was better for the dynamic task than for the static task. Performance on the inverted condition was comparable.

Complex expression labelling tasks. Figure E2 shows the results. The ANOVA revealed a significant main effect of orientation, indicating controls' performance was better on the upright condition of dynamic and static tasks compared to the inverted condition $\left(M_{\text {upright }}=75.81 \%, S D_{\text {upright }}=11.87 \% ; M_{\text {inverted }}=72.39 \%, S D_{\text {inverted }}=11.92 \% ; F(1,137)=\right.$ 
205.21, $p<.001, \eta_{p}^{2}=.60$ ). There was also a significant main effect of stimulus type, indicating that controls' performance was slightly lower on the dynamic task than on the static task $\left(M_{\text {dynamic }}=73.43 \%, S D_{\text {dynamic }}=11.70 \% ; M_{\text {static }}=74.97 \%, S D_{\text {static }}=12.42 \% ; F(1\right.$, $\left.137)=9.40, p=.003, \eta_{p}^{2}=.06\right)$. The interaction between orientation and stimulus type was not significant, $F(1,137)=1.48, p=.226, \eta_{p}^{2}=.01$.

\section{Stimulus Type}

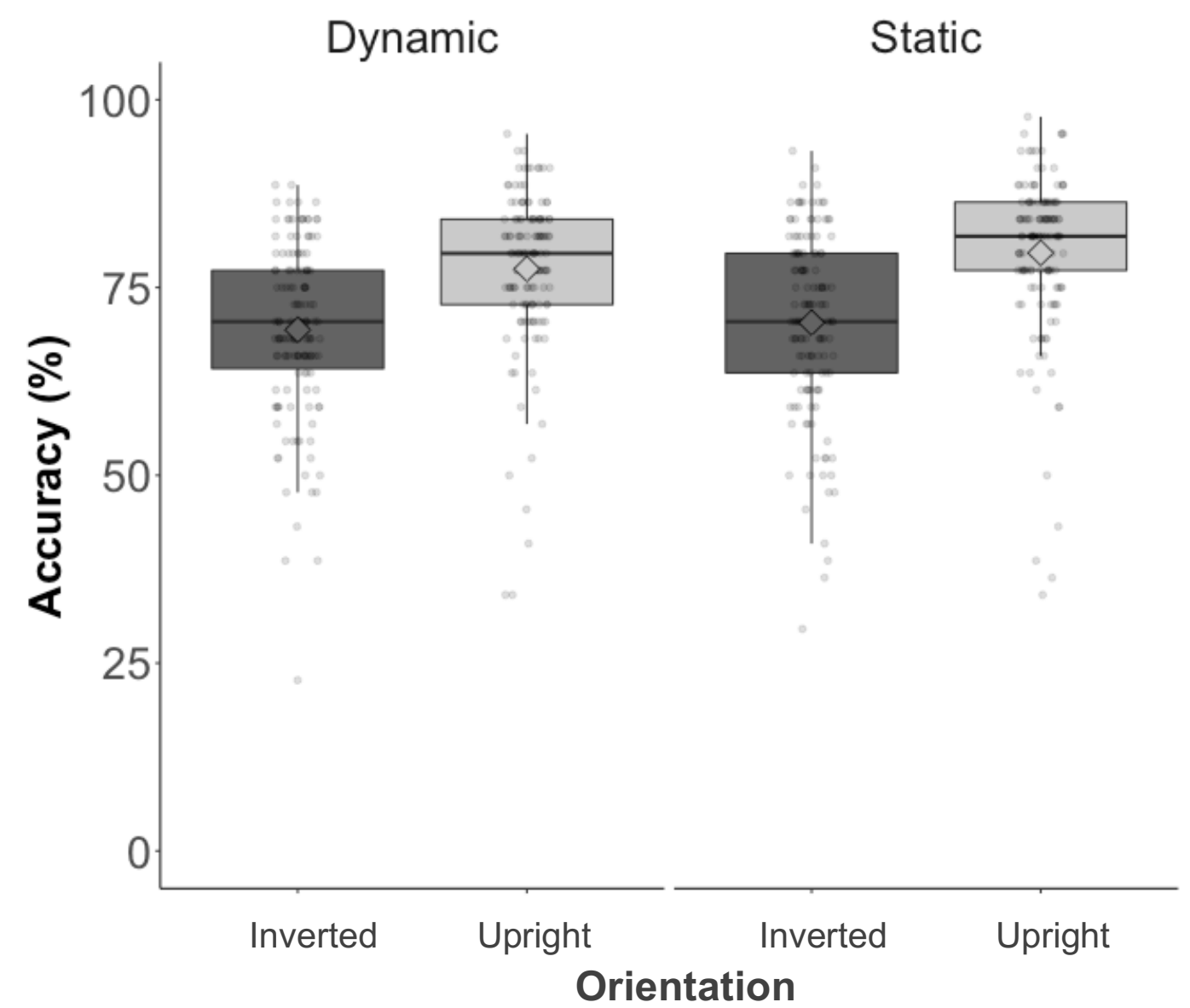

Figure E2. Boxplots of controls' accuracy on the inverted and upright conditions of the dynamic (left) and static (right) complex expression labelling tasks. Points represent individual data. Diamonds represent the mean score for each condition.

Regarding the three checks, first, controls did not show ceiling or floor performance on either orientation of both stimulus types. Second, both the dynamic and static tasks produced comparable inversion effects. Third, controls performed better overall on the static task compared to the dynamic task.

\section{E.3 Prosopagnosics' descriptive statistics}


Prosopagnosics' accuracy and trimmed mean response times on the upright and inverted trials of the Study 2 tasks are presented in Table E3 and E4, respectively.

Table E3. Prosopagnosics' accuracy on the upright and inverted trials of the Study 2 tasks.

\begin{tabular}{llcc}
\hline Expression Type & Stimulus Type & $\begin{array}{c}\text { Upright } \\
M(S D)\end{array}$ & $\begin{array}{c}\text { Inverted } \\
\end{array}$ \\
& Static & $59.51(9.50)$ & $46.39(8.48)$ \\
Basic & Dynamic & $61.86(10.98)$ & $49.11(10.27)$ \\
& Static & $78.23(9.21)$ & $64.04(10.57)$ \\
Complex & Dynamic & $76.84(10.54)$ & $65.12(9.83)$ \\
& & & \\
\hline
\end{tabular}

Table E4. Prosopagnosics' trimmed mean response times on the upright and inverted trials of the Study 2 tasks.

\begin{tabular}{llcc}
\hline Expression Type & Stimulus Type & $\begin{array}{c}\text { Upright } \\
M(S D)\end{array}$ & $\begin{array}{c}\text { Inverted } \\
M(S D)\end{array}$ \\
\hline Basic & Static & $1902(236)$ & $1916(269)$ \\
& Dynamic & $2963(389)$ & $3329(703)$ \\
Complex & Static & $4483(411)$ & $4518(380)$ \\
& Dynamic & $6670(796)$ & $6549(830)$ \\
\hline
\end{tabular}

\section{E.4 Median response time analyses}

In addition to trimmed mean response times, I also analysed median response times (see Table E5) to further check that differences in response time could not account for the pattern of results observed in accuracy.

Dissociation between basic and complex expressions. Figure E3 shows the results. I ran a 2 (expression type: basic, complex) x 2 (group: prosopagnosic, control) mixed-design ANOVA on response times for upright trials, with expression type as the within-subjects factor and group as the between-subjects factor. There was a significant main effect of group, 


\section{FACIAL EXPRESSION PROCESSING IN PROSOPAGNOSIA}

indicating that prosopagnosics were slower than controls across both expression types $\left(M_{\text {prosopagnosic }}=3982 \mathrm{~ms}, S D_{\text {prosopagnosic }}=1623 \mathrm{~ms} ; M_{\text {control }}=3783 \mathrm{~ms}, S D_{\text {control }}=1654 \mathrm{~ms}\right.$; $\left.F(1,214)=10.80, p=.001, \eta_{p}^{2}=.05\right)$. There was also a significant main effect of expression type, indicating that both groups were slower with complex than with basic expressions $\left(M_{\text {complex }}=5413 \mathrm{~ms}, S D_{\text {complex }}=611 \mathrm{~ms} ; M_{\text {basic }}=2297 \mathrm{~ms}, S D_{\text {basic }}=407 \mathrm{~ms} ; F(1,214)=\right.$ $\left.6161.82, p<.001, \eta_{p}^{2}=.97\right)$. Importantly, the interaction between expression type and group was not significant, indicating that the dissociation I observed in accuracy cannot be accounted for by response time differences, $F(1,214)=0.17, p=.683, \eta_{p}^{2}<.01$.

Table E5. Controls' and prosopagnosics' median response times on the upright and inverted trials of the Study 2 tasks.

\begin{tabular}{llrlll}
\hline $\begin{array}{l}\text { Expression } \\
\text { Type }\end{array}$ & Stimulus Type & $\begin{array}{r}\text { Upright } \\
\text { Controls } \\
M\end{array}$ & $\begin{array}{l}\text { Prosopagnosics } \\
(S D)\end{array}$ & $\begin{array}{c}\text { Inverted } \\
\text { Controls }\end{array}$ & $\begin{array}{l}\text { Prosopagnosics } \\
(S D)\end{array}$ \\
\hline \multirow{2}{*}{ Basic } & Static & $1618(309)$ & $1891(373)$ & $1648(298)$ & $2112(479)$ \\
& Dynamic & $2820(540)$ & $2978(556)$ & $2866(570)$ & $3075(620)$ \\
& Static & $4150(640)$ & $4449(482)$ & $4237(635)$ & $4492(424)$ \\
& Dynamic & $6544(875)$ & $6611(836)$ & $6448(1464)$ & $6484(875)$ \\
& & & & & \\
\hline
\end{tabular}




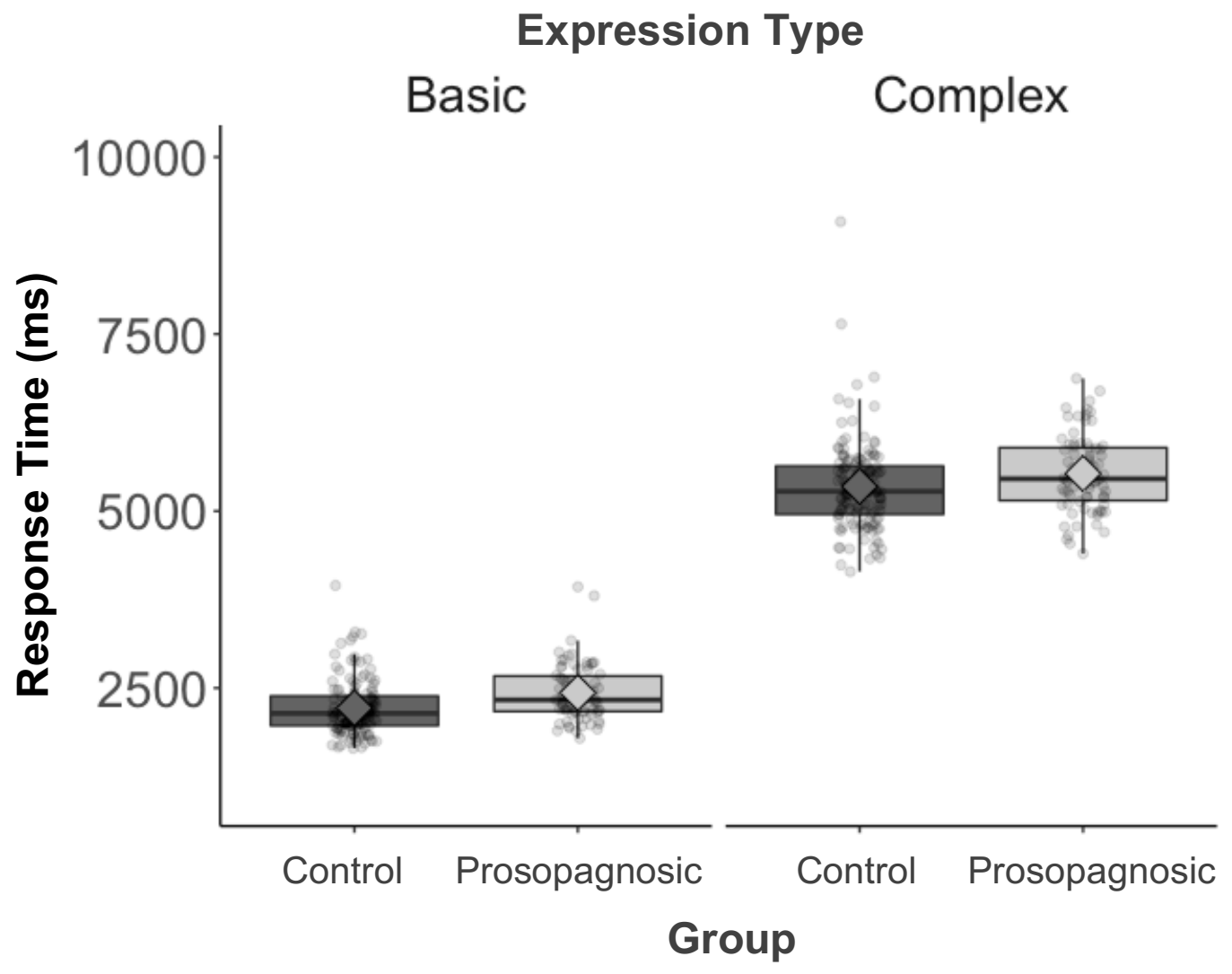

Figure E3. Boxplots of controls' and prosopagnosics' median response times on the basic (left) and complex (right) facial expression labelling tasks for upright trials, collapsed across stimulus type. Points represent individual data. Diamonds represent mean score for each condition.

Inversion effects. Figure E4 shows the results. I ran a 2 (expression type: basic, complex) x 2 (group: prosopagnosic, control) mixed-design ANOVA on response time inversion effects, with expression type as the within-subjects factor and group as the between-subjects factor. There was a significant main effect of expression type $(F(1,214)=$ $\left.10.44, p=.001, \eta_{p}^{2}=.05\right)$, but the main effect of group was not significant, $F(1,214)=1.23$, $p=.269, \eta_{p}^{2}<.01$. There was a significant interaction between expression type and group, $F(1,214)=4.43, p=.037, \eta_{p}^{2}=.02$. Post hoc t-tests revealed that controls' and prosopagnosics' inversion effects were not comparable for the basic expression tasks $\left(M_{\text {control }}\right.$ $=-38 \mathrm{~ms}, S D_{\text {control }}=113 \mathrm{~ms} ; M_{\text {prosopagnosic }}=-159 \mathrm{~ms}, S D_{\text {prosopagnosic }}=224 \mathrm{~ms} ; t(214)=5.27, p$ $<.001, \mathrm{~d}=.75$. Specifically, prosopagnosics had a larger negative value inversion effect than controls, indicating that they spent more time on inverted trials than upright trials relative to controls. Given that prosopagnosics spent more time on inverted trials rather than upright trials, their similar-sized inversion effect in accuracy to controls' cannot be accounted for by 


\section{FACIAL EXPRESSION PROCESSING IN PROSOPAGNOSIA}

response time differences. On the complex tasks, controls' and prosopagnosics' inversion effects were of comparable size, indicating that the inversion effects observed in accuracy are not accounted for by response time differences $\left(M_{\text {control }}=5 \mathrm{~ms}, S D_{\text {control }}=602 \mathrm{~ms}\right.$; $\left.M_{\text {prosopagnosic }}=42 \mathrm{~ms}, S D_{\text {prosopagnosic }}=276 \mathrm{~ms} ; t(214)=0.51, p=.609, \mathrm{~d}=.07\right)$.

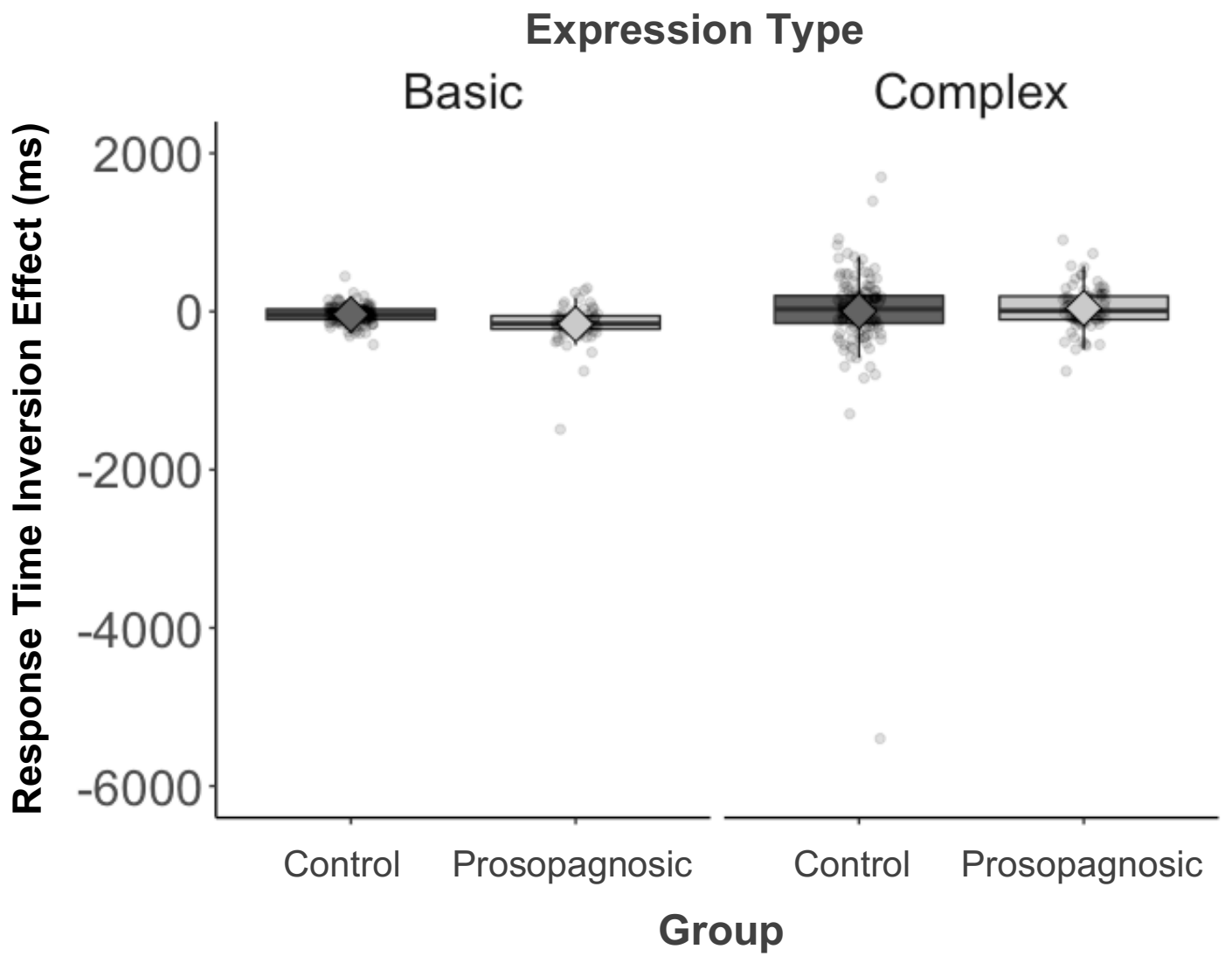

Figure E4. Boxplots of prosopagnosics' and controls' inversion effects in median response times on the basic (left) and complex (right) facial expression labelling tasks, collapsed across stimulus type. Points represent individual data. Diamonds represent mean score for each condition.

\section{E.5 Adjusted SATQ analyses}

I computed a Pearson product-moment correlation coefficient to assess the relationship between prosopagnosics' adjusted SATQ scores and their performance on the basic expression tasks. Figure E5 shows the correlation. There was a negative correlation between prosopagnosics' adjusted SATQ scores and their performance on the basic expression tasks, $r(76)=-.24, p=.031$ (the correlations computed with the adjusted SATQ scores and the unadjusted scores were comparable, $z=-1.29, p=.196)$, indicating that as autism traits increase, performance on the basic expression tasks decreases. 


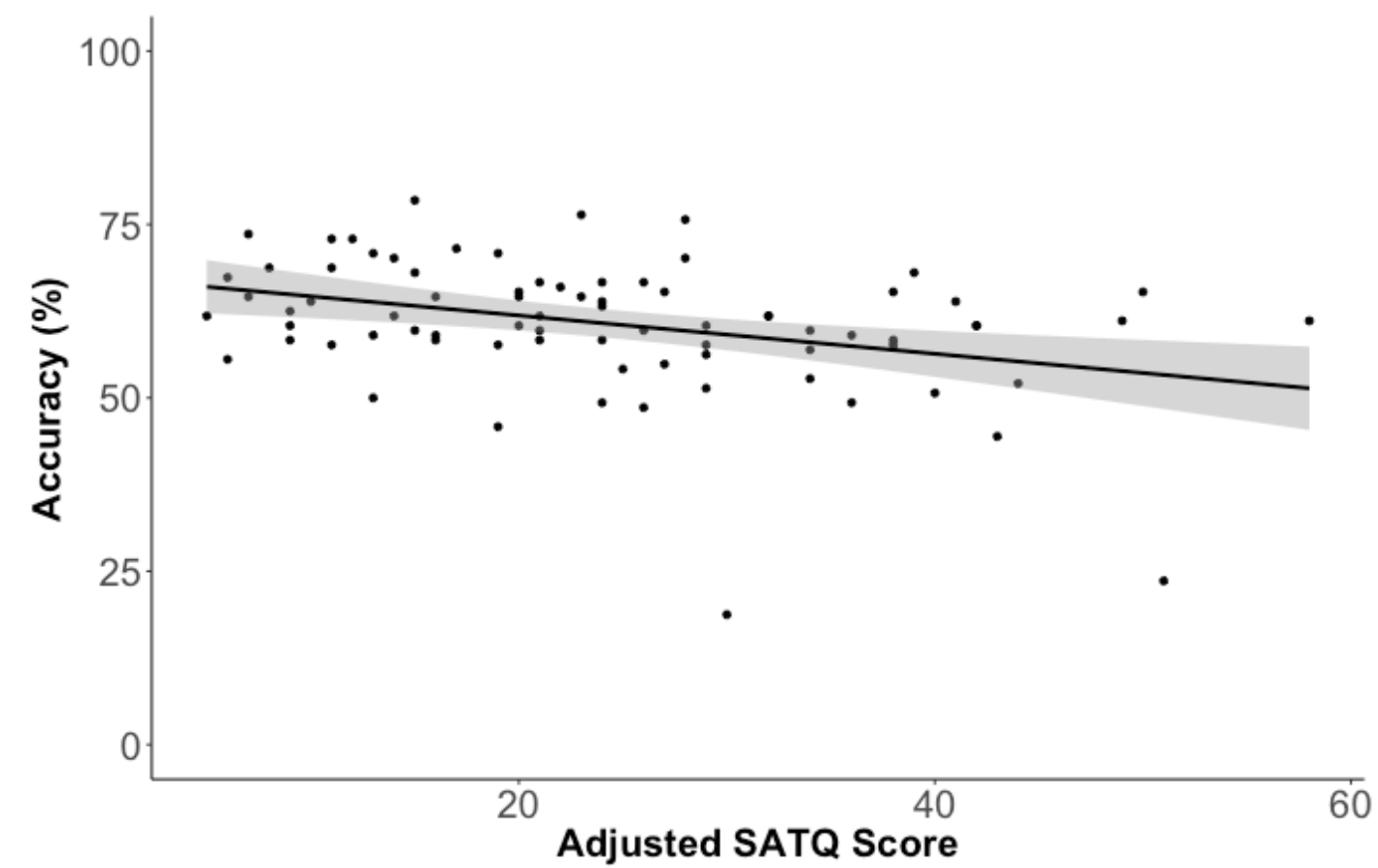

Figure E5. Scatterplot with line of best fit for prosopagnosics' adjusted SATQ scores and their performance on the basic expression tasks on upright trials, collapsed across stimulus type. Grey shading represents the 95\% confidence interval.

\section{E.6 Individual expression analyses}

Despite the lack of impairments for individual expressions in Study 1, it is possible that prosopagnosics might demonstrate deficits for individual expressions when they are required to label them. Here, I analyse individual expressions from the basic expression task because the complex expression task does not have enough trials for each expression.

I calculated prosopagnosics' and controls' accuracy for each facial expression on the basic expression tasks (these values are presented in Table E6). Figure E6 shows the results. I ran a 6 (facial expression: angry, fear, sad, happy, surprise, and disgust) x 2 (group: prosopagnosic, control) mixed-design ANOVA on accuracy for upright trials, with facial expression as the within-subjects factor and group as the between-subjects factor. There were significant main effects of facial expression $\left(F(4.26,911.40)=407.93, p<.001, \eta_{p}^{2}=.66\right)$ and group $\left(F(1,214)=7.01, p=.009, \eta_{p}^{2}=.03\right)$. These main effects were qualified by a significant interaction between facial expression and group, $F(5,1070)=7.51, p<.001, \eta_{p}^{2}=$ .03. I conducted post-hoc comparisons to break down this interaction (see Table E6 for $t$-, $p$-, and Cohen's $d$ values from these tests). Both groups performed similarly for anger, sad, and 


\section{FACIAL EXPRESSION PROCESSING IN PROSOPAGNOSIA}

surprise, but prosopagnosics showed deficits for disgust, fear, and happy. These results suggest that prosopagnosics may have specific deficits at recognising particular expressions.

Table E6. Prosopagnosics' and controls' accuracy on upright trials for each expression in the basic expression labelling tasks, and t-and p-values from post hoc t-tests.

\begin{tabular}{lccccc}
\hline Expression & $\begin{array}{c}\text { Controls } \\
M(S D)\end{array}$ & $\begin{array}{c}\text { Prosopagnosics } \\
M(S D)\end{array}$ & $t$ value & $p$ value & Cohen's $d$ \\
\hline Angry & $51.12(16.26)$ & $47.76(18.17)$ & 1.40 & .163 & 0.20 \\
Disgust & $63.92(15.10)$ & $41.98(20.83)$ & 8.91 & $<.001$ & 1.27 \\
Fear & $42.36(14.51)$ & $37.45(18.59)$ & 2.15 & .032 & 0.31 \\
Happy & $93.18(8.95)$ & $90.06(13.29)$ & 2.06 & .041 & 0.29 \\
Sad & $63.07(15.15)$ & $64.96(18.83)$ & 0.81 & .422 & 0.11 \\
Surprised & $71.17(14.78)$ & $71.90(16.65)$ & 0.35 & .740 & 0.05 \\
\hline
\end{tabular}




\section{Facial Expression}

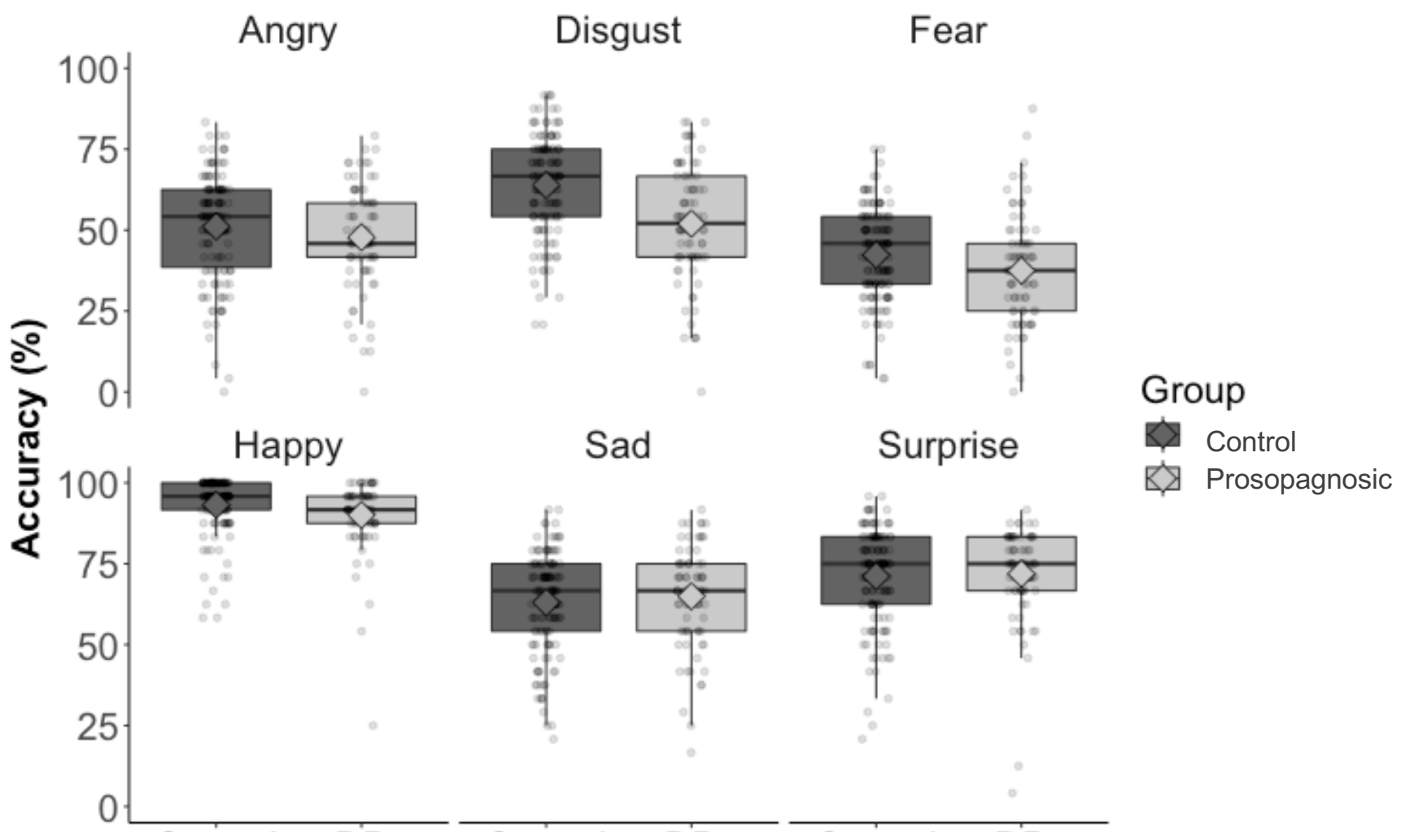

Figure E6. Boxplots of prosopagnosics' and controls' accuracy for each facial expression in the basic expression labelling tasks for upright trials. Points represent individual data. Diamonds represent the mean score for each condition.

I also ran response times analyses to determine whether speed-accuracy trade-offs could account for the pattern of accuracy results. I calculated trimmed mean response times for each expression in the basic expression labelling tasks (see Table E7 for these values). I ran a 6 (facial expression: anger, disgust, fear, happy, sad, surprise) x 2 (group: prosopagnosic, control) mixed-design ANOVA on response times on upright trials, with facial expression as the within-subjects factor and group as the between-subjects factor. There were significant main effects of facial expression $(F(3.34,705.12)=258.60, p<.001$, $\left.\eta_{p}^{2}=.55\right)$ and group $\left(F(1,211)=23.40, p<.001, \eta_{p}^{2}=.10\right)$, which were qualified by a significant interaction between facial expression and group, $F(5,1055)=12.20, p<.001, \eta_{p}^{2}$ $=.05$. To break down this interaction, I ran post hoc comparisons $(t-, p$-, and Cohen's $d$ values from these tests are presented in Table E7). Prosopagnosics were slower than controls for anger, disgust, and fear. In contrast, prosopagnosics' and controls' response times were 


\section{FACIAL EXPRESSION PROCESSING IN PROSOPAGNOSIA}

comparable for happy, sad, and surprise. Importantly, prosopagnosics were not faster than controls for disgust, fear, and happy, indicating that their deficits with disgust, fear, and happy expressions cannot be accounted for by response time differences. I ran the same analyses with median response times and found a similar pattern of results.

Table E7. Prosopagnosics' and controls' trimmed mean response times on upright trials for each expression in the basic expression labelling tasks, and t-, $p$-, and Cohen's $d$ values from post hoc t-tests.

\begin{tabular}{lccccc}
\hline Expression & $\begin{array}{c}\text { Controls } \\
M(S D)\end{array}$ & $\begin{array}{c}\text { Prosopagnosics } \\
M(S D)\end{array}$ & $t$ value & $p$ value & Cohen's $d$ \\
\hline Angry & $2540(455)$ & $2778(416)$ & 3.81 & $<.001$ & 0.54 \\
Disgust & $2317(375)$ & $2643(497)$ & 5.43 & $<.001$ & 0.77 \\
Fear & $2762(576)$ & $3230(574)$ & 5.75 & $<.001$ & 0.82 \\
Happy & $2006(359)$ & $2144(28)$ & 2.93 & .004 & 0.42 \\
Sad & $2350(411)$ & $2477(335)$ & 2.32 & .021 & 0.33 \\
Surprised & $2295(367)$ & $2424(335)$ & 2.56 & .011 & 0.36 \\
\hline
\end{tabular}

I also wanted to assess whether prospagnosics recognise particular expressions similarly to controls. Such an analysis is particularly interesting considering prosopagnosics showed a selective deficit for disgust, fear, and happy. It is possible that prosopagnosics engage alternative mechanisms for disgust, fear, and happy, but use typical mechanisms for sad, surprise, and angry. I calculated inversion effects for each facial expression (see Table E8 for these values). I ran a 6 (facial expression: angry, disgust, fear, happy, sad, surprise) x 2 (group: prosopagnosic, control) mixed-design ANOVA on inversion effects, with facial expression as the within-subjects factor and group as the between-subjects factor. There was a significant main effect of facial expression, indicating that the size of the inversion effects differed across expressions $\left(F(4.43,948.72)=51.46, p<.001, \eta_{p}^{2}=.19\right)$. This finding is not particularly important because the task was not designed to produce similar-sized inversion effects for the six expressions. The main effect of group was not significant, $F(1,214)=0.61$, $p=.437, \eta_{p}^{2}<.01$. There was a significant interaction between facial expression and group, 


\section{FACIAL EXPRESSION PROCESSING IN PROSOPAGNOSIA}

$F(5,1070)=2.54, p=.027, \eta_{p}^{2}=.01$. I conducted post hoc t-tests to break down this interaction (Table E8 shows and $t$-, $p$-, and Cohen's $d$ values from these tests). Interestingly, prosopagnosics' showed reduced inversion effect for angry, suggesting the use of atypical mechanisms to recognise it. Prosopagnosics' and controls' inversion effects for disgust, fear, and happy were of comparable size, suggesting that they use similar mechanisms to process them as controls. Prosopagnosics' and controls' inversion effects were also of comparable size for sad and surprise.

Table E8. Prosopagnosics' and controls' inversion effects in accuracy for each expression in the basic expression labelling tasks, and t-, $p$-, and Cohen's $d$ values from post hoc t-tests.

\begin{tabular}{lccccc}
\hline Expression & $\begin{array}{c}\text { Controls } \\
M(S D)\end{array}$ & $\begin{array}{c}\text { Prospagnosics } \\
M(S D)\end{array}$ & $t$ value & $p$ value & Cohen's $d$ \\
\hline Angry & $23.64(14.64)$ & $16.99(13.76)$ & 3.27 & .001 & 0.47 \\
Disgust & $22.34(14.67)$ & $21.63(17.29)$ & 0.32 & .749 & 0.05 \\
Fear & $6.94(13.30)$ & $8.23(13.14)$ & 0.65 & .492 & 0.10 \\
Happy & $7.64(8.77)$ & $7.96(11.88)$ & 0.23 & .822 & 0.03 \\
Sad & $14.73(17.08)$ & $16.83(18.15)$ & 0.85 & .397 & 0.12 \\
Surprised & $6.23(12.10)$ & $5.98(10.50)$ & 0.15 & .878 & 0.02 \\
\hline
\end{tabular}

Overall, the results from the individual expression analyses indicate that prosopagnosics' small deficits for basic expression recognition may be driven by problems with disgust, fear, and happy. Relative to controls, however, prosopagnosics showed comparable inversion effects for disgust, fear, and happy, suggesting that despite their poorer ability to recognise these expressions, they may use similar mechanisms as controls to process them. The deficit with fear recognition in prosopagnosics is in line with Biotti and Cook's (2016) finding. Unlike Biotti and Cook, however, I did not observe a deficit with surprise. The deficit with happy recognition is consistent with Burns and colleagues (2017) finding that prosopagnosics adapt to (and thus presumably process) happy expressions abnormally. 


\section{Appendix F}

\section{Development of the complex expression tasks}

Pilot studies to select stimuli and trials. Stimuli consisted of $1000 \mathrm{~ms}$ screen recordings (using QuickTime media player v10.6.3 and iMovie v10.1.6) and screen shots of facial expressions captured from 33 films. All films were from non-English speaking countries to decrease the likelihood that participants would be familiar with the actors. I ran four pilot studies to select targets, distractors and emotional adjectives for each trial.

First pilot study. Three researchers independently assigned emotional adjectives to describe 619 potential target and/or distractor stimuli. Researchers viewed the static image and dynamic video clip versions of each stimulus. I assigned adjectives to stimuli if at least two of three researchers put forward identical or synonymous (e.g., worried and anxious) adjectives. For each stimulus either one or two potential adjectives were assigned.

Second pilot study. One-hundred-and-eighteen mTurk participants each rated a random subset of 73-74 facial expressions on how well they matched their assigned adjectives. They used a Likert scale ranging from 1 to $6(1=$ entirely disagree to $6=$ entirely agree) to perform these ratings. For stimuli that had two possible adjectives, I selected the adjective with the highest mean rating above four as the most appropriate adjective for a given stimulus. If no adjectives reached this criterion for a given stimulus, the stimulus was eliminated as a potential target or distractor. For each set of stimuli for a given actor (ranging between 3-15 stimuli), the stimuli with the highest agreement ratings were selected as targets.

Third pilot study. Ninety-eight mTurk participants each rated a random subset of 73-74 stimuli (composed of the targets and their potential distractors) on intensity (i.e., how strongly they portray the expression suggested by the adjective). They made these ratings on a Likert scale ranging from 1 to $5(1=$ not at all intense to $5=$ very intense $)$. Only distractors with similar mean intensity ratings to the target were selected (i.e., within $+/-1.75$ of the targets mean intensity). Targets were eliminated if there were not two or more potential distractors that matched this criterion.

Fourth pilot study. One-hundred-and-four mTurk participants judged which of two sequentially presented stimuli (the target and a distractor stimulus) best matched the target's adjective. Participants did this with a random subset of 96-98 stimulus pairs, roughly half of which were presented in upright and inverted orientation. Targets were eliminated if they were judged more accurately in the inverted orientation compared to the upright orientation. 


\section{FACIAL EXPRESSION PROCESSING IN PROSOPAGNOSIA}

Distractor stimuli were selected only if they were chosen less than $30 \%$ of the time compared to the target. This resulted in 51 targets from 26 films.

\section{Glossary of emotional adjectives ${ }^{10}$}

Amused: finding something funny

Example: I was amused by a funny joke someone told me.

Confused: puzzled, perplexed

Example: Lizzie was so confused by the directions given to her, she got lost.

Depressed: miserable

Example: George was depressed when he didn't receive any birthday cards.

Disappointed: displeased, disgruntled

Example: Manchester United fans were disappointed not to win the Championship.

Distrustful: suspicious, doubtful, wary

Example: The old woman was distrustful of the stranger at her door.

Dubious: doubtful, suspicious

Example: Peter was dubious when offered a surprisingly cheap television in a pub.

Excited: delighted, eager, enthusiastic

Example: Lucy was excited to meet her new pet puppy.

Hateful: showing intense dislike

Example: The two sisters were hateful to each other and always fighting.

Intrigued: very curious, very interested

Example: A mystery phone call intrigued Zoe.

Joking: being funny, playful

Example: Gary was always joking with his friends.

Mocking: showing that you think somebody/something is ridiculous

Example: Jen is always mocking Simons lack of awareness.

Perplexed: bewildered, puzzled, confused

Example: Frank was perplexed by the disappearance of his garden gnomes.

Pleased: feeling happy about something

\footnotetext{
10 Some of the adjectives were sourced from the Mind in the eyes test glossary (Baron-Cohen, Wheelwright, Hill, Raste, \& Plumb, 2001).
} 


\section{FACIAL EXPRESSION PROCESSING IN PROSOPAGNOSIA}

Example: Genie was pleased with the muffins she baked

Preoccupied: absorbed, engrossed in one's own thoughts

Example: Worrying about her mother's illness made Debbie preoccupied at work.

Regretful: sorry

Example: Lee was always regretful that he had never travelled when he was younger.

Shocked: to feel surprised and upset.

Example: Pablo was shocked to find out that Kenny and Blair were dating.

Smug: pompous, egotistical, conceited

Example: The lecturer had a smug look on his face when he failed the worst student in the class.

Suspicious: disbelieving, suspecting, doubting

Example: After Sam had lost his wallet for the second time at work, he grew suspicious of one of his colleagues.

Uneasy: unsettled, apprehensive, troubled

Example: Karen felt slightly uneasy about accepting a lift from the man she had only met that day.

Unimpressed: unfeeling, uninterested

Example: The man was unimpressed with his brother's wedding speech.

Upset: agitated, worried, uneasy

Example: The man was very upset when his mother died.

Worried: anxious, fretful, troubled

Example: When her cat went missing, the girl was very worried.

Pilot studies to match static and dynamic tasks for difficulty and inversion effect

size. The 51-trial version of the static and dynamic tasks were piloted to check that they were matched in difficulty and produced similar sized inversion effects. Ninety-nine mTurk participants completed the static version of the task either in upright $(n=54)$ or inverted $(n=$ $45)$ orientation. The mean score was $79.56 \%(S D=10.41 \%)$ in the upright condition and $63.70 \%(S D=11.09 \%)$ in the inverted condition. Better performance in the upright condition compared to the inverted condition indicates that the static task is tapping face specific processing. 


\section{FACIAL EXPRESSION PROCESSING IN PROSOPAGNOSIA}

One-hundred-and-two participants completed the dynamic task. Data was excluded from four individuals because of stimuli loading errors and from six individuals whose fast response times (medians less than $4000 \mathrm{~ms}$, as it takes $4000 \mathrm{~ms}$ for all three stimuli in the sequence to be shown) indicated that they were not engaging with the task. Of the remaining 92 participants, 53 had completed the task in the inverted condition and 39 completed it in the upright condition. The mean score was $73.21 \%(S D=10.71 \%)$ in the upright condition and $67.50 \%(S D=9.39 \%)$ in the inverted condition.

Based on the above results, I removed a selection of trials to make the static and dynamic tasks' difficulty and inversion effect sizes more comparable. Specifically, I removed given trials from the static and dynamic tasks if participants performed at $10 \%$ or greater accuracy on the inverted condition relative to the upright condition on the dynamic task. The final version of the complex expression labelling tasks had 44 targets from 26 films.

It should be noted that the majority of past studies (except one; Duchaine et al., 2009) that measured complex expression labelling used the Reading the Mind in the Eyes test (Baron-Cohen et al., 2001). The stimuli used in the Reading the Mind in the Eyes test only show the eye region of faces. In contrast, the complex expression labelling tasks that I developed uses whole-face stimuli. In everyday life when we interact with people we can typically see their whole face, rather than just individual facial features (e.g., their eyes). Therefore, by using whole-face stimuli, rather than eye-region stimuli, Study 2 should provide a more ecologically valid assessment of complex expression labelling in prosopagnosia than past studies that used the Reading the Mind in the Eyes test. 